\section{NATIONAL LIBRARY}

Public Archives Building

OTTAWA 2

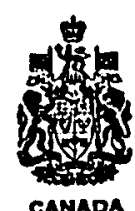

BIBLIOTHËQUE NATIONALE

Étifice des ARCHIVes pUbliques

OITAWA 2

WAME OF AUTHOR.........................

TITLE OF THESIS..... Intermediary steps in the enzymatic conversion

of tryptophan to IAA in cell free systems from

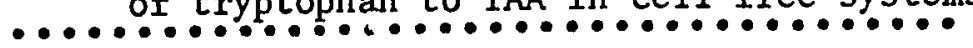

higher plants.

$\bullet \bullet \bullet \bullet \cdots \cdots \cdots \cdots \cdots \cdots \cdots \cdots \cdots \cdots \cdots \cdots \cdots \cdots \cdots \cdots \cdots \cdots$

Carleton University, Ottawa, Ontario.

UNIVERSITY.

DEGREE....... P.

YEAR GRANTED . . 1969

Permission is hereby granted to THE NATIONAL IIBRARY OF CANADA to microfilm this thesis and to lend or sell copies of the film.

The author reserves other pubilcation rights, and neither the thesis nor extensive extracts from It may be printed or otherwise reproduced without the author's written permission.

PERMANENT ADDRESS:

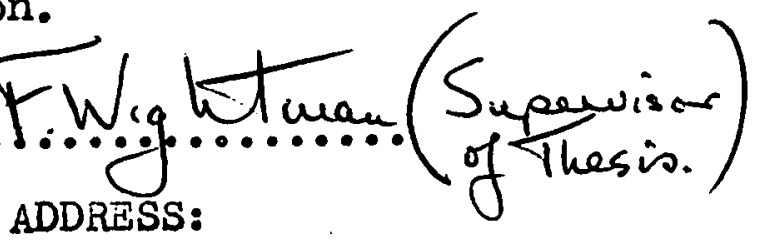

$$
\begin{aligned}
\text { c/o Department of Biology, } \\
\text { Carleton University, } \\
\text { OTTAWA, Ontario. }
\end{aligned}
$$

DATED.................. 


\title{
INTERMEDIARY STEPS IN THE ENZYMATIC CONVERSION OF TRYPTOPHAN TO IAA IN CELL FREE SYSTEMS FROM HIGHER PLANTS.
}

\author{
by \\ DANIEL COHEN, M.Agr.SC.
}

\begin{abstract}
A thesis submitted to the Faculty of Graduate Studies in partial fulfilment of the requirements for the degree of Doctor of Philosophy
\end{abstract}

\author{
Carleton University \\ Ottawa, Ontario \\ October, 1968
}

C)Daniel cohen 1968 
The undersigned hereby recommend to the Faculty of Graduate Studies acceptance of this thesis, submitted by Daniel Cohen, M.Agr.Sc., in partial fulfilment of the requirements for the degree of Doctor of Philosophy.
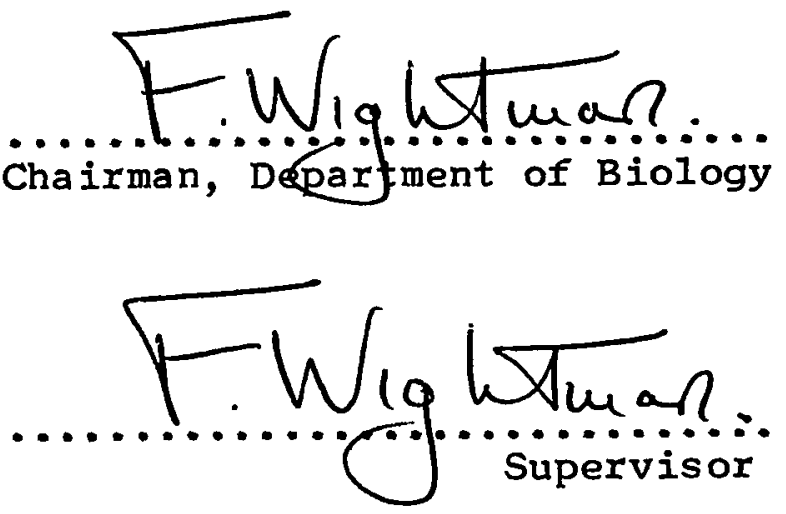
Abstract

There is considerable evidence from tracer studies that tryptophan (TTP) is the primary precursor of 3-indoleacetic acid (IAA) in higher plants. 3-Indolepyruvic acid (IPyA) and 3-indoleacetaldehyde (IAAId) have been proposed as intermediates in this conversion but their enzymatic formation from tryptophan using purified cell free preparations has not been demonstrated.

The aim of the present study was to seek chemical evidence for the formation of these likely intermediary compounds during the conversion of TTP to IAA by purified enzyme preparations from mung bean and tomato tissues. In addition, the properties of the individual enzymes involved in each step of this biosynthetic pathway would also be examined.

The transamination of tryptophan in the presence of $\alpha$-ketoglutarate was the first reaction studied. Tryptophan transaminase was clearly demonstrated in sephadex-purified cytoplasmic supernatant (SNS) and mitochondrial preparations from both mung bean seedlings and tomato shoot tips. For both plants, about $90 \%$ of the enzyme activity was found in the SNS and less than $10 \%$ was found in the mitochondrial preparation. Following ammonium sulphate fractionation of the SNS preparation, TTP-transaminase was recovered with the highest activity in the 40-50\% fraction and a 6-fold purification was achieved.

The indole product of the transaminase reaction was isolated and provisionally identified as IPyA from the 
chromatographic properties and UV spectroscopy of both the free acid and its 2,4-dinitrophenylhydrazone. Conclusive proof of the identity of the suspected IPyA-DNPH came from a comparison of its IR spectrum with that given by authentic IPy A-DNPH.

An attempt was made to study the metabolism of IPyA directly but this work was not successful because the problems arising from the instability of authentic IPyA in aqueous media were not overcome. There are, however, several lines of indirect evidence obtained in this work which point to decarboxylation of IPyA to IAAId.

The metabolism of IAAld was studied and the presence of an aldehyde dehydrogenase and an alcohol dehydrogenase catalysing the oxidation and reduction of IAAld respectively was clearly shown. Both enzymes were NAD-ciependent and were located predominantly in the cytoplasmic supernatant fraction. Aldehyde dehydrogenase activity was assayed by the formation of IAA from IAAld under standard conditions. Alcohol dehydrogenase activity was determined either by the measurement of tryptophol (Tol) formation from IAAld, or by spectrophotometric measurement of the initial rate of $\mathrm{NADH}_{2}$ utilisation with either IAAld or propionaldehyde as substrates. The spectrophotometric assay was used to study the kinetics of alcohol dehydrogenase and $\mathrm{Km}$ values were determined for propionaldehyde, ethanol, IAAld and $\mathrm{NADH}_{2} \cdot$

2-Mercaptoethanol was found to stabilize dehydrogenase activity during several purification steps. Partial purification of the enzymes was achieved by ammonium sulphate fractionation and the results show that at least two alcohol 
dehydrogenases are present in mung bean SNS preparations, one of which catalyses the reduction of IAA much faster than the other. By modification of the reaction conditions it was possible to demonstrate the reversibility of the alcohol dehydrogenase reduction of IAAld. IAA was formed from Tol and the reaction was inhibited by $\mathrm{NaHSO}_{3}$, which points to the involvement of IAAld as an intermediate. Aldehyde dehydrogenase was purified 10-fold and separated from alcohol dehydrogenase by fractional pH precipitation. Gel filtration studies using Sephadex G-200 enabled approximate molecular weights to be assigned for each of the enzymes studied.

Evidence is also presented for the formation of To1 from TTP and the conversion was inhibited by the addition of $\mathrm{NaHSO}_{3}$ to the reaction mixture. With an enzyme preparation from mung beans, the addition of $\mathrm{NaHSO}_{3}$ to the reaction mixture was shown to result in the accumulation of IAAld. This finding clearly points to the role of this compound as an important intermediate in the metabolism of TTP.

It is concluded from this study that all the enzymes necessary for converting L-tryptophan to IAA, via IPyA and IAAld as intermediary compounds, are present in mung bean seedlings and tomato shoot tissues. 


\section{ACKNOWLEDGMENTS}

It gives me pleasure to record my appreciation to the many people who provided assistance and encouragement during the course of this study. Special thanks are die to Dr. F. Wightman for his advice and support, both during the experimental work and in the preparation of this manuscript. Mr. J.C. Forest and Mr. R.A. Gibson gave technical assistance in some experiments and Dr. L.C. Fowke and Mr. K. Brasch assisted in the preparation of the electron micrograph. I am also grateful to members of faculty and staff of Carleton University for helpful discussions and the generous provision of facilities. Finally, I wish to thank my wife, Valerie,

for her understanding and tolerance in the typing of this manuscript.

This study was undertaken during the tenure of a Teaching Fellowship from Carleton University and a Studentship from the National Research Council of Canada. This financial assistance is gratefully acknowledged. 
TABLE OF CONTENTS

Page

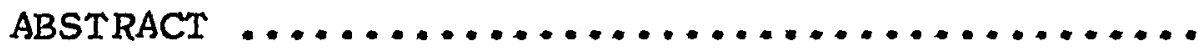

iii

ACKNOWLEDGMENTS

vi

LIST OF TABLES

$\mathbf{x i}$

LIST OF FIGURES

xiv

ABBREVIATIONS AND FORMULAE OF INDOLE COMPOUNDS..

xvii

I. INTRODUCTION..................... 1

II. LITERATURE REVIEW .................. 4

A. Natural Occurrence and Stability of Simple Indoles .................

B. Enzymes catalysing the Metabolism of

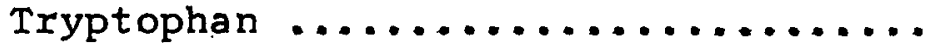

C. Enzymes catalysing the Metabolism of 3-Indolepyruvic Acid ..............

D. Enzymes catalysing the Metabolism of

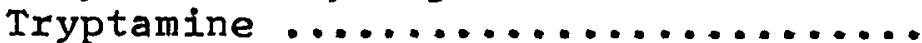

E. Enzymes catalysing the Metabolism of 3-Indolea cetaldehyde .............

F. Enzymes catalysing the Metabolism of other Indoles

III. MATERIALS AND METHODS .............

A. Growth of the Plant Material .......

B. Chemicals used in this Investigation.

C. Buffers employed ................

D. Preparation of Enzyme Fractions from

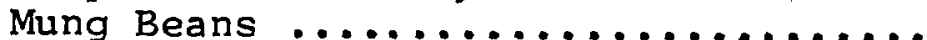


Page

E. Gel Filtration using Sephadex G-200 ..

F. Preparation of Enzyme Fractions from Tomato Shoot Tips

G. Chromatographic and Colorimetric Method for estimating Glutamate ............

65

H. Extraction of Free Indoles ..........

I. Chromatographic Analysis of Free Indole Metabolites ................

$J$. Preparation and Fractionation of 2,4-Dinitrophenylhydrazones of Indole Carbonyl Compounds ...............

K. Chromatography of Hydrazone Fractions. 80

L. UV and IR Spectroscopy of Indole Products ....................... 85

M. Standard Enzyme Assay Systems .......

IV. EXPERIMENTAL RESULTS .................. 92

A. Transamination of Tryptophan......... 92

B. Decarboxylation of 3-Indolepyruvic Acid ..........................

C. Oxidation and Reduction of 3-Indoleacetaldehyde

D. The Separation of Transaminase and Dehydrognnase Enzymes by Chromatography on Sephadex G-200 ................

E. Investigation of Tomato Shoot Tip Enzymes .......................

F. Activity of Enzyme Preparations from Light-grown Mung Beans ............

V. DISCUSSION ......................... 212

VI. SUMMARY ......................... 226

VII. BIBLIOGRAPHY ..................... 231 
LIST OF TABLES

Page

A. Reported $\mathrm{Km}$ values for aromatic amino acids given by three transaminase preparations .......................

1. Grams of solid ammonium sulphate to be added to each $100 \mathrm{ml}$ of solution to reach

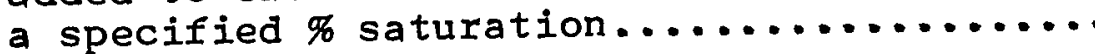

60

2. Rf values of hydrazones using MBzBuW and colour reactions with the DMAC reagent......

3. Rf of hydrazones on thin-layer silica gel plates............................

4. Transaminase activity of mung bean enzyme fractions.

5. Intracellular distribution of transaminase activity in mung bean enzyme fractions......

6. Effect of increasing volume of bursting medium on the solubilisation of mitochondrial transaminase from mung bean tissue.........

7. Reproducibility of the extraction procedures used for isolating soluble mitochondrial and cytoplasmic supernatant protein fractions with transaminase activity..............

8. Characteristics of the UV spectra of IPyADNPH eluted from TLC plates.............. 105

9. Characteristics of UV spectra of suspected and authentic IAAId-DNPH and IAId-DNPH.

10. Extraction of hydrazones labelled with ${ }^{14} \mathrm{C}$ from soluble mitochondrial reaction mixtures.

11. Purification of tryptophan transaminase from mung bean cytoplasmic supernatant preparations. 
Page

12. DMAC and DNPH-reacting bands in the ACID and NEUTRAL ether extracts from tryptophan transaminase reaction mixtures...........

13. DMAC and DNPH reaction of authentic indole compounds following chromatography in

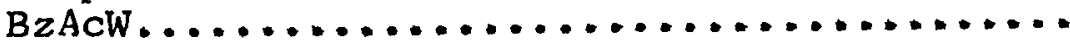

14. Substrate specificity of the tryptophan transaminase from mung bean cytoplasmic

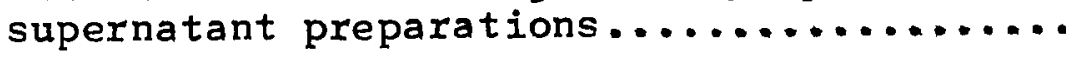

15. The effect of $\mathrm{pH}$ in the tryptophan transaminase reaction mixture on the intensity of DMAC-reacting bands in NEUTRAL and ACID ether extracts ......................

16. Rf values and colour reactions of compounds present in the NEUTRAL ether extracts chromatographed in carbontetrachloride: a cetic...........................

17. Formations of IAA and Tol from IAAld by mung

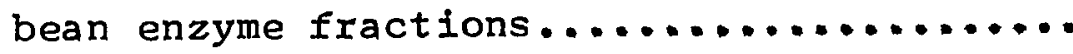

18. The effect of $\mathrm{NAD}$ and $\mathrm{NADH}_{2}$ on the formation of IAA and Tol by a Sephadex-purified cytoplasmic supernatant fraction.

19. The effect of $\mathrm{pH}$ and cofactors on the metabolism of IAAld by mung bean enyme

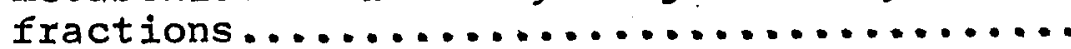

20. Instability of alcohol dehydrogenase during fractionation of a cytoplasmic supernatant preparation in the absence of 2 -mercapto-

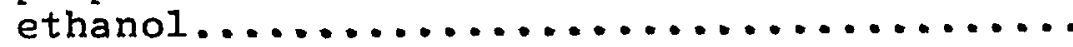

21. Purification of alcohol dehydrogenase in mung bean cytoplasmic supernatant preparations by means of $\mathrm{MnCl}_{2}$ treatment and ammonium sulphate precipitation. Activity was measured by the spectrophotometric assay using propionaldehyde as substrate.........

22. Purification of alcohol dehydrogenase from mung bean cytoplasmic supernatant preparations. Activity was measured by the spectrophotometric assay using propionaldehyde as substrate.... 156 
Page

23. Purification of alcohol dehydrogenase from mung bean cytoplasmic supernatant preparations. Activity was measured by the indole product assay using IAAld as sub-

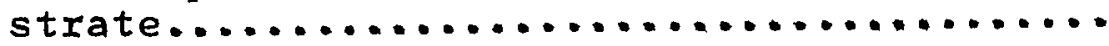

24. Purification of aldehyde dehydrogenase from mung bean cytoplasmic supernatant preparations. Activity was measured by the indole product assay using IAAId as substrate.

25. Recovery of aldehyde dehydrogenase from a mung bean cytoplasmic supernatant preparation as measured by IAA formation in the

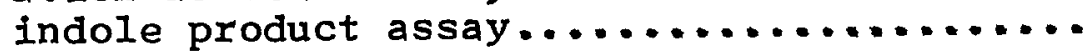

26. $\mathrm{pH}$ Precipitation of aldehyde dehydrogenase from mung bean cytoplasmic supernatant

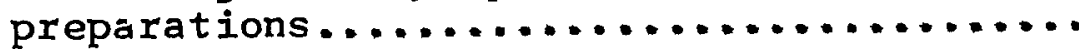

27. The denaturation of alcohol dehydrogenase in mung bean cytoplasmic supernatant preparations with decreasing $\mathrm{pH} . . . . . . .$.

28. Isoelectric precipitation of aldehyde dehydrogenase and alcohol dehydrogenase from mung bean cytoplasmic supernatant preparations...........................

29. The stability of aldehyde dehydrogenase and alcohol dehydrogenase in a cytoplasmic supernatant preparation at $\mathrm{pH} 4.2 \ldots \ldots \ldots \ldots$

30. Fractionation of enzymes by Sephadex G-200 chromatography using the $40-60 \%\left(\mathrm{NH}_{4}\right)_{2} \mathrm{SO}_{4}$ fraction obtained from a mung bean cytoplasmic supernatant preparation..........

31. Fractionation of enzymes by Sephadex G-200 chromatography using the $40-60 \%\left(\mathrm{NH}_{4}\right)_{2} \mathrm{SO}_{4}$ fraction obtained from a $\mathrm{MnCl}_{2}$-treated cytoplasmic supernatant preparation........

32. Approximate molecular weights of the enzymes froin mung bean cytoplasmic supernatant fractions ........................

33. Transaminase activity of tomato shoot-tip enzyme fractions.................... 
Page

34. Intracellular distribution of transaminase activity in tomato shoot-tip fractions....

35. Oxidation and reduction of IAAld by tomato enzymes .........................

36. Purification of tryptophan transaminase in tomato shoot-tip cytoplasmic supernatant preparations......................

37. Purification of aldehyde dehydrogenase in tomato shoot-tip cytoplasmic supernatant preparations......................

38. Measurement of Tol in NEUTRAL ether extracts of tomato and mung bean reaction mixtures..

39. Optical density of DMAC-reacting bands on chromatograms of the BASIC ether extracts from tomato and mung bean reaction

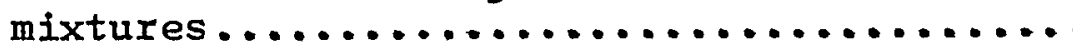

40. Plant material used for comparison of light-and dark-grown mung beans.........

41. Relative TTP-transaminase activity of lightand dark-grown mung beans.............

42. Evidence of aldehyde and alcohol dehydrogenase activities in light- and dark-grown mung beans.......................

43. Evidence for transaminase activity in cytoplasmic supernatant fractions from 12 -day old mung bean seedlings..........

44. Evidence for aldehyde and alcohol dehydrogenase activities in cytoplasmic supernatant fractions from 12-day old mung bean seedlings. Activity was measured by the indole product assay system............

45. Optical density of DMAC-reacting bands on chroma tograms of NEUTRAL ether extracts developed in two solvent systems.........

46. Cptical density of DMAC-reacting bands on chromatograms of ACID ether extracts developed in BzAcW.................. 
Page

47. Optical density of DMAC-reacting bands on chromatograms of the BASIC ether extracts developed in two solvent systems.......... 211

48. A comparison of some properties of the alcohol dehydrogenase from mung bean and pea seedlings 


\section{LIST OF FIGURES}

Page

i. Flowsheet for the preparation of cell

fractions.........................

2. Extraction schedule for the preparation

of NEUTRAL, ACID and BASIC ether extracts

of reaction mixtures when tryptophan was

used as substrate....................

69

3. Extraction schedule for the preparation of a NEUTRAL and ACID ether extract of reaction mixtures when 3-indoleacetaldehyde was used as substrate..................

4. Relationship between optical density and the peak height on the densitometer trace, measured as percentage of full scale deflection..........................

5. Relationship of IAA concentration to optical density using the standard chromatographic procedure given in the text..............

6. Relationship of Tol concentration to optical density using the standard chromatographic procedure given in the text.............

7. Relationship of IAld concentration to optical density using the standard chromatographic procedure given in the text.............

8. Relationship of ICA concentration to optical density using the standard chromatographic procedure given in the text.............

9. Extraction schedule for the preparation of hydrazone fractions..................

10. Electron micrograph of a section through a mitochondrial pellet. Glutaraldehyde-osmic fixation, Mag. 36,000 x..............

11. Thin-layer chromatogram of ACID HYDRAZONE fraction prepared from standard transaminase reaction mixtures incubated for 6 hours.... 
Page

12. UV spectra of yellow and orange bands of IPyA-DNPH eluted from TLC plates. Spectra are shown for the bands of authentic IPyADNPH and also samples of IPyA-DNPH extracted from Mito and SNS reaction mixtures...

104

13. IR spectra of the orange band of authentic IPyA-DNPH and IPyA-DNPH extracted from Mito

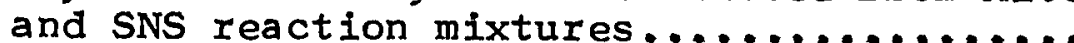

14. IR spectra of yellow and orange bands of

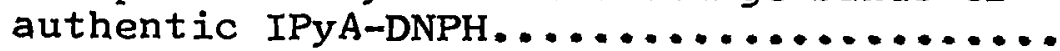

15. Two-dimensional thin-layer chromatograms of yellow and orange forms of authentic IPYA-DNPH

16. Thin-layer chromatogram of NEUTRAL HYDRAZONE fraction from standard transaminase reaction mixture incubated for 6 hours............

17. Thin-layer chromatograms of authentic and suspected bands of IAAld-DNPH and IAId-DNPH eluted from preparative TLC layer chromatograms of NEUTRAL HYDRAZONE fraction........

18. UV spectra of authentic and suspected IAAId

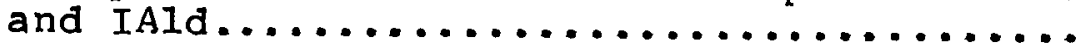

19. Paper chromatograms of NEUTRAL plus ACID ether fraction from standard transaminase reaction mixtures incubated for 6 hours....

20. Effect of $\mathrm{pH}, \mathrm{NAD}$ and $\mathrm{NADH}_{2}$ on the formation of indole products from IAAld............

21. The relationship of reaction rate to enzyme concentration with propionaldehyde as substrate.........................

22. Reaction rate as a function of propionaldehyde concentration.......................

23. Reaction rate as a function of $\mathrm{NADH}_{2}$ concentration.

24. Reaction rate as a function of ethanol

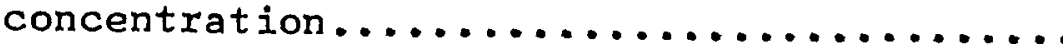


25. The relationship of reaction rate to enzyme concentration with IAAld as substrate.........................

26. Reaction rate as a function of IAAld concentration......................

27. Recovery of aldehyde dehydrogenase in ammonium sulphate fractions without or

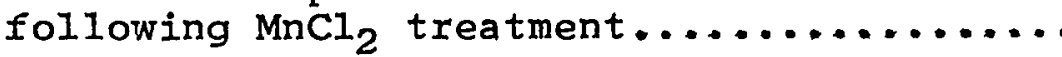

28. Paper chromatograms of NEUTRAL + ACID ether extracts from reaction mixtures containing IAAld as substrate showing requirement for pyridine nucleotide cofactor............

29. The conversion of tryptophol to IAA catalysed by ammonium sulphate fractions of a mung bean cytoplasmic supernatant preparation, in the presence or absence of $10 \mathrm{mM}$ sodium bisulphite....................

30. $\mathrm{pH}$ Precipitation of aldehyde dehydrogenase from a mung bean cytoplasmic supernatant preparation.

3I. UV spectra of compounds eluted from chromatograms of NEUTRAL ether extract developed in BzAcW.............................

32. UV spectra of compounds eluted from chromatograms of ACID ether extracts developed in $\mathrm{BzACW}$. 
Abbreviations and Formulae of Indole Compounds:

Tryptophan

TTP<smiles>NC(Cc1c[nH]c2ccccc12)C(=O)O</smiles>

3-Indolepyruvic acid

IPyA

$\mathrm{R}-\mathrm{CH}_{2}-\mathrm{C}-\mathrm{COOH}$

3-Indolelactic acid

ILA

$\mathrm{R}-\mathrm{CH}_{2}-\underset{\mathrm{OH}}{\mathrm{CH}}-\mathrm{COOH}$

3-Indoleacetaldehyde

IAAld

$\mathrm{R}-\mathrm{CH}_{2}-\mathrm{CHO}$

3-Indoleacetic acid

IAA

$\mathrm{R}-\mathrm{CH}_{2}-\mathrm{COOH}$

Tryptophol

Tol

$\mathrm{R}-\mathrm{CH}_{2}-\mathrm{CH}_{2} \mathrm{OH}$

Tryptamine

Tam

$\mathrm{R}-\mathrm{CH}_{2}-\underset{\mathrm{N}}{\stackrel{\mathrm{CH}}{\mathrm{C}} \mathrm{H}_{2}}$

3-Indoleglyoxylic acid

$\mathrm{R}-\mathrm{C}-\mathrm{COOH}$

3-Indoleglycollic acid

$\underset{\text { O̊dH }}{\mathrm{R}-\mathrm{COOH}}$

3-Indolea ldehyde

IAld

$\mathrm{R}-\mathrm{CHO}$

3-Indolecarboxylic acid

ICA

$\mathrm{R}-\mathrm{COOH}$ 


\section{INT RODUCTION}

Studies in this laboratory have been directed for a number of years to the elucidation of the pathway of biosynthesis of IAA in higher plants. Tracer experiments carried out with excised shoot systems have provided good evidence that tryptophan is the primary precursor of this important plant growth hormone (Wightman, 1962, 1964; Hope, 1963; Schneider, 1965). However, the expected involvement of the key intermediate compounds, 3-indolepyruvic acid and 3-indoleacetaldehyde, has not been convincingly demonstrated from these in vivo experiments and the percentage conversion to free IAA was found to be small. From these studies it appeared that the production of IAA in vivo was rigidly controlled.

Some attempts have been made to study the conversion of tryptophan to IAA in cell free systems, but the rate of this conversion was again found to be very low (Wildman, Ferri and Bonner, 1947; Gordon and Sanchez Nieva, 1949; Gordon, 1956). Indeed, in order to detect the formation of IAA in these experiments, it was found necessary to employ a sensitive bioassay such as the Avena curvature test.

Since the time of these early studies, improved techniques in enzymology have permitted the separation and characterisation of a large number of enzymes. A number of enzymes catalysing reactions involving tryptophan and other possible precursors of IAA have been demonstrated in animal systems 
(see Literature Review) and the importance of adding specific cofactors to promote enzyme activity has been clearly shown. Moreover, the conditions required for each reaction were found to differ appreciably.

In view of this work, it appeared that the low rate of conversion of tryptophan $\longrightarrow$ IAA previously reported in plant enzyme preparations may have resulted from the absence of essential cofactors, or the use of reaction conditions unfavourable for one or more of the enzymies involved. It seemed reasonable to anticipate that, as a first approach to the problem, enzymes with similar properties to those found in animal systems might be present in higher plants and that standard methods of enzymology could be used to extract, purify and assay these enzymes. This approach was successfully adopted in recent work by Wightman and Fowden (1966). who convincingly demonstrated the presence of a transaminase in mung bean mitochondria which catalysed the conversion of L-tryptophan to 3-indolepyruvate.

The experiments to be described here were designed to study the metabolism of L-tryptophan using partially-purified plant enzyme systems extracted from mung bean seedlings and tomato shoot tips. In particular, the aim was to seek unequivocal evidence for the individual reactions in the reaction sequence shown below:

$$
\text { L-TTP } \longrightarrow \text { IPyA } \longrightarrow \text { IAAId } \longrightarrow \text { IAA. }
$$


Such evidence should include the extraction and identification of the product of each reaction and also a study of the characteristics of each enzyme involved. 


\section{LITERATURE REVIEW}

Over the past thirty years many reviews have been written on the natural occurrence, biochemistry and physiology of auxins. Early work in the field was summarised by Went and Thimann (1937) and more recent books by Leopold (1955) and Audus (1959) review the work of the 1940s and 1950s. Stowe (1959) wrote an extensive review of the natural occurrence and metabolism of simple indoles found in plants, and Gordon (1961) discussed the biogenesis of 3-indoleacetic acid (IAA). More recent work has been discussed in the reviews by Fawcett (1961), Wightman (1962) and Shantz (1966) and in two theses from this department, Hope (1963) and Schneider (1965).

These reviews clearly show that the only naturallyoccurring indoles with auxin activity per se are IAA and, in some cases, 3-indoleacetonitrile (IAN) (Fawcett, 1961). Other naturally-occurring indoles may show auxin activity, but only after enzymatic conversion to IAA. The activity of any of these compounds in a bioassay is usually related to the ability of the plant tissue to convert the compound to IAA. This group of compounds includes tryptophan (TTP), tryptamine ( $\mathrm{Tam}), 3$-indolepyruvic acid (IPyA), 3-indoleacetaldehyde (IAAld), and tryptophol (Tol). Such indole compounds may be considered as auxin precursors (Gordon, 1961). In many cases the activity of IAN is a result of its conversion to IAA and therefore IAN should also be considered an 
IAA precursor. A third group of naturally-occurring indoles exhibit no auxin activity and some of this group have been shown to be degradation products of IAA or one of the auxin precursors. This group of compounds includes 3-indolealdehyde (IAId) and 3-indolecarboxylic acid (ICA).

There is a considerable body of evidence to suggest that tryptophan is the primary precursor of IAA in higher plant tissues. This evidence, reviewed by Gordon (1961), includes the wide occurrence of TTP as a free amino acid and the correlation between the levels of TTP and the ability of the tissues to convert TTP to IAA. In addition, there is evidence that TTP is the precursor of IAA in the fungus Rhizopus suinus (Thimann, 1935), bacteria (Kaper and Veldstra, 1958) and animals (Weissbach et a1., 1959).

Based on this evidence, biochemistry and plant physiology textbooks for many years have shown the biosynthetic pathway to IAA as originating with TTP, passing through either IPyA or Tam to IAAld and then finally to IAA. The proposed pathways are shown below:

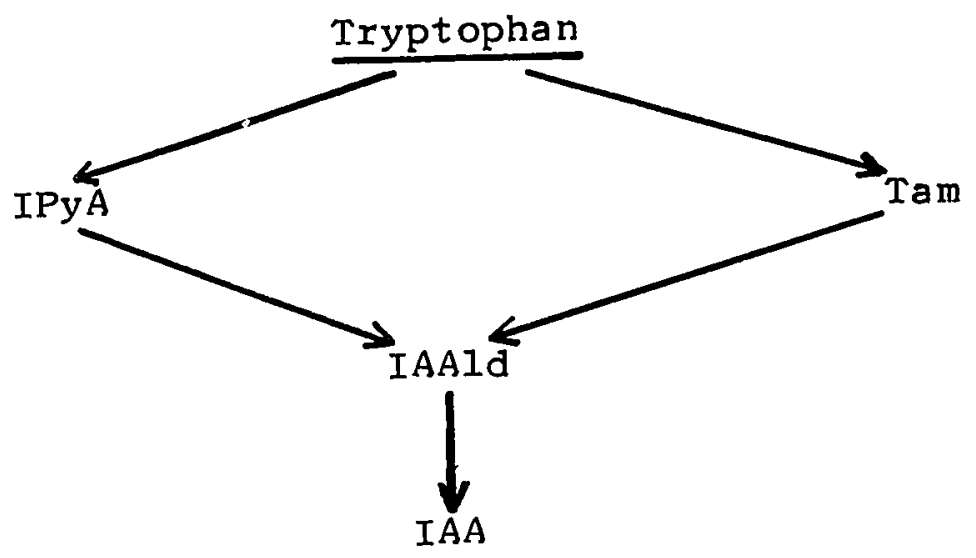


In recent years, there... has been increasing evidence of the presence of non-indole auxins in plant tissues. Vendrig (1967) discusses a steroid-like auxin from coleus, and Lewis and co-workers have attempted to purify a non-indole auxin from citrus fruit which exhibits some of the properties of a $\beta$-naphthol (Lewis et a1., 1965; Khalifah et aI., 1965). Both the coleus and citrus auxins appear to be active in the Avena curvature bioassay. Although these compounds are of interest to an overall understanding of growth regulation in plants, they fall outside the scope of this work and will not be considered further.

A. Natural Occurrence and Stability of Simple Indoles

\section{Tryptophan:}

Tryptophan is the predominant indole compound in most plant tissues. It exists both as a constituent of proteins and as a free amino acid. Virtanen and Laine (1936) were the first to consider changes in the tryptophan content of protein during the life of a plant. The proportion of tryptophan in protein remained constant except just before flowering, when values temporarily rose.

When tomato plants were grown in nutrient culture solutions with and without zinc, it was shown by Tsui (1948) that both total tryptophan and free auxin levels were markedly decreased before visible deficiency symptoms appeared. When zinc was added to the plants both tryptophan and auxin levels rose. Leaf discs from both zinc deficient and control plants were 
shown to convert TTP to auxin at the same rate and Tsui concluded that in zinc deficient plants, TTP synthesis was inhibited and this resulted in lower levels of auxin synthesis.

Interest has also been shown in the levels of free TTP in plants. Christiansen and Thimann (1950) showed that TTP was a prominent amino acid in pea epicotyls and this has subsequently been confirmed by Lawrence and Grant (1963) who also found TTP in pea roots. However, these latter workers did not detect TTP in either the root or shoot tips of peas after 3 or 5 days of germination. Attempts have been made to correlate the levels of free TTP with the level of free auxin in the tissue. Nitsch (1952) reported that the level of free TTP varied in a similar manner to that of free auxin in the developing strawberry achene. An even greater accumulation of TTP was found in the receptacle tissue in which auxin levels were low. Lund (1956) has shown that a fall in free TTP coincided with a rise in auxin levels in the styles and ovaries of tobacco.

In view of the incorporation of TTP into proteins, the level of free TTP in plant cells must represent an equilibrium between its synthesis and utilisation. Stowe (1959) concluded that "... there appears to be more than enough free tryptophan to serve the plant as the source of indoleacetic acid formed by these tissues". In contrast, Gordon (1961) suggested that the level of IAA "... is controlled in part by the availability of tryptophan in a highly competitive system". The biosynthesis of TTP has been studied by Greenberg and Galston (1959), Wightman, Chisholm and Neish (1961), and more recently by 
Chen and Boll (1968). These studies all confirm that indole can act as a precursor for TTP and the reaction can be represented as follows:

$$
\text { Indole }+ \text { L-serine } \longrightarrow \text { L-tryptophan }
$$

No experimental evidence has yet been presented for the involvement of 3-indoleglycerol phosphate in the above reaction in higher plants. Chen and Boll (1968) found TTP-synthetase activity in pea stems and a lower activity in pea roots, but could not detect any activity in tomato roots. The distribution of this enzyme may well be a determining factor in the distribution of free TTP in plant tissues.

With regard to the chemical properties of tryptophan, traces of IAA have been detected in synthetic samples by the use of bioassay techniques. However, there is no evidence of contamination by IAA or any other indole compound using chromatographic and colorimetric techniques. Schneider (1965) has shown that $\mathrm{D}, \mathrm{L}-\mathrm{TTP}-3^{14} \mathrm{C}$ may contain as many as 6 radioactive contaminants which were ether extractable. It is clear that samples of radioactive TTP should either be extracted with ether prior to use in an experiment, or adequate controls should be included in the experiment.

\section{Indolepyruvic acid:}

There have been a number of reports of the isolation of IPyA from higher plant tissues, but in most cases the properties of the extracted compound differed from those of synthetic 
IPyA. In particular, early reports of the isolation of IPyA involved chromatography in an ammoniacal solvent (Stowe and Thimann, 1954; V1itos and Meudt, 1954; Hitchcock et a1., 1955) but Bentley et al. (1956) have convincingly demonstrated thrat IPyA is completely broken down in ammonia-containing solvents and this has been confirmed in this laboratory and by several other workers (Kaper and Veldstra, 1958; Winter, 1964).

Crystaline IPyA exists as the enol tautomer (Stowe, 1955; Kaper et al., 1963) and is quite stable in the dry state. In mildly alkaline, aqueous solution, tautomerisation to the keto form occurs rapidly and in the equilibrium mixture less than $6 \%$ of the IPyA exists as the enol tautomer (Spencer and Knox, 1962). Under these mild, alkaline conditions, breakdown occurs rapidly unless oxygen is excluded and even then, IAId is formed (Schwarz and Bitencourt, 1960; Schwarz, 1961). Pitt (1962) has shown that IAld is formed as a direct oxidation of the enolate ion with the formation of oxalate. The reaction can be represented as:

$$
\mathrm{R}-\mathrm{CH}=\underset{\mathrm{OH}}{\mathrm{C}}-\mathrm{COO}^{-}+\mathrm{O}_{2} \longrightarrow \mathrm{R}-\mathrm{CHO}+\underset{\mathrm{COO}^{-}}{\mathrm{COO}^{-}}
$$

where $\mathrm{R}$ represents the indole nucleus or another aromatic ring system. Under acidic conditions of chromatography, both the enol and keto tautomers of IPyA appear to be stable. Schwarz (1961) was able to clearly separate the tautomers by acid chromatography, obtain UV spectra of the two forms and demonstrate their interconversion. 
The degradation products of IPyA in the presence of oxygen have never been fully determined. Under ammoniacal conditions, IAA, IAld, 3-indoleglyoxylic acid, 3-indoleglycollic acid and 3-indoleacetamide have all been suggested as breakdown products and chromatographic, chromogenic and UV spectral data support these identifications (Bentley et al., 1956; Kaper and Veldstra, 1958). The decomposition of IPyA in solution to form IAA has been shown by Wildman, Ferri and Bonner (1947), Stowe (1955) and Gordon and Paleg (1961). Stowe (1959), in reviewing the work of Schwarz (1957), notes that IAAld, 3-indolenine-acetaldehyde and 3-indolelactic acid were also proposed as breakdown products of IPyA. After reading the original paper, it is clear that Schwarz's identification of these compounds was based on insufficient data. For example, the UV spectrum for the suspected IAAld bears no resemblance to that of authentic IAAld as described by Gray (1959). Both Larsen (1951a) and Fawcett (1961) attribute Wildman, Ferri and Bonner (1947) with a demonstration of the decomposition of IPyA to form IAAld and they further refer to the UV spectrum obtained by Schwarz (1957) as supporting evidence. This reference to the work of Wildman et al. is clearly a mistake since these authors make no such claim and, for the reason given above, the UV spectrum obtained by Schwarz was not of IAAld.

There is, however, one other claim that solutions of IPyA will spontaneously decompose to yield IAAld. Gordon and Sanchez Nieva (1949b) claim to have extracted a neutral 
compound from solutions of IPyA which could be converted to IAA by the "soil" treatment of Larsen (1944). They identify this neutral compound as IAAld. The source and purity of the IPyA used in the experiment was not given and chromatographic procedures were not then available to further characterise the neutral compound. Since the work of Gordon and Sanchez Nieva has never been confirmed, their claim that IAAld arose spontaneously from IPyA must be viewed with caution.

The true identity of the compound observed by Hitchcock et al. (1955) and referred to as IPyA came from the later work of Row, Sanford and Hitchcock (1961). These workers retracted the earlier identification and demonstrated that the compound is in fact 3-indoleacety $I-D, L$-aspartic acid (IAAsp). This latter compound was shown by Andreae and Good (1955) to be a product when IAA was incubated with etiolated pea tissue. The paper by Row et al. (1961) was the first report of its natural occurrence in plants and they also suggest that the compound referred to by Vlitos and Meudt (1954) as IPyA was probably another instance of the presence of IAAsp in plant tissue.

Winter (1964), on the other hand, presented good evidence for the natural occurrence of a compound in corn seed which appeared to have al1 the properties of authentic IPyA. The extracted compound had an Rf identical to authentic IPyA in several acidic solvent systems and on ammoniacal chromatography, both the extracted and authentic compounds broke down 
to give an identical pattern of six decomposition products (cf. Kaper and Veldstra, 1958). Under acidic chromatographic conditions, the chromogenic reactions of the extracted and authentic IPyA were identical. UV spectra were also presented for both the enol tautomer and its conversion to the keto tautomer in $0.1 \mathrm{~N} \mathrm{NaOH}$. This report, however, remains the only convincing demonstration of IPyA in higher plant tissues and even here the evidence comes from dry kernels and not from an actively growing tissue.

Several reports of the formation of IPyA from TTP in plant tissues have appeared. The thesis of Dannenburg (1957) and the paper by Dannenburg and Liverman (1957) have often been referred to in support of this conversion. However, the evidence put forward by these workers is based entirely on the position of spots on autoradiographs of chromatograms of ether extracts obtained from the TTP- ${ }^{14} \mathrm{C}$ fed tissue. Supporting evidence, such as UV spectra or chromogenic reactions, is entirely lacking. Furthermore, the supposed IPyA zone was located following ammoniacal chromatography, which would seem impossible in view of the chromatographic properties of IPyA as demonstrated by Bentley et al. (1956) and Kaper and Veldstra (1958). Perhaps this zone represented IAAsp, but quite clearly, Dannenburg and Liverman did not demonstrate IPyA formation.

The work of Libbert and co-workers presents quite a different problem in interpretation. Libbert and Brunn (1961) claimed to demonstrate the formation of IPyA, 3-indolelactic acid (ILA) and tryptophol (Tol) from TTP, catalysed by a 
crude enzyme preparation from peas. However, Wichner and Libbert $(1968 \mathrm{a}, \mathrm{b})$ maintain that these compounds were formed as a result of bacterial contamination and not as a result of plant enzymes. In contrast, the enzymatic formation of IPyA from TTP by a soluble enzyme fraction prepared from mung bean mitochondria has been convincingly demonstrated by Wightman and Fowden (1966). A non-enzymatic reaction between TTP and quinones to form IPyA was described by Gordon and Paleg (1961) and this work, together with the findings of Wightman and Fowden, will be discussed later.

\section{Tryptamine:}

Although tryptamine (Tam) has often been implicated in the biosynthetic pathway to IAA, there have been very few reports of its natural occurrence in higher plants. Unlike IPyA, Tam appears to be stable in aqueous solution, and so the paucity of data on its natural occurrence must be attributed to factors other than its breakdown during extraction procedures. In particular, since Tam is a basic indole, it can only be extracted into ether if the $\mathrm{pH}$ of the aqueous phase is distinctly alkaline. Most workers have examined the indole compounds of plants only by extraction into acid and neutral ether fractions and in all these investigations, Tam would not have been extracted, even if present. Secondly, since Tam is inactive in some bioassay systems such as the Avena curvature test, its presence would again be undetected in some of the earlier investigations. Thirdly, even if Tam 
is an intermediate in the biosynthesis of IAA, it might not be possible to detect it chromatographically unless large quantities of tissue were used.

In the cases where Tam has been identified, its presence may result either from an increased synthesis or the absence of Tam-degrading enzymes. The first report of the natural occurrence of Tam in higher plants was made by White (1944). In an extensive study of the alkaloids of the Leguminosae, White found that the stems, leaves and flowers of Acacia floribunda contained a mixture of tryptamine and phenylethylamine. In the flowers, these two bases each represented about $0.5 \%$ of the dry weight and in the stems and leaves, tryptamine predominated and represented about $0.2 \%$ of dry weight. Small quantities of Tam were detected in one closely related species, $\underline{A}$. pruinosa, but not in another, A. Iongifolia. White (1957) later reported the isolation of Tam from other Acacia species. The mechanism of Tam accumulation in these species has never been elucidated, but it is difficult to envisage a physiological role for such high concentrations. The accumulation of other related indole alkaloids, including gramine, has also never been explained physiologically.

There have been three reports of the accumulation of Tam in ripening fruits. West (1958) demonstrated the accumulation of serotonin (5-hydroxytryptamine) in ripening bananas but could not detect any Tam. Tam was also found in tomatoes and the level rose from $0.18 \mu \mathrm{g} / \mathrm{g}$ to $3.75 \mu \mathrm{g} / \mathrm{g}$ as the fruit ripened. Traces of serotonin were also detected. 
These results were extended by West (1959), who showed the distribution of both Tam and serotonin in the ripening tomato fruit. The greatest concentration of Tam was found in the pulp and washed pips of ripe tomatoes and the highest concentration of serotonin was found in the pulp. Although the expected precursors to Tam and serotonin would be TIP and 5-hydroxytryptophan respectively, these compounds were not detected in any extracts and the problem of the synthesis of these compounds was not resolved.

Udenfriend, Lovenberg and Sjoerdsma (1959) confirmed the findings of West concerning the changes in serotonin content of banana peel during ripening. They report that they were unable to detect either 5-hydroxytryptophan or 5-hydroxytryptophan decarboxylase activity in the green banana. This again raises the interesting problem of the precursor of these amines in higher plants. Udenfriend et al. also investigated the content of indole amines in a variety of fruit and vegetables. Tam was detected in 6 and serotonin in 7 of the 12 plants examined and these were all ripe fruits. It is interesting to note that in some plants only one of the amines was detected and the other was absent. One example has already been mentioned, namely the occurrence of high levels of serotonin in banana skin; another example would be the detection of Tam, but not of serotonin, in the blue plum. Since Tam was only detected in ripe fruit and was absent in unripe fruit, it is difficult to envisage tryptamine as a precursor of IAA in these tissues. 
One further claim for the presence of Tam in higher plants comes from the work of Hemberg (1958) on the auxins in maize kernels. Hemberg demonstrated the presence of three compounds which reacted to both ninhydrin and :Etrilick's reagent. These compounds appeared to be interconvertible on repeated chromatography in a number of solvents. Authentic Tam was shown to behave in a similar manner in the solvents employed. Since more specific methods are now available for the identification of Tam (eg. Udenfriend et al., 1959) there is a need for a reinvestigation of this problem. This is particularly desirable in view of the suggestion by skoog (1937) that Tam might be the auxin precursor translocated from the endosperm to the coleoptile tip and the demonstration by Yamaki and Nakamura (1952) that enzymes in the corn embryo can convert Tam to IAA.

In addition to these reports on the natural occurrence of tryptamine, there have been many references to the work of Dannenburg and Liverman (1957) as having demonstrated the formation of Tam from TTP (see Stowe, 1959; Fawcett, 1961; Gordon, 1961). The thes is of Dannenburg (1957) showed the presence of a compound in the basic ether fraction which was identified as Tam on the basis of its position on autoradiographs. This compound was formed from radioactive TTP by watermelon slices, Avena coleoptile segments and an acetone powder from Avena coleoptiles. The same compound also appeared to be formed from radioactive indoleacetonitrile by Avena coleoptile tissue. The chemical conversion of IAN 
to Tam has been accomplished by reduction with sodium and alcohol (White, 1944) but this reaction would not appear to be favoured energetically in a biological system. Since neither chromogenic reactions nor UV spectra were presented by Dannenburg and Liverman (1957) to support the identification of Tam, their results and conclusions should be treated with extreme caution.

According to Fawcett (1961), "IAA was formed from tryptophan via tryptamine and IAAld in pineapple (Gordon and Sanchez Nieva, 1949b) and maize (Yamaki and Nakamura, 1952)". These workers were able to show the conversion of either TTP or Tam to IAA but neither of the groups demonstrated the formation of Tam from TTP. The ability of a tissue to convert Tam to IAA cannot be taken as evidence that TTP decarboxylation occurs in vivo, unless it can also be shown that Tam is present in the tissue or can be formed from TTP. As far as the present author is aware, this has been demonstrated in only the one instance discussed below. Phelps and Sequeira (1967) fed radioactive TTP to whole tobacco plants or to cell free homogenates from the stem tips. In both cases a basic radioactive compound could be extracted which gave a violet-coloured Ehrlich reaction, co-chromatographed with authentic Tam in several solvent systems and exhibited fluroescence and excitation maxima similar to authentic Tam. It appears that in this work, the compound extracted was indeed tryptamine and further investigation of the characteristics of the Tam-forming enzyme would be of interest. 


\section{Indoleacetaldehyde:}

The presence of a neutral compound with growth-promoting properties was first reported by Larsen (1939) in extracts of etiolated epicotyls of peas and broad bean and hypocotyls of sunflower. Subsequent investigation led to the conclusion that this compound was identical with 3-indoleacetaldehyde (IAAld). However, in 1952, Jones et a1. reported the presence of indoleacetonitrile in cabbage and it was suggested that this neutral indole may account for some of the activity previously attributed to IAAld.

Larsen and co-workers have continued to investigate the occurrence and biosynthesis of IAAld and also its conversion to IAA. At first, this work was hindered by the lack of pure authentic IAAld. When attempts were made to concentrate and purify IAAld, polymerisation occurred (Larsen, 1951a). The active compound was characterised by the ability of xanthine oxidase (Schardinger enzyme) to convert IAAld to an active auxin, presumably IAA. Diffusion velocity and lability in either hot acid or alkali were also used as criteria for its identification.

Several other workers reported the presence of IAAld in plant tissues. Of these, Gordon and Sanchez Nieva (1949a) were able to demonstrate the presence of IAAld in pineapple leaves and also in dandelion roots. Characterisation methods included the formation of dimedone and sodium bisulphite addition products. In addition, this neutral compound was converted to an acid auxin which was shown to be active in the Avena curvature test. Yamaki and Nakamura (1952) studied the 
chromatographic properties of suspected IAAld extracted from germinating maize embryos and used the ability of IAAld to form a bisulphite addition product as a means of preliminary purification. These workers were able to show that the suspected IAAId was identical in all respects to an authentic sample synthesised from TTP and isatin by the method of Larsen (1944). Furthermore, the suspected IAAld was closely correlated with the level of IAA in the extract. Enzymes which could convert TTP, Tam, or IAAId to IAA were also described but no properties of these enzymes were investigated.

A simplified method of synthesising IAAId was described by Gray (1959) and it was shown that if IAAld is stored as the bisulphite addition product, it is quite stable. Larsen and Aasheim (1961), using purified samples of IAAId, were able to show that IAAld was present in peas and to confirm that the neutral indole in cabbages was not IAAId but IAN. This work has been extended by Rajagopal (1967a) who was able to demonstrate IAAld in both peas and sunflower and was able to show its conversion to IAA. Rajagopal (1968) has also shown that IAAld is present in peas grown under aseptic conditions, although the level was lower than in the non-aseptic plants.

Despite the above evidence for the natural occurrence of IAAld, the compound has never been extracted from plant tissue in sufficient quantity to be chemically characterised. Recently, Rajagopal (1967a) extracted $820 \mathrm{~g}$ of etiolated pea shoots and obtained enough IAAId to record a UV spectrum. 
The characteristics of this spectrum, however, were only those of a typical indole compound (Kaper et al., 1963b) and from the experience of the present author, more information would have been obtained by preparing the 2,4-dinitrophenylhydrazone of IAAld and recording its UV spectrum.

With regard to the possible precursor of IAAId, Clarke and Mann (1957) have demonstrated the enzymatic conversion of Tam to IAAld in cell free systems from pea seedlings. However, the natural occurrence of Tam or its formation from TTP has never been demonstrated in pea plants. In one report, Libbert and Brunn (1961) claimed to detect the formation of Tam in cell free systems from pea seedlings, but Wichner and Libbert $(1968 \mathrm{a}, \mathrm{b})$ have retracted this claim and account for the formation of Tam as an expression of bacterial contamination. Phelps and Sequeira (1967) have shown IAAld formation from either Tan or TTP in cell free systems from tobacco shoot tips and, as previously noted, these authors were also able to show Tam formation from TTP. This paper presents the only evidence available for the reaction steps, TTP $\longrightarrow$ Tam $\longrightarrow$ IAAId; in a single tissue, and even in this work the possibility of bacterial activity was not excluded.

Unequivocal proof of the enzyme formation of IAAld from IPyA is not yet available. The claim of Gordon and Sanchez Nieva (1949b) for a non-enzymatic decarboxylation has already been critically discussed. In later work, Gordon (1956) claims that X-irradiation specifically 
inactivated an enzyme catalysing the oxidation of IAAld to IAA in whole mung bean seedlings and, as a result, when cell free homogenates from X-irradiated plants were incubated with TTP, a neutral compound identified as IAAId accumulated in the reaction mixture. Gordon maintained that neither IPyA nor Tam were intermediates in the formation of the compound identified as IAAld. This identification appears to rest largely on the ability of "coleoptile preparations" to convert the neutral compound to IAA. However, 3-indoleacetamide is another neutral compound which can be converted to IAA by wheat coleoptiles (Seeley et al., 1956) and Riddle and Mazelis (1965) have shown that peroxidase catalyses the conversion of TTP to 3 -indoleacetamide. In the light of this later work, the neutral compound described by Gordon should be reexamined.

5. Indoleacetic acid and its conjugation compounds:

Evidence for the presence of IAA in higher plant tissues has been fully discussed in numerous reviews (eg. Bentley, 1958; Stowe, 1959; Gordon, 1961). There has been some interest in recent years in the formation of 3-indoleacetylaspartic acid (Good, Andreae and Van Ysselstein, 1956) and 1-(3-indoleacety1)B-D glucose (Zenk, 1961). The formation of these compounds is reviewed by Shantz (1966) and it appears that they are synthesised from IAA, possibly as a detoxication mechanism. Good et al. (1956) also showed that indoleacetamide was formed 
when IAA was fed to plant tissues but, as shown above, many tissues can hydrolyse indoleacetamide to IAA (Seeley. et al., 1956) and this reaction is catalysed by an amidase enzyme (Riddle and Mazelis, 1965).

\section{Other simple indoles:}

Larsen (1951a) suggested that tryptophol (Tol) might be formed from IAAld by a "dismutation" reaction but did nd demonstrate its presence in plants. Hope (1963) was able to show that a compound with identical chromatographic and chromogenic properties to Tol was present in tomato shoots and that this compound increased greatly when the tissue was fed TTP. Wightman (1964) demonstrated that Tol was also formed when 3 -indolelactic acid was fed to cut tomato shoots. Rajagopal (1967) has shown the natural occurrence of Tol in sunflower seedlings. Unequivocal evidence for the occurrence of Tol in cucumber seedlings was presented by Rayle and Purves (1967) who used mass spectroscopy, gas chromatography and UV spectroscopy to identify the compound.

Henbest, Jones and Smith (1953) isolated indoleacetonitrile (IAN) from cabbage and Wightman (1962) has shown that IAN $-{ }^{14} \mathrm{C}$ is formed when $T T P-{ }^{14} \mathrm{C}$ is fed to cabbage heads. IAN can be oxidised to IAA by many kinds of tissue segments. (Seeley et al., 1956; Thimann and Mahadevan, 1958). Kutacek and Prochazka (1964) have shown that IAN is formed from glucobrassicin in Brassica tissue and tracer experiments 
showed that the indole component of this glucoside is derived from tryptophan. Several other indole compounds have been isolated from plant tissues, but since they are either breakdown products of IAA or their relationship to IAA metabolism is not known, they will not be reviewed here. Information regarding many of these compounds is presented by Stowe (1959).

\section{B. Enzymes catalysing the Metabolism of Tryptophan}

\section{Transaminase:}

Experiments by Wilson, King and Burris (1954) demonstrated that many amino acids will act as substrates for plant transaminases. Using a particulate and a supernatant fraction from white lupine as a source of enzyme, these workers demonstrated a slow rate of transamination between tryptophan and $\alpha$-ketoglutaric acid $(\alpha-K G)$. Subsequently, Gamborg and Wetter (1963) purified an enzyme from 10-day old light-grown mung bean seedlings which was particularly active towards aromatic amino acids. Pyruvate was shown to be as effective as $\alpha$-ketoglutarate as the amino group acceptor. The assay system for their enzyme employed a spectrophotometric procedure derived from Lin et al. (1958a) based on the shift in the absorption of aromatic $\alpha$-keto acids in alkali or in borate buffer. None of these workers, however, isolated and chemically characterised the expected keto acid product, 3-indolepyruvic acid, from their reaction systems. 
Wightman and Fowden (1966), in a study of the mitochondrial tryptophan transaminase of etiolated mung bean seedlings, clearly showed the formation of glutamate in the presence of $\alpha$-ketoglutarate and also unequivocally demonstrated the formation of IPyA. Their identification of IPyA was based on the isolation of its dinitrophenylhydrazone which was characterised by IR spectroscopy and hydrogenation to tryptophan.

Although the enzyme studied by Gamborg and Wetter (1963) was originally considered to be relatively specific for aromatic amino acids, a later study (Gamborg, 1965) indicated that a wider spectrum of amino acids may be catalysed by the same enzyme. This point is of considerable importance because, if other amino acids can compete for the same active site on the transaminase molecule, they would competitively inhibit tryptophan transamination. Wightman (personal communication) has shown that mitochondria, isolated from roots, hypocotyls and cotyledons of 4-day old etiolated mung bean and Lens seedlings, contain an active tryptophan transaminase. Gamborg and Keeley (1966) have also studied the aromatic amino acid transaminase activity during germination of light-grown mung bean seedlings. Transaminase activity in the shoot increased gradually over the first 12 days and the high level of activity at that time was maintained at least over the next 10 days. In the cotyledons, transaminase activity also increased but at a slower rate and when the cotyledons 
senesced at about 9 days, their transaminase activity per gram fresh weight was only one quarter that of the shoot tissue. This study was carried out using phenylalanine and pyruvate as substrates, but Gamborg and Wetter (1963) had previously studied the enzyme from 17-19 day old mung bean shoots with TTP and $\alpha$-ketoglutarate or pyruvate as substrates. In contrast to these results, the enzyme extracted from etiolated mung bean mitochondria by Wightman and Fowden (1966) was much more active with $\alpha$-ketoglutarate as the amino group acceptor than with pyruvate as the acceptor.

A more detailed study has been made of the aromatic amino acid transaminases of rat liver. Lin et al. (1958a,b) demonstrated two independent tryptophan transaminases and they claim that these enzymes are distinct from other aromatic amino acid transaminases. One of these enzymes required $\alpha$-ketoglutarate and the other pyruvate as the amino acceptor. The former enzyme was adaptive and its activity was increased by hydrocortisone administration (Lin, 1959). Jacoby and La Du (1964) showed that tyrosine: $\alpha$-ketoglutarate transaminase purified 500-fold, also catalysed the transamination of a number of aromatic amino acids including phenylalanine and tryptophan. The increase in tryptophan: $\alpha$-ketoglutarate transaminase activity following hydrocortisone induction could be accounted for by the increase in tyrosine: $\alpha$-ketoglutarate transaminase. These results indicate that there is more than one tryptophan 
transaminase, and at least one of these enzymes is not as specific as proposed by Lin et al. (1958b)

Similar results have been obtained by Tangen, Fonnum and Haavaldsen (1965) who suggested the presence of 3 aromatic amino acid transaminases in rat brain tissue, which they have named transaminases I, II and III. These enzymes were shown to exhibit their main activity towards dihydroxyphenylalanine, other phenyl amino acids, and indole amino acids respectively. Following 100-fold purification, transaminase II still catalysed the transamination of tryptophan at $33 \%$ the rate of tyrosine. Transaminase III, on the other hand, when purified 25-fold was found to transaminate tryptophan at $300 \%$ the rate of tyrosine. These two transaminases also differed in their activity towards amino acceptors; transaminase II preferring $\alpha$-ketoglutarate while transaminase III had a slight preference for oxalacetate. The activity towards pyruväte was not reported for either enzyme. The enzymes could not be separated by Sephadex G-200 chromatography, which suggests that both enzymes had very similar molecular weights .

All the transaminases discussed above appear to have a $\mathrm{pH}$ optimum of $8.0-8.5$ and require the addition of pyridoxal phosphate for optimum activity. The affinity of the enzymes for the amino acid substrate was always found to be low (see Table A), whereas their affinity for $\alpha$-ketoglutarate was greater and a $\mathrm{Km}$ value around 
$1 \times 10^{-3} \mathrm{M}$ has been reported (Gamborg and Wetter, 1963; Lin et a1., 1958a).

Table A. Reported $\mathrm{km}$ values for aromatic amino acids given by three transaminase preparations.

Reaction catalysed:
$\mathrm{Km}$ for Amino Acid

$$
\text { Source of Enzyme* } 3
$$

L-Phenyla lanine: $\alpha-K G$

L-Tyrosine: $\alpha-\mathrm{KG}$

L-Tryptophan : $\alpha-K G$
$4.0 \times 10^{-4}$

$2.7 \times 10^{-4}$

$1.7 \times 10^{-3}$
$8.0 \times 10^{-2}$

$3.4 \times 10^{-3} \quad 1.5 \times 10^{-3}$

$1.0 \times 10^{-2} 3.0 \times 10^{-2}$

* Source of Enzyme: 1. Mung bean shoots (Gamborg and Wetter, 1963).

2. Rat liver (Lin et a1., 1958a).

3. Rat liver (Jacoby and La Du, 1964).

\section{Decarboxylase:}

In view of the potential importance of this reaction and the apparent confusion in the literature over the demonstration of tryptophan decarboxylase activity, it would appear worthwhile to review the evidence for this enzyme. Tryptophan carboxylase (EC. 4.1.1.27) catalyses the reaction shown below:

$$
\text { L-Tryptophan } \longrightarrow \text { tryptamine }+\mathrm{CO}_{2}
$$

The first evidence for this reaction came from the work of Ewins andilaidlaw (1910) who compared the product obtained from the action of putrifying bacteria on tryptophan with authentic Tam synthesised by Ewins. For the authentic free 
base, Ewins (1911) reported an m.p. of $145-146^{\circ} \mathrm{C}$, but this value has never been confirmed and both Manske (1931) and White (1944) obtained values of $118^{\circ} \mathrm{C}$ and $116^{\circ} \mathrm{C}$ respectively. However, the m.p. of $246^{\circ} \mathrm{C}$ for the Tam-hydrochloride and $244^{\circ} \mathrm{C}$ for the Tam-picrate obtained by Ewins were identical to the values obtained by Manske and White and the description of the colour and shape of the crystals were also the same. Perley and Stowe (1966), in discussing this work, misrepresent the results of both Ewins (1911) and Manske (1931). Laidlaw (1911) outlines the synthesis of Tam from TTP by "... putrid pancreas subculture which had been shown to be capable of forming $\beta$-imidazolylethylamine from histidine and p-hydroxyphenylethylamine from tyrosine" . The product was isolated as the picrate salt and had the same crystal colour and shape and also melting point as the authentic Tam synthesised by Ewins (1911). This paper, therefore, represents the first report of TTP decarboxylation, although the identity of the bacteria in the culture was not known.

Werle and Mennicken (1937) presented evidence for the decarboxylation of TTP to Tam and this evidence was accepted by the Enzyme Commission who assigned a specific number, EC. 4.1.1.27 to the enzyme (Dixon and Webb, 1964). TTP decarboxylase was detected in guinea pig kidney by Weissbach et al. (1959) and this enzyme was purified 100-fold by Lovenberg, Weissbach and Udenfriend (1962). These studies suggested that a single non-specific aromatic L-amino acid decarboxylase catalysed the decarboxylation of a number of aromatic 
amino acids including tryptophan, 5-hydroxytrytophan, tyrosine, and histidine. The $\mathrm{pH}$ optimum of this enzyme was about 9.0 for all amino acids except DOPA, which was unstable at this $\mathrm{pH}$. This result is of interest because the $\mathrm{pH}$ optimum of other amino acid decarboxylases is below 6.0 (Gale, 1957).

Weissbach et al. (1959) also demonstrated that human faecal bacteria could convert TTP to Tam or IAA. Mitoma and Udenfriend (1960) isolated a pure bacterial strain from the same faecal sample used by Weissbach et al. This strain was similar to Streptococcus faecalis and could decarboxylate L-TTP. With lyophilised bacterial cells, the $\mathrm{pH}$ optimum of the enzyme was 5.6 and the activity of a dialysed, cell free preparation was stimulated by pyridoxal phosphate. Perley and Stowe (1966) reported the isolation of a single strain of Bacillus cereus which could decarboxylate L-TTP. Cell free preparations had a $\mathrm{pH}$ optimum of 8.0 and required the addition of pyridoxal phosphate for enzyme activity. The $\mathrm{pH}$ optimum of this enzyme appears to be similar to the kidney enzyme of Lovenberg et a1. (1962) and quite different from the other bacterial enzymes studied by Mitoma and Lovenberg (1960).

Libbert (1961) identified Tam as a product of TTP metabolism by crude cell free preparations from light-grown pea plants. Wichner and Libbert (1968a) claim that similar preparations from sterile pea plants did not produce Tam and concluded that Tam was entirely of bacterial origin. Phelps and Sequeira (1967) also demonstrated the formation 
of Tam from TTP using a crude, cell free homogenate from tobacco shoot tips as the source of enzyme. Although the reaction period was only 1 hour, the possibility of bacterial metabolism being involved here cannot again be excluded. There is thus, as yet, no report of the characterization and purification of a TTP-decarboxylase from higher plant tissues.

\section{Peroxidase:}

One of the first workers to study tryptophan oxidation in higher plants was Wiltshire (1953), who demonstrated that peroxidase in pea seedling extracts oxidised TTP in the presence of a peroxidase generating system. Amine oxidase was also present in the extracts and this enzyme formed $\mathrm{H}_{2} \mathrm{O}_{2}$ when a suitable amine substrate was added. Glucose oxidase and glucose could replace the amine oxidase system and a suitable concentration of $\mathrm{H}_{2} \mathrm{O}_{2}$ also accelerated the peroxidase reaction. Catalase, which breaks down $\mathrm{H}_{2} \mathrm{O}_{2}$, inhibited the reaction when a high concentration was added.

This latter result indicated that peroxidase competed with catalase for the peroxidase in the reaction mixture. Cyanide completely inhibited the reaction at $10^{-3} \mathrm{M}$ but this was due, at least in part, to inhibition of the formation of $\mathrm{H}_{2} \mathrm{O}_{2}$ by amine oxidase. The pea seedling peroxidase catalysed the oxidation of both $D$ - and L-tryptophan at the same rate but the product of the reaction was never characterised. 
Wiltshire also demonstrated the oxidation of both D- and L-TTP in model systems containing horseradish peroxidases and using either the glucose-glucose oxidase system for generating $\mathrm{H}_{2} \mathrm{O}_{2}$, or simply adding small amounts of $\mathrm{H}_{2} \mathrm{O}_{2}$ to the system. High initial concentrations of $\mathrm{H}_{2} \mathrm{O}_{2}$ were found to inhibit the reaction. The oxidation product with horseradish peroxidase or purified pea seedling peroxidase was a red-brown which was not 3-hydroxykynurenine, a product of liver tryptophan peroxidase.

Riddle and Mazelis (1964, 1965) and Klambt (1964) demonstrated a very different reaction in which horseradish peroxidase catalysed the oxidative decarboxylation of TTP to 3-indoleacetamide. In this reaction, pyridoxal phosphate and $\mathrm{Mn}^{++}$were specifically required as cofactors. The enzyme appeared to catalyse the oxidation of a number of amino acids and was studied in most detail with methionine as substrate (Mazelis, 1962). The requirement for $\mathrm{Mn}^{++}$could not be replaced by any other divalent ion and the requirement for pyridoxal phosphate was also specific. A reaction mechanism to account for the reaction was proposed by Mazelis and Ingraham (1962) and has been modified by Riddle and Mazelis (1965) to account for the formation of IAA directly from tryptophan. In the suggested mechanism, the amino acid and pyridoxal phosphate form a Schiff base which would react with the perferryl ion, $\mathrm{FeO}_{2}{ }^{++}$, of peroxidase complex III. Decarboxylation would then take place with a loss of Feo. The product would then be a Schiff base consisting of 
pyridoxal phosphate and the amide. This base could either hydrolyse to form the amide or, following nucleophilic attack by $\mathrm{OH}^{-}$, yield the acid. The final reaction steps can be represented as shown below:

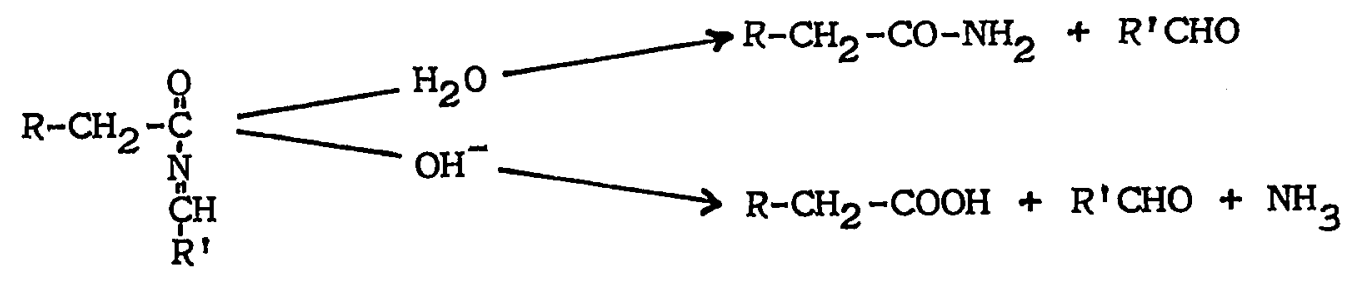

where $R$ represents indole and $R^{\prime}-$ CHO represents pyridoxal phosphate.

More recently, Reed and Crecelius (1967) have studied the oxidative decarboxylation of tryptophan using extracts of etiolated and light-grown pea epicotyl by measuring the evolution of ${ }^{14} \mathrm{CO}_{2}$ from $\mathrm{TTP}-1-{ }^{14} \mathrm{C}$. Extracts of 1 ight-grown peas contained a heat stable dialysable inhibitor of TTP decarboxylation which was not present in the extracts of dark-grown peas. When the activity of dialysed preparations from Iight-and dark-grown peas were compared, the darkgrown preparation was 10 times more active. Reed and Creselius consider that the enzyme is "quite similar to IAA-oxidase and other peroxidases". No requirement for $\mathrm{H}_{2} \mathrm{O}_{2}, \mathrm{Mn}^{++}$, pyridoxal phosphate or any other cofactor was reported. The authors were not able to identify the product of the reaction but ruled out IPyA, Tam, IAAld, 5-hydroxytryptamine or 3-indoleacetamide as products. In view of the widespread distribution of peroxidase enzymes in higher plants, the possible participation of this class of enzyme 
in the breakdown of tryptophan must always be considered.

\section{Deaminase:}

The deamination of phenylalanine has been shown by Koukol and Conn (1961) to be catalysed by L-phenylalanine ammonia-lyase (EC. 4.3.1.5) and this enzyme has been detected in a wide range of plants (Young, Towers and Neish, 1966). A similar enzyme, tyrase (L-tyrosine ammonia-lyase, EC. 4.3.1) has been demonstrated by Neish (1961) and the distribution of this enzyme is also discussed by Young et a1. (1966). The enzymes have not been detected in animal tissues or in non-vascular plants. Their distribution appears to be correlated with the ability of the plant to synthesise phenylpropanoid precursors of Iignin. The reaction catalysed by these enzymes may be represented as follows:

$$
\mathrm{R}-\mathrm{CH}_{2}-\underset{+}{\mathrm{CH}}-\mathrm{NH}_{3}-\mathrm{COO} \longrightarrow \mathrm{R}-\mathrm{CH}=\mathrm{CH}-\mathrm{COO}^{-}+\mathrm{NH}_{4}^{+}
$$

Neish (1961) and Young and Neish (1966) have studied the substrate specificity of the enzymes. Only the L-isomer of phenylalanine tyrosine and a number of other substituted phenylalanines were deaminated. Neish (1961) obtained a very low rate of ammonia release from L-tryptophan using a partially purified tyrase preparation from barley stems. However, the indole product of the reaction was not identified and the possibility of a peroxidative deamination cannot be excluded. The product expected from deamination 
by an ammonia-lyase would be 3-indoleacrylic acid and this compound has never been found as a naturally occurring indole in higher plants. Present evidence indicates, then, that L-tryptophan is not subject to deamination by the action of an ammonia-lyase enzyme.

\section{Catechol oxidase:}

Gordon and Paleg (1961) reported the presence of catechol oxidase in light-grown mung bean seedlings which, in the presence of pheñols, oxidised tryptophan to IPyA. The reaction sequence can be represented as follows:

$$
\begin{aligned}
& \text { (i) } 2 \text { o-diphenol }+\mathrm{O}_{2} \longrightarrow 2 \text { o-quinone }+2 \mathrm{H}_{2} \mathrm{O} \\
& \text { (ii) o-quinone }+\operatorname{TTP} \longrightarrow \text { IPyA } \longrightarrow \text { IAA. }
\end{aligned}
$$

The first reaction is catalysed by catechol oxidase (o-Diphenol oxidoreductase, EC. 1.10.3.1, also referred to as polyphenol oxidase, phenolase or tyrosinase). This reaction has a $\mathrm{pH}$ optimum of 8.0 and has only very low activity below $\mathrm{pH} 7.0$. The second reaction is non-enzymatic and Gordon and $\mathrm{Paleg}$ showed a reaction between chemically produced benzoquinone and TTP. IPyA was identified as a product of the reaction by using radioactive TTP and isolating labelled IPyA as the p-nitrophenyl hydrazone. Most of the IPyA broke down by non-enzymatic reactions to form IAA and the extent of the total reaction sequence was determined by measuring IAA formation colorimetrically.

The primary role of this enzyme in vivo has not yet been determined. There is some evidence that several 
catechol oxidases exist in higher plants located specifically in the chloroplastic, mitochondrial and supernatant fractions (Mayer and Friend, 1960). Furthermore, a large portion of the enzyme appears to be latent in some tissues (Kenten, 1957) and in some cases can only be released with proteolytic enzymes (Mayer, 1966). Gordon and Paleg (1961) suggest that this enzyme may play an important role in the formation of IAA only after a plant tissue has been wounded.

\section{Enzymes of an unknown nature:}

This review of tryptophan-metabolising enzymes has so far discussed five enzymes which have been partially characterised and named. There have been numerous papers, however, which report the metabolism of ITP to IAA by whole plants, tissue slices, tissue homogenates or cell free systems in which the nature of the enzyme or enzymes catalysing the conversion have never been determined. Since a number of enzymatic steps may well be involved in this conversion, it is not clear from these studies which reaction was rate-limiting since only the formation of IAA was measured. In view of the widespread distribution of peroxidase and catechol oxidase in plant tissues, the contribution of these enzymes to TTP breakdown would be expected especially if the enzyme preparations were undialysed and the conversion carried out under aerobic conditions. 
Enzymatic conversion of TTP to IAA was first demonstrated by Wildman, Ferri and Bonner (1947) in spinach leaves. The system required oxygen and was inhibited by dialysis and cyanide. These characteristics suggest that the enzyme catalysing the initial conversion of TTP may have been a peroxidase. The amount of IAA formed after 3.5 hours, however, was only $0.005 \%$ of the TTP in the reaction medium. Similarly, in the work of Gordon and Sanchez Nieva (1949b), the amount of IAA produced after 4 hours of incubation with a crude leaf brei was on $1 y 0.024 \%$ of the TTP added.

In most biochemical studies, such low percentage conversion values would probably be classed as insignificant. It was, in fact, only the high sensitivity of the Avena curvature test which permitted the determination of such small amounts of IAA produced in these early experiments.

In later work by Gordon (1958) the properties of the tryptophan $\longrightarrow$ IAA converting system in mung bean seedlings were studied. Here again, the rate of conversion was very low (0.07\% per hour) but later work with similar preparations showed a 15-fold stimulation by the addition of catechol to the reaction medium. Gordon, however, could not demonstrate TTP metabolism with a mung bean mitochondrial preparation, but more recently Wightman and Fowden (1966) have shown that similar preparations contain an active TTP-transaminase which requires the addition of $\alpha$-ketoglutaric acid and pyridoxal phosphate. The pH optimum of the transaminase was found to 
be 8.5. It is apparent from this later study, that the low rate of convergion... reported by many of the early workers was a result of the absence of cofactors or unsuitable reaction conditions.

C. Enzymes catalysing the Metabolism of 3-Indolepyruvic Acid

As discussed earlier, 3-indolepyruvic acid is very unstable in aqueous solution and gives $r$ ise to IAA spontaneously. Several workers have attempted to use IPyA as the substrate for enzyme preparations which have been shown to convert TTP to IAA (Wildman, Ferri and Bonner, 1947; Gordon and Sanchez Nieva, 1949b) but they found that the formation of IAA without enzyme was as great or greater than in the presence of enzyme preparations. Gordon and Paleg (1961) suggested, but did not demonstrate, that catechol oxidase enhanced the conversion of IPyA to IAA. Lin et aI. (1958a) found evidence for an enzymatic breakdown of IPyA in rat liver extracts which was not inhibited by EDTA or anaerobiosis, but the products of the reaction could not be detected by spectrophotometric or chromatographic methods.

The evidence for IPyA formation from TTP transamination has already been discussed. Kretovitch (1965) claims that when IPyA is infiltrated into plant tissues, TTP is formed, suggesting that the transaminase reaction is reversible in plant tissues. In this regard, it is pertinent that IPyA can replace TTP in the diet of rats (Stowe,1961), indicating that the molecule must be transformed to TTP by the animal tissues. 
IPyA was also characterised as a reaction product of glycollate oxidase activity when 3-indolelactic acid (ILA) was provided as substrate (Gamborg, Wetter and Neish, 1962). The action of this enzyme is irreversible however, and would not account for the formation of ILA in tomato $t$ issues (Wightman, 1964). Weber and Zannoni (1968) have demonstrated two $\mathrm{NADH}_{2}$-dependent enzymes in mammalian heart tissue which catalyse the reduction of aromatic $\alpha$-keto acids. One of these is lactate dehydrogenase which catalyses the reduction of aromatic $\alpha$-keto acids at a slow rate compared with the reduction of pyruvate. The second enzyme specifically catalyses the reduction of aromatic $\alpha$-keto acids and has no activity towards pyruvate. IPyA was shown to be a substrate for the second enzyme, and although this enzyme has not been demonstrated in extracts of plant tissues, its presence would account for the formation of ILA in certain plant tissues (Wightman, 1964).

Gordon (1961) suggested that IPyA might be decarboxylated by a reaction sequence analagous to the pyruvate dehydrogenase complex which oxidatively decarboxylates pyruvate to acetyl-CoA. In such a reaction sequence, IAAld would not occur as a free intermediate. Gordon (1961) claims that the conversion of TTP to IAA by a cell free extract from coleus buds was enhanced by the addition of lipoic acid but the details of this work have not been published. An enzyme which converts pyruvate to acetaldehyde is widely distributed in higher plants (Utter, 1963). This 
enzyme, pyruvate decarboxylase (EC. 4.1.1.1), has been highly purified from wheat germ and from yeast and requires the thiamine pyrophosphate and $\mathrm{Mg}^{++}$as cofactors. The $\mathrm{pH}$ optimum of the enzyme is 6.0. The yeast enzyme has been shown to decarboxylate higher homologues of pyruvate up to $\alpha$-ketocaproate, but phenylpyruvic acid was not metabolised. It is possible that IPyA is decarboxylated by an enzyme with very similar properties to pyruvate decarboxylase. The possibility that IPyA might be a substrate for peroxidase action should also be considered. Although there is no reference to the testing of IPyA as a substrate. Conn and Seki (1957) reported that the phenylpyruvic acid was oxidised by horseradish peroxidase.

\section{Enzymes catalysing the Metabolism of Tryptamine}

It has been known for some time that some plant tissues can convert tryptamine to an active auxin (Skoog, 1937; Gordon and Sanchez Nieva, 1949b). At least two enzymes have been demonstrated which can catalyse the breakdown of Tam, namely, an amine oxidase and a peroxidase. Werle and Roewer (1950) observed that a monoamine oxidase in higher plant tissues would catalyse the oxidation of Tam. This had previously been shown for an amine oxidase from animal tissues by Blaschko, Richter and Schlossmann (1937). A more detailed study of the amine oxidase in the pea plant has been carried out by Kenten and Mann (1952), 
Mann (1955, 1961) and Clarke and Mann (1957). This work clearly established that an enzyme with a pH optimum of 8.5 would catalyse the following reaction:

tryptamine $+\mathrm{H}_{2} \mathrm{O}+\mathrm{O}_{2} \longrightarrow 3$-indoleacetaldehyde $+\mathrm{H}_{2} \mathrm{O}_{2}+\mathrm{NH}_{3}$.

Clarke and Mann (1957) showed that the enzyme was slowly inactivated when tryptamine was used as substrate. This inactivation would be reduced by the addition of catalase to the reaction mixture to remove $\mathrm{H}_{2} \mathrm{O}_{2}$. With low tryptamine concentrations and short reaction times, Clarke and Mann were able to demonstrate yields of IAAld as high as $90 \%$ of the theoretical yield. Both dimedone and 2,4-dinintropheny1hydrazone derivatives of the reaction product were prepared and were shown to be identical with the comparable derivatives of authentic IAAld.

The action of peroxidase on Tam was also studied by Clarke and Mann (1957). The oxidation of Tam by this enzyme was found to depend on an external source of $\mathrm{H}_{2} \mathrm{O}_{2}$ and was unaffected by $\mathrm{Mn}^{++}$at the concentrations tested. This action of peroxidase was contrasted with the requirements for the oxidation of IAAld. In the latter case, no external source of $\mathrm{H}_{2} \mathrm{O}_{2}$ was required and the rate of oxidation was increased by $\mathrm{Mn}^{++}$. 
E. Enzymes catalysing the Metabolism of 3-Indoleacetaldehyde

Larsen, whose work in demonstrating the natural occurrence of IAAld was reviewed earlier, also demonstrated the enzymatic conversion of IAAld to IAA (Larsen, 1944, 1949). It was found that treatment of this neutral auxin with "soil" or milk gave rise to an acidic auxin which was highly active in the Avena curvature test. Xanthine oxidase (Schardinger enzyme) purified from milk was shown to catalyse the reaction. In later work, Larsen (1951b) postulated a dismutation reaction in which the oxidation and reduction of IAAld were coupled, but in 1962 Larsen et al. suggested that the "dismutase" might contain two separable enzymes, an aldehyde dehydrogenase and an alcohol dehydrogenase.

\section{Xanthine oxidase:}

This enzyme is the old Schardinger enzyme originally purified from milk (xanthine:oxygen oxidoreductase EC. 1.2 . 1.6). It has been shown that, in addition to catalysing the oxidation of xanthine to uric acid, the enzyme will catalyse the oxidation of a large number of aldehydes, including IAAld, to the corresponding carboxylic acid (Bray, 1963). The reactions may be represented as follows:

$$
\begin{aligned}
& \text { (i) Xanthine }+\mathrm{O}_{2}+\mathrm{H}_{2} \mathrm{O} \longrightarrow \text { urate }+\mathrm{H}_{2} \mathrm{O}_{2} \\
& \text { (ii) aldehyde }+\mathrm{O}_{2}+\mathrm{H}_{2} \mathrm{O} \longrightarrow \text { carboxylic acid }+\mathrm{H}_{2} \mathrm{O}_{2}
\end{aligned}
$$

It can be seen that both reactions require oxygen and that 
$\mathrm{H}_{2} \mathrm{O}_{2}$ is produced. If catalase is not added to the reaction mixture, the $\mathrm{H}_{2} \mathrm{O}_{2}$ can either act as substrate for peroxidase or, in some cases, it will react chemically (Meister and Wellner, 1963), as in the following reaction:

$$
\mathrm{RCH}_{2}-\mathrm{CO}-\mathrm{COOH}+\mathrm{H}_{2} \mathrm{O}_{2} \longrightarrow \mathrm{RCH}_{2}-\mathrm{COOH}+\mathrm{CO}_{2}+\mathrm{H}_{2} \mathrm{O} \text {. }
$$

Thus, if $\mathrm{R}$ is the indole moiety, IPyA would give rise to IAA by this reaction.

Although Gordon (1961) suggested that an aldehyde oxidase might catalyse the oxidation of IAAld in vivo, such an enzyme has never been demonstrated in higher plants. Xanthine oxidase itself has been purified from animal tissues and microorganisms, and aldehyde oxidases with different specificities are also known from these sources. Kenten (1953) investigated the aerobic oxidation of phenylacetaldehyde, but found this reaction to be catalysed by peroxidase, not aldehyde oxidase.

\section{Peroxidase:}

The ability of this enzyme to catalyse the oxidation of TTP, Tam and IPyA has already been discussed. Kenten (1953) showed that either purified horseradish peroxidase or pea seedling sap catalysed the oxidation of phenylacetaldehyde to benzaldehyde and formic acid. The reaction was promoted by $\mathrm{Mn}^{++}$and consumed $\mathrm{O}_{2}$, but no external source of $\mathrm{H}_{2} \mathrm{O}_{2}$ was required. Since catalase inhibited the reaction, it was suggested that $\mathrm{H}_{2} \mathrm{O}_{2}$ was formed as an obligatory intermediate 
in the reaction. 1-Naphthylacetaldehyde was also oxidised but the product of this reaction was not isolated. Kenten suggested, however, that the expected product would be 1-naphthylaldehyde.

Clarke and Mann (1957) demonstrated that IAAld, formed by the action of amine oxidase on Tam, was further oxidised by peroxidase. This oxidation was not dependent on an external source of $\mathrm{H}_{2} \mathrm{O}_{2}$ and was stimulated by the addition of $\mathrm{Mn}^{++}$. IAA did not accumulate in the reaction mixture and the authors suggest that 3 -indolealdehyde was the most likely product.

\section{Aldehyde dehydrogenase:}

The properties of aldehyde dehydrogenase extracted from animals and microorganisms have been reviewed by Jacoby (1963) and in recent years, there have been several reports of aldehyde dehydrogenase activity in higher plant tissues. Aldehyde dehydrogenases catalyse a number of reactions in which pyridine nucleotide coenzymes (PN) participate. The general reaction is summarised as follows:

$$
\mathrm{R}-\mathrm{CHO}+\mathrm{PN}+\mathrm{HA} \longrightarrow \mathrm{R}-\mathrm{COA}+\mathrm{PNH}_{2} \cdot
$$

In most cases HA represents water, and so a carboxylic acid is formed. In this case, the reaction is irreversible, because of the large change in free energy for the reaction. However," some aldehyde dehydrogenases are known to catalyse a reaction in which $\mathrm{HA}$ can be phosphate or coenzyme $A$, in 
which case the reaction product is an acyl-phosphate or acylCoA respectively. In the latter case, the change in free energy is small and the reaction can be reversed.

Aldehyde dehydrogenases extracted from animal sources have a broad specificity for the aldehyde substrate and Weissbach, Redfield and Udenfriend (1957) clearly demonstrated that guinea pig kidney aldehyde dehydrogenase will catalyse the oxidation of IAAId, as shown in the following reaction:

$$
\mathrm{IAAId}+\mathrm{NAD}+\mathrm{H}_{2} \mathrm{O} \longrightarrow \mathrm{IAA}+\mathrm{NADH}_{2}
$$

These workers were able to couple the activity of this enzyme with an amine oxidase catalysed oxidation of tryptamine and measured the formation of both IAA and $\mathrm{NADH}_{2}$.

Dietrich (1966) demonstrated the capacity of cell free extracts from a number of rat tissues to oxidise IAAld and showed that the oxidation was NAD-dependent. Mitochondriall, microsomal and supernatant enzymes were demonstrated and it was found that the properties of the enzyme varied depending on the intracellular localisation. Erwin and Dietrich (1966) purified the aldehyde dehydrogenase from bovine brain 100-fold and found the optimum $\mathrm{pH}$ to be 10, with an irreversible denaturation of the enzyme above this $\mathrm{pH}$. Using a fluorometric method for determining $\mathrm{NADH}_{2}$ formation, a wide range of substrates were assayed at $\mathrm{pH} 9.6$, but IAAId was not included in these results. When the activity of the enzyme towards IAAId was determined, the assay of Dietrich (1966) was used, in which IAA formation was measured at $\mathrm{pH} 7.4$ 
rather than 9.6. Unfortunately, no reason was given for the change in assay procedure and the absence of any comparison between the two assays.

Raison, Henson and Rienits (1966) studied the aldehyde dehydrogenase activity of rabbit liver and found that they could separate two enzymes. One of these specifically catalysed the oxidation of aromatic aldehydes and the other specifically catalysed the oxidation of aliphatic aldehydes. Both of these enzymes were NAD-dependent. The activity of the enzymes were assayed at $\mathrm{pH} 7.0$ because at a higher $\mathrm{pH}$, solutions of one of the substrates, gentis aldehyde, underwent non-enzymatic changes which interfered with the assay.

Microorganisms contain a number of aldehyde dehydrogenases which require either NAD or NADP for activity (Jacoby, 1963). Some of these enzymes, such as yeast alcohol dehydrogenase (Steinman and Jacoby, 1967) or the aromatic aldehyde dehydrogenases from Pseudomonas (Stachow, Stevenson and Day, 1967) are activated by $\mathrm{K}^{+}$, while others are activated by $\mathrm{Mg}^{++}$ (Jacoby, 1963). In most cases, the enzymes require the presence of mercaptan to preserve enzyme activity.

To date, there have been only a few reports of aldehyde dehydrogenase in higher plant tissues. Davies (1956) solubilised an aldehyde dehydrogenase from pea epicotyl mitochondria. Later work showed that the enzyme was a glycolaldehyde dehydrogenase (Davies, 1960). Another aldehyde dehydrogenase which catalysed the oxidation of long-chain fatty aldehydes to the corresponding acids was demonstrated 
by Martin and Stumpf (1959). This enzyme was found in the microsomal fraction of peanut cotyledons. More recently Liu, Oppenheim and Castelfranco (1965) purified a second NAD-specific aldehyde dehydrogenase from peanut cotyledons. This latter enzyme was detected only in the very high speed supernatant fraction after removal of the microsomal fraction. Oppenheim and Castelfranco (1967) used a preparation of this enzyme which had been purified over 100-fold and was free from alcohol dehydrogenase activity. The optimum $\mathrm{pH}$ for the enzyme was found to be 8.6-9.0, above which the enzyme was rapidly inactivated. The enzyme was stabilized by glutathione, but cysteine, mercaptoethanol and coenzyme $A$ were found to be inhibitory. One interesting property of the enzyme was the apparent activation by phosphate ions. Phosphate could be replaced by arsenate but not pyrophosphate. There was no evidence that active acetyl compounds, such as acetyl-P or acety1-CoA, were formed.

The oxidation of IAAld to IAA using crude enzyme preparations from higher plants has been demonstrated by a number of workers (Gordon and Sanchez Nieva, 1949b; Larsen, $1949,1951 b)$ but the properties of the enzymes were not determined. The abstract of a paper by Shigemura and Gordon (1960) reports that the aldehyde oxidising activity of an Avena coleoptile acetone powder was precipitated in two distinct ammonium sulphate fractions (1.e. 0-30\% and 40-50\%). However, the details of this work have never been published. 


\section{Alcohol dehydrogenase:}

The characteristics of alcohol dehydrogenases (alcohol: NAD oxidoreductase, EC. 1.1.1.1) extracted from horse 11ver and yeast have been studied extensively (Sund and Theorell, 1963). There have also been a number of reports of the presence of this enzyme in higher plants (Sund and Theore11, 1963; Cossins et al., 1968). Alcohol dehydrogenase catalyses a reversible reaction which can be represented as follows:

$$
\mathrm{R}-\mathrm{CHO}+\mathrm{NADH}_{2} \longrightarrow \mathrm{R}-\mathrm{CH}_{2} \mathrm{OH}+\mathrm{NAD}
$$

The equilibrium lies far to the right at $\mathrm{pH} 7.0$, but can be displaced towards the left at alkaline pH (Bonnichsen, 1965).

The presence of alcohol dehydrogenase activity in the leaves of spinach, sugarbeet, sunflower and tobacco was reported by Arnon (1952) and, in the following year, stafford and Vennesland (1953) obtained a partially purified preparation of the enzyme from wheat germ. Davies (1956) extracted an alcohol dehydrogenase from pea epicotyl mitochondria which required NAD and showed high activity at $\mathrm{pH} 9.1$. Cossins and Turner (1962) demonstrated NAD-dependent alcohol dehydrogenase activity in the cotyledons of germinating peas. In more recent work, this enzyme has been purified 25-fold and has been shown to be very unstable even in the presence of 2-mercaptoethanol (Cossins et a1., 1968). The enzyme has been found in the high speed supernatant fraction after removal of mitochondria and microsomes. It displayed broad 
specificity towards aliphatic alcohols but was more specific in its requirements for NAD; NADP was utilised at only $1 \%$ of the rate for NAD. The $\mathrm{Km}$ values for the enzyme with respect to ethanol, acetaldehyde, $\mathrm{NAD}$ and $\mathrm{NADH}_{2}$ were reported and compared with values obtained for the yeast and liver enzymes. With ethanol as substrate, the $\mathrm{pH}$ optimum was 8.8 whereas with acetaldehyde, the $\mathrm{pH}$ optimum was 6.3 . In contrast with the instability of the enzyme found by Cossins and coworkers, Suzuki (1966) also extracted alcohol dehydrogenase from pea cotyledons, but did not report any instability of the enzyme.

Although alcohol dehydrogenase, isolated from a variety of sources, has been shown to exhibit broad substrate specificity, neither IAAld nor Tol have been reported as substrates. Klungsoyr (1964) demonstrated the formation of both Tol and IAA from IAAld by cell free preparations from Acetobacter xylinum, and this reaction occurred irrespective of whether $\mathrm{NADH}_{2}$ was added or not. The addition of $\mathrm{NADH}_{2}$, however, did appear to increase the level of both Tol and IAA in the reaction mixture. 


\section{F. Enzymes catalysing the Metabolism of other Indoles}

Several other enzymes have been extracted from higher plants which catalyse reactions with simpler indole compounds. These include amidase, which hydrolyses 3-indoleacetamide, and two enzymes which may be involved in the formation and oxidation of 3-indoleacetonitrile, namely, 3-indoleacetaldoxime hydro-lyase and nitrilase respectively. The enzymes which degrade IAA will not be discussed here since several extensive reviews are available on this topic, including those by Galston and Hillman (1961) and Hare (1964).

\section{Amidase:}

Riddle and Mazelis (1965) demonstrated the presence of an enzyme in homogenates of cabbage seedlings which converted 3-indoleacetamide to IAA. The enzyme was not purified and activity was lost on dialysis.

\section{3-Indoleacetaldoxime hydro-lyase:}

Kumar and Mahadevan (1963) showed that a cell free system from cabbage leaves could hydrolyse 3-indoleacetaldoxime to 3-indoleacetonitrile (IAN). The enzyme was also found in

Gibberella fujikuroi and the enzyme from this source has been extracted and purified (Shukla and Mahadevan, 1968). Enzyme activity was stimulated by pyridoxal phosphate.

\section{Nitrilase:}

Thimann (1953) first suggested that some plants must be able to convert IAN to IAA and he was able to show that a 
preparation from oats could convert IAN to an acid auxin. In subsequent work Thimann and Mahadevan (1964) and Mahadevan and Thimann (1964) purified the enzyme catalysing this reaction and studied its distribution and properties. The enzyme was found only in members of the Gramineae, Cruciferae and Musaceae. The enzyme catalyses a direct conversion of IAN to IAA and ammonia without a free amide intermediate. The reaction is anaerobic and the enzyme is not specific for IAN, but will catalyse the hydrolysis of a wide range of substituted aryl nitriles and some aliphatic nitriles. 


\section{MATERIALS AND METHODS}

\section{A. Growth of the Plant Material}

\section{Mung bean seedlings:}

Mung bean seeds (Phaseolus aureus), showing a high percentage germination, were purchased locally. The seeds were soaked for 6 hours in shallow pyrex dishes, then washed thorcughly with running tap water and spread on wet vermicu1ite in pyrex dishes. A damp sheet of whatman 3 MM chromatography paper covered the seeds and an inverted pyrex dish was used to maintain high humidity. The dishes were then placed in the dark at $25^{\circ} \mathrm{C}$ for 3 days, after which time the hypocotyls measured 3 inches. The entire seedlings were then used as experimental material.

In some experiments, light-grown seedlings were used. In this case the seedlings were grown as described above for 2 days. They were then transferred to either a high humidity box with continuous incandescent light or a growth cabinet with a 16 hour photoperiod.

\section{Tomato seedlings:}

Plants of the garden tomato (Lycopersicon esculentum Mill.) var. Big Boy were grown for 3 weeks in growth cabinets with a 16 hour photoperiod, then transferred for a further two 
weeks to air conditioned greenhouses with a day temperature of $75^{\circ} \mathrm{C}$ and a 16 hour photoperiod. By this time about 8 leaves had expanded and the actively growing tip of each plant, which included the apex and the leaves up to 3 inches in length, was excised and used as experimental material. 
B. Chemicals used in this Investigation

Chemical

$\alpha$-Ketoglutaric acid

L-Tryptophan

3-Indolepyruvic acid

3-Indolelactic acid

3-Indoleacetic acid

3-Indoleacetaldehyde-bisulphite

3-Indoleacetamide

3-Indolealdehyde

Tryptopho1

Tryptamine

3-Indolepyruvic acid (impure)

3-Indolecarboxylic acid

Propionaldehyde (redistilled before

p-Dimethylaminocinnamaldehyde

2,4-Dinitrophenylhydrazine

Nicotinamide adenine dinucleotide

Nicotinamide adenine dinucleotide (reduced)

Pyridoxal phosphate

Thiamine pyrophosphate

Ninhydrin

Bovine serum albumin Fraction IV

Sephadex G-25

Sephadex G-200
Abbreviation used in text

$(\alpha-K G)$

(TTP)

IPyA

ILA

IAA

IAAld-bis

IAAm

IAId

To1

Tam

IPyA

ICA

use)

DMAC

DNPH

NAD Nutritional Biochem. $\mathrm{NADH}_{2}$

BSA

Calbiochem. Pharmacia

Suppliex

General Biochem.

Regis

$\bullet$

$\cdots$

$\cdot$

$\cdots$

Aldrich 


\section{Buffers employed}

1. Buffered sucrose: This buffer was used as a grinding meäium when a mitochondrial fraction was required. It was also used to resuspend and wash the mitochondrial pellets. The medium contained $0.1 \mathrm{M} \mathrm{K}_{2} \mathrm{HPO}_{4}, 0.01 \mathrm{M}$ EDTA and $0.4 \mathrm{M}$ sucrose. The $\mathrm{pH}$ was adjusted to $\mathrm{pH} 8.5$ with $1 \mathrm{~N} \mathrm{KOH}$.

2. Bursting medium: After the preparation of a mitochondrial fraction, soluble mitochondrial enzymes were extracted by allowing the mitochondria to swell and burst in a medium at $\mathrm{pH} 8.5$ containing $0.1 \mathrm{M} \mathrm{K}_{2} \mathrm{HPO}_{4}$ and $0.1 \% \mathrm{v} / \mathrm{v}$ of the nonionic Shell detergent, $\mathrm{OPC}-45$.

3. Phosphate-EDTA buffer: In early experiments investigating the metabolism of 3-indoleacetaldehyde, this medium contained only $0.1 \mathrm{M} \mathrm{K}_{2} \mathrm{HPO}_{4}$ and $0.01 \mathrm{M}$ EDTA. The $\mathrm{pH}$ was adjusted to either $\mathrm{pH} 7.5$ or $\mathrm{pH} 8.5$ with $1 \mathrm{~N} \mathrm{KOH}$.

4. Standard buffer: In later experiments involving enzyme purification it was found necessary to add $0.01 \mathrm{M}$ 2-mercaptoethanol (EtSH) to the phosphate-EDTA buffer to maintain enzyme activity. The medium containing EtSH was then used for all subsequent experiments and will be referred to as "Standard buffer".

5. Sephadex equilibration buffer: Sephadex G-25 columns were equilibrated with $0.1 \mathrm{M}$ phosphate buffer, adjusted to either $\mathrm{pH} 7.5$ or $\mathrm{pH}$ 8.5. In enzyme purification experiments, 
where EtSH was added to the grinding medium, $0.005 \mathrm{M} \mathrm{EtSH}$ was also added to the Sephadex equilibration buffer.

D. Preparation of Enzyme Fractions from Mung Beans

\section{Preparation of mitochondrial fractions:}

Whole seedlings were washed free of vermiculite, drained, weighed, and chilled at $4^{\circ} \mathrm{C}$ for 1 hour. The required sample of seedlings was then ground for 30 seconds in a Waring blendor containing $50 \mathrm{ml}$ of chilled buffered sucrose at pH 8.5 for every $100 \mathrm{~g}$ fresh weight of seedlings. The brei was squeezed through cheesecloth and the filtrate was centrifuged at $3,000 \times \mathrm{g}$ for $15 \mathrm{~min}$. to sediment cell fragments, nuclei, and most of the starch grains (see flowsheet, Fig. 1 ). The supernatant was then centrifuged at $10,000 \times \mathrm{g}$ for $15 \mathrm{~min}$. to obtain crude mitochondrial pellets and a supernatant, which was decanted and used for the preparation of a cytoplasmic supernatant fraction (see following section).

The crude mitochondrial pellets were resuspended in a small volume of buffered sucrose in the centrifuge tubes using a glass pestle which loosely fitted the centrifuge tube. Buffered sucrose was added to equal the volume of supernatant decanted after the second centrifugation and the suspension was then recentrifuged at $10,000 \times \mathrm{g}$ for $15 \mathrm{~min}$. This washing procedure was repeated three times to remove cytoplasmic contamination, reducing the volume of the resuspended mitochondria each time, so that the final resuspension volume was $40 \mathrm{ml}$. 


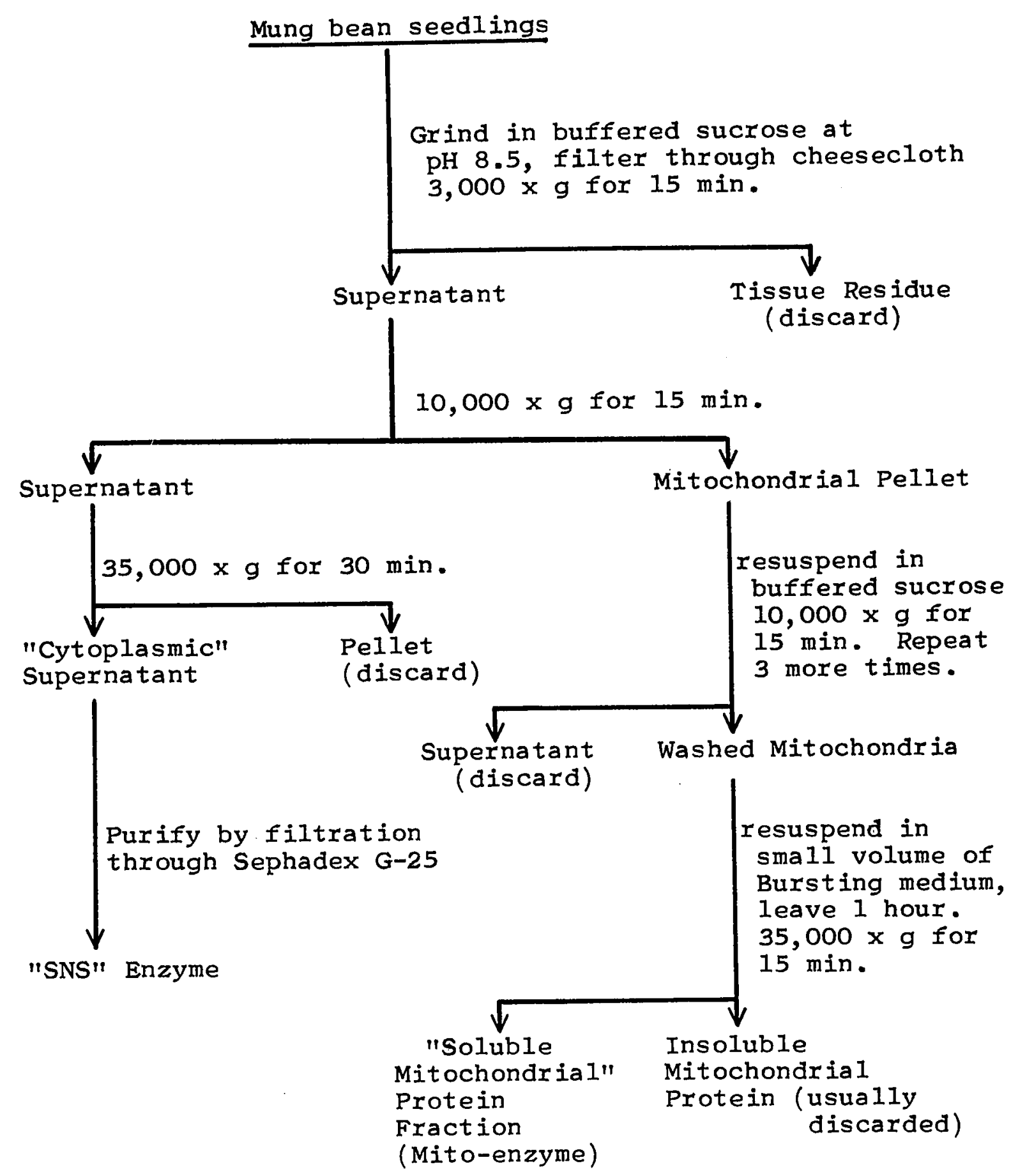

Figure 1. Flowsheet for the preparation of cell fractions. 
The final pellet of washed mitochondria was resuspended in $5 \mathrm{ml}$ of bursting medium (previous section) and was left 1 hour on ice, after which it was centrifuged to give a pellet of mitochondrial membranes and a clear supernatant of soluble mitochondrial protein (Mito-enzyme).

\section{Preparation of cytoplasmic supernatant fraction:}

The supernatant from the first centrifugation at 10,000 $x \mathrm{~g}$ (see Figure 1 ) was recentrifuged at $35,000 \times \mathrm{g}$ for $30 \mathrm{~min}$. to obtain the cytoplasmic supernatant enzyme. A portion of the supernatant from this high-speed centrifugation was then purified by passage through a column of sephadex G-25 to give the "SNS" fraction.

Different sizes of column were used for Sephadex G-25 filtration, depending on the size of the sample to be purified. The bed volume of the column was always at least 4 times the volume of the sample, as recommended by Pharmacia Ltd. and the volume of eluate collected was not more than $80 \%$ of the void volume of the column. Thus, for a column of $60 \mathrm{ml}$ total volume (Vt), the maximum sample volume would be $15 \mathrm{ml}$. The volume of eluate before the protein front emerges from the column, known as the void volume (Vo), would be $24 \mathrm{ml}$. This was discarded and the next 18-19 $\mathrm{ml}$ of eluate was collected $(\mathrm{Ve}=24+18=42 \mathrm{ml})$.

From these values, a partition coefficient Kav can be calculated which can give information on the smallest molecule which can contaminate the protein fraction. 


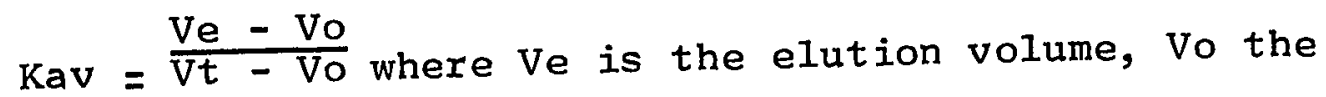
void volume, and $\mathrm{Vt}$ the column volume. Thus $\mathrm{Kav}=\frac{42-24}{60-24}$ $=\frac{18}{36}=0.5$.

Since the fractionation range for Sephadex G-25 is approximately 1,000-5,000 for peptides, a molecule which entered the column in the first $\mathrm{ml}$ of sample would have a range of $1,000-2,000$ to leave the column by an elution volume of $42 \mathrm{ml}$. Thus amino acids, organic acids, and simple sugars would be removed. Aromatic compounds are absorbed to sephadex to some degree and are retarded in their movement through the gel (Flodin, 1962). Phenolic compounds would therefore be removed from the protein samples.

In experiments where a mitochondrial fraction was not required, the procedure for the preparation of cytoplasmic supernatant fractions was modified. Seedlings were ground in phosphate-EDTA buffer at $\mathrm{pH} 7.5$ or $\mathrm{pH} 8.5$ in a Waring blendor and the brei was squeezed through cheesecloth. The filtrate was centrifuged at $35,000 \times \mathrm{g}$ for $30 \mathrm{~min}$. to obtain a cytoplasmic supernatant which was purified by passage through a column of sephadex G-25. The cytoplasmic supernatant prepared in this way behaved identically in a11 respects with the cytoplasmic supernatant fraction isolated in the presence of $0.4 \mathrm{M}$ sucrose.

For enzyme purification experiments, the enzyme fraction used was always the cytoplasmic supernatant fraction prepared from seedlings ground without $0.4 \mathrm{M}$ sucrose. However, it was found necessary to add $0.01 \mathrm{M}$ 2-mercaptoethanol (EtSH) to al1 buffers to maintain the activity of enzymes metabolising the oxidation and reduction of IAAld. 
3. Precipitation of inactive protein with manganous chloride:

Stafford and Vennesland (1953) used manganous chloride at a final concentration of $0.02 \mathrm{M}$ to precipitate nucleic acid from aqueous extracts of wheat germ in an investigation of the activity of alcohol dehydrogenase. Suzuki (1966) also used this method as a first step in the purification of alcohol dehydrogenase from pea seedlings, although the initial extract had been prepared using $0.1 \mathrm{M} \mathrm{Na}_{2} \mathrm{HPO}_{4}$ as the grinding medium. On the addition of manganous chloride to $0.1 \mathrm{M}$ $\mathrm{Na}_{2} \mathrm{HPO}_{4}$ alone, a heavy precipitate of insoluble manganous phosphate forms. Nevertheless, Suzuki found that the activity per mg protein rose by $70 \%$ as a result of this treatment, indicating that a large amount of inactive protein had been precipitated.

In the present work the procedure of Suzuki was followed: $2.04 \mathrm{ml}$ of $1 \mathrm{M}$ manganous chloride was added to each $100 \mathrm{ml}$ of a cytoplasmic supernatant preparation which was left on ice for 1 hour. The heavy precipitate produced by this treatment was removed after 1 hour by centrifugation at $10,000 \times \mathrm{g}$ for $10 \mathrm{~min}$. The supernatant fraction was either purified by passage through a column of Sephadex G-25 or was further fractionated by ammonium sulphate precipitation. 
4. Ammonium sulphate fractionation:

Ammonium sulphate precipitation was used to fractionate both the cytoplasmic supernatant preparation and the supernatant following treatment with manganous chloride. Solid ammonium sulphate was added and dissolved with the aid of a magnetic stirrer, the preparations being kept at $0^{\circ} \mathrm{C}$ in a container of crushed ice. The amount of ammonium sulphate required to give the desired \% saturation was taken from Table 1 given by Green and Hughes (1955) - These values refer to $\%$ saturation at $25^{\circ} \mathrm{C}$, that is, where a saturated solution is $4.1 \mathrm{M}$; at $0^{\circ} \mathrm{C}$ the molarity of a saturated solution falls to $3.9 \mathrm{M}$. However, in enzyme fractionation experiments, it is usual to take $100 \%$ saturation of an ammonium sulphate at $25^{\circ} \mathrm{C}$, not at $0^{\circ} \mathrm{C}$ (Dixon and Webb, 1964). The amounts of ammonium sulphate required to achieve each successive \% saturation is shown in Table 1.

Table 1. Grams of solid ammonium sulphate to be added to each $100 \mathrm{ml}$ of solution to reach a specified \% saturation.*

\begin{tabular}{cc}
\hline $\begin{array}{c}\text { Initial and Final } \\
\text { \% Saturation }\end{array}$ & g. added \\
\hline $0-40 \%$ & 24.3 \\
$40-50 \%$ & 6.3 \\
$50-60 \%$ & 6.6 \\
$60-80 \%$ & 14.3 \\
\hline
\end{tabular}

* Values derived from Green and Hughes (1955). 
Following the addition of each aliquot of ammonium sulphate, the enzyme mixture was stirred for 1 hour after which the precipitate was sedimented by centrifugation at $10,000 \times \mathrm{g}$ for $10 \mathrm{~min}$. The supernatant was decanted and the volume determined. Using this volume, the amount of ammonium sulphate required for the next fractionation step was calculated. Precipitates collected at the \% saturation levels shown in Table 1 were suspended in a small volume of standard buffer, approximately $1 / 20$ the volume of the original supernatant, and were then left on ice overnight.

It was found that the precipitates obtained from the $\mathrm{MnCl}_{2}$-treated cytoplasmic supernatant redissolved readily. On the other hand, supernatant precipitates which had not been treated with manganous chloride gave rise to heavy precipitates in the 0-40\% and 40-50\% fractions which did not redissolve even when left overnight at $0^{\circ} \mathrm{C}$. Precipitates were removed from these and other fractions by centrifugation at $10,000 \times \mathrm{g}$ for $10 \mathrm{~min}$. and the clear supernatants were desalted by passage through Sephadex G-25.

5. $\mathrm{pH}$ precipitation of aldehyde dehydrogenase:

Fractional precipitation by the lowering of $\mathrm{pH}$ has been used in the purification of aldehyde dehydrogenase from yeast (Black, 1955), beef liver (Racker, 1955), and peanut cotyledons (Liu et al., 1965). This procedure effectively separated aldehyde dehydrogenase from alcohol dehydrogenase in these tissues and was therefore attempted with cytoplasmic supernatant preparations from mung beans. 
To measure $\mathrm{pH}$, a Metrohm combination micro electrode Type $\mathrm{X}$ was used with a Beckman Zeromatic pH meter. The electrode was chilled in iced water and the meter was calibrated, using Beckman standard buffer ( $\mathrm{pH} 7.12$ ) and $0.05 \mathrm{M}$ potassium hydrogen phthalate ( $\mathrm{pH} 4.0)$, both prechilled to $0-2^{\circ} \mathrm{C}$. These buffers were chosen because their $\mathrm{pH}$ was known to remain almost constant between $0^{\circ} \mathrm{C}$ and $25^{\circ} \mathrm{C}$. In this way, the electrode was calibrated at the experimental“ temperature over the $\mathrm{pH}$ range used in the experiment.

An aliquot of a cytoplasmic supernatant preparation, prepared in the usual way in the presence of $0.01 \mathrm{MEtSH}$, was chilled to $0-2^{\circ} \mathrm{C}$ in a $40 \mathrm{ml}$ centrifuge tube and the $\mathrm{pH}$ was lowered by adding single drops of $0.1 \mathrm{M}$ citric acid. The preparation was constantly stirred with a small magnetic bar and the $\mathrm{pH}$ was monitored throughout. The heavy precipitate which formed at $\mathrm{pH} 6.0$ was sedimented by centrifugation at $10,000 \mathrm{xg}$ for $10 \mathrm{~min}$. The clear supernatant was then lowered successively to $\mathrm{pH} 5.6,5.4,5.2,5.0,4.8,4.6$, and 4.4 and the precipitates formed at each stage were sedimented by centrifugation at $10,000 \times \mathrm{g}$ for $10 \mathrm{~min}$. Each of these precipitates was then dissolved in standard buffer.

\section{Protein determination:}

The protein content of all fractions was determined by the method of Lowry et a1. (1951) using bovine serum albumin (Calbiochem. Fraction IV) as the protein standard and recording the extinction at $550 \mathrm{mu}$ with a Bausch and Lomb Spectronic 20. 


\section{E. Gel Filtration using Sephadex G-200}

Column chromätography using dextran gels provides a convenient method of separating enzymes on the basis of molecular weight. The method, as described by Andrews (1965), can be used not only to determine the approximate molecular weight of an enzyme, but also to separate and purify some enzymes. Sephadex G-200 (Pharmacia (Canada) Ltd.) was used in these experiments.

A sample of Sephadex G-200 was allowed to swell in distilled water for 3 days at $4^{\circ} \mathrm{C}$. A column was then prepared by the method recommended by Pharmacia, (Technical Data Sheet No.6), to ensure that the operating pressure on the gel never exceeded $15 \mathrm{~cm}$. The column used was Sephadex laboratory column $1.5 \mathrm{~cm} \times 100 \mathrm{~cm}$, purchased from Pharmacia Ltd. The gel bed was packed to either $45 \mathrm{~cm}$ or $57 \mathrm{~cm}$ and was then equilibrated with phosphate buffer at $\mathrm{pH} 7.5$ containing $0.1 \mathrm{M}$ EtSH. All these and subsequent operations were conducted at $4^{\circ} \mathrm{C}$.

To obtain calibration values for the column, small amounts of Blue Dextran 2,000 (Pharmacia, MW. 2,000,000) and Cytochrome C. (N.B.C., MW. 12,000) were mixed with the enzyme sample just before the sample was applied to the column. This was done by layering the sample beneath the eluant on the top of the column using a fine plastic tube attached to the end of a pipette. The sample was eluted with the same buffer that was used to equilibrate the column. A thin plastic tube ( $1 \mathrm{~mm}$ ) was connected to the 
base of the column and the end was positioned to give an operating pressure of $15 \mathrm{~cm}$. Samples of either $4.3 \mathrm{ml}$ or $5.1 \mathrm{ml}$ were collected using a siphon attachment on an automatic fraction collector.

The elution volume (Ve) of Blue Dextran 2,000 was taken as the void volume (Vo) of the column and samples were collected until the sample of Cytochrome $C$ had been eluted. Andrews (1965) showed that the distribution of proteins in the fractionation range from 5,000 to 800,000 (MW) was almost linear when plotted on semilog paper as the ratio $\mathrm{Ve} / \mathrm{No}$ against the MW of marker enzyme proteins. The data reported by Andrews has been used to assign an approximate MW to the enzyme peaks determined by subsequent assay procedures.

F. Preparation of Enzyme Fractions from Tomato Shoot Tips

The preparation of enzyme fractions from tomato shoot tips followed the procedure outlined for mung beans except that the initial tissue was ground with a mortar and pestle, and a greater amount of buffer was required to obtain a tissue brei.

The tomato shoot tips were collected at the stage described above, weighed and chilled at $4^{\circ} \mathrm{C}$ for 1 hour. The shoot tips were then finely chopped with a knife and ground with a large mortar and pestle using washed sea sand as a grinding aid. Only a small amount of buffer was added 
at first in order to efficiently grind the tissue, but the total volume of buffer used was $150 \mathrm{ml}$ for every $100 \mathrm{~g}$ of shoot tips.

When a mitochondrial fraction was required, buffered sucrose was used as the grinding medium. When only a cytoplasmic soluble fraction was required, the $0.4 \mathrm{M}$ sucrose was omitted. 2-Mercaptoethanol was added to all buffers in enzyme purification experiments. The ground shoot tips were squeezed through cheesecloth and subsequent fractionation procedures follow the methods described for mung beans.

\section{G. Chromatographic and Colorimetric Method for Estimating Glutamate}

To determine the amount of glutamic acid formed by the transamination reaction between L-tryptophan and $\alpha$-ketoglutaric acid, $0.4 \mathrm{ml}$ aliquots of the reaction mixture were removed at intervals and added to $1.2 \mathrm{mI}$ of methanol.. The protein precipitates were pelleted by centrifugation and $100 \mathrm{ul}$ aliquots of the clear methanolic supernatants were then applied as 1.5 inch bands on sheets of whatman No. 4 chromatography paper. The solvent system employed was n-butanol:acetic acid:water, mixed 90:10:29 by volume, and chromatography was by the descending method in a large cabinet lined with stainless steel. Solvent was also placed in a tray at the bottom of the cabinet to saturate the atmosphere. The chromatograms were developed until the solvent ran off the end of the paper (about 12 hours). By this time, the glutamate band had migrated about 4 inches. 
The glutamic acid content in each sample was determined colorimetrically using the ninhydrin-cadmium reagent of Atfield and Morris (1961) prepared as follows: $100 \mathrm{mg}$ of cadmium acetate were first dissolved in $10 \mathrm{ml}$ of distilled water. To this solution, $2 \mathrm{ml}$ of acetic acid and $100 \mathrm{ml}$ of acetone were added, followed by $1 \mathrm{~g}$ of ninhydrin (N.B.C.). The chromatograms were thoroughly wetted with this reagent using a plastic squeeze bottle. After allowing the acetone to evaporate in a fume hood, the papers were placed in an oven at $90^{\circ} \mathrm{C}$ for approximately $5 \mathrm{~min}$. to allow colour development. The papers were then stored for $I$ hour in the dark to allow full colour development, after which the glutamic acid bands were cut from each chromatogram, placed separately into test tubes and the coloured product eluted with $5 \mathrm{ml}$ of methanol over a period of 3 hours. The colour intensity of each eluate was then determined by measuring the absorption at $500 \mathrm{m \mu}$ using a Bausch and Lomb Spectromic 20 colorimeter. Aliquots of authentic glutamic acid were treated identically to the experimental samples and were used to obtain a standard curve in each experiment. A straight line was consistently obtained over the range 1-20 $\mu \mathrm{g}$. The background absorption on each chromatography sheet varied slightly, depending on the length of time the papers were developed in the oven and the exact oven temperature. For this reason all the time samples from each reaction mixture were run on the same chromatography sheet. The absorption value obtained for the 0 time sample was then treated as a 
blank and was subtracted from the absorption value obtained for other time samples.

H. Extraction of Free Indoles

Simple indole compounds can be fractionated on the basis of their partition coefficients between an organic solvent and an aqueous solution at different $\mathrm{pH}$ values. If the compound contains ionisable groups, the partition coefficient of individual compounds can often be altered by the addition of an acid or a base to the aqueous phase. Thus, indolic acids cannot be extracted into an apolar organic phase unless the $\mathrm{pH}$ of the aqueous phase is below the pKa of the acid, and conversely, indolic bases cannot be extracted into an apolar organic phase unless the $\mathrm{pH}$ is above the pKa of the base. The actual choice of the organic solvent is determined by a number of factors:

a) the partition coefficient at several $\mathrm{pH}$ values.

b) the ease with which the two phases separate; the formation of emulsions can be a severe hindrance.

c) the solubility of other compounds in the organic phase; for instance, apolar solvents do not dissolve sugars which can interfere with chromatography.

d) the solubility of water in the organic phase; water can be difficult to remove when extracts are concentrated.

e) the boiling point of the solvent; a low boiling point allows rapid concentration of extracts. 
A number of solvents have been used by workers in different fields; toluene has been widely used by investigators of urinary indoles, where a clinical centrifuge is used to aid phase separation, but diethyl ether has been the most widely used solvent for the extraction of plant indoles. Diethyl ether, hereafter referred to as ether, was accordingly used in this work for fractionation procedures carried out to obtain the free indoles arising from the metabolism of tryptophan. The ether was always freshly distilled to remove organic peroxides which arise spontaneously during storage. In a later section, the use of ethyl acetate in the fractionation of 2,4-dinitrophenylhydrazones of indoles containing a carbonyl group will be described.

The ether fractionation procedures employed were adapted to the requirements of individual experiments. In some cases it was not necessary to separate acidic and neutral auxins and in this case, the $\mathrm{pH}$ of the reaction mixture was lowered to $\mathrm{pH}$ 2.5-3.0 prior to ether extraction by the addition of a predetermined volume of $\mathrm{IN}_{3} \mathrm{PO}_{4}$. The $\mathrm{pH}$ was checked with a meter and the reaction mixture was then extracted three times with ether. This combined ACID plus NEUTRAL ether fraction could, if desired, be further separated by extraction with $0.05 \mathrm{M}$ tris buffer at $\mathrm{pH} 8.5$, which removed acidic indoles and left a NEUTRAL ether fraction. The acidic indoles could be recovered by acidification to $\mathrm{pH} 3.0$ followed by reextraction into ether to yield an ACID ether fraction. At all times, the extraction was carried out three times with at least an equal volume of ether or tris buffer. 


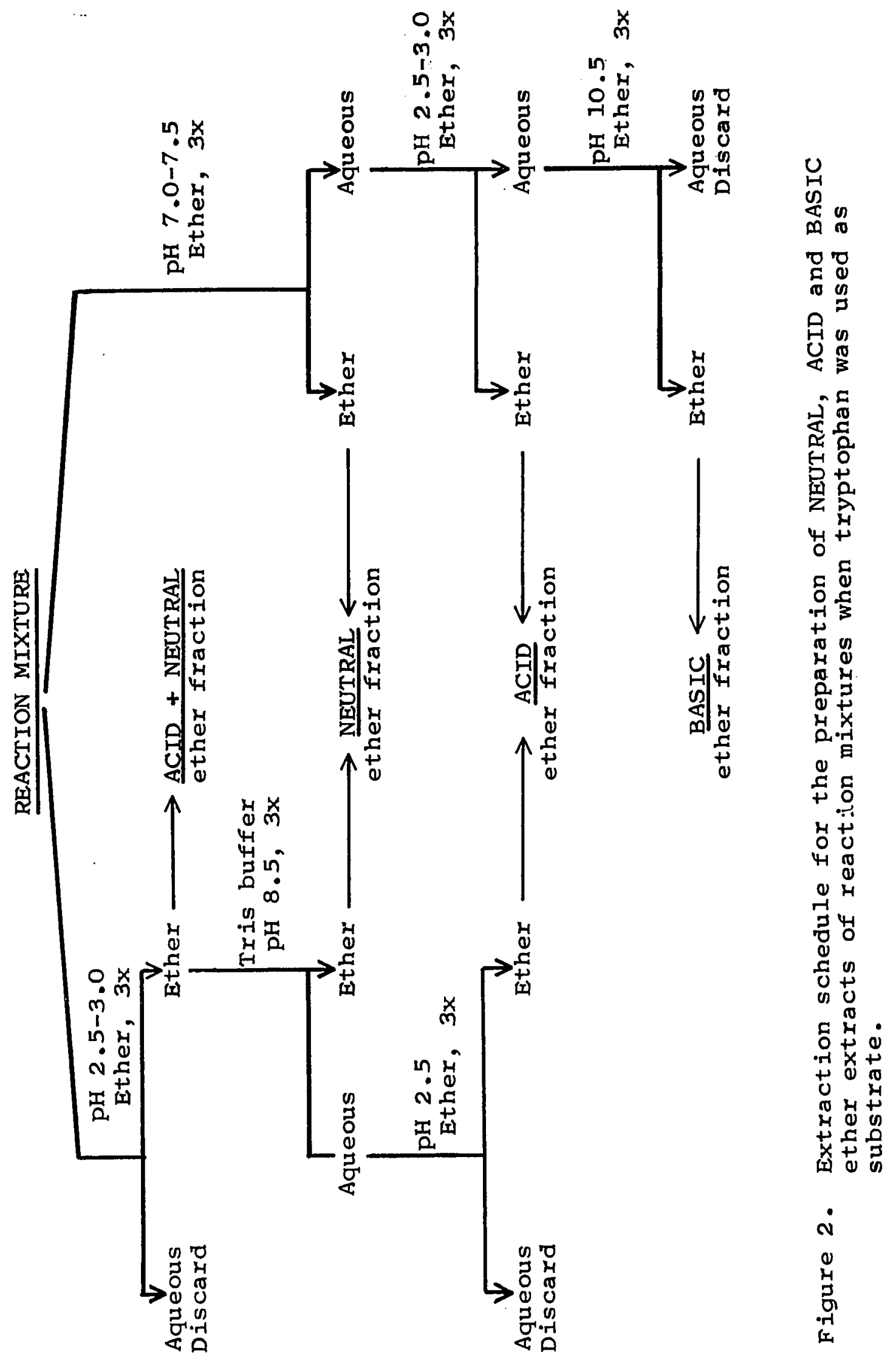


In other experiments, the $\mathrm{pH}$ of the reaction mixture was adjusted to $\mathrm{pH} 7.0-7.5$ and was extracted three times with ether to give a NEUTRAL ether fraction. The $\mathrm{pH}$ of the reaction mixture was then lowered to $\mathrm{pH} 2.5-3.0$ with IN $\mathrm{H}_{3} \mathrm{PO}_{4}$ and was reextracted three times with ether to give an ACID ether fraction. The compounds found in the NEUTRAL and ACID ether fraction were not affected by the alternative extraction schedules.

To determine whether tryptamine was formed as a decarboxylation product of tryptophan, BASIC ether extracts were prepared in some experiments. Following extraction with ether at $\mathrm{pH} 2.5-3.0,5 \mathrm{~N} \mathrm{KOH}$ was added to raise the $\mathrm{pH}$ of the reaction mixture to $\mathrm{pH}$ 10.5. Subsequent ether extraction would then extract any tryptamine present. These extraction schedules are shown in Figure 2 .

When 3-indoleacetaldehyde (IAAld) was used as substrate, it was necessary to add a fresh solution of sodium bisulphite to give a final concentration of $0.1 \mathrm{M}$ in the reaction mixture, prior to acidification. This treatment forms a bisulphite addition product with the residual IAAld which does not break down on acidification of the reaction mixture to $\mathrm{pH} 2.4$, and so allows the extraction of both neutral and acidic indole products but prevents the extraction of unreacted IAAld. This extraction procedure is illustrated in Figure 3. Since the carbonyl group of 3-indolealdehyde (IAld) is alpha to the aromatic ring, this compound does not form a stable bisulphite adduct. Consequently, when IAld was present in a reaction mixture, it was extracted into the combined NEUTRAL plus ACID ether fraction. 


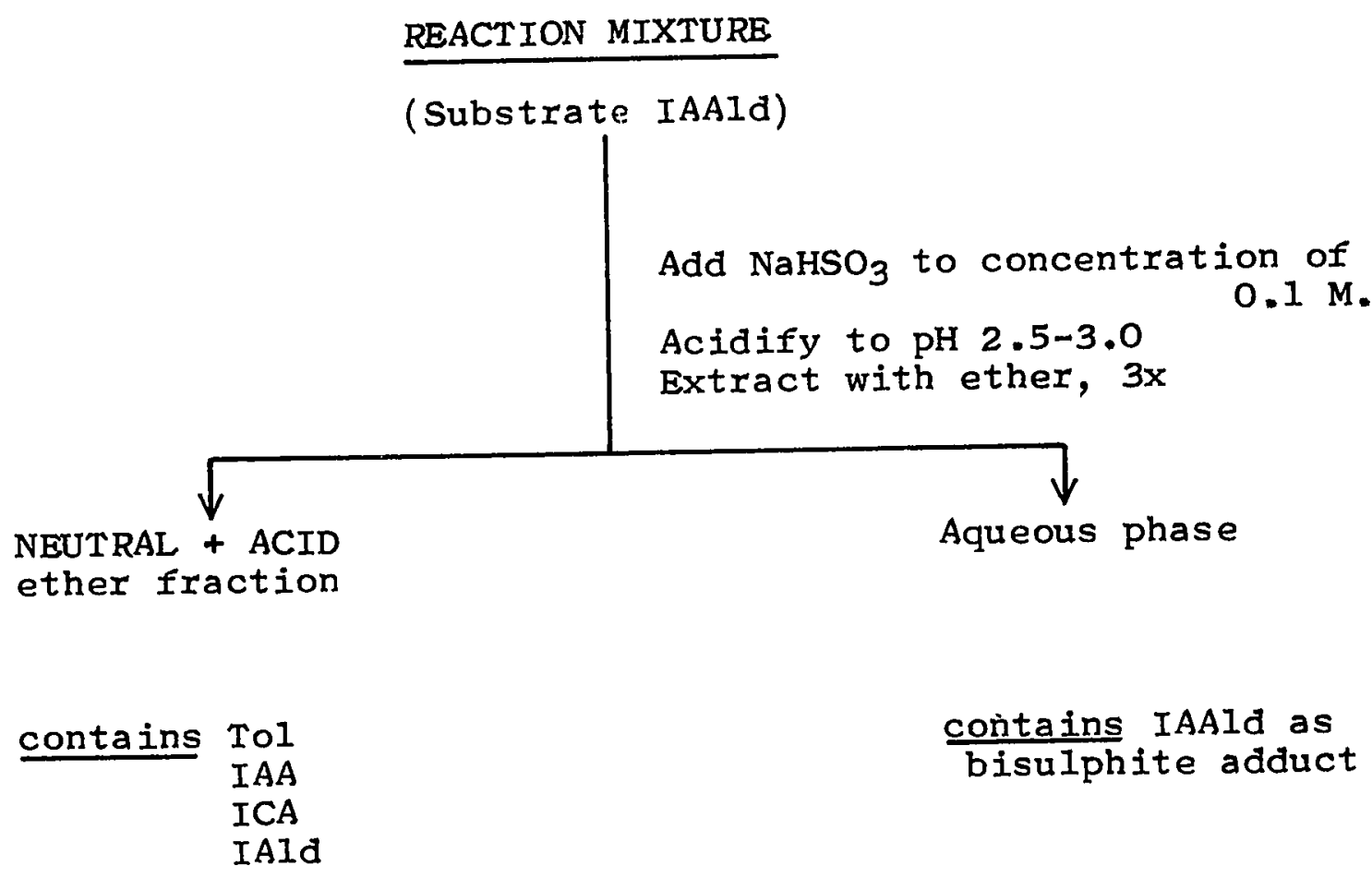

Figure 3. Extraction schedule for the preparation of a NEUTRAL and ACID ether extract of reaction mixtures when 3-indoleacetaldehyde was used as substrate. 
The ability of IAAId to form a bisulphite adduct was also used in attempts to isolate IAAld as a reaction product. Sodium bisulphite was added to reaction mixtures to a final concentration of $0.01 \mathrm{M}$ or $0.03 \mathrm{M}$ prior to incubation with TTP or IPyA as substrates. It was anticipated that if IAAId was formed as a reaction product it should be stabilised as a bisulphite adduct. The extraction procedure for such reaction mixtures followed Figure 2, except that additional sodium bisulphite was added at the end of the incubation to a final concentration of $0.1 \mathrm{M}$. Following ether extraction at $\mathrm{pH} 7.0-7.5$ to remove the NEUTRAL ether fraction and at $\mathrm{pH}$ 2.5-3.0 to remove the ACID ether fraction, the $\mathrm{pH}$ was raised to $\mathrm{pH} 10.5$, when IAAId would be freed from the bisulphite moiety and would then be extracted into ether along with the basic indole compounds. It was also found that this extraction schedule did not extract most of the IPyA in the reaction medium because IPyA can also form an addition product with bisulphite. This addition product was not broken at $\mathrm{pH} 2.5$, but if the aqueous phase following ether extraction at $\mathrm{pH} 10.5$ was then acidified to $\mathrm{pH} 2.5$ and immediately reextracted with ether, IPyA was found in this second ACID ether fraction. 
I. Chromatographic Analys is of Free Indole Metabolites

\section{Paper chromatography:}

Free indoles were separated by the standard chromatographic methods of this laboratory (Wightman, 1964; Schneider, 1965). Whatman No. 1 paper was used throughout. Two sizes of Shandon all-glass tanks were used: $13.5 \times 7 \times 14.5$ inches for ascending chromatography and $20 \times 8 \times 20$ inches for descending chromatography.

For ascending chromatography the solvent used almost exclusively was isopropanol:28\% ammonium hydroxide:water (IAmW) mixed 8:1:1 by volume. Chromatograms were left to develop overnight in this solvent and the paper was removed when the solvent had ascended 9-10 inches. The solvent front was marked immediately and the paper was dried in a fume hood.

For descending chromatography, the solvent used almost exclusively was benzene:acetic acid:water (BzAcW). This solvent was mixed in the ratio $2: 2: 1$ by volume and only the upper acidic benzene phase was used. To prevent the formation of a second water front on the paper during chromatography, the solvent was filtered through filter paper. In hot weather, even this filtration was ineffective in preventing phase separation, but the addition of $5 \mathrm{ml}$ of methanol to each $100, \mathrm{ml}$ of the upper phase gave good results. The addition of methanol increased the Rf values slightly, but did not alter the relative position of known indoles. The solvent front was allowed to move 10 inches, after 
which the paper was dried in a fume hood. The solvent front was located with a UV lamp and its position was then marked.

\section{Quantitative estimation of indoles:}

Basically, the method consisted of applying all extracts as a band of standard width and, after chromatographic development, indole metabolites were detected on the chromatogram by use of the DMAC reagent. The intensity of the colour reaction obtained was proportional to the amount of the indole present and was measured with a densitometer.

All extracts were applied to the chromatography paper as a standard 2 inch band. Following development, the chromatogram was dried and then carefully observed under a UV lamp. The edges of UV absorbing or fluorescing zones were marked with a soft pencil. This preliminary detection with UV light was useful in locating the indole bands and for indicating the spread and distortion of the bands. A 1.5 inch strip cut from the centre of each chromatographically separated band was used for a quantitative determination of indole products using the DMAC reagent. The remaining edges of the band, each approximately 0.25 inches wide, were used for confirmatory identifications with other reagents. The DMAC reagent was prepared as follows: $0.05 \mathrm{~g}$ of $\mathrm{p}$-dimethylaminocinnamaldehyde was dissolved in $5 \mathrm{ml}$ of $12 \mathrm{~N} \mathrm{HCl}, 95 \mathrm{ml}$ of acetone was then added and the reagent used immediately. The 1.5 inch chromatogram strips were 
dipped individually in the DMAC reagent and each strip was then placed in an oven at $60^{\circ} \mathrm{C}$ for approximately 30 seconds.. The exact time was determined empirically from the development of reaction colour, the dryness of the chromatogram, and the absence of a strong $\mathrm{HCl}$ odour. By this time, maximum colour had developed for indoles which reacted rapidly with the reagent and the intensity of each band was measured using a Photovolt densitometer, Model 52C, equipped with a Varicord variable response recorder. A $595 \mathrm{~m} \mu$ filter was used in the densitometer. The recorder was calibrated so that there was a linear relationship between optical density and peak height between 0 and 0.7 O.D. units as shown in Figure 4. Using this curve, the optical density (O.D.) of each band was determined. The solvent IAmW gave very sharp banding and the O.D. obtained for the DMAC reaction of known amounts of IAA or Tol were reproducible. Measured aliquots containing 0.5-25 $\mu \mathrm{g}$ of authentic IAA and Tol were applied as 2 inch bands and developed in IAmW in the same manner as described above for the extracts of reaction mixtures. 1.5 inch strips were dipped in DMAC reagent and the O.D. of each band was recorded to give a standard curve for each of these indoles (Figures 5, 6).

The reaction of 3 -indolecarboxylic acid (ICA) with DMAC reagent was slow and full colour development was only recorded after leaving the chromatograms for 24 hours in the dark. A standard curve was prepared for known aliquots of ICA, chromatographed in IAmW and treated with DMAC. 


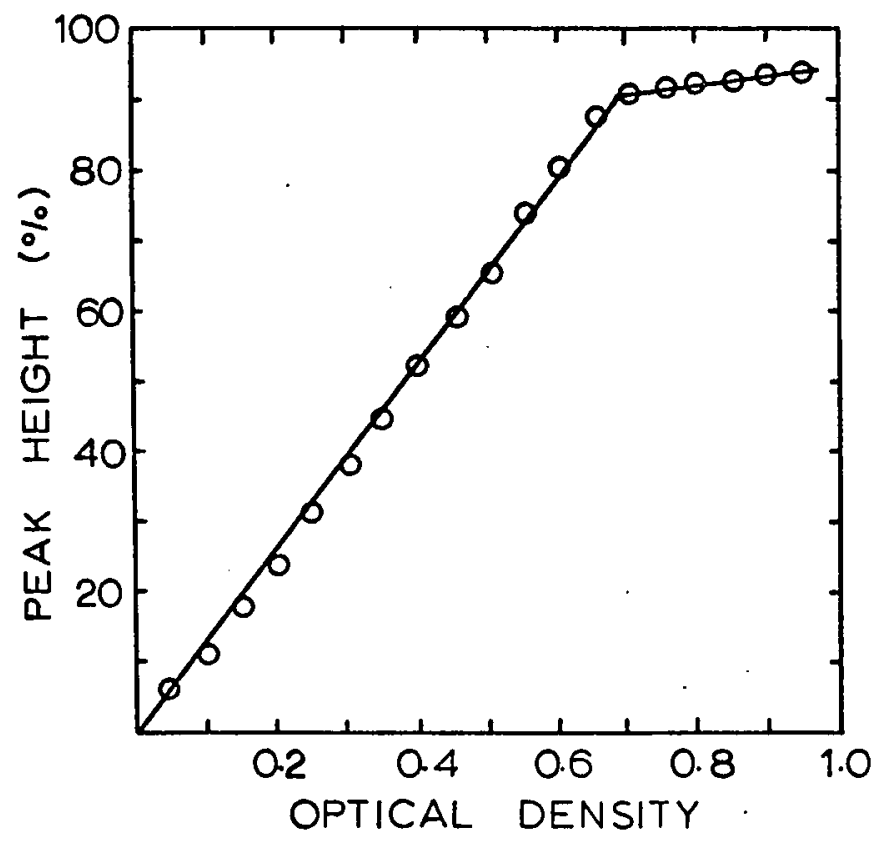

Figure 4. Relationship between optical density and the peak height on the densitometer trace, measured as percentage of full scale deflection. 


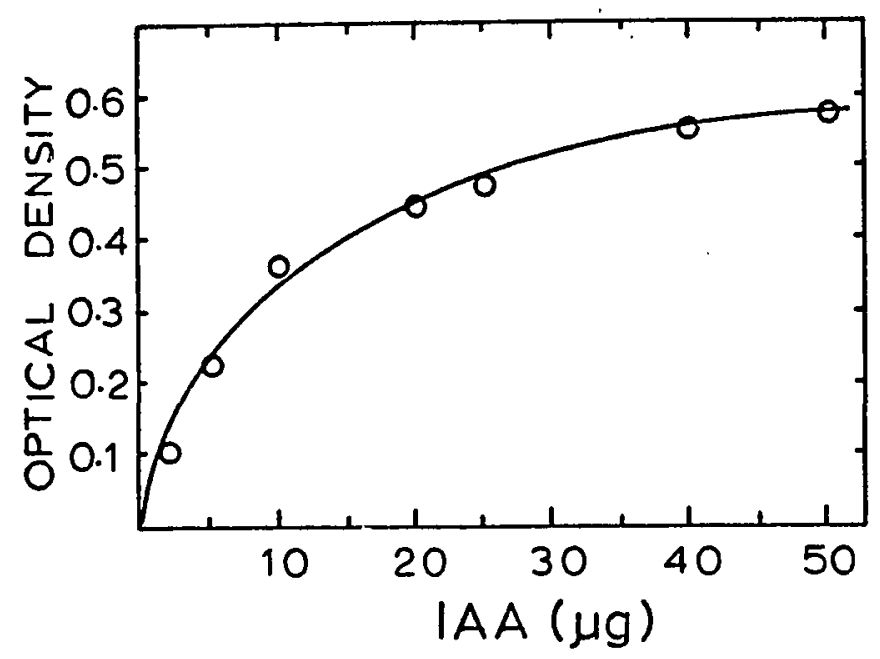

Figure 5. Relationship of IAA concentration to optical density using the standard chromatographic procedure given in the text.

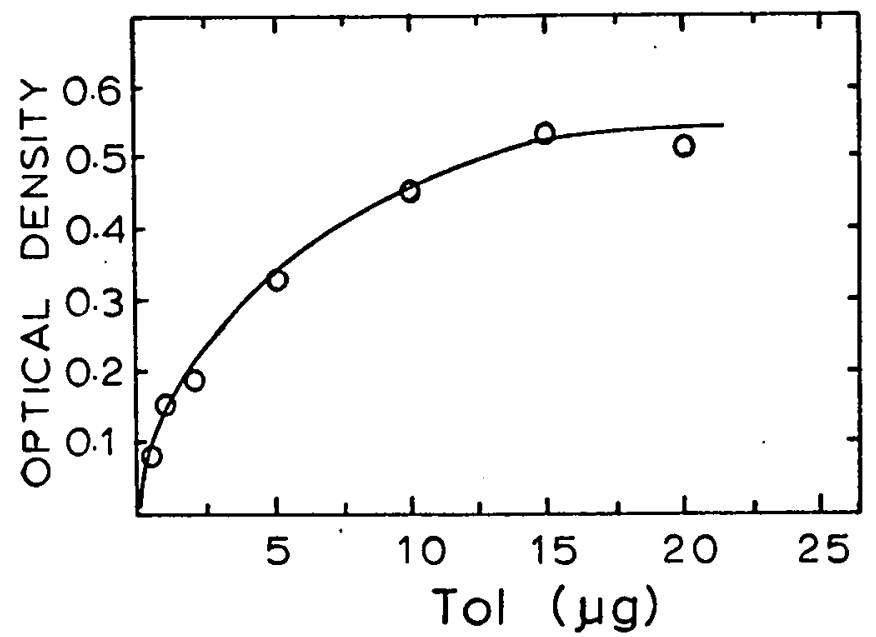

Figure 6. Relationship of Tol concentration to optical density using the standard chromatographic procedure given in the text. 
The O.D. measurements were recorded after 24 hours (Figure 7)

The Rf of 3-indolealdehyde (IAld) was the same as Tol in the solvent IAmW, but the reaction of this compound with DMAC reagent was very slow and so its presence on an IAmW chromatogram did not interfere with the quantitative estimation of Tol whenever this compound was present. On the other hand, IAld reacted rapidly with the DNPH reagent, prepared by mixing a saturated solution of 2,4-dinitrophenylhydrazine in $2 \mathrm{~N} \mathrm{HCl}$ with ethanol in the ratio $1: 4 \mathrm{v} / \mathrm{v}$. This reagent was applied as a fine spray to both sides of the chromatogram strip until the paper was wet. The paper was then left in the fume hood to dry and the O.D. of the IAld-DNPH band was measured with the densitometer using a neutral density filter instead of the usual $595 \mathrm{~m} \mu$ filter. A standard curve obtained from known amounts of IAld is shown in Figure 8.

When $\mathrm{BzAcW}$ was used as the developing solvent, the width of the indole bands was variable and the optical density measured in the densitometer could not be related to a standard curve. The results of experiments in which $\mathrm{BzAcW}$ was used to separate indole compounds are therefore expressed as the optical density of a particular band applied over a standard width. Comparisons of the optical density of a band in different extracts within an experiment are valid as an index of the amount of this compound present. 


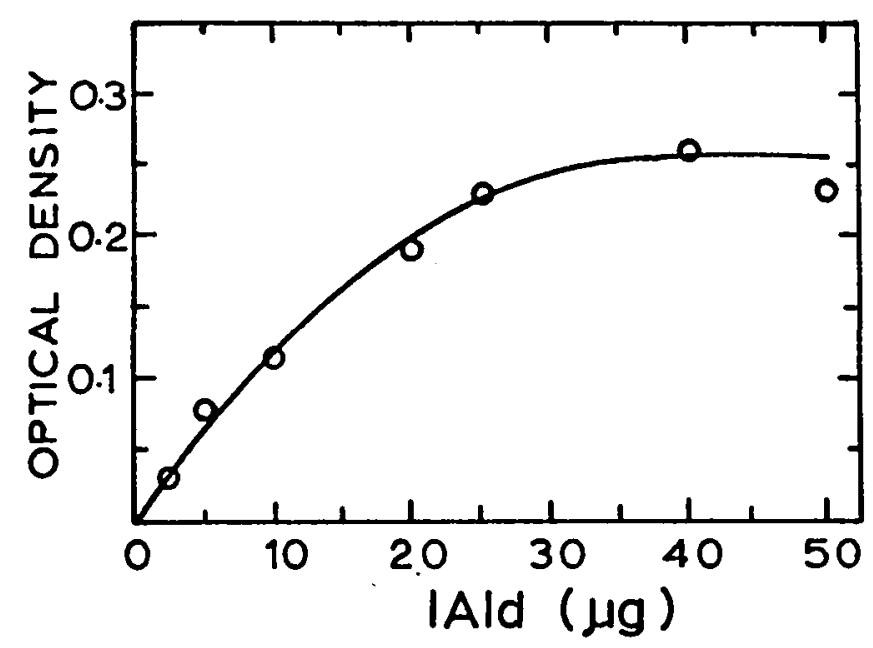

Figure 7. Relationship of IAld concentration to optical density using the standard chromatographic procedure given in the text.

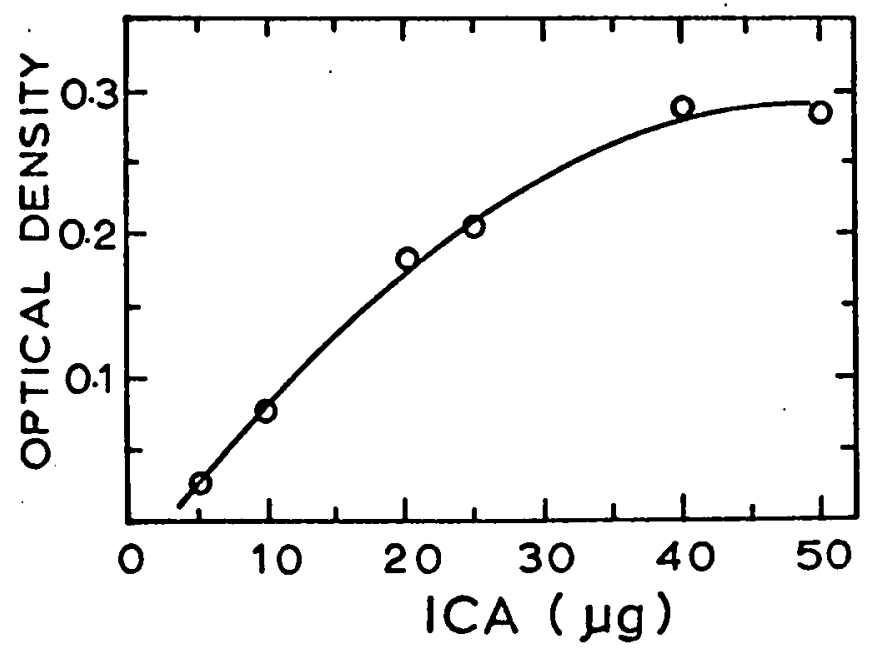

Figure 8. Relationship of ICA concentration to optical density using the standard chromatographic procedure given in the text. 
J. Preparation and Fractionation of 2,4-Dinitropheny1hydrazones of Indole Carbonyl Compounds

The formation of 3-indolepyruvic acid (IPyA) during transamination was demonstrated by isolating the acid as its 2,4-dinitrophenylhydrazone (IPyA-DNPH) . A warm solution of 2,4-dinitrophenylhydrazine (DNPH) in $2 \mathrm{~N} \mathrm{HCl}$ was added to the reaction mixture at the end of the incubation period. This mixture was then left in a refrigerator overnight and on the following morning the precipitated hydrazones and protein were collected by centrifugation, when most of the unreacted DNPH remained in the supernatant. The pellet was extracted with ethyl acetate to give a fraction which contained not only IPyA-DNPH but also the hydrazone of $\alpha$-ketoglutaric acid $(\alpha-K G-D N P H)$ and the hydrazones of other acidic or neutral carbonyl compounds present.

Separation of the IPyA-DNPH from the large excess of $\alpha-K G-D N P H$ was based on the observation of Katsuki et al. (1961) that the 2,4-dinitrophenylhydrazones of $\alpha$-keto-mono carboxylic acids, but not the $\alpha$-keto-dicarboxylic acid, $\alpha-K G$, can be extracted into ethyl acetate from a dilute $\mathrm{Na}_{2} \mathrm{CO}_{3}$ solution containing $\mathrm{Na}_{2} \mathrm{SO}_{4}$. It was found in the present work that the large excess of $\alpha-K G-D N P H$ was removed from the initial ethyl acetate fraction by extraction into a solution of $0.05 \mathrm{M}$ tris buffer at $\mathrm{pH} 9.5$ saturated with $\mathrm{Na}_{2} \mathrm{SO}_{4}$ - The ethyl acetate phase would then contain IPyA-DNPH, residual 2,4-DNPH and any neutral hydrazones (MIXED HYDRAZONE fraction). 
Further fractionation of the MIXED HYDRAZONE fraction was carried out using solvent partitioning between $0.05 \mathrm{M}$ tris buffer at pH 9.5 and ethyl acetate. This procedure is shown in Figure 9. Ethyl acetate was selected as the extraction solvent in preference to diethyl ether because it gave a cleaner separation of acid and neutral hydrazones.

Ethyl acetate extract of DNP-Hydrazones

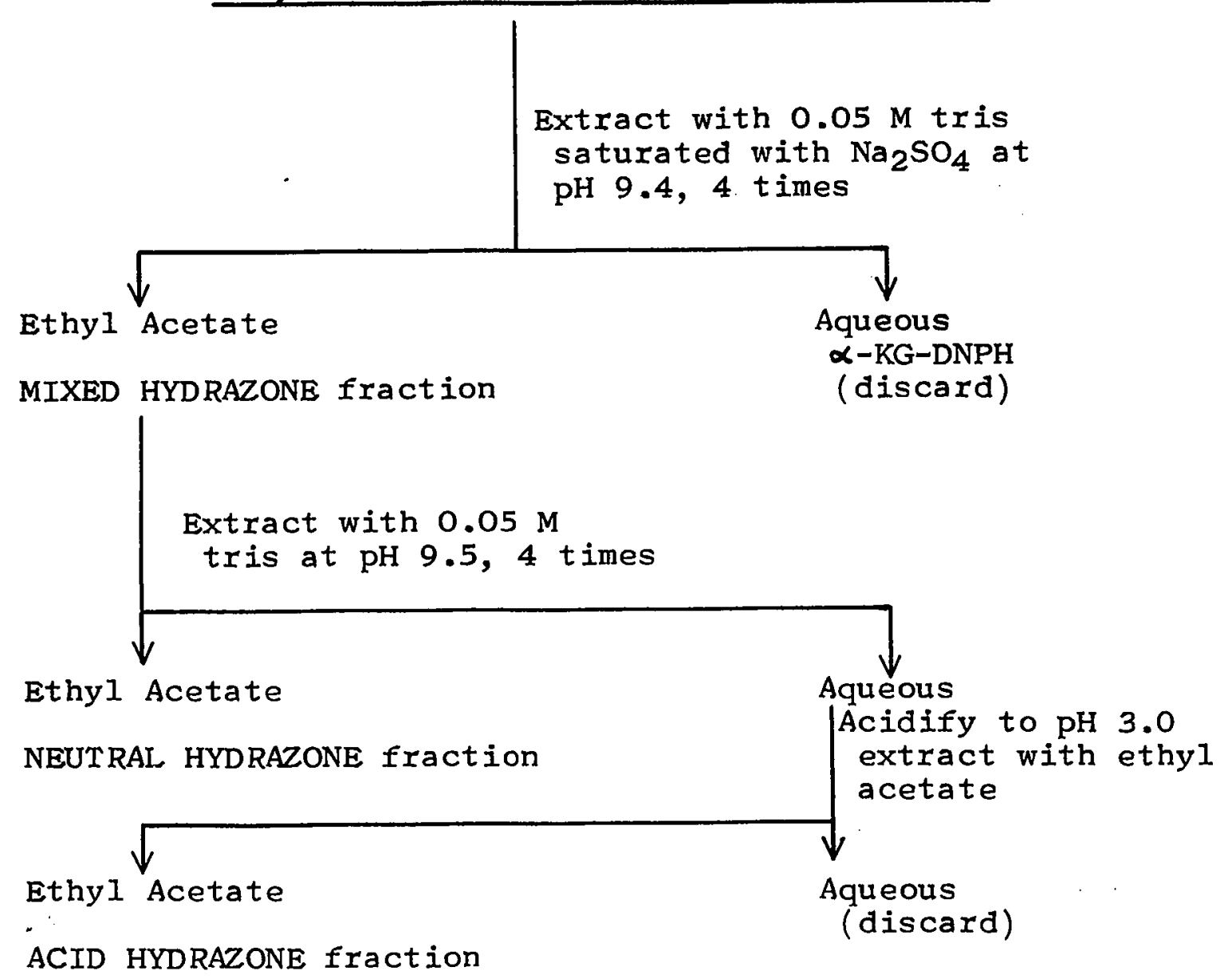

Figure 9. Extraction schedule for the preparation of hydrazone fractions. 
Authentic 2,4-dinitrophenylhydrazones of IPyA, IAAld, IAld, and $\alpha-K G$ were prepared as follows:

With $\alpha-K G$ or IAAld-bisulphite, $20 \mathrm{mg}$ were dissolved in $1 \mathrm{ml}$ of distilled water. With IPyA or IAld, $20 \mathrm{mg}$ were dissolved in $1 \mathrm{ml}$ of methanol. $10 \mathrm{ml}$ of a saturated solution of DNPH in $2 \mathrm{~N} \mathrm{HCl}$ was added to each of the above solutions. The mixtures were left for 1 hour at room temperature, after which the precipitates were recovered by filtration. Each precipitate was washed with two $5 \mathrm{ml}$ aliquots of $2 \mathrm{~N} \mathrm{HCl}$ to remove unreacted DNPH and then dissolved in ethyl acetate. IAld-DNPH is only sparingly soluble in ethyl acetate and benzene was also added to obtain a solution. The ethyl acetate solutions of $\alpha-K G-D N P H$ and IAAld-DNPH were concentrated, dried over $\mathrm{Na}_{2} \mathrm{SO}_{4}$ and used directly as chromatographic standards. The ethyl acetate solution of IPyA-DNPH was further purified by extraction into $0.05 \mathrm{M}$ tris buffer at $\mathrm{pH} 9.5$. The tris solution of IPyA-DNPH was acidified and the IPyA-DNPH recovered by extraction into ethyl acetate. This solution was concentrated, dried over $\mathrm{Na}_{2} \mathrm{SO}_{4}$ and used as a chromatographic standard. The benzeneethyl acetate solution of IAld-DNPH was dried over $\mathrm{Na}_{2} \mathrm{SO}_{4}$ and used directly as a chromatographic standard. 


\section{K. Chromatography of Hydrazone Fractions}

Wightman and Fowden (1966) separated the acid hydrazones $\propto-K G-D N P H$ and IPyA-DNPH by descending paper chromatography, using whatman $3 \mathrm{MM}$ paper and isopropanol: acetate buffer $(0.1 \mathrm{M}, \mathrm{pH} 5.0) \operatorname{mixed} 1: 1 \mathrm{v} / \mathrm{v}$ as the solvent system. Although these workers obtained sharp banding and reasonably good separation, it was found in the present investigation that methanol:benzene:n-butanol:water (MBzBuW) mixed $2: 1: 1: 1$ by volume gave very sharp banding and better separation of the acid hydrazone marker (Table 2). Both IPYA-DNPH and IAAId-DNPH react with the DMAC reagent to give a purple reaction. This reaction was used to confirm the identification of hydrazone bands of these compounds.

Table 2. Rf values of hydrazones using MBzBuW and colour reactions with the DMAC reagent.

\begin{tabular}{lccc}
\hline Compound & Rf & Colour & Colour with DMAC \\
\hline$\alpha-K G-D N P H$ & .68 & pale yellow & - \\
IPyA-DNPH & .78 & yellow-orange & purple \\
IAAld-DNPH & .98 & yellow & purple \\
IAld-DNPH & .98 & red-brown & - \\
DNPH & .88 & yellow-orange & - \\
\hline
\end{tabular}

Although a wide range of paper chromatographic solvents was tested (see Meister and Abendschein, 1956) none were found to separate the neutral hydrazones IAAId-DNPH and IAld-DNPH satisfactorily. However, these hydrozones could 
be readily separated on thin-layer plates of silica gel G. using the solvent, benzene: ethyl acetate (BzE) mixed 95:5 v/v. With this solvent the acidic hydrazones, $\propto-K G-D N P H$ and IPyA-DNPH, did not move off the origin. When a small amount of acetic acid was added to the solvent to give benzene:acetic acid:ethyl acetate (BzAcE) mixed 90:5:5 by volume, a separation of all components was achieved.

Hydrazones can exist as cis-trans (also referred to as syn-anti) isomers about the $\mathrm{C}=\mathrm{N}$ double bond. Chromatography on TLC plates separates the isomers of IPyA-DNPH and $\alpha-K G-D N P H$ so that each hydrazone appears as two distinct bands. The absolute Rf values of these compounds were variable but authentic markers were used on each plate. Representative Rf values for TLC separations of the hydrazones are presented in Table 3.

Table 3. Rf of hydrazones on thin-layer silica gel plates.

\begin{tabular}{|c|c|c|c|}
\hline Compound & \multicolumn{3}{|c|}{ Rf in: } \\
\hline $\begin{array}{l}\alpha-K G-D N P H \\
\text { IPyA-DNPH } \\
\text { IAAId-DNPH } \\
\text { IAId-DNPH } \\
\text { DNPH }\end{array}$ & $\begin{array}{l}.00 \\
.00 \\
.55 \\
.25 \\
.16\end{array}$ & $\begin{array}{l}.12 \\
.25 \\
.72 \\
.47 \\
.30\end{array}$ & $\begin{array}{l}.19 \\
.34 \\
\text { streaking } \\
\text { to } .78\end{array}$ \\
\hline
\end{tabular}

* BzE ....benzene:ethyl acetate mixed 95:5 v/v. BzAcE . benzene:acetic acid:ethyl acetate mixed 90:5:5 by volume. 
It can be seen that, with the acidic solvent, $B z A c E$, DNPH streaks to give a second band which is a salt of DNPH formed during chromatography (Smith, 1960). The main band of DNPH is located between the two bands of IPyA-DNPH and is a possible contaminant if the bands of IPyA-DNPH are eluted. To avoid this, the TLC plate can be developed first with $\mathrm{BzE}$ and then with $\mathrm{B} z \mathrm{ACE}$ in the same direction. Using this technique, any unreacted DNPH in the hydrazone mixture would be clearly separated from IPyA-DNPH.

\section{UV and IR Spectroscopy of Indole Products}

To record the UV spectrum of an indole product or its hydrazone, the compound was eluted from a paper or thinlayer chromatogram with methanol. All UV spectra were recorded in methanol using a Bausch and Lomb spectronic 505 recording spectrophotometer.

Infrared spectra were also recorded for the two isomers of IPyA-DNPH. Bands of the isomers were eluted from paper or thin-layer chromatograms and concentrated in a rotary evaporator. The samples were dried on glass microscope slides and nujol mulls were prepared using a small spatula. A razor blade was used to transfer each mull to an $\mathrm{NaCl}$ plate and spectra were recorded using a Beckman IR 8 spectrophotometer. 


\section{Standard Enzyme Assay Systems}

1. Tryptophan-transaminase assay (TTP: $\alpha-K G$ aminotransferase):

The enzyme fractions tested for TTP-transaminase activity were always purified by passage through a column of Sephadex $\mathrm{G}-25$. The assay reaction mixture was prepared by mixing the following solutions in the proportions shown:

$2 \mathrm{ml}$ of purified enzyme fraction,

$1 \mathrm{ml}$ of $120 \mathrm{mM} \mathrm{TTP}$,

$1 \mathrm{ml}$ of $40 \mathrm{mM} \propto-\mathrm{KG}$ plus $0.4 \mathrm{mM}$ pyridoxal phosphate. All reactants were prepared in $0.1 \mathrm{M} \mathrm{K}_{2} \mathrm{HPO}_{4}$ solution and the final pH of the complete reaction mixture was adjusted to $\mathrm{pH} 8.5$.

A $0.4 \mathrm{ml}$ aliquot was immediately removed and added to $1.2 \mathrm{ml}$ of methanol as the zero time sample. The reaction mixture was then incubated at $35^{\circ} \mathrm{C}$. Further aliquots were removed at 2,4 , and 6 hours and added to methanol. The amount of glutamate in each of these aliquots was determined by the chromatographic analysis described earlier.

From this data the rate of the transamination reaction could be calculated in pmoles of glutamate formed per hour. An international unit of an enzyme is defined as the amount of an enzyme which breaks down 1 mmole of a substrate per minute under optimal conditions. In this case, the formation of 1 umole of glutamate/minute is taken as the enzyme unit. A milliunit (mU) of TTP-transaminase would then catalyse the formation of 1 mole glutamate/minute. The 
data from experiments on the purification of TTP-transaminase have been expressed on this basis.

\section{Aldehyde dehydrogenase (IAAld-NAD oxidoreductase):}

The only assay for this enzyme involved the extraction and chromatographic determination of the amount of IAA formed when the enzyme was incubated in the presence of both IAAld and NAD. The rate of this reaction was very slow, but IAA formation appeared to increase Iinearly over a 3 hour period. The assay reaction mixture was prepared as follows:

$1 \mathrm{ml}$ of enzyme fraction at $\mathrm{pH} 7.5$,

$0.25 \mathrm{ml}$ of solution containing $1.5 \mathrm{mg}$ IAAld-bisulphite, $0.25 \mathrm{ml}$ of solution containing $1.5 \mathrm{mg}$ of NAD and $1.5 \mathrm{mg}$ of $\mathrm{NADH}_{2} \cdot$

The $\mathrm{pH}$ of the reaction mixture was adjusted to 7.5 and the final concentration of the metabolites was: $3.8 \mathrm{mM}$ IAAld, $1.5 \mathrm{mM} \mathrm{NAD}, 1.5 \mathrm{mM} \mathrm{NADH}_{2}$. The reaction mixture was incubated at $35^{\circ} \mathrm{C}$ for 3 hours, after which $1 \mathrm{M} \mathrm{NaHSO}_{3}$ was added to give a concentration of $0.1 \mathrm{M}$ and $1 \mathrm{M} \mathrm{H}_{3} \mathrm{PO}_{4}$ was then added to lower the $\mathrm{pH}$ to 3.0 . $20 \mathrm{ml}$ of freshly distilled ether was added; the tubes were shaken vigorously and placed in a freezer at $-15^{\circ} \mathrm{C}$ until the aqueous phase had frozen. The ether was then decanted and reduced in volume. An aliquot of this ACID plus NEUTRAL ether extract was then used to measure the content of IAA by the chromatographic and densitometric procedures outlined previously. A unit of enzyme is defined as the amount which produces $1 \mu$ IAA in 3 hours under the standard conditions of incubation. 
In-preliminary experiments, the rate of formation of IAA was compared using the same concentrations of free IAAId or its bisulphite addition product, IAAId-bis. Free IAAId was recovered from a solution of the IAAId-bis by raising the $\mathrm{pH}$ to 9.5 followed by extraction into ether. The ether was then evaporated and the free IAAld dissolved. It was always found that as much or more IAA was formed from the IAAId-bis as from free IAAId and because of its initial stability, the bisulphite addition product was used as substrate in all subsequent experiments.

Deitrich (1966) has shown that IAAId-bis dissociates $50 \%$ at $\mathrm{pH} 6.9$ and $100 \%$ at $\mathrm{pH} 9.6$. At concentrations of free IAAld above $0.05 \mathrm{M}$, a white precipitate (presumably a polymer of IAAld) formed rapidly even at $0^{\circ} \mathrm{C}$. Thus, by using IAAld as the bisulphite addition compound at $\mathrm{pH} 7.5$, free IAAId should form to more than $50 \%$ of the added concentration and as IAAld was utilised in the reaction, more should be released from the addition compound.

The addition of $\mathrm{NADH}_{2}$ to the reaction mixture allowed a simultaneous assay of alcohol dehydrogenase activity (see next section).

\section{Alcohol dehydrogenase (Tol-NAD oxidoreductase):}

This enzyme was assayed by two different assay procedures involving the reduction of IAAId to Tol. The first assay was run simultaneously with the assay for aldehyde dehydrogenase activity and involved a measure of the formation of Tol. 
This assay is referred to as the indole product assay system. The second assay involved a spectrophotometric determination of the utilisation of $\mathrm{NADH}_{2}$.

\section{a) Indole product assay system}

When an enzyme fraction was incubated with IAAld-bis and NAD, Tol was formed in addition to IAA. This formation was greatly stimulated by the further addition of $\mathrm{NADH}_{2}$ to the reaction mixture. Although the primary purpose of the assay was to measure aldehyde dehydrogenase activity and to purify this enzyme, records were also kept of the production of Tol as a measure of the presence of a second enzyme, alcohol dehydrogenase, to determine whether a separation of the two enzymes was achieved by any of the purification steps. Unlike the aldehyde dehydrogenase which produced IAA at a constant rate over the 3 hour incubation period, the alcohol dehydrogenase activity appeared to be high initially and to decline so that no further formation of Tol was detected after about 1 hour. However, as will be shown in the Results section, the final level of Tol found in the reaction mixture correlates very well with the initial rate of the reaction as measured by a spectrophotometric assay of $\mathrm{NADH}_{2}$ utilisation. In the spectrophotometric assay, a decrease in activity was also found, even after 30 seconds with very active enzyme fractions. The reason for this decrease in the rate of the reaction is not known, but is probably, at least in part, an inhibition of the enzyme by the aldehyde substrate. 
The level of Tol in the reaction mixture after the 3 hour incubation appears to be a valid index of the alcohol dehydrogenase present in enzyme fraction. A unit of alcohol dehydrogenase activity is therefore defined as the amount of enzyme which produces $1 \mu \mathrm{g}$ of Tol in 3 hours under the standard assay conditions.

\section{b) Spectrophotometric assay system}

Alcohol dehydrogeaase can be assayed spectrophotometrically by measuring the oxidation of $\mathrm{NADH}_{2}$ with an aldehyde as substrate (Suzuki, 1966). Such an assay has the advantage of being both rapid and sensitive. The following procedure was modified from the method of Suzuki:

i) an aliquot of the enzyme fraction was pipetted into a $1 \mathrm{~cm}^{2}$ silica cuvette.

ii) $0.05 \mathrm{ml}$ of $3.75 \mathrm{mM} \mathrm{NADH}_{2}$ was then added.

iii) $0.1 \mathrm{M}$ phosphate buffer at $\mathrm{pH} 7.0$ was added to give a volume of $2.95 \mathrm{ml}$.

Using a Bausch and Lomb Spectronic 505 recording spectrophotometer, the extinction at $340 \mathrm{~m} \mu$ was recorded for $1 \mathrm{~min}$. against a reference cuvette containing water. The change in extinction was never greater than 0.01 , indicating that endogenous substrates had been removed in the enzyme purification procedures. The value obtained was used as a blank value and was later subtracted from the value obtained with added substrate.

iv) $0.05 \mathrm{ml}$ of substrate was added, mixed rapidly using a plastic rod with a flattened end and the extinction at $340 \mathrm{mpl}$ was recorded over the following $1 \mathrm{~min}$. 
Two substrates were used in this assay; $0.8 \mathrm{M}$ propionaldehyde (to give a final concentration of $13 \mathrm{mM}$ in the assay) and $0.12 \mathrm{M}$ IAAld-bis (to give a final concentration of $2 \mathrm{mM}$ in the assay). When very active enzyme preparations were used, the rate of the reaction began to slow down after 15 or 30 seconds and only the most rapid reaction rate was used as a measure of the initial reaction rate. A unit of enzyme is defined as that amount which causes an initial change of extinction $(\Delta \mathrm{E} 340)$ of .001 per minute under the standard reaction conditions. All spectrophotometric determinations were made at room temperature. 


\section{EXPERIMENTAL RESULTS}

\section{A. Transamination of Tryptophan}

\section{Intracellular distribution of tryptophan transaminase:}

In a typical experiment designed to study the intracellular distribution of tryptophan transaminase in mung bean tissue, $200 \mathrm{~g}$ of etiolated, 4-day old seedlings were ground in $100 \mathrm{ml}$ of buffered sucrose at $\mathrm{pH} 8.5$ using a Waring blendor. The homogenate was then fractionated by the centrifugation procedure outlined in Figure 1 to yield an SNS-enzyme fraction and a soluble mitochondrial enzyme fraction. The pellet of mitochondrial membranes obtained in the final centrifugation of the mitochondrial fraction was also resuspended in $5 \mathrm{ml}$ of standard buffer at $\mathrm{pH} 8.5$ to give an insoluble mitochondrial fraction.

Aliquots of the three enzyme fractions were assayed for TTP-transaminase activity. Reaction mixtures in which the substrates L-tryptophan (ITP) and $\alpha$-ketoglutaric acid $(\alpha-K G)$ were omitted were also set up as control systems. The three reaction mixtures examined were prepared as follows:

a) $1 \mathrm{ml}$ enzyme fraction alone plus $1 \mathrm{~m} 1$ phosphate buffer.

b) $1 \mathrm{ml}$ enzyme fraction plus $0.5 \mathrm{ml}$ of $40 \mathrm{mM} \alpha-\mathrm{KG}$ and $0.5 \mathrm{ml}$ phosphate buffer.

c) $1 \mathrm{ml}$ enzyme fraction plus $0.5 \mathrm{ml}$ of $40 \mathrm{mM} \alpha-\mathrm{KG}$ and $0.5 \mathrm{ml}$ of $120 \mathrm{mM}$ TTP.

In addition al1 mixtures contained $0.1 \mathrm{mM}$ pyridoxal phosphate 
and the final pH was 8.5. Incubation was for 6 hours at $35^{\circ} \mathrm{C}$. At $0,2,4$, and 6 hours, $0.4 \mathrm{ml}$ samples were taken and added to $1.2 \mathrm{ml}$ of methanol. The glutamate content of these samples was determined by the chromatographic and colorimetric procedures described earlier. The results obtained, expressed as umoles glutamate formed per $\mathrm{ml}$ of enzyme, are shown in Table 4.

Table 4. Transaminase activity of mung bean enzyme fractions.

\begin{tabular}{|c|c|c|c|c|c|c|}
\hline \multirow[t]{2}{*}{$\begin{array}{l}\text { Enzyme } \\
\text { Fraction }\end{array}$} & \multirow{2}{*}{$\begin{array}{l}\text { Type of } \\
\text { Reaction } \\
\text { Mixture* }\end{array}$} & \multicolumn{5}{|c|}{$\begin{array}{l}\text { MMoles Glutamate/m1 Enzyme } \\
\text { Fraction after: }\end{array}$} \\
\hline & & $\overline{0}$ & $\mathrm{hr}$ & $2 \mathrm{hr}$ & $4 \mathrm{hr}$ & $6 \mathrm{hr}$ \\
\hline $\begin{array}{l}\text { Cytoplasmic } \\
\text { supernatant }\end{array}$ & $\begin{array}{l}1 \\
2 \\
3\end{array}$ & $\begin{array}{l}0 \\
0 \\
0\end{array}$ & & $\begin{array}{l}0 \\
0.12 \\
0.43\end{array}$ & $\begin{array}{l}0 \\
0.18 \\
1.00\end{array}$ & $\begin{array}{l}0 \\
0.31 \\
1.68\end{array}$ \\
\hline $\begin{array}{l}\text { Soluble } \\
\text { mitochondrial }\end{array}$ & $\begin{array}{l}1 \\
2 \\
3\end{array}$ & $\begin{array}{l}0 \\
0 \\
0\end{array}$ & & $\begin{array}{l}0 \\
0.12 \\
0.93\end{array}$ & $\begin{array}{l}0 \\
0.06 \\
2.00\end{array}$ & $\begin{array}{l}0 \\
0.06 \\
3.30\end{array}$ \\
\hline $\begin{array}{l}\text { Insoluble } \\
\text { mitochondrial }\end{array}$ & $\begin{array}{l}1 \\
2 \\
3\end{array}$ & $\begin{array}{l}0 \\
0 \\
0\end{array}$ & & $\begin{array}{l}0 \\
0.25 \\
0.37\end{array}$ & $\begin{array}{l}0 \\
0.25 \\
0.87\end{array}$ & $\begin{array}{l}0 \\
0.25 \\
1.43\end{array}$ \\
\hline
\end{tabular}

* The content of the reaction mixtures is given in the text.

As seen from this table, in the absence of $\alpha-K G$ and TTP (reaction mixture No. 1) no glutamate was detected in any assay, indicating that proteolysis had not occurred in any of the protein fractions during the reaction period. In the presence of $\alpha-K G$ alone (reaction mixture No. 2 ) only very small 
amounts of glutamate were formed, indicating that almost all of the free amino acids in the protein fractions had been removed by Sephadex filtration or by the mitochondrial washing procedures. However, when both $\alpha-K G$ and TTP were included in the reaction mixture (No.3), glutamate was formed at a constant rate over the 6 hour incubation period. To determine the specific activity and contribution of each enzyme fraction to the total transaminase activity, the protein content and volume of each fraction must be considered. The data in Table 4 have been recalculated with these factors in mind and the resultant values are presented in Table 5. The glutamate formed in reaction mixture No. 3 and the rate of transamination was determined graphically for each enzyme fraction. In Table 5, one milliunit of enzyme activity (mU) is the amount of enzyme which forms 1 mole of glutamate per minute under the standard assay conditions.

Although it is apparent that the soluble mitochondrial enzyme had a specific activity over 6 times that of the cytoplasmic enzyme, the activity in the soluble mitochondrial fraction was only 5\% of the total activity. The insoluble mitochondrial fraction contained $2 \%$ of the total activity or $30 \%$ of total mitochondrial activity. The cytoplasmic fraction contained over $90 \%$ of the total activity, although its specific activity was the lowest of the three fractions. 
Table 5. Intracellular distribution of transaminase activity in mung bean enzyme fractions.

\begin{tabular}{lcccccc}
\hline $\begin{array}{l}\text { Enzyme } \\
\text { Fraction }\end{array}$ & Vol & \multicolumn{2}{c}{ Enzyme Activity* } & $\begin{array}{c}\text { Protein } \\
\text { (mg/mI) }\end{array}$ & $\begin{array}{l}\text { Specific } \\
\text { Activity } \\
\text { (mU/mg } \\
\text { protein) }\end{array}$ \\
\hline $\begin{array}{l}\text { Cytoplasmic } \\
\text { supernatant }\end{array}$ & 200 & 4.5 & 900.0 & 92.5 & 13.2 & 0.34 \\
$\begin{array}{l}\text { Soluble } \\
\text { mitochondrial }\end{array}$ & 5 & 10.1 & 50.5 & 5.2 & 4.0 & 2.53 \\
$\begin{array}{l}\text { Insoluble } \\
\text { mitochondrial }\end{array}$ & 5 & 4.5 & 22.5 & 2.3 & 9.6 & 0.47 \\
$\begin{array}{l}\text { Total } \\
\text { mitochondrial }\end{array}$ & 10 & & 73.0 & 7.5 & & \\
\hline
\end{tabular}

* A milliunit (mU) of enzyme forms 1 nmole glutamate/min. under standard assay conditions.

The mitochondrial activity which remained Insoluble after 1 hour in the bursting medium may represent either the activity of unburst mitochondria or tightly bound enzyme. Greater solubilisation might be achieved by increasing the ratio of bursting medium to mitochondrial pellet. This was attempted by serially diluting the final mitochondrial suspension in bursting medium. After 1 hour all samples were centrifuged at $35,000 \times \mathrm{g}$ for $30 \mathrm{~min}$. and the soluble mitochondrial fraction from each was assayed at different protein concentrations. As seen from the data in Table 6, an increase in the volume of bursting medium did not increase the soluble transaminase activity. Furthermore, the table shows that there is a linear relationship between enzyme concentration and glutamate formation. 
Table 6. Effect of increasing volume of bursting medium on the solubilisation of mitochondrial transaminase from mung bean tissue.

\begin{tabular}{|c|c|c|c|c|c|}
\hline \multirow{2}{*}{$\begin{array}{l}\text { Volume of } \\
\text { Bursting } \\
\text { Medium }\end{array}$} & \multirow{2}{*}{$\begin{array}{l}\text { Dilution } \\
\text { Factor } \\
\text { for Assay }\end{array}$} & \multirow{2}{*}{$\frac{\text { Enzyme }}{(\mathrm{mU} / \mathrm{m} 1)}$} & \multirow{2}{*}{$\frac{\text { Activity* }}{(\operatorname{Tota} 1 \mathrm{mU})}$} & \multirow{2}{*}{$\begin{array}{l}\text { Protein } \\
\text { (mg/mi) }\end{array}$} & \multirow{2}{*}{$\begin{array}{l}\text { Specific } \\
\text { Activity } \\
\text { (mU/mg } \\
\text { protein) }\end{array}$} \\
\hline & & & & & \\
\hline 10 & $\begin{array}{l}1 \\
2 \\
4\end{array}$ & $\begin{array}{l}7.04 \\
3.74 \\
1.82\end{array}$ & $\begin{array}{l}70.4 \\
74.8 \\
72.8\end{array}$ & $\begin{array}{l}4.6 \\
(2.3) * * \\
(1.15) * *\end{array}$ & $\begin{array}{l}1.53 \\
1.62 \\
1.58\end{array}$ \\
\hline 20 & $\begin{array}{l}1 \\
2\end{array}$ & $\begin{array}{l}3.96 \\
1.82\end{array}$ & $\begin{array}{l}79.2 \\
72.8\end{array}$ & $\begin{array}{l}2.6 \\
(1.3) * *\end{array}$ & $\begin{array}{l}1.52 \\
1.40\end{array}$ \\
\hline 40 & 1 & 1.93 & 77.2 & 1.4 & 1.38 \\
\hline
\end{tabular}

* A milliunit (mU) of enzyme forms 1 nmole glutamate/min. under standard assay conditions.

* These values are derived from the unbracketed value above.

Table 7 presents a summary of the results from a number of experiments examining distribution of transaminase activity between the high-speed cytoplasmic supernatant and the soluble mitochondrial fractions. Both the distribution of the enzyme activity between the two fractions and the activity per $g$ fresh weight demonstrate the reproducibility of the experimental procedure. Preparation of the mitochondrial fraction involved four resuspensions to remove contaminating cytoplasm and it is possible that this 'washing' procedure may have solubilised some transaminase loosely bound to intact mitochondria and caused damage and loss of mitochondria. The supernatant fractions from each of these washes were not collected and assayed for activity and therefore transaminase loss during the washing procedure remains undetermined. 


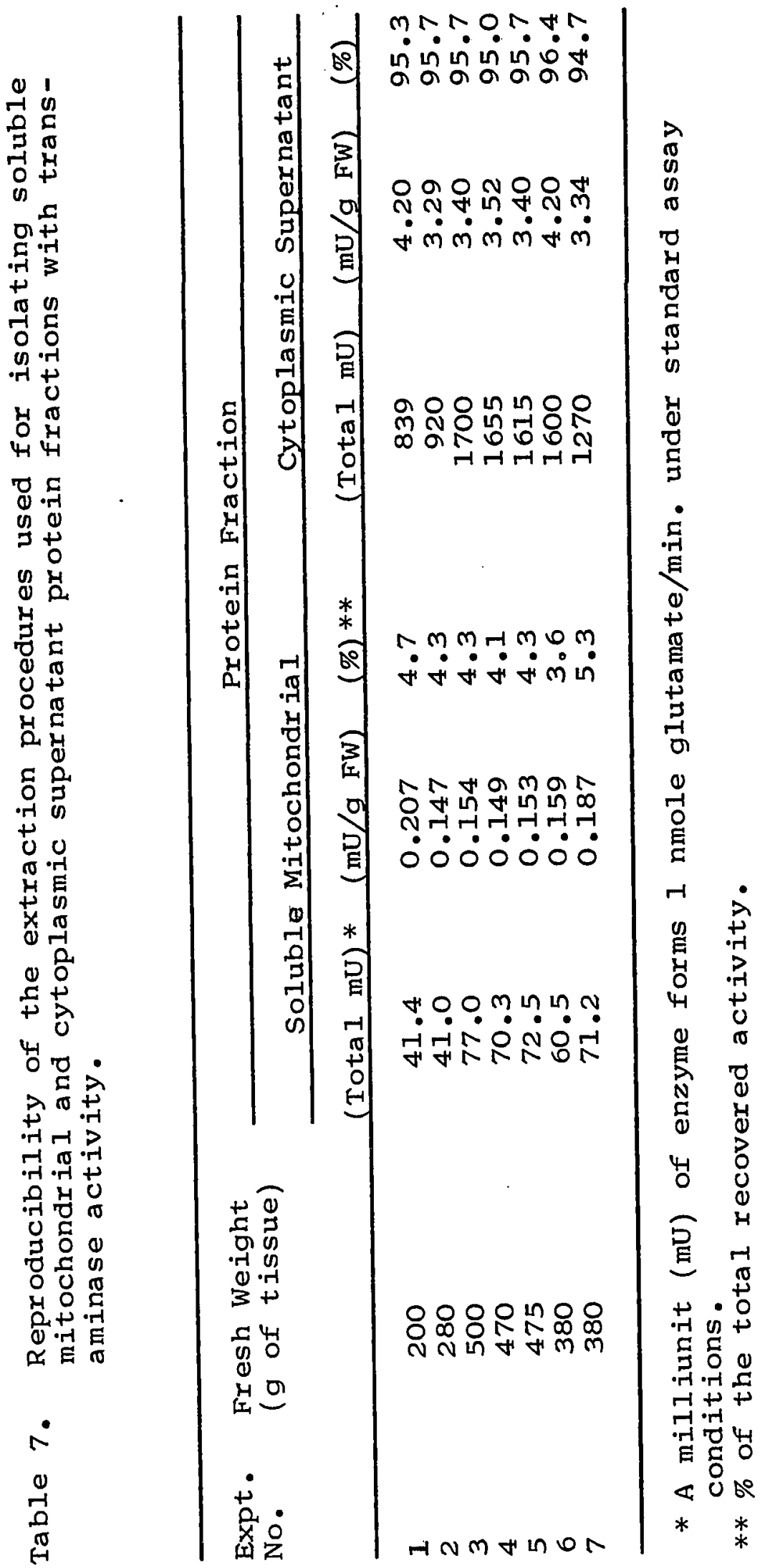


It should be emphasized that one of the main purposes of the mitochondrial washing procedure was to demonstrate that at least some of the transaminase activity was clearly associated with the mitochondrial fraction. The fact that the transaminase activity in the soluble mitochondrial protein fraction represents such a constant proportion of the total activity is good evidence for a mitochondrial transaminase.

The purity of the mitochondrial fraction was checked by electron microscopy. An aliquot of the final mitochondrial resuspension in buffered sucrose was fixed by adding glutaraldehyde to a final concentration of $6 \%$. The fixed mitochondria were then pelleted and post-fixed in osmium tetroxide. The pellet was dehydrated, embedded and prepared for electron microscopy. An electron micrograph (Fig. 10) of a section of the mitochondrial pellet shows that the predominant organelles in the fraction were indeed mitochondria, although some microsomal vesicles were also present. The mitochondria do show signs of swelling and it is possible that their outer membrane might have been damaged. In this connection, Bonner (1967) noted that the addition of phosphate buffer to the isolation medium leads to mitochondrial rupture and the extraction of cytochrome $C$. Phosphate buffer should therefore be avoided when mitochondria with good respiratory control are required, but in the present work the recovery of a good yield of mitochondria with minimal contamination was the main requirement and phosphate buffered sucrose was found to be very satisfactory. 
It should be emphasized that one of the main purposes of the mitochondrial washing procedure was to demonstrate that at least some of the transaminase activity was clearly associated with the mitochondrial fraction. The fact that the transaminase activity in the soluble mitochondrial protein fraction represents such a constant proportion of the total activity is good evidence for a mitochondrial transaminase.

The purity of the mitochondrial fraction was checked by electron microscopy. An aliquot of the final mitochondrial resuspension in buffered sucrose was fixed by adding glutaraldehyde to a final concentration of $6 \%$. The fixed mitochondria were then pelleted and post-fixed in osmium tetroxide. The pellet was dehydrated, embedded and prepared for electron microscopy. An electron micrograph (Fig. 10) of a section of the mitochondrial pellet shows that the predominant organelles in the fraction were indeed mitochondria, although some microsomal vesicles were also present. The mitochondria do show signs of swelling and it is possible that their outer membrane might have been damaged. In this connection, Bonner (1967) noted that the addition of phosphate buffer to the isolation medium leads to mitochondrial rupture and the extraction of cytochrome C. Phosphate buffer should therefore be avolded when mitochondria with good respiratory control are required, but in the present work the recovery of a good yield of mitochondria with minimal contamination was the main requirement and phosphate buffered sucrose was found to be very satisfactory. 


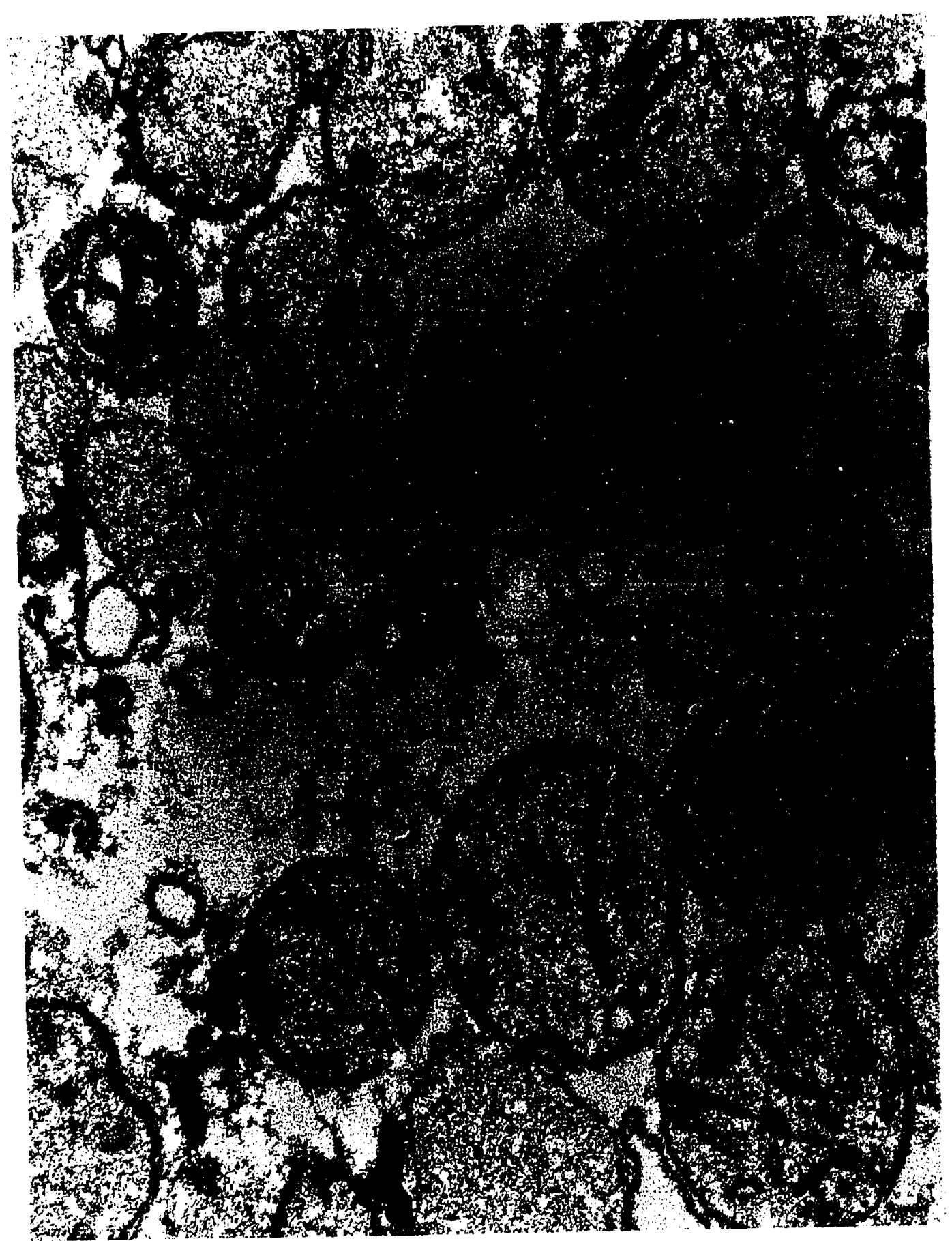

Figure 10. Electron micrograph of a section through a mitochondrial pellet. Glutaraldehyde-osmic fixation, Mag. 36,000 x. 


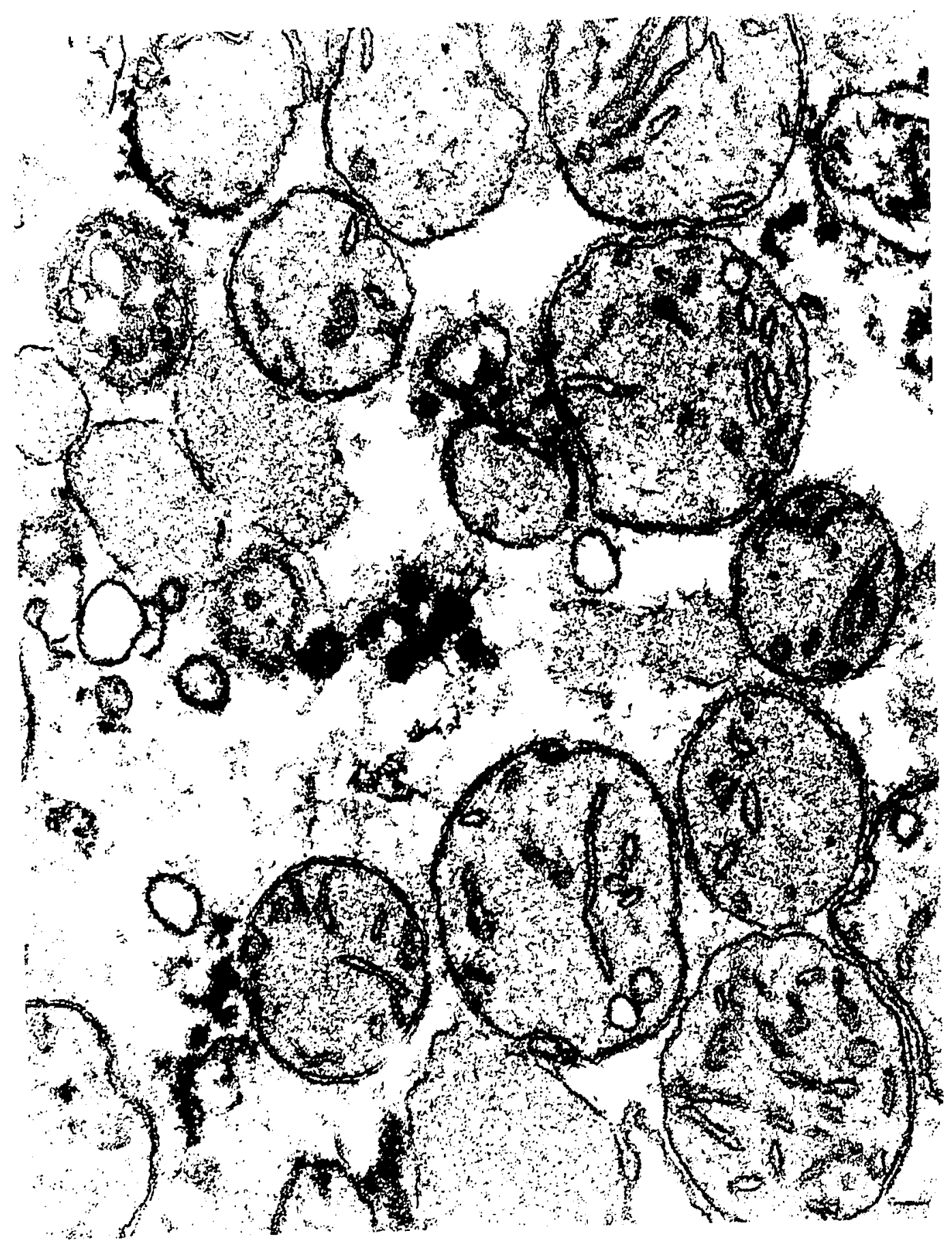

Figure 10. Electron miarograph of a section through a mitochondrial pellet. Glutaraldehyde-osmic fixation, Mag. $36,000 \mathrm{x}$. 


\section{The indole product of transamination:}

Wightman and Fowden (1966) showed conclusively that IPyA was formed as the primary indole product of tryptophan transamination by soluble mitochondrial protein fractions, although no attempt was made to measure the rate of IPyA formation. It was, therefore, not possible to compare the quantities of glutamate and IPyA formed and hence determine from their data whether the IPyA in the reaction mixture was also being broken down either chemically or enzymatically. Since IPyA is known to be unstable in purely aqueous solutions (Bentley et al., 1956; Kaper and Veldstra, 1958; Kaper et al., 1963a,b), breakdown products may also be formed in the proteinaceous system studied by Wightman and Fowden. These breakdown products might include IAA and IAld as shown by Shaw et a1. (1958), but 3-indoleacetaldehyde has never been demonstrated as a breakdown product of IPyA (see Literature Review). However, if an enzyme were present in the system which enzymatically decarboxylated IPyA, then IAAld might also be present in the reaction mixture. In this case, it should be possible to extract and identify IAAld as its 2,4-dinitrophenylhydrazone.

In the present investigation, the aim was first to demonstrate that IPyA was formed as the primary indole product of transamination by cytoplasmic supernatant protein fractions, and then to investigate whether any other indole compounds were formed enzymatically in the reaction mixture.

To investigate the formation of IPyA, soluble mitochondrial 
protein (Mito) and Sephadex-purified, cytoplasmic supernatant protein (SNS) fractions were prepared as described in the previous section. TTP-transaminase assay systems were prepared and incubated at $35^{\circ} \mathrm{C}$ for 6 hours. At the end of this period, a hot solution of 2,4-dinitrophenylhydrazine in $2 \mathrm{~N} \mathrm{HCl}$ (containing $6 \mathrm{mg} \mathrm{DNPH} / \mathrm{ml}$ ) was added to the reaction mixture which was then placed in a refrigerator overnight. The following morning, the precipitated hydrazones and protein were collected by centrifugation. Hydrazones were extracted from the pellet with ethyl acetate and both ACID HYDRAZONE and NEUTRAL HYDRAZONE fractions were prepared as outlined previously in the Materials and Methods section.

a) Chromatography of the ACID HYDRAZONE fraction

Paper chromatograms of the ACID HYDRAZONE fraction prepared from both Mito and SNS reaction mixtures were developed in methanol:benzene: n-butanol:water (MBzBuW). A compact, yellow-orange band was found at Rf.78 from both Mito and SNS preparations which had been incubated with TTP and $\alpha-K G$, but was not found if the enzyme preparation was boiled or if TTP was omitted from the reaction mixture. This band was identical in both colour and Rf with authentic IPyA-DNPH. When the chromatograms were sprayed with the DMAC reagent, the suspected and authentic IPyA-DNPH bands gave an identical deep purple reaction. Thus, it appears that IPyA was formed as the immediate indole product of the transamination of tryptophan by SNS as well as Mito enzyme fractions. 
When the ACID HYDRAZONE fraction was examined by thinlayer chromatography (TLC) using silica gel plates and benzene:acetic acid:ethyl acetate ( $\mathrm{BzACE}$ ) as the developing solvent, the IPyA-DNPH band was split into two components (Fig. 11). The upper band was yellow, while the lower band was orange. Both bands gave the typical colour reaction of IPYA-DNPH when sprayed with the DMAC reagent with the lower band giving the more intense reaction. Both the yellow and the orange bands were present on chromatograms of the Mito and SNS preparations as well as chromatograms of authentic IPyA-DNPH. However, the ratio of the intensities of the two bands was found to vary. The orange band was more intense on chromatograms of the Mito and SNS preparations, whereas the ratio of the yellow to the orange band varied between samples of authentic IPyA-DNPH.

It has been established that 2,4-dinitrophenylhydrazones can exist as two geometric isomers, cis and trans, about the $\mathrm{C}=\mathrm{N}$ bond and that these isomers differ in their $\mathrm{UV}$ and $\mathrm{IR}$ spectra (Ramirez and Kirby, 1954; Isherwood and Cruickshank, 1954; Jones et a1., 1956). The question, therefore, arose as to whether the bands appearing on the TLC plate were cis and trans isomers of IPyA-DNPH.

Samples of authentic IPyA-DNPH and samples of the hydrazones prepared from both Mito and SNS reaction mixtures were streaked on TLC plates and developed in BzACE. The yellow and the orange bands of all samples were then scraped off the plates and eluted into methanol. The UV spectrum of each eluate was recorded (Fig. 12). An exact correspondence 


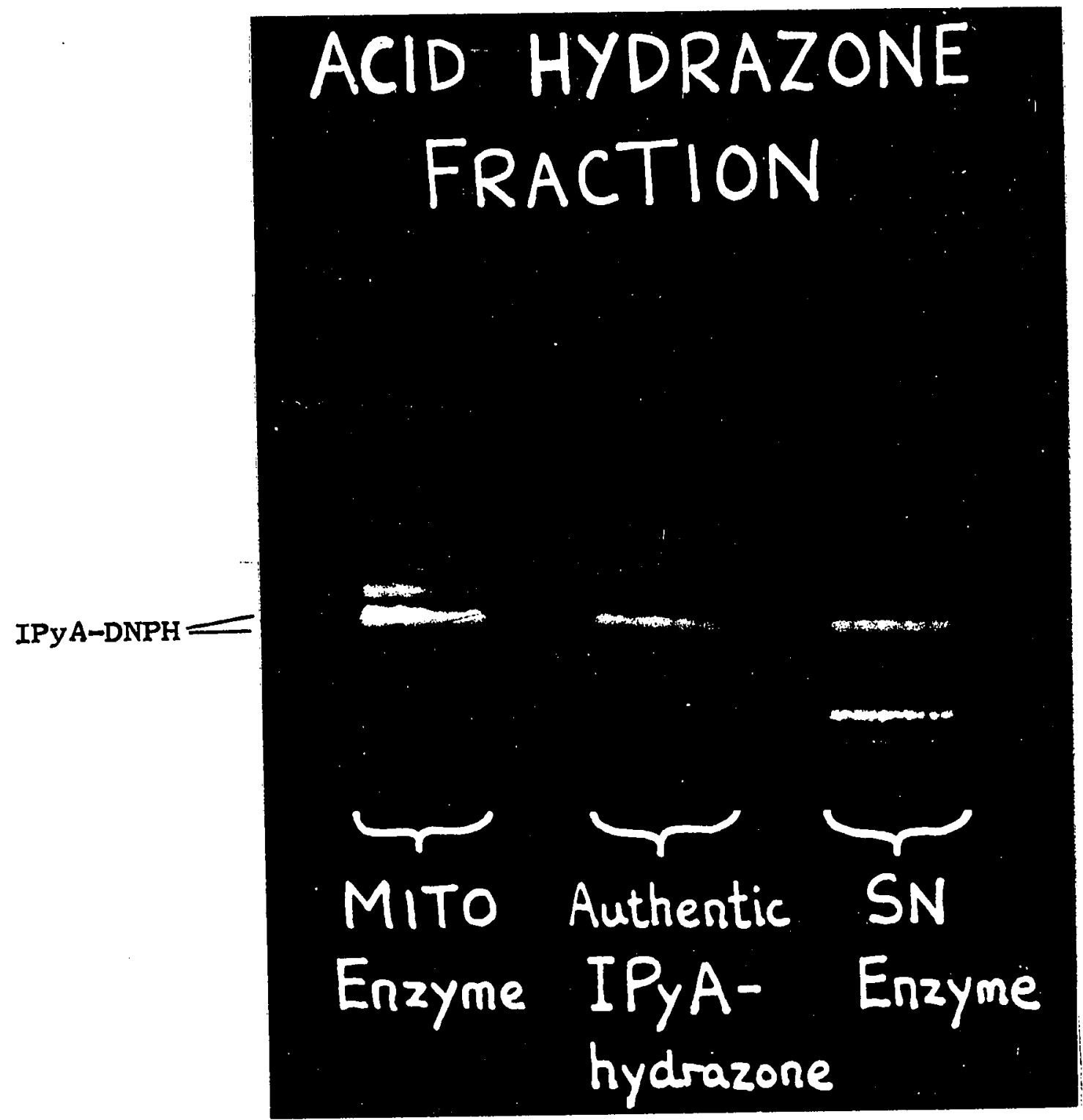

Figure 11. Thin-layer chromatogram of ACID HYDRAZONE fraction prepared from standard transaminase reaction mixtures incubated for 6 hours. The reaction mixtures contained either mitochondrial (Mito) or sephadex-purified cytoplasmic supernatant (here shown as $\mathrm{SN}$ ) preparations from mung bean seedlings. Chromatogram developed in BzAcE. The Rf's of the yellow (upper) and orange (lower) bands of IPyA-DNPH are indicated. 


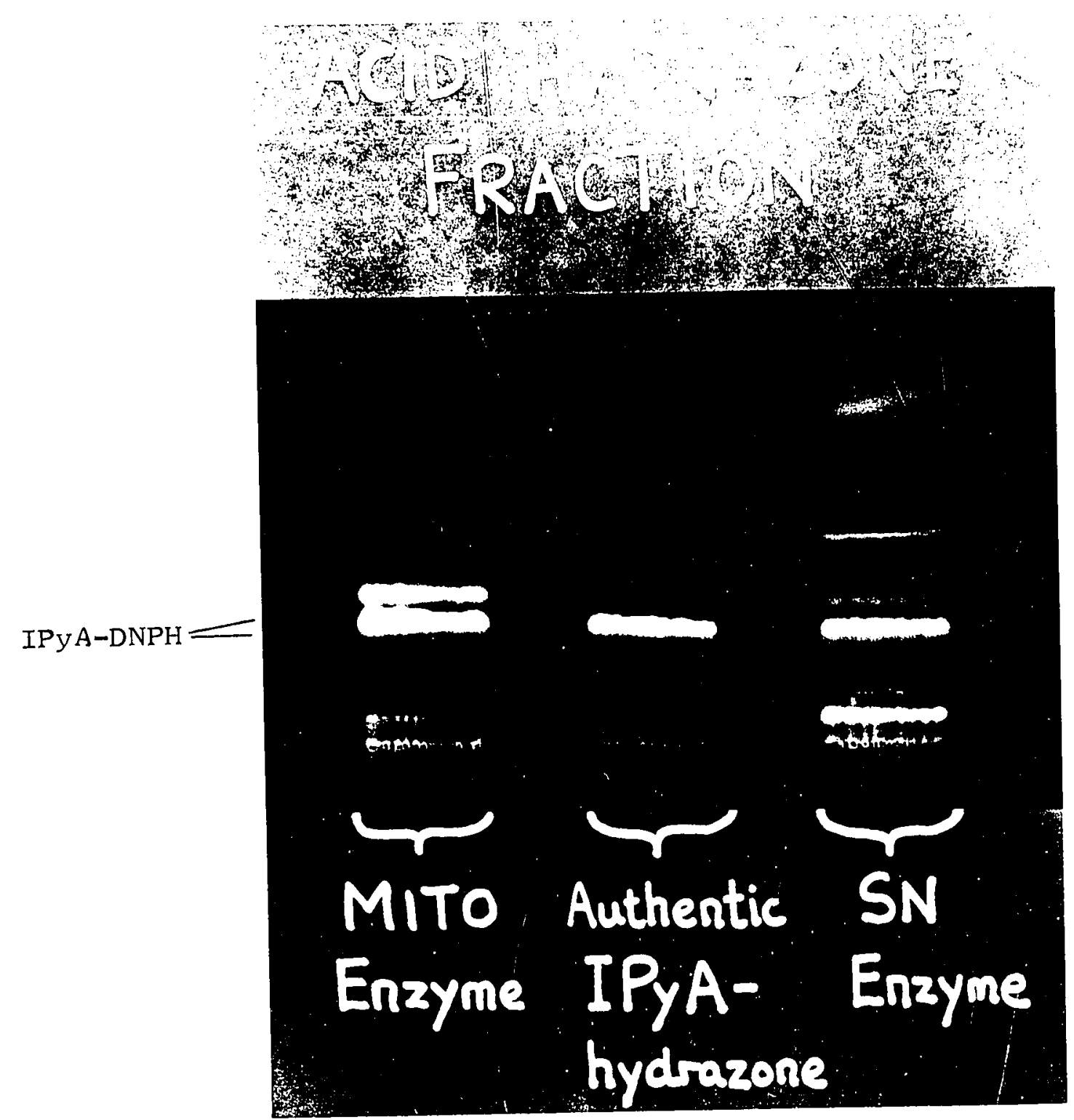

Figure 11. Thin-layer chromatogram of ACID HYDRAZONE fraction prepared from standard transaminase reaction mixtures incubated for 6 hours. The reaction mixtures contained either mitochondrial (Mito) or sephadex-purified cytoplasmic supernatant (here shown as $\mathrm{SN}$ ) preparations from mung bean seedlings. Chromatogram developed in BzAcE. The Rf's of the yellow (upper) and orange (lower) bands of IPy A-DNPH are indicated. 

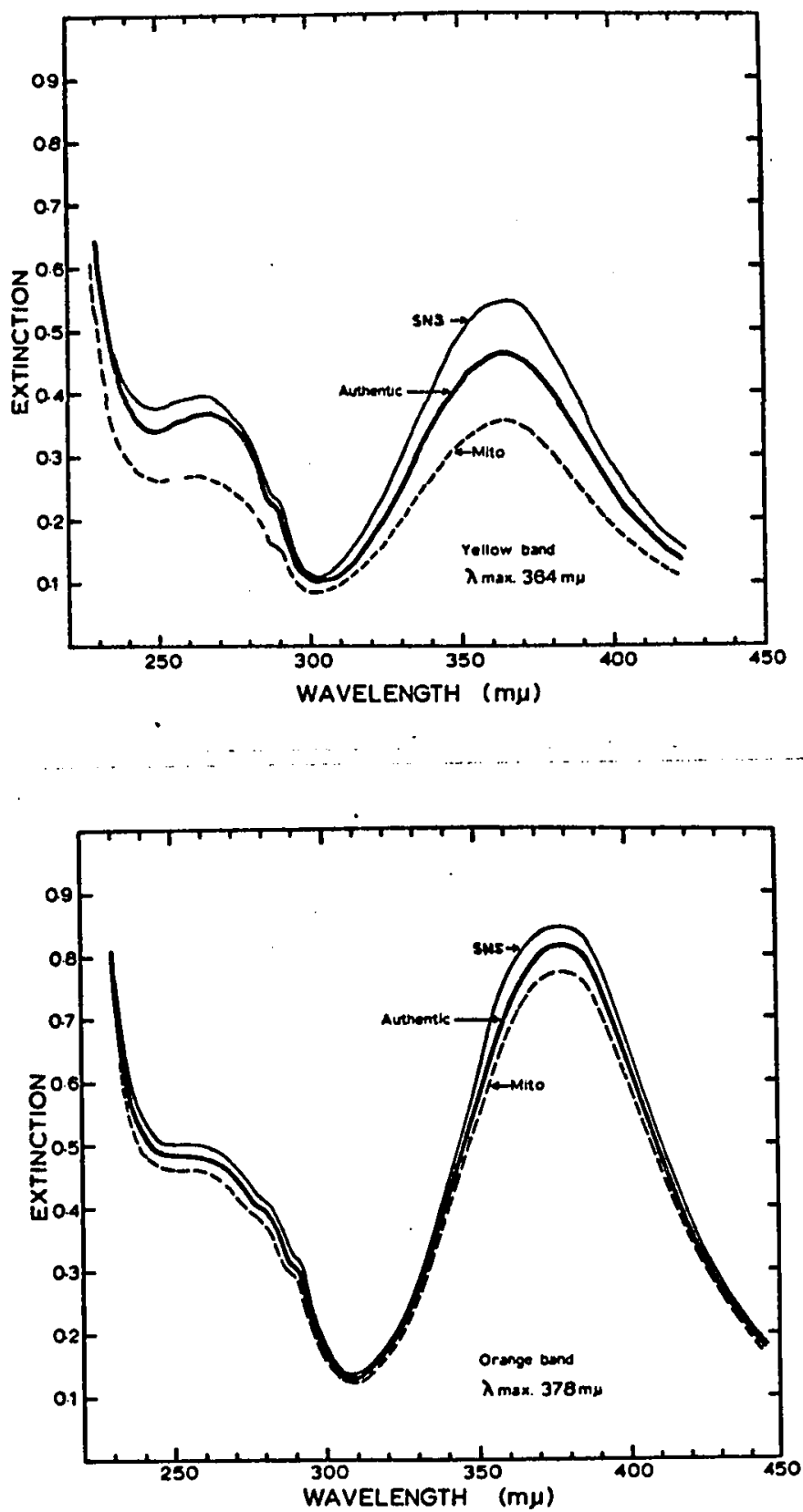

Figure 12. UV spectra of yellow and orange bands of IPyA-DNPH eluted from TLC plates. Spectra are shown for the bands of authentic IPyADNPH and also samples of IPyA-DNPH extracted from Mito and SNS reaction mixtures. 
was found between the spectra from all samples of the yellow band and there was also an exact correspondence of the spectra from all samples of the orange band. Although the typical indole spectrum (max. 260-280 $\mathrm{m} \mu$ and a shoulder at $290 \mathrm{~m} \mu$ ) can be seen in the samples of both bands, the positions of the absorption due to the hydrazone moiety were different in the yellow and the orange bands (Table 8). Differences of this magnitude in the max. of cis and trans isomers were reported by Ramirez and Kirby (1954) and Jones et a1. (1956).

Table 8. Characteristics of the UV spectra of IPyA-DNPH eluted from TLC plates.

Band

Wavelength of absorption peaks Indole molety Hydrazone moiety maximum shoulder maximum

\begin{tabular}{llll}
\hline & & & \\
Yellow & $266 \mathrm{m \mu}$ & $290 \mathrm{m \mu}$ & $364 \mathrm{m \mu}$ \\
Orange & $258 \mathrm{m \mu}$ & $290 \mathrm{m \mu}$ & $378 \mathrm{m \mu}$
\end{tabular}

For further examination, eluates from the TLC plates were concentrated and rechromatographed on paper using $\mathrm{MBzBuW}$ as the developing solvent. The Rf of all eluates was identical (Rf.85), but the orange eluates chromatographed to give a more compact band than the yellow eluates. The orange bands of authentic IPyA-DNPH and the IPyA-DNPH extracted from Mito and SNS reaction mixtures were eluted from the paper chromatograms into methanol and concentrated in a rotary evaporator. The samples were then transfered to glass microscope 
slides and dried. Nujol mulls were prepared and IR spectra recorded on a Beckman IR 8 spectrophotometer (Fig. 13). Although intensity of the absorption peaks are low, it can be seen that there is a correspondence in the spectra obtained from all three samples. However, there was no obvious absorption peak due to the carbonyl group of the acid. The IR spectra obtained by Wightman (Wightman and Cohen, 1968) show a medium intensity absorption peak at $1680 \mathrm{~cm}^{-1}$, probably due to the carboxyl group, which is not present on the spectra shown in Figure 13.

There was an insufficlent quantity of the yellow band of IPyA-DNPH on any of the paper chromatograms to obtain an IR spectrum. Since the absorption peak at $1680 \mathrm{~cm}^{-1} \mathrm{might}$ be due to the yellow band appearing on thin layer chromatograms, a larger sample of authentic IPyA-DNPH was streaked on two $750 \mathrm{mu}$ silica gel plates and developed in BzAcE. The yellow and orange bands were scraped off and eluted with methanol. The eluates were concentrated and nujol mulls were prepared from both samples as described above. The IR spectra of these samples are shown in Figure 14. Neither spectrum contains a strong absorption peak due to carbonyl around $1700 \mathrm{~cm}^{-1}$ but a weak, broad zone of absorption was found around $1680 \mathrm{~cm}^{-1}$. If IPyA-DNPH was present as a carboxylate anion, the carbonyl absorption peak would be expected at 1550-1610 cm (Cross, 1964) and might be masked by other strong peaks in this region resulting from the hydrazione moiety. Differences between the spectra appear to be mainly differences in intensity 


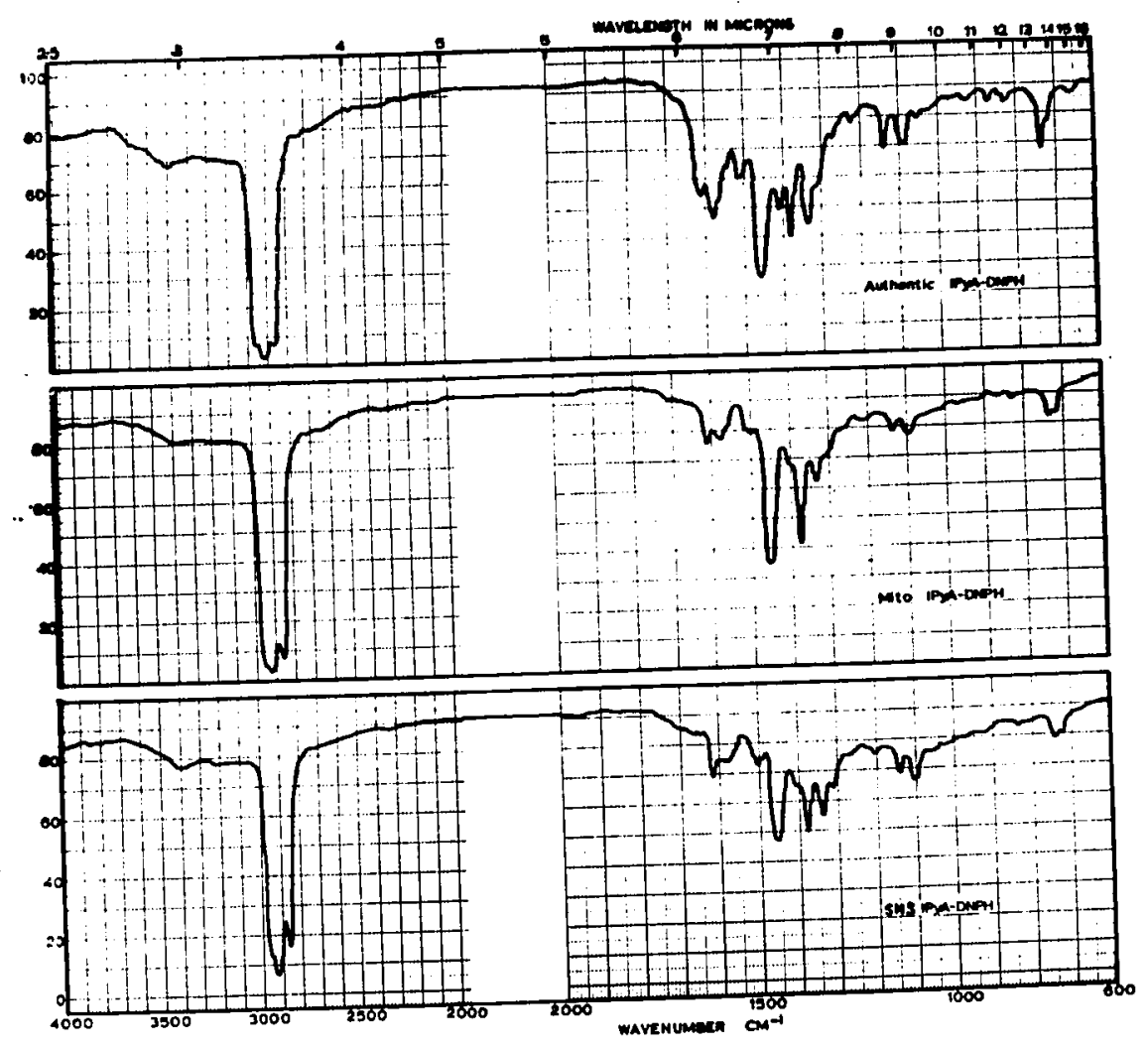

Figure 13. IR spectra of the orange band of authentic IPyA-DNPH and IPyA-DNPH extracted from Mito and SNS reaction mixtures. top: Authentic IPyA-DNPH, middle: Mito IPyA-DNPH, bottom: SNS IPYA-DNPH 


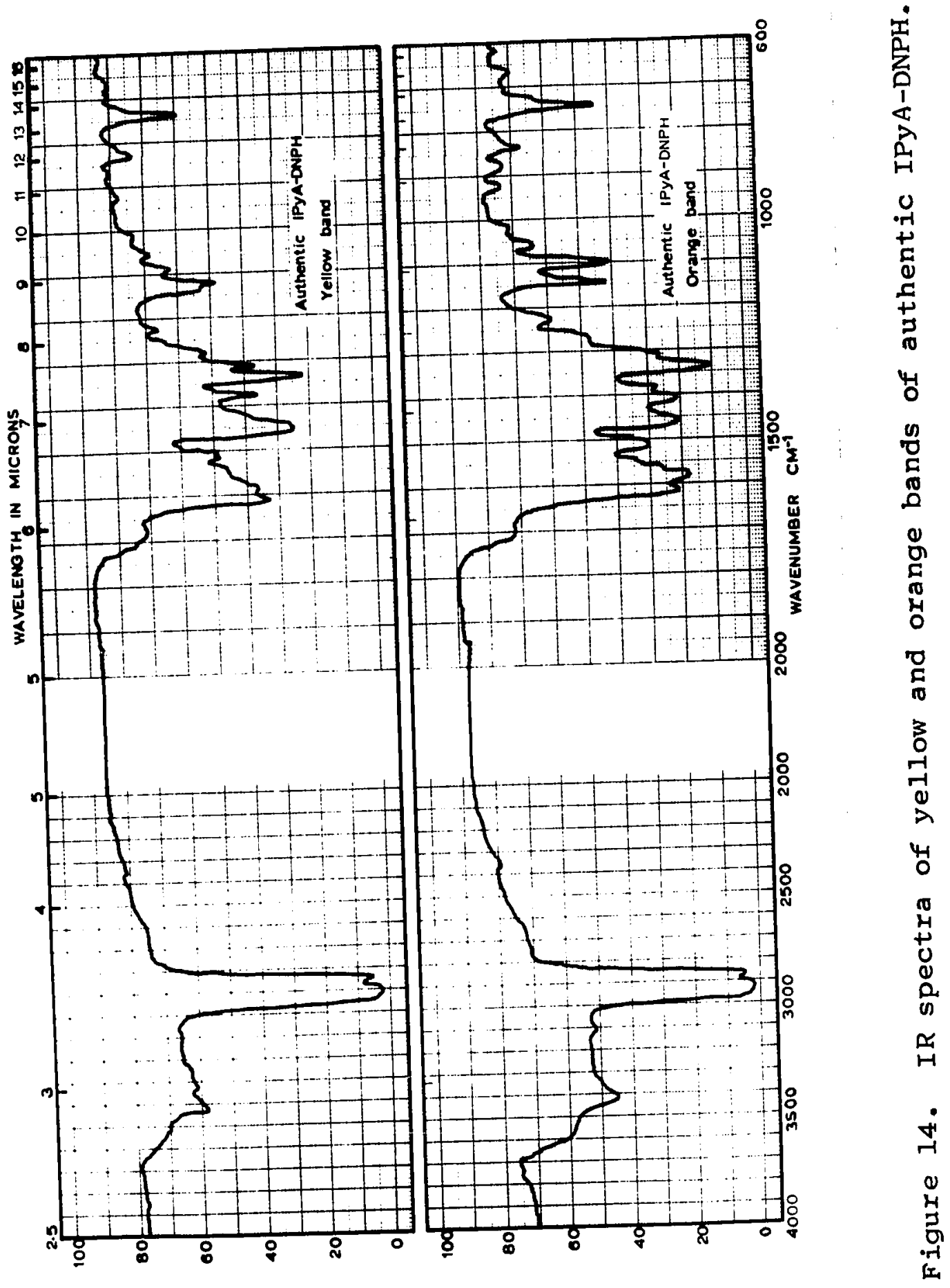


of individual peaks, for example, $1095 \mathrm{~cm}^{-1}, 1380 \mathrm{~cm}^{-1}$ and $1510 \mathrm{~cm}^{-1}$. However, the absorption peak at $1410 \mathrm{~cm}^{-1}$ was found only in the spectrum of the orange form. If the two forms are in fact geometric isomers of IPyA-DNPH, then interconversion of one form to the other should occur under acidic conditions when protonation might allow rotation of the $\mathrm{C}=\mathrm{N}$ bond. In order to determine whether interconversion took place under conditions of acidic chromatography, TLC plates were spotted with eluates of the yellow and orange bands and these plates were developed in two directions using $B z A C E$. Further samples of the two eluates and a sample containing both forms were also run on the same plate in each direction. The chromatograms were then sprayed with the DMAC reagent and are shown in Figure 15. The yellow form showed evidence of conversion to the orange form, but conversion of the orange form to the yellow form took place only to a very limited extent. It appears, therefore, that the orange and yellow forms represent cis and trans isomers of IPyA-DNPH and the orange form should be the thermodynamically favoured configuration. The two isomers may be represented as follows :

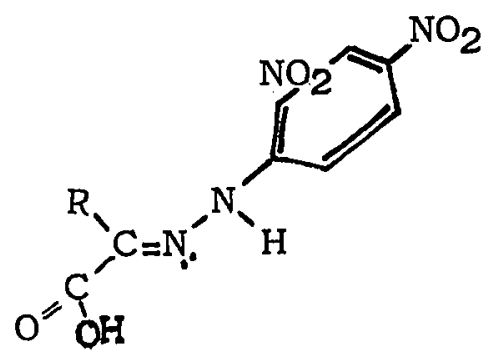

where $\mathrm{R}=$ indole nucleus<smiles>[R]C1=N[Y]([H])(c2ccc([N+](=O)[O-])cc2[N+](=O)[O-])N[Z1](O)C1=O</smiles> 


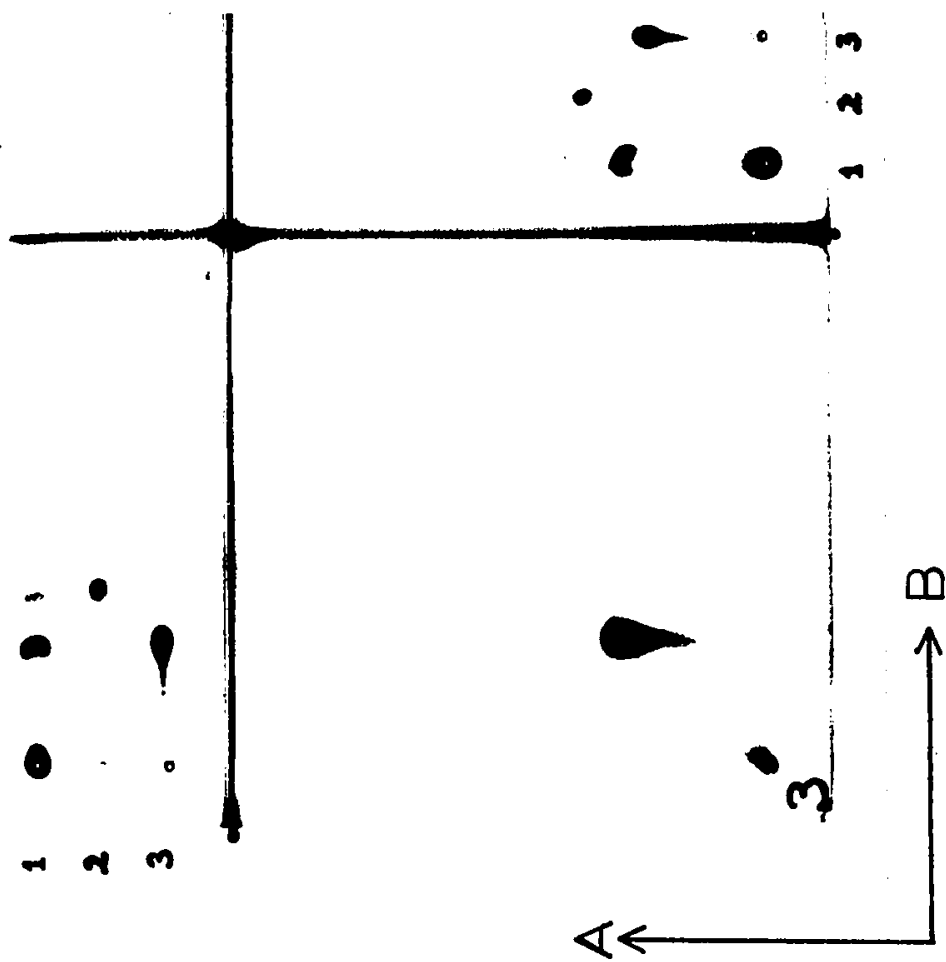

†ैष

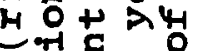

斗

苍㗨兵

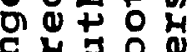

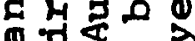

मू० ण

ס क्षे

用

ه

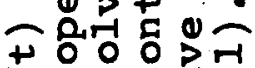

4

त 0004

一

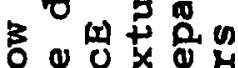

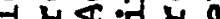

光券昌会

人电。园

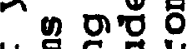

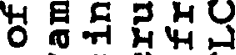

兵的约出

琞名

मे का

ô on

ठ

$+H \cup$

塄它.

$4000 \mathrm{H}$

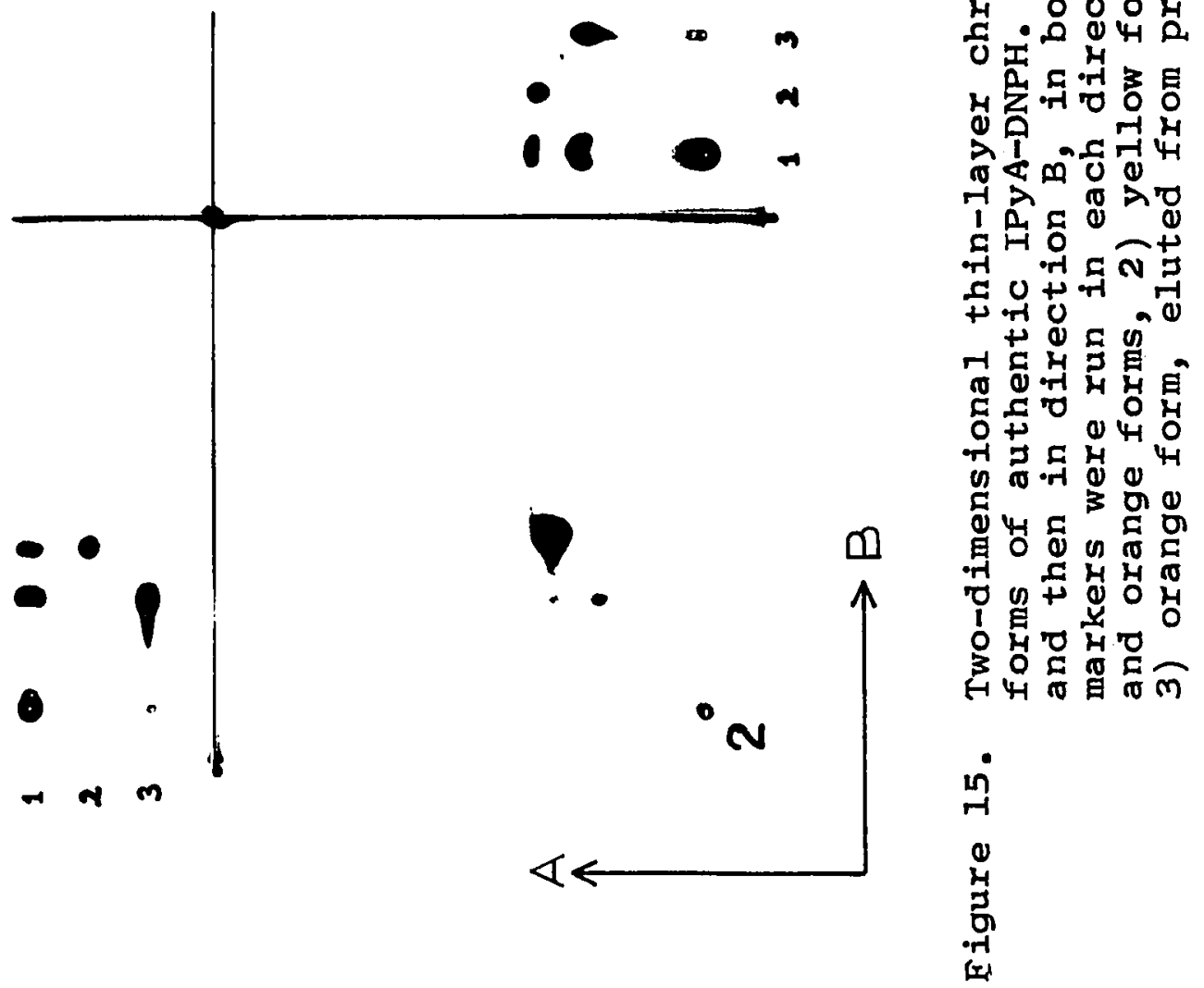




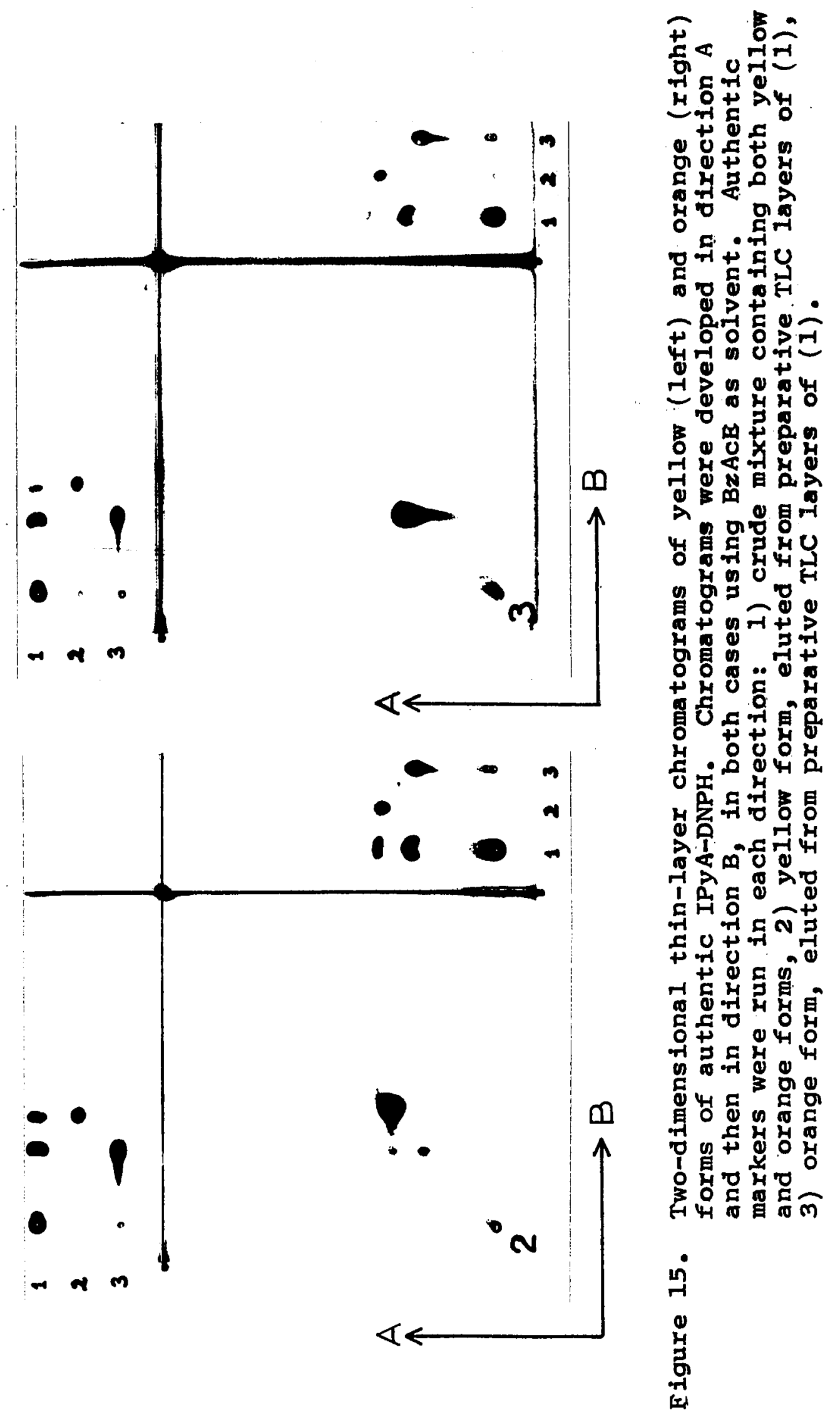


On the evidence presented here, it is not possible to assign a definite structure to the yellow or orange isomer. It is clear, however, that the IPyA-DNPH formed from the IPyA produced in Mito and SNS reaction mixtures is identical in its behaviour and properties with IPyA-DNPH produced from authentic IPyA.

b) Chromatography of the NEUTRAL HYDRAZONE fraction

The NEUTRAL HYDRAZONE fractions prepared from both Mito and SNS reaction mixtures (as described earlier) were chromatographed on TLC plates using the solvent benzene:ethyl acetate (BzE). Many bands were found on these chromatograms (Fig. 16), but two of the bands coincided both in colour and Rf with authentic IAAld-DNPH and IAld-DNPH. To obtain further amounts of the two suspected compounds, neutral hydrazone fractions prepared from an SNS reaction mixture were chromatographed on preparative ILC layers (750 mu). The technique of multiple running of the plate in the same solvent ( $B z E$ ) was employed. This technique gave very sharp banding of the hydrazones and the bands corresponding to IAld-DNPH and IAAId-DNPH were eluted. UV spectra were recorded of these eluates and compared with the spectra of authentic IAId-DNPH and IAAId-DNPH. Although the position of the absorption peaks were similar (Table 9), the spectrum of the suspected IAAld-DNPH did not show a shoulder at $290 \mathrm{m \mu}$ and the spectrum of the suspected IAId-DNPH showed a minimum at $290 \mathrm{~m} \mu$ which was not shown by the authentic IAld-DNPH. 
IAAId-DNPH

IAId-DNPH
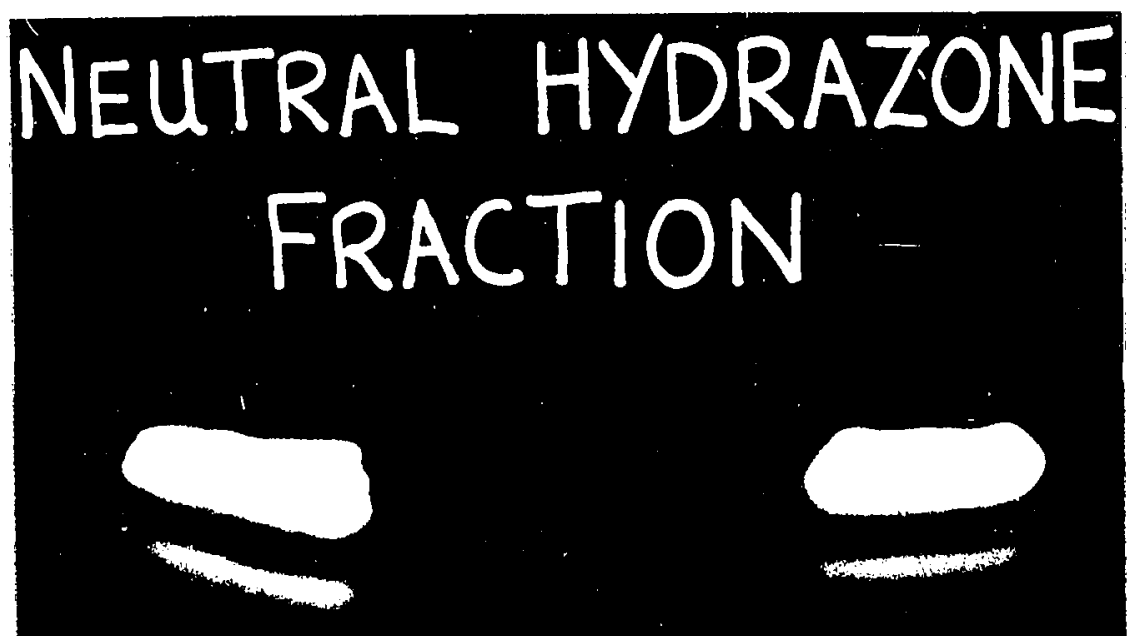

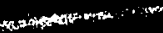
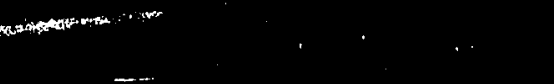

$\rightarrow \cos 20$

$\operatorname{trit} 2 \times 2$
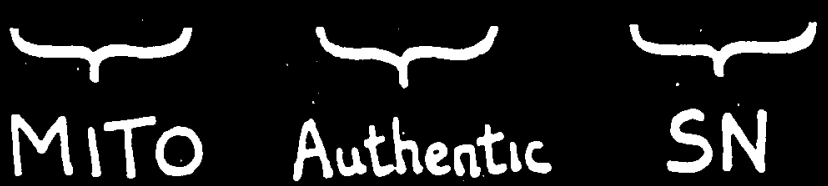

Authentic SN Enzyme

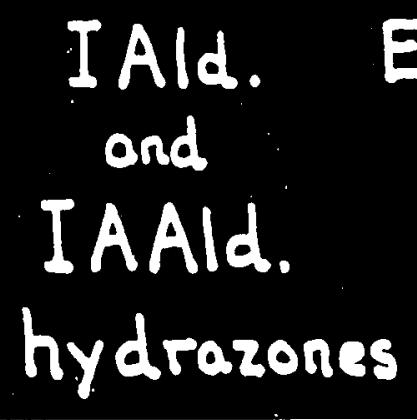

Figure 16. Thin-layer chromatogram of NEUTRAL HYDRAZONE fraction from standard transaminase reaction mixture incubated for 6 hours. Reaction mixtures contained either mitochondrial (Mito) or sephadexpurified cytoplasmic supernatant (here shown as SN) preparations from mung bean seedlings. Chromatograms developed in BzE. The Rf's of authentic IAAld-DNPH and IAld-DNPH are indicated. 
Table 9. Characteristics of UV spectra of suspected and authentic IAAId-DNPH and IAId-DNPH.

Compound

Wavelength of absorption peaks (mp)

Authentic IAAId-DNPH

Suspected IAAld-DNPH

270

270

290 (shoulder)

357

Authentic IAld-DNPH

Suspected IAId-DNPH

260

260

300 (minor)

322 (minor) 396

To further purify the suspected hydrazones, the eluates from the preparative ILC layers were concentrated and rerun on $250 \mathrm{m \mu}$ TLC layers together with the authentic hydrazone samples (Fig.17). These bands were eluted and the UV spectra were recorded. As shown in Figure 18, the spectra of the suspected and authentic IAAld-DNPH are very similar except for the absence of the shoulder at $290 \mathrm{mp}$. This shoulder, however, is characteristic of the indole nucleus. On spraying a duplicate plate with the DMAC reagent, the band of authentic IAAId-DNPH gave an instant purple colour reaction, whereas the corresponding suspected IAAId-DNPH band did not react. From this evidence it would appear that the suspected IAAldDNPH sample differs from the authentic sample, both in its reaction with the DMAC reagent and in the absence of a shoulder in the UV spectrum. It is possible, however, that the suspected band is not pure and that the characteristics of IAAld-DNPH are obscured by an impurity. 


\section{NEUTRAL HYDRAZONE FRACTION}

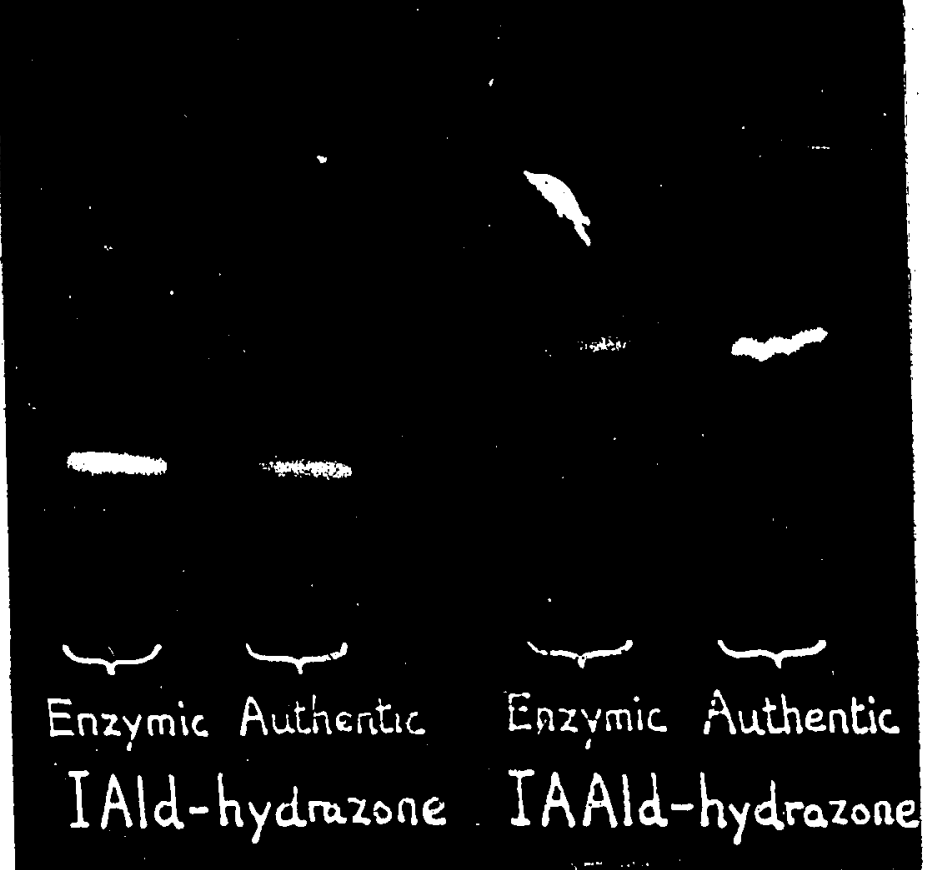

Figure 17. Thin-layer chromatograms of authentic and suspected bands of IAAld-DNPH and IAId-DNPH eluted from preparative TLC layer chromatograms of NEUTRAL HYDRAZONE fraction (see Fig. 16). Developing solvent $\mathrm{BzE}$. 

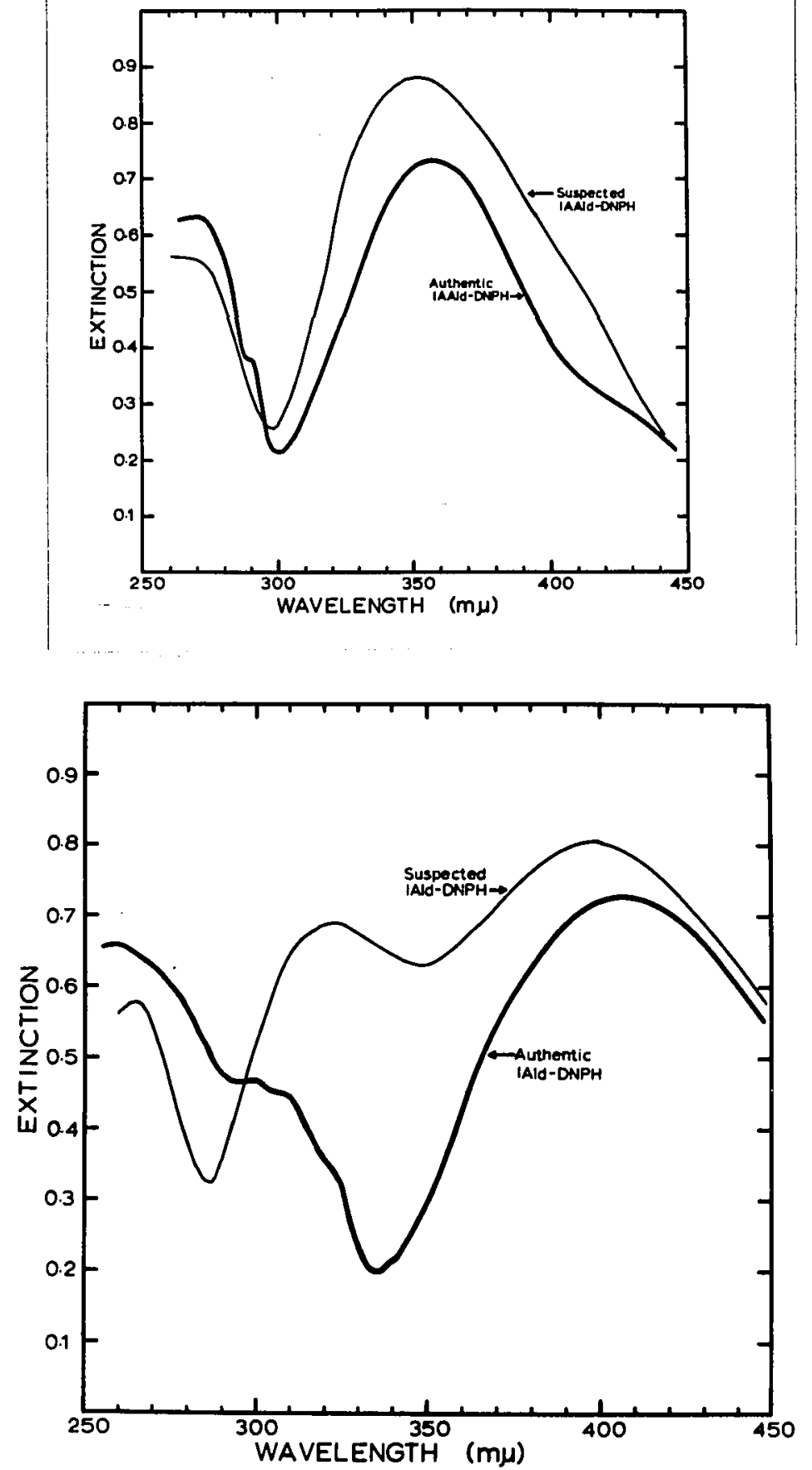

Figure 18. UV spectra of authentic and suspected IAAId (top) and IAld (bottom). 
The spectra of the authentic and suspected bands of IAld-DNPH were also shown to differ (Fig. 18); the minimum at $286 \mathrm{mp}$ had become more pronounced with further chromatography. It appears that in this case also, the suspected band is either incorrectly identified or at least contains an impurity. Neither the authentic IAId-DNPH band nor the corresponding band reacted with the DMAC reagent.

3. Transamination experiment with $D, L$-tryptophan-3-14 C:

Since it was not possible to Identify the suspected IAAld-DNPH and IAId-DNPH from their UV spectra, it was declded to investigate whether these hydrazone bands became labelled in a radioactive experiment using $\mathrm{D}, \mathrm{L}$-tryptophan$3{ }^{14} \mathrm{C}$ as substrate. In this experiment, only Mito enzyme was used but similar results have recently been obtained by Gibson and Wightman (1968) using SN enzyme.

The experimental procedures were identical with those used previously, except that $D, L$-tryptophan- $3-{ }^{14} \mathrm{C}$ was added to the L-TTP substrate at the rate of $0.5 \mathrm{\mu c} / \mathrm{mg}$. Reaction mixtures were set up using both boiled and standard Mito enzyme and samples were removed during the incubation period to determine the rate of glutamate formation.

In the boiled enzyme system, no glutamate was detected even after 6 hours, indicating that transaminase enzymes had been inactivated. In the standard system there was a steady increase in glutamate formation which resulted in the formation of 0.9 moles per $m 1$ reaction mixture at the 
end of the 6-hour incubation period. Assuming that IPyA was formed at an equivalent rate, this represents a conversion of 3\% of the TTP originally present.

After 6 hours of incubation, hydrazones were prepared from the remaining reaction mixtures and were fractionated to obtain a MIXED HYDRAZONE fraction, as described in the Materials and Methods section. Samples were taken at each stage of the fractionation procedure for liquid scintillation counting. The radioactivity in each sample was measured using a Packard Tricarb liquid scintillation counter equipped with external standardisation and the results were calculated as $\mathrm{dpm} / \mathrm{ml}$ reaction mixture and also as percentage of the initial radioactivity present in the reaction mixture (Table 10). There was considerable quenching in the samples because the hydrazones were yellow and counting efficiency in some samples was as $10 \mathrm{w}$ as $45 \%$.

As was expected, the radioactivity measured in $\alpha-\mathrm{KG}-\mathrm{DNPH}$ fraction was low in both the boiled and standard systems. Autoradiographs of paper chromatograms developed in MBzBuW revealed a weak radioactive band at $R f .87$ which was more intense in the standard system. This band probably represents free indole acids such as IAA. The radioactivity in the MIXED HYDRAZONE fraction was low in the boiled system and autoradiographs of paper chromatograms revealed a very weak band at Rf.97. In the standard system, a considerable increase in radioactivity was found. Autoradiographs showed an intense band which coincided with the yellow-orange band of IPyA-DNPH and an increase in the intensity of the weak band at $R f .97$. 


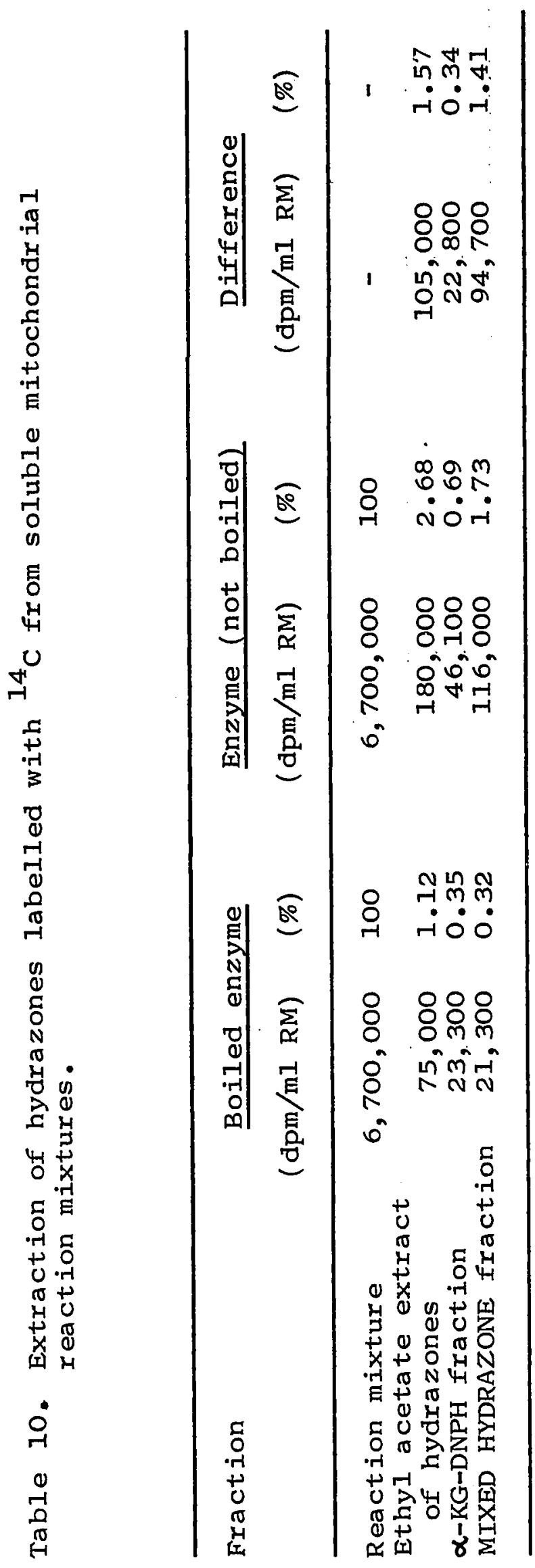


This latter band would contain neutral hydrazones and was at the Rf of both IAAId-DNPH and IAId-DNPH.

It can be seen from Table 10 that the difference in radioactivity between the MIXED HYDRAZONE fraction from the standard and boiled systems represents $1.41 \%$ of the radioactivity in $\mathrm{D}, \mathrm{L}-\mathrm{TTP}-3-{ }^{14} \mathrm{C}$ in the initial reaction mixture. Assuming that the 50\% of the D, L-TTP represents the L-isomer, the conversion of L-TTP to radioactive hydrazones would be $2.8 \%$, which compared very well with the $3 \%$ conversion calculated from the glutamate formation.

The MIXED HYDRAZONE fraction was also chromatographed on TLC plates using both $\mathrm{BzE}$ and $\mathrm{BzACE}$ as solvents in order to separate the neutral hydrazones. When autoradiographs were prepared of the plates developed in $\mathrm{BzE}$, two radioactive zones were detected. These correspond in Rf with IAId-DNPH and IAAId-DNPH; however, the same bands were also found in the boiled enzyme preparation, although their intensity was much lower. Similarly, on the plate developed in $B z A C E$, these two bands were located at the Rf's of authentic IAId-DNPH and IAAld-DNPH, the intensity of the bands again being much higher in the case of the standard enzyme. IPyA-DNPH was the most prominent compound on the chromatogram of the standard enzyme, but this compound was not found in the boiled system.

In conclusion, it has been shown that the major tryptophan metabolic product in the reaction mixture was IPyA. Furthermore, the increase in radioactivity in the MIXED HYDRAZONE fraction from the standard system agrees 
very well with the percentage transamination as measured by glutamate formation. Two neutral radioactive zones were also found in the standard system, and these compounds had the same Rf's as IAId-DNPH and IAAld-DNPH in the two solvent systems employed. In view of the fact that these compounds were also found in smaller amounts in the boiled system, whereas IPyA-DNPH was not present in this system, there must be some doubt that IPyA was the only precursor of these compounds.

\section{Purification of tryptophan transaminase:}

In a later section of this thesis, an investigation of the enzymes metabolising 3-indoleacetaldehyde.(IAAld) will be reported. In these experiments, it was found that unless 2-mercaptoethanol (EtSH) was added to all solutions, the enzymes were unstable. An attempt was made to separate and concentrate these IAAld-metabolising enzymes by ammonium sulphate precipitation and, at the same time, each enzyme fraction was assayed for TTP-transaminase activity. The results of these assays are reported here.

Mung bean seedlings were ground in standard buffer containing $0.01 \mathrm{M}$ EtSH at $\mathrm{pH} 7.5$ and a cytoplasmic supernatant fraction was prepared in the usual way (page 58). This preparation was divided in half; one portion was kept on ice while manganous chloride was added to the other to precipitate inactive protein and nucleic acid. Ammonium sulphate was then added in increasing amounts to both the cytoplasmic supernatant 
and the $\mathrm{MnCl}_{2}$-treated supernatant to give $40 \%, 50 \%, 60 \%$ and $80 \%$ saturation. The precipitates which formed at each stage were collected by centrifugation, resuspended in a small volume of standard buffer containing EtSH and left overnight at $0^{\circ} \mathrm{C}$. On the following morning, undissolved protein was removed by centrifugation and the supernatants obtained, together with aliquots of the original cytoplasmic supernatant and the $\mathrm{MnCl}_{2}$-treated supernatant were desalted by passage through columns of Sephadex G-25. The eluates from these columns were tested for TTP-transaminase activity using the standard assay procedure described in the first section. The results of a typical experiment are presented in Table 11.

Although $15 \%$ of the initial activity was not recovered after the precipitation with $\mathrm{MnCl}_{2}$, this treatment gave a 4-fold increase in specific activity of the enzyme by removing $80 \%$ of the protein. The recovery of transaminase activity on subsequent ammonium sulphate precipitation was not affected by the $\mathrm{MnCl}_{2}$ treatment and $30 \%$ of the initial activity was recovered in the 40-50\% fractions, both in the presence and absence of $\mathrm{MnCl}_{2}$. The highest specific activity was also found in these fractions, a purification of nearly 6-fold having been obtained in the 40-50\% fraction following $\mathrm{MnCl}_{2}$ treatment.

In this experiment, soluble indoles were extracted with ether from the reaction mixtures at the end of the 6 hour incubation period to give ACID and NEUTRAL ether extracts. 


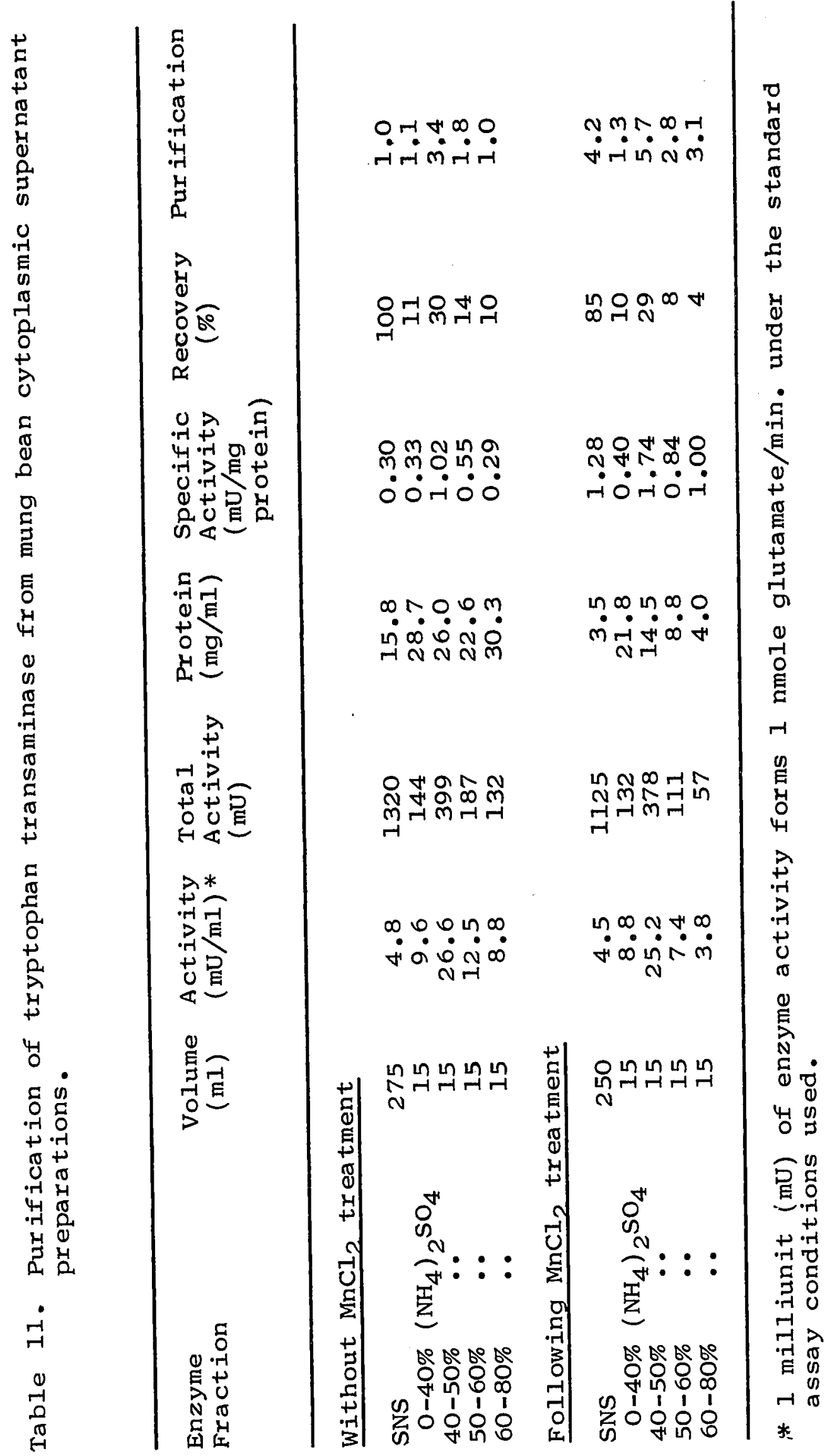


Aliquots of these extracts were chromatographed on paper using $\mathrm{BzACW}$. The chromatograms were then lightly sprayed with the DNPH reagent to detect carbonyl compounds. Care was taken that the reagent never penetrated to the reverse side of the paper. When the paper was dry, the reverse side was sprayed lightly with the DMAC reagent. This double spraying technique allows the detection of compounds which react to two reagents and, since one chromatogram is used, an exact comparison of $\mathrm{Rf}$ and colorimetric characteristics of each band is possible. The bands observed with the two reagents were marked and the intensity of the reaction was assessed by an arbitrary scale of absent $(-)$, weak $(+)$, medium $(+t)$ or strong $(++t)$. The results of this experiment are presented in Table 12 and the characteristics of authentic indoles co-chromatographed and sprayed under the same conditions are presented in Table 13.

Six DMAC-reacting bands were detected. Five of these bands were also detected with the DNPH reagent. Band at Rf.16: The crims on band which developed rapidly with the DMAC reagent was found in all extracts but was most intense in extracts of reaction mixtures which contained 50-60\% and 60-80\% ammonium sulphate fractions. Although the Rf was almost identical with that of ILA (Rf.14), the colour reaction of ILA with DMAC is a distinct bluepurple. Furthermore, whereas ILA gave no reaction with DNPH, the unknown band reacted slowly to give a weak brown coloux. This unknown compound will hereafter be referred to as "X". 
Table 12. DMAC and DNPH-reacting bands in the ACID and NEUTRAL ether extracts from tryptophan transaminase reaction mixtures.

Enzyme

Fraction
Intensity of band at Rf: *

$\begin{array}{llllll}.16 & .33^{1} & .43 & .55 & .56 & .75\end{array}$

Without $\mathrm{MnCl}_{2}$ treatment

SNS

$\mathrm{O}-40 \%\left(\mathrm{NH}_{4}\right)_{2} \mathrm{SO}_{4}$

40-50\%

$50-60 \%$

$60-80 \%$

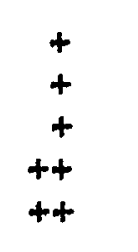

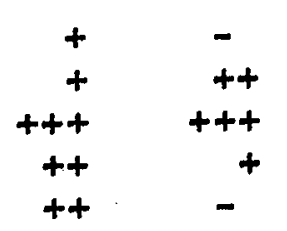

$\begin{array}{rr}+ & - \\ ++ & - \\ ++ & - \\ + & ++ \\ + & ++\end{array}$

Following $\mathrm{MnCl}_{2}$ treatment

SNS

$\mathrm{O}-40 \%\left(\mathrm{NH}_{4}\right)_{2} \mathrm{SO}_{4}$

$40-50 \%$

$50-60 \%$

$60-80 \%$
+
+
+
+
+

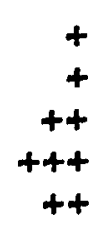

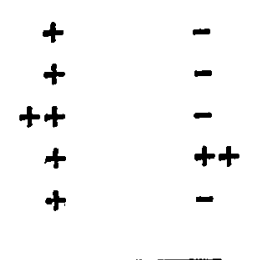

Chàracteristics of reacting band:

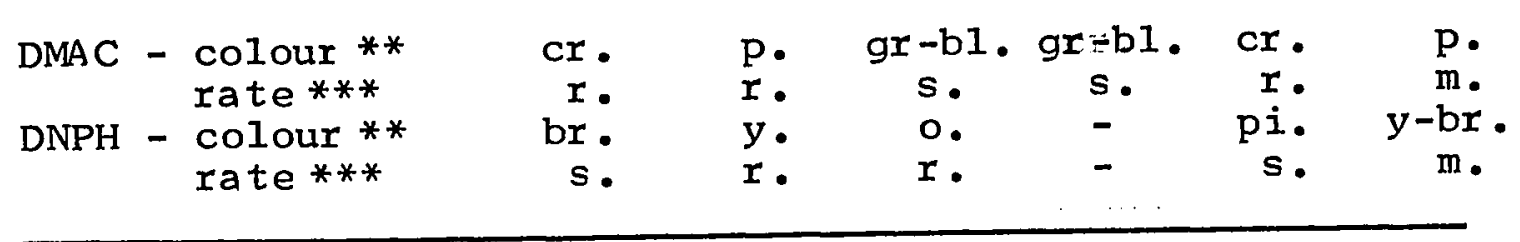

* Intensity of colour reaction: - absent, + weak, ++ medium, +++ strong.

* Colour of reacting band: br. brown, cr. crimson, gr-bl. green-blue, o. orange, p. purple, pi. pink, y. yellow, y-br . yellow-br own.

** Rate of colour reaction: r. rapid (0-2 min.), m. medium $(2-5$ min. $), s_{.}$slow $(1-2$ days $)$. 
Table 13. DMAC and DNPH reaction of authentic indole compounds following chromatography in BzAcW.

\begin{tabular}{|c|c|c|c|c|c|}
\hline \multirow[t]{2}{*}{ Compound } & \multirow[t]{2}{*}{ Rf } & \multicolumn{2}{|c|}{ DMAC reaction } & \multicolumn{2}{|c|}{ DNPH reaction } \\
\hline & & Colour* & Rate** & Colour* & Rate** \\
\hline $\begin{array}{l}\text { ILA } \\
\text { IPyA } \\
\text { IAId } \\
\text { ICA } \\
\text { IAA } \\
\text { IAAId }\end{array}$ & $\begin{array}{l}.14 \\
.33 \\
.43 \\
.55 \\
.56 \\
.70\end{array}$ & $\begin{array}{r}\mathrm{bl}-\mathrm{p} \\
\mathrm{p} \\
\mathrm{gr}-\mathrm{b} 1 \\
\mathrm{gr}-\mathrm{b} 1 \\
\mathrm{cr} \\
\mathrm{p}\end{array}$ & $\begin{array}{l}r . \\
r . \\
\text { s. } \\
\text { s. } \\
\text { r. } \\
\text { m. }\end{array}$ & $\begin{array}{c}- \\
\text { y. } \\
\text { o. } \\
\bar{p} \\
\text { y. }\end{array}$ & $\begin{array}{l}- \\
r . \\
r . \\
\text { s. } \\
r .\end{array}$ \\
\hline
\end{tabular}

* Colour of reacting band: b1-p. blue-purple, cr. crimsón, gr-bl. green-blue, o. orange, p. purple, pi. pink, $y$. yellow.

* Rate of colour reaction: r. rapid (0-2 min.), m. medium $(2-5$ min.), s. slow (1-2 days).

Band at Rf.33: This band is identical with IPyA in both its Rf and colour reactions to DMAC and DNPH. It was formed by all enzyme fractions but particularly by the 40-50\% ammonium sulphate fraction. The intensity of the colour reaction was compared with the rate of transamination measured by the formation of glutamate (Table 11). The greatest level of both IPyA and glutamate were found in reaction mixtures containing the 40-50\% fractions. However, the intensity of the IPyA bands on chromatograms of the extracts from 50-60\% and 60-80\% fractions was lower than was expected from the transamination data. This was probably the result of partial breakdown of IPyA to other compounds in these extracts. 
Band at Rf.43: This band reacted rapidly to the DNPH reagent to give an orange band which was identical in colour and Rf with authentic IAld. Reaction to the DMAC reagent was very slow but a green-blue band appeared overnight; again characteristic of IAld. The intensity of this band was greatest on chromatograms from extracts containing the 40-50\% fraction and the 50-60\% fraction (following $\mathrm{MnCl}_{2}$ treatment). IAld probably arises through the action of an oxidase or peroxidase on IPyA.

Band at Rf.55: This band was only visible after 2-3 days. After this time a green-blue band became visible as the crimson colour of the IAA band (Rf.56) began to fade. This green-blue band coincided in colour and Rf with authentic ICA. It was formed to the greatest extent in reaction mixtures containing $0-40 \%$ and $40-50 \%$ fractions and did not coincide with distribution of IAId in the reaction mixtures, although IAld is considered to be the precursor of ICA (Fawcett, Taylor, Wain and Wightman, 1958).

Band at Rf.56: This band, which gave a crimson colour with DMAC, was identified as IAA on the basis of both colour and Rf. With the DNPH reagent a pink colour appeared slowly, probably due to acid oxidation. The level of IAA present appeared to be correlated with the level of IPyA on the chromatogram.

Band at Rf.75: This purple band had the same colour reaction with DMAC as IAAId and the Rf was also similar. The 
reaction with the DNPH reagent yielded a yellow-brown zone. This compound was found only in extracts of the reaction mixtures containing the $50-60 \%$ and $60-80 \%$ ammonium sulphate fractions and the 50-80\% ammonium sulphate fraction following $\mathrm{MnCl}_{2}$ treatment.

The formation of these indole compounds was also investigated in an experiment in which the $40-50 \%$ and $50-60 \%$ ammonium sulphate fractions were compared. Ether extracts were prepared and duplicate chromatograms were run in $\mathrm{BzACW}$; one chromatogram was dipped in DMAC and the other was sprayed with DNPH. Figure 19 shows a photograph of the chromatograms taken the following morning. The results are very similar to those presented in Table 12 .

On the chromatogram dipped in DMAC the most intense spot was IPyA (Rf.37) in the extract of the reaction mixture containing the 40-50\% fraction. There was considerably less IPyA in the 50-60\% fraction. The unknown compound $X$ (Rf.20) and IAA (Rf.60) were present in both extracts but the suspected IAAld spot (Rf.75) was found only in the 50-60\% fraction.

On the chromatogram sprayed with DNPH the orange reaction of IAld (Rf.47) was particularly prominent in the $50-60 \%$ fraction. IPyA and the unknown compounds $\mathrm{X}$ and $\mathrm{Y}$ also reacted. A further orange-reacting zone was detected at $R f .12$ in the $50-60 \%$ fraction and the $R f$ and colour reaction of this spot are identical with those of authentic 3-indoleglyoxylic acid. 


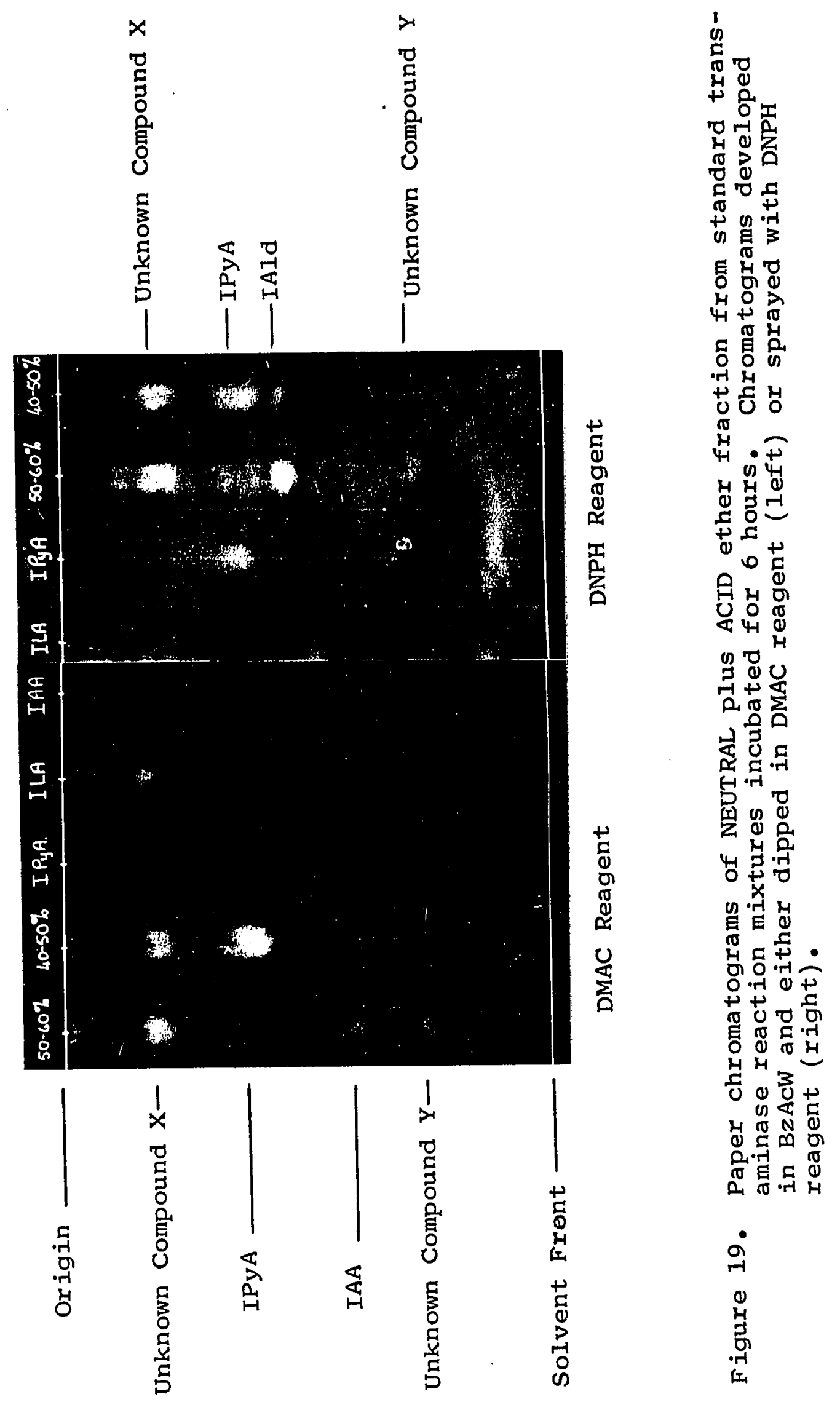


In the next section, an investigation of the factors affecting the production of the suspected IAAld zone will be reported. It will also be shown in a later section that the IAAld-metabolising enzymes are precipitated with the greatest activity in the 50-60\% ammonium sulphate fraction. From the experiments reported above, it is clear that by ammonium sulphate precipitation the tryptophan transaminase enzyme can not only be concentrated and the specific activity increased approximately 6-fold, but also partial separation can be achieved from the enzymes which catalyse the breakdown of IPyA and IAAld.

\section{Substrate specificity of tryptophan transaminase:}

The substrate specificity of the TTP-transaminase of cytoplasmic supernatant was checked in the following experiment. Aliquots of SNS-enzyme were incubated with $30 \mathrm{mM}$ L-TTP and $10 \mathrm{mM}$ of either $\alpha-K G$, pyruvate or oxalacetate to determine the specificity of the amino group acceptor. A further aliquot of SNS-enzyme was incubated with $30 \mathrm{mM}$ D-TTP and $10 \mathrm{mM} \alpha-K G$ to check the stereospecificity of the amino group donor. All reaction mixtures also contained $0.1 \mathrm{mM}$ pyridoxal phosphate and the $\mathrm{pH}$ was adjusted to 8.5. Aliquots were removed in the usual manner at $0,2,4$ and 6 hours for a determination of amino acid formation.

The results shown in Table 14 clearly demonstrate the marked preference of the enzyme for $\alpha-K G$ as the amino group acceptor. This agrees with the results obtained by Wightman and Fowden (1966) with mitochondrial TTP-transaminase. 
Table 14. Substrate specificity of the tryptophan transaminase from mung bean cytoplasmic supernatant preparations.

Amino Acid
formed

$$
\text { formed }
$$

Rate of Reaction (nmole amino acid formed $/ \mathrm{min} . / \mathrm{ml}$ enzyme)

$$
\begin{aligned}
& \text { L-TTP : pyruvate } \\
& \text { L-TTP : oxa la cetate } \\
& \text { L-TTP: } \alpha-K G \\
& \text { D-TTP : } \alpha-K G
\end{aligned}
$$

alanine

aspartate

a lanine

glutamate

none
0.45

$0.30 * *$

3.80

0

* The concentration of substrates is given in the text.

* No aspartate was detected on the chromatograms. However, some alanine formed, presumably because of the spontaneous decarboxylation of oxalacetate to pyruvate in the reaction mixture.

Table 14 also demonstrates the stereospecificity of the requirement for TTP; transaminase activity was not detected when D-TTP was used as amino group donor.

In a later experiment, the ability of ammonium sulphate fractions to metabolise D-TTP was checked. Again, no transaminase activity was detected, even with the 40-50\% fraction which was the most active with L-TTP. However, when ACID ether extracts of reaction mixtures were chromatographed, a weak spot of IAA was detected on chromatograms of the $50-60 \%$ and the 60-80\% fractions. This result suggests the presence of another TTP-metabolising enzyme which is capable of supporting the conversion of D-TTP to IAA at a slow rate. The nature of this enzyme was not investigated. 


\section{B. Decarboxylation of 3-Indolepyruvic Acid}

The evidence for this reaction step was discussed in the Introductory section. As pointed out there, metabolic studies using IPyA have seldom been attempted and no specific IPyA-degrading enzyme has been described. Lin et al. (1958) have shown that IPyA can be broken down enzymatically, but the product of this reaction could not be detected on paper chromatograms. The claim of Gordon and Sanchez Nieva (1949b) that IPyA spontaneously decomposes to yleld IAAld had never been substantiated. Bentley et al. (1956) reported that IPyA is converted to IAA under strong alkaline conditions in the presence of $\mathrm{H}_{2} \mathrm{O}_{2}$ and Schwarz (1961) showed that under acidic chromatographic conditions, IAld could be detected in addition to the tautomers of IPyA. However, IAId was not detected in fresh solutions of IPyA but only after standing in solutions of $\mathrm{NaHCO}_{3}$ (Schwarz and Bitancourt, 1960). Upon chromatography in ammoniacal solvents, many decomposition products are formed of which IAA, IAId, 3-indoleglycollic acid, 3-indoleglyoxylic acid, and 3-indoleacetamide have been identified by Bentley et al. (1956) and by Kaper and Velstra (1958). However, neither IAAId nor Tol have been demonstrated as decomposition products of IPyA by paper chromatographic procedures.

In order to show the enzymatic decarboxylation of IPyA to IAAId, it would be necessary to demonstrate the formation of IAAld as a reaction product, or alternatively, to couple the decarboxylation of IPyA to an alcohol dehydrogenasecatalysed reduction of IAAld (see next section) and demonstrate 
the formation of Tol. Because of the instability of IPyA in purely aqueous solutions under neutral or weakly basic conditions, it might be advantageous to demonstrate the decarboxylation reaction in a proteinaceous system in which IPyA is generated from TTP by the activity of a transaminase enzyme. In this type of system, IPyA appears to be more stable (Wightman and Fowden, 1966). This might be due to a stabilization of IPYA by the protein in the system, or because solutions of the keto tautomer, which is formed in the transamination reaction, are more stable than solutions of the enol tautomer which is the form of crystalline IPyA. The enzyme, pyruvate decarboxylase, has been purified from yeast and higher plants and catalyses the decarboxylation of pyruvic acid. This enzyme has a pH optimum of 6.0 and requires the addition of thiamine pyrophosphate and divalent metal ions such as $\mathrm{Mg}^{++}$for optimum activity (Utter, 1965). The yeast enzyme has also been shown to decarboxylate some higher homologues of pyruvate, but not phenylpyruvate. It is possible that IPyA is decarboxylated by an enzyme with similar properties to yield IAAld.

It was shown in a previous section that a compound very similar to IAAld was formed from TTP by an enzyme in the 50-60\% ammonium sulphate fraction from a cytoplasmic supernatant preparation. The Rf of this compound on paper chromatograms was very close to authentic IAAld and it reacted with the DMAC reagent to give a purple colour typical of IAAld. With the DNPH reagent, it reacted slowly to give 
a yellow-brown colour, whereas IAAld reacted with the DNPH reagent more quickly to give the yellow hydrazone, IAAld-DNPH. In view of the similarities between the unknown compound and IAAId, its formation was further investigated in the following experiment.

A cytoplasmic supernatant preparation of mung bean seedlings was fractionated with ammonium sulphate and the 50-60\% fraction was desalted by passage through Sephadex G-25. $45 \mathrm{ml}$ of the eluate was mixed with ITP, $\alpha-\mathrm{KG}$ and pyridoxal phosphate to give final concentrations of $30 \mathrm{mM}$, $10 \mathrm{mM}$ and $25 \mathrm{ug} / \mathrm{ml}$ respectively. This is the standard reaction mixture for transaminase determinations when the $\mathrm{pH}$ is adjusted to 8.5. In the present experiment, however, the mixture was divided into three $30 \mathrm{ml}$ portions which were adjusted to $\mathrm{pH} 6.0, \mathrm{pH} 7.0$ and $\mathrm{pH} 8.0$. Each of these portions was divided into three $10 \mathrm{ml}$ aliquots and one of the following solutions was then added to each aliquot:

(i) $1 \mathrm{ml}$ distilled water.

(ii) $1 \mathrm{ml}$ distilled water containing $1 \mathrm{mg}$ of thiamine pyrophosphate and $1.2 \mathrm{mg} \mathrm{MgSO}_{4}$.

(iii) $1 \mathrm{ml}$ distilled water containing $1 \mathrm{mg}$ of thiamine pyrophosphate, $1.2 \mathrm{mg} \mathrm{MgSO}_{4}$ and $10 \mathrm{mg} \mathrm{NADH}_{2}$. Neglecting the small change in concentration which resulted from the adjustment of $\mathrm{pH}$, the final concentrations of the components of the reaction mixture (where included) were as follows: $27 \mathrm{mM}$ TTP; $9 \mathrm{mM} \alpha-\mathrm{KG}$; $0.09 \mathrm{mM}$ pyridoxal phosphate; $0.2 \mathrm{mM}$ thiamine pyrophosphate; $0.9 \mathrm{mM} \mathrm{MgSO}_{4}$; $1.3 \mathrm{mM} \mathrm{NADH}$. 
The reaction mixtures were incubated at $35^{\circ} \mathrm{C}$ and aliquots were removed at $0,2,4$, and 6 hours for a determination of the rate of transamination. The highest rate of transamination was found in the reaction mixture at $\mathrm{pH} 8.0$ and this rate was reduced by $36 \%$ at $\mathrm{pH} 7.0$ and by $78 \%$ at $\mathrm{pH} 6.0$. At the end of 6 hours, the reaction mixtures were ether extracted, first at $\mathrm{pH} 7.0$ and then at $\mathrm{pH} 2.5$ to obtain NEUTRAL and ACID ether fractions. These extracts were analysed by paper chromatography using BzAcW as the developing solvent. The Rf of each DMACreacting band was recorded and an estimate of its relative intensity was made using the arbitrary scale of absent $(-)$, weak $(+)$, medium $(++)$ or strong $(+++)$. The Rf's of both authentic markers and the experimentally formed indole compounds were lower than usual because a double front formed during the development of the chromatogram. The overall separation of the compounds on the chromatogram was, however, quite good.

The inclusion of thiamine pyrophosphate and $\mathrm{Mg}^{++}$or $\mathrm{NADH}_{2}$ to the reaction mixtures did not appear to influence the reaction products. The results from the ACID ether extracts (Table 15) show that only a small amount of IPyA was detected at $\mathrm{pH} 6.0$. At $\mathrm{pH} 7.0$ and 8.0 , four bands were detected representing IPyA, ICA, IAA and the unknown compound $x$. It is interesting to note that more IPyA was detected in the reaction mixture incubated at $\mathrm{pH} 7.0$ than at $\mathrm{pH} 8.0$, although, as was mentioned above, the rate of transamination 
was higher at $\mathrm{pH} 8,0$. This finding is probably due to the greater conversion of IPyA to further products at $\mathrm{pH} 8.0$, and hence the greater amounts of ICA, IAA and the unknown $X$ that were found in the reaction mixture incubated at this $\mathrm{pH}$.

Table 15. The effect of $\mathrm{pH}$ in the tryptophan transaminase reaction mixture on the intensity of DMACreacting bands in NEUTRAL and ACID ether extracts.

Rf

DMAC-reaction

Colour* Rate**
Identity Intensity of Band*** at $\mathrm{pH}:$

$6.0 \quad 7.0 \quad 8.0$

ACID extracts

$\begin{array}{rrrrrrr}.07 & \text { cr. } & \text { r. } & \text { X } & - & + & +++ \\ .19 & \text { P. } & \text { r. } & \text { IPyA } & + & +++ & ++ \\ .50 & \text { gr-bI. } & \text { s. } & \text { ICA } & - & +1+t \\ .52 & \text { P. } & \text { I. } & \text { IAA } & - & + & ++\end{array}$

NEUTRAL oxtracts

.37

.80 s.

m.
IAId $\mathrm{Y}$

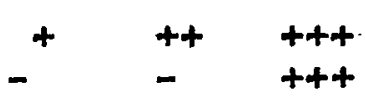

Authentics

$\begin{array}{rrrr}.17 & \mathrm{p} . & \mathrm{r} . & \text { IPyA } \\ .37 & \mathrm{gr}-\mathrm{bI} \cdot & \mathrm{s} . & \text { IAId } \\ .45 & \mathrm{gr}-\mathrm{bI} & \mathrm{s} . & \text { ICA } \\ .50 & \mathrm{p} . & \mathrm{r} . & \text { IAA } \\ .65 & \mathrm{p} . & \mathrm{m} . & \text { IAAId }\end{array}$

* Colour of reacting bands: cr. crimson, gr-bl. green-blue, p. purple.

* Rate of colour reaction: r. rapid $(0-2 m i n)$, m. medium $(2-5$ min. $)$, s. slow (1-2 days).

*** Intensity of colour reaction: - absent, + weak, ++ medium, +++ strong. 
Only two DMAC-reacting bands were detected in the NEUTRAL ether extracts (Table 15). One band at Rf.37 was Identified as IAId on the basis of its Rf and colour reaction and was found in all extracts, with the intensity of the band increasing with the $\mathrm{pH}$. The second band at Rf.80 was found only in the extract from the $\mathrm{pH} 8.0$ mixture. The $\mathrm{Rf}$ of this band was greater than that of authentic IAAld. To investigate whether the compound was indoleacetonitrile (IAN), the neutral extracts from both the $\mathrm{pH} 7.0$ and $\mathrm{pH} 8.0$ reaction mixtures were rechromatographed using carbon tetrachloride:acetic acid as the developing solvent (Wightman, 1962). The results show that this unknown compound " $Y$ "is neither IAAld nor IAN (Table 16), and so the identity of the band remains undetermined.

In other experiments, an attempt was made to use IPyA as a substrate for cytoplasmic supernatant preparations. No chromatographic evidence was found for the formation of IAAld, Tol or the unknown compound $Y$. On the other hand, even in controls without enzyme or with bolled enzyme, chromatography of ether extracts showed intense bands of IAA, IAId and the unknown compound $x$. No significant increase in the intensity of any of these bands was found with the normal, unboiled enzyme preparation. From this result it is clear that the unknown compound $\mathrm{X}$ can arise non-enzymatically from IPyA. Furthermore, if IAAld or Tol were formed, they would represent only a very small proportion of the products formed nonenzymatically from IPyA. 
ב

客

다.

$+\stackrel{+}{0}$

(1)

告:

4 .

a

ơ

है

\%

合

$0+$

Ho

每

ने

파

(1)

4

م.

\%

궁

0 \%

万

동

(n)

ț

$\rightarrow$

$>$

4

$\stackrel{\dot{0}}{r-1}$

$\underset{\substack{\infty \\ 0}}{0}$

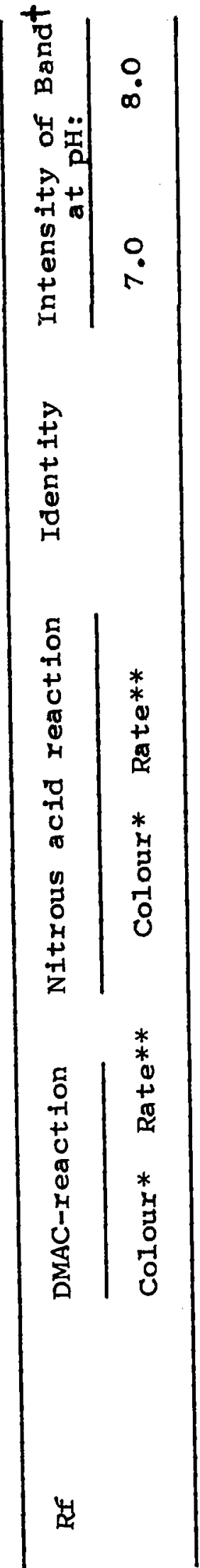

$+t$

$\pm$

$\bigcup_{H}^{\varangle}$

$\overbrace{\substack{0 \\ 0}}^{\circ}$

N

I

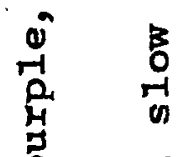

B. is

a.

बे क्न

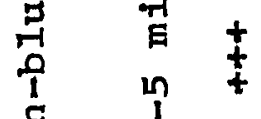

$\mathbb{4}_{H}^{-4}$

in

i) $\dot{1}$

में

ثُ

ஸ்

$\dot{B} \dot{H}$

rí $\dot{0} \dot{0}$

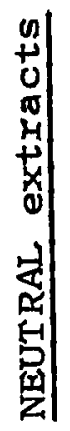

ठ

ํำ

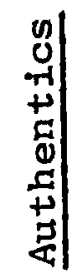

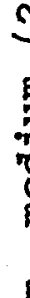

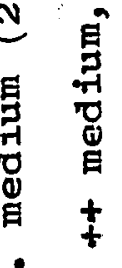

焉

म

مै

مी

盛 $\stackrel{\text { H }}{ }$

in $\quad \ddot{0}$ 岂

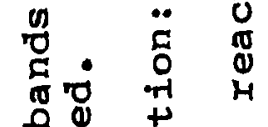

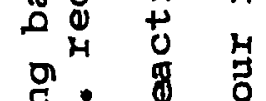

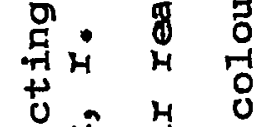

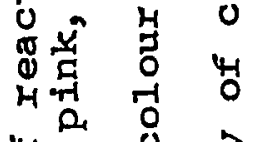

岁: 0 会

मू

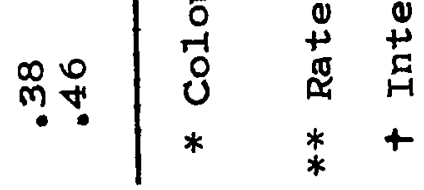


C. Oxidation and Reduction of 3-Indoleacetaldehyde

Preliminary experiments showed that enzymes in a high speed supernatant fraction from a mung bean $t$ issue homogenate were capable of catalysing the oxidation and reduction of IAAld. The following more detailed study was designed to investigate the intracellular localisation of these enzymes, to characterise and, if possible, separate the enzymes.

\section{Intracellular distribution of the enzymes:}

Mung bean seedlings were ground either in phosphateEDTA buffer or in buffered sucrose, both at $\mathrm{pH} 7.0$, and the brei was then fractionated by the standard centrifugation procedure shown in Figure 1. The washed mitochondria were finally resuspended in a small volume of buffered sucrose to give the mitochondrial fraction. A portion of the final $35,000 \times g$ supernatant from both the phosphate-EDTA buffer and buffered sucrose preparations were purified by passage through a column of Sephadex G-25.

Samples of each enzyme fraction were incubated with 3-indoleacetaldehyde-bisulphite (IAAld-biS) to a final concentration of $3.8 \mathrm{mM}$. After 4 hours of incubation at $35^{\circ} \mathrm{C}$, the reaction was stopped by adding I $\mathrm{M}$ phosphoric acid to lower the $\mathrm{pH}$ to 2.5 and then dry sodium bisulphite was added to give a concentration of $0.1 \mathrm{M}$. This procedure effectively binds the unreacted IAAld as the bisulphite addition product which is not extracted by ether. After 
ether extraction of the acidified reaction mixtures, the extracts were concentrated and examined by ascending paper chromatography in IAmW. The indole compounds were visualised on the chromatogram by treatment with DMAC reagent. The density of each band was recorded using the photovolt densitometer.

Table 17. Formation of IAA and Tol from IAAld by mung bean enzyme fractions.

Source of Enzyme

IAA

Tol

$\mu \mathrm{g} / \mathrm{mI}$ enzyme* $\mu \mathrm{g} / \mathrm{mI}$ enzyme*

Phosphate-EDTA buffer

$10,000 \times g$ Supernatant

$35,000 \times g$ Supernatant

0.6

1.0

5

$35,000 \times g$ Supernatant

1.0

purified with Sephadex G-25

Buffered Sucrose

Mitochondrial

$35,000 \times g$ Supernatant

0.6

1.0

$\overline{10}$

$35,000 \times g$ Supernatant

purified with Sephadex G-25 1.0

* Reaction mixtures contained $5 \mathrm{mls}$ of enzyme fraction and 23 umoles of IAAId-bisulphite to a final volume of $6 \mathrm{ml}$. The $\mathrm{pH}$ of the reaction mixtures was 7.0 and incubation was at $35^{\circ} \mathrm{C}$ for 3 hours.

The results in Table 17 show that IAA was formed by all the enzyme fractions examined and this activity was not lost when a fraction was first purified by passage through sephadex G-25. In contrast, Tol formation only occurred in the 
reaction systems containing supernatant enzyme fractions and this activity was lost completely if the fraction was passed through Sephadex G-25, which suggests the loss of a coenzyme during the procedure. No Tol-forming activity was found in the mitochondrial enzyme fraction.

Table 18. The effect of $\mathrm{NAD}$ and $\mathrm{NADH}_{2}$ on the formation of IAA and Tol by a Sephadex-purified cytoplasmic supernatant fraction.

\begin{tabular}{lcc}
\hline Cofactor* & \multicolumn{1}{c}{ IAA } & Tol \\
& $\mu \mathrm{g} / \mathrm{mI}$ enzyme* & $\mu \mathrm{g} / \mathrm{m} 1$ enzyme* \\
\hline No cofactor & 0.3 & 0.4 \\
NAD & 2.4 & 3.5 \\
NADH $_{2}$ & 3.0 & 25.0 \\
\hline
\end{tabular}

* Reaction mixtures contained $2 \mathrm{ml}$ of enzyme fraction, 9.5 umoles of IAAld-bisulphite and 3.75 moles of the appropriate cofactor to the final volume of $2.5 \mathrm{ml}$. The $\mathrm{pH}$ of the reaction mixtures was 7.0 and incubation was at $35^{\circ} \mathrm{C}$ for 3 hours.

The effect of adding the coenzymes $\mathrm{NAD}$ and $\mathrm{NADH}_{2}$ was tested using a Sephadex-purified 35,000 x g supernatant fraction obtained from a phosphate-EDTA buffer homogenate. As seen from the data in Table 18, IAA formation was increased by the addition of NAD and also by the addition of $\mathrm{NADH}_{2}$, whereas Tol formation was stimulated much more by the addition of $\mathrm{NADH}_{2}$ than by $\mathrm{NAD}$.

From these experiments the following observations can be made. Firstly, the mitochondrial fraction showed some 
IAA-forming activity but did not appear to have any Tolforming activity, though this lack of Tol-forming activity may be due to an absence of $\mathrm{NADH}_{2}$. In the cytoplasmic supernatant fraction there appears to be $\mathrm{NAD}-\mathrm{NADH}_{2}$-dependent enzymes which catalyse both-the oxidation and reduction of IAAId to IAA and Tol. The data in Table 18 suggests that the oxidation and reduction may be coupled as shown below:

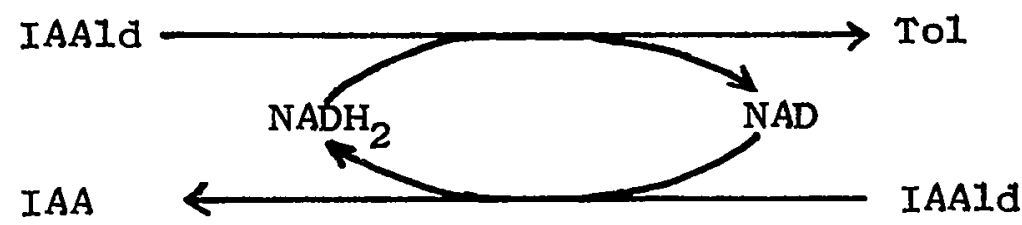

It is clear, however, that the coupling is not obligatory since, with the addition of $\mathrm{NADH}_{2}$, the amount of Tol formed was 8 times more than the amount of IAA.

\section{Effect of $\mathrm{pH}$ on IAA and Tol formation:}

The effect of $\mathrm{pH}$ on the oxidation and reduction of IAAld was next examined using a sephadexed preparation of high speed supernatant protein obtained from tissue homogenised in standard buffer. Samples of the supernatant fraction were adjusted to $\mathrm{pH} 5.5,6.5,7.5,8.5$ and 9.5 and IAAld-bis was added as substrate in the presence: of either NAD or $\mathrm{NADH}_{2}$ as coenzymes. The chromatographic results from this experiment were quantitatively assessed using an arbitrary scale from 1-5, depending on the intensity of the reaction of the indole products to DMAC and DNPH reagents. The values obtained are presented graphically in Figure 20. 


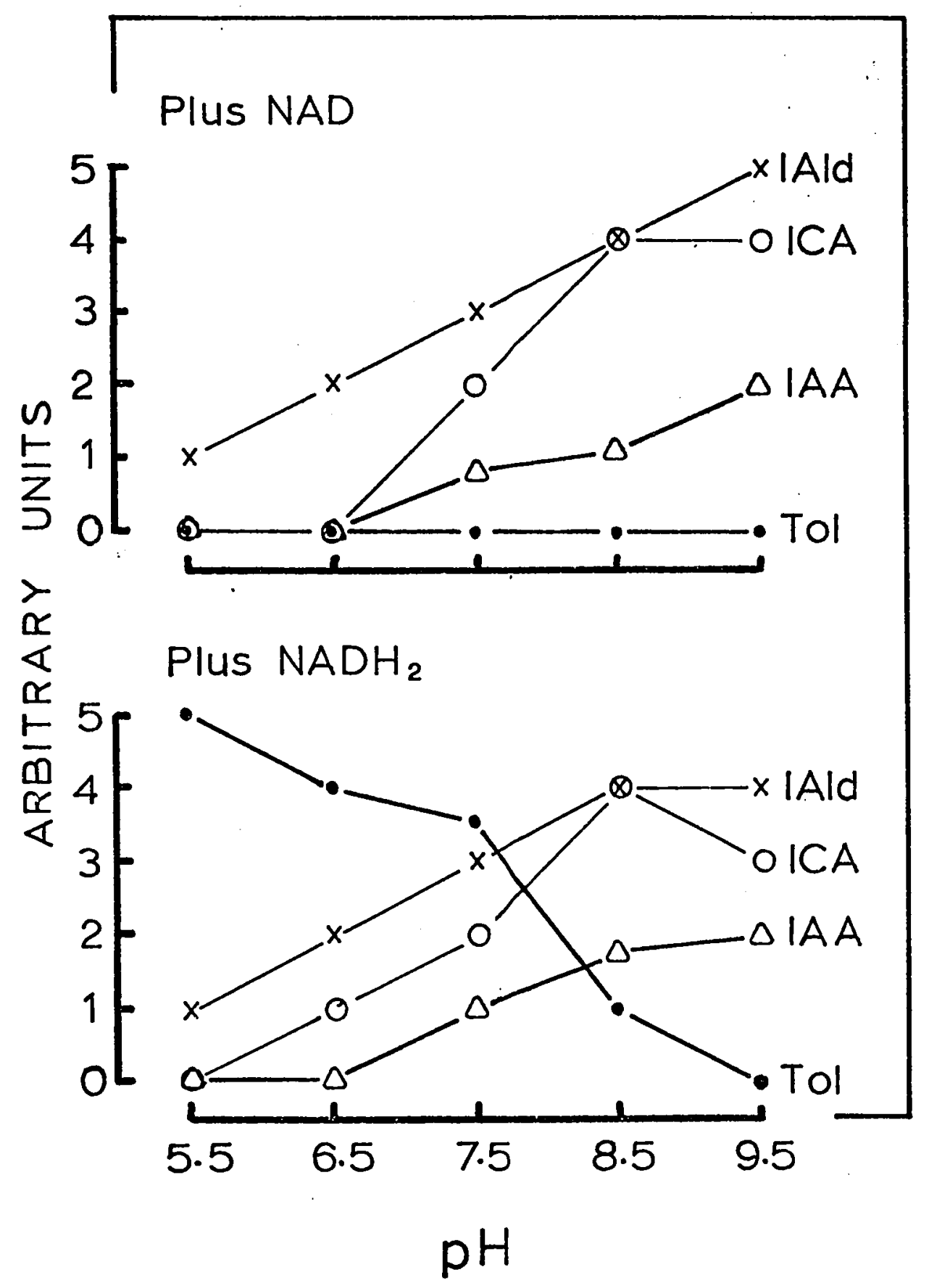

Figure 20. Effect of $\mathrm{pH}, \mathrm{NAD}$ and $\mathrm{NADH}_{2}$ on the formation of indole products from IAAld.

Reaction mixtures contained $2 \mathrm{ml}$ of SNS enzyme, 9.5 umoles IAAld-biS and 3.75 moles of the appropriate cofactor. The final volume was $2.5 \mathrm{ml}$ and incubation was at $35^{\circ} \mathrm{C}$ for 3 hours. 
It can be seen that the rate of formation of IAA, ICA and IAld increased with increasing $\mathrm{pH}$, and that the formation of these products did not appear to be affected by the cofactor used. The formation of Tol, however, only occurred when $\mathrm{NADH}_{2}$ was provided as the cofactor and was clearly greatest at $\mathrm{pH} 5.5$ and barely detectable at $\mathrm{pH} 9.5$. This result can be explained if it is assumed that Tol formation in the presence of $\mathrm{NAD}$ is regulated by the $\mathrm{NADH}_{2}$ generated by IAA synthesis. In this experiment the amount of IAA formed at $\mathrm{pH} 7.5$ was very low and the amount of $\mathrm{NADH}_{2}$ generated would have been insufficient to stimulate Tol synthesis. At higher $\mathrm{pH}$ levels, although more IAA was formed and presumably more $\mathrm{NADH}_{2}$ generated, the alkaline conditions were clearly unfavourable for Tol-formation activity.

The effect of $\mathrm{pH}$ on these reactions is similar to the effect of $\mathrm{pH}$ on the activity of liver or yeast alcohol and aldehyde dehydrogenases reported by sund and Theorel1 (1963) and Jacoby (1963). Studies on these enzymes have shown that reactions requiring $\mathrm{NADH}_{2}$ as cofactor (reductions) are favoured by high $\mathrm{H}^{+}$concentration (i.e. low $\mathrm{pH}$ ), since $\mathrm{H}^{+}$ions take part in the reaction (Conn and Stumpf, 1963).

The effect of $\mathrm{pH}$ on IAAld metabolism was further checked in a fractionation experiment similar to the one reported in the previous sub-section. Mung bean seedlings were ground either in standard buffer or in buffered sucrose and the homogenates partially purified by differential centrifugation. During this procedure a mitochondrial pellet was collected from the buffered sucrose preparation. The mitochondria were 
washed by resuspension in the buffered sucrose medium and after further centrifugation, they were resuspended in a 'bursting medium'. After 1 hour, the preparation was centrifuged at $35,000 \times \mathrm{g}$ for $30 \mathrm{~min}$. to obtain the soluble mitochondrial protein fraction. At the same time, cytoplasmic supernatant fractions were collected from both the initial homogenates following centrifugation at $35,000 \times \mathrm{g}$ for $30 \mathrm{~min}$. Aliquots of both kinds of supernatant fractions and the entire mitochondrial protein fraction were purified by passage through columns of Sephadex G-25.

The three fractions were assayed for enzyme activity at either $\mathrm{pH} 5.5$ or $\mathrm{pH}$ 8.5, using IAAld as substrate and in the presence or absence of $\mathrm{NAD}$ or $\mathrm{NADH}_{2}$. As seen from the data in Table 19 , at pH 5.5 no IAA was formed by any protein fraction and Tol was formed only in the presence of $\mathrm{NADH}_{2}$. At $\mathrm{pH} 8.5$ a trace of IAA was formed by both supernatant fractions but not by the mitochondrial fraction and in all fractions, Tol formation was less than at $\mathrm{pH}$ 5.5. A low level of IAld was observed in all extracts of reaction mixtures incubated at $\mathrm{pH} 5.5$, but no ICA was detected. At the higher $\mathrm{pH}$, IAld formation was greatly increased in the supernatant fractions but not in the mitochondrial fraction. In addition, ICA was formed by the supernatant fractions at the higher $\mathrm{pH}$. The formation of IAld and ICA is apparently enzymatic because of the differential effects of $\mathrm{pH}$ on the formation of these compounds in the supernatant and mitochondrial fractions. These compounds probably arise by the action of a peroxidase enzyme on IAAld (Kenten, 1953; Clarke and Mann, 1957). 


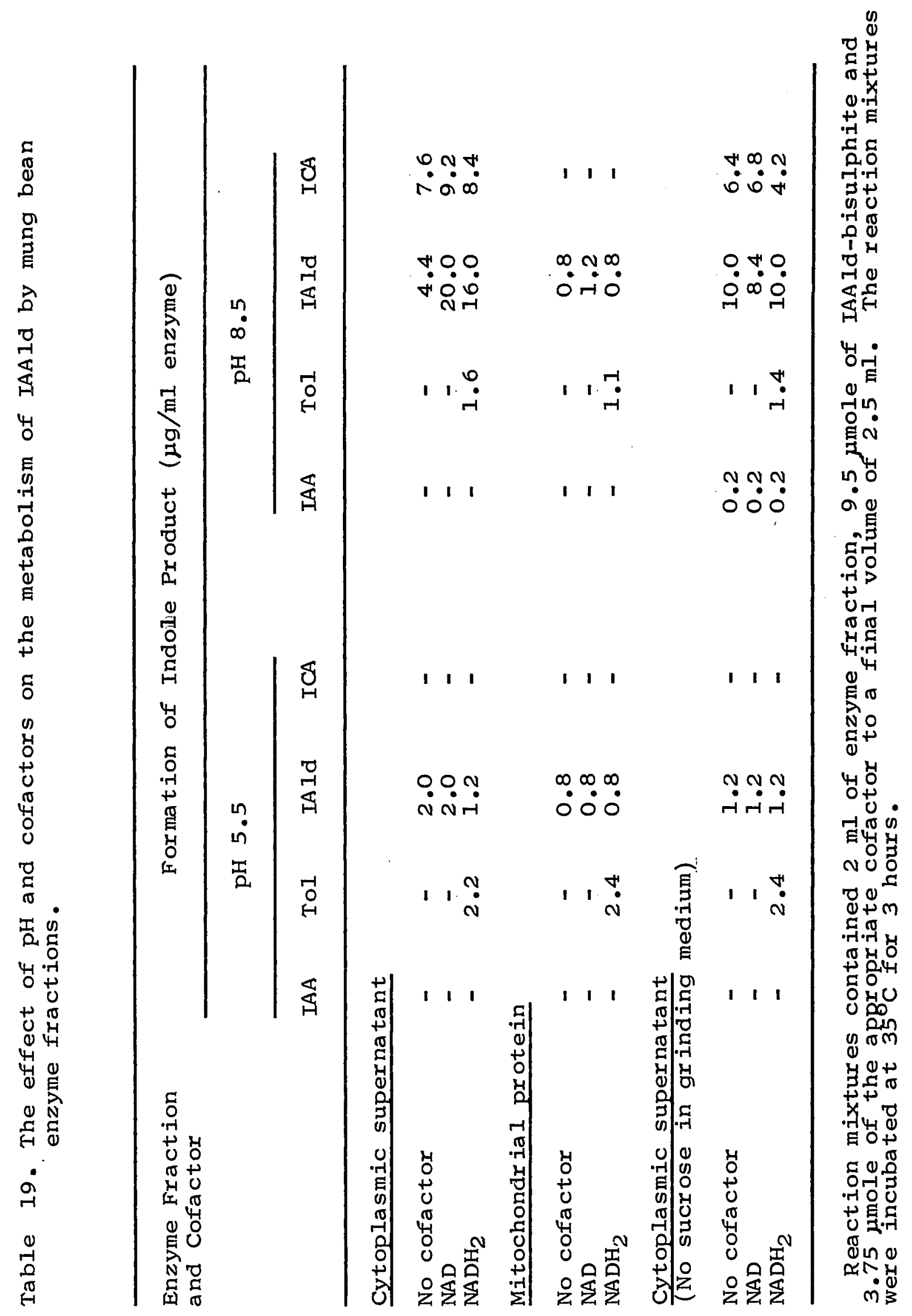


This experiment also demonstrates that mitochondrial protein contains an $\mathrm{NADH}_{2}$-dependent enzyme which converts IAAId to Tol. However, the amount of this enzyme in the mitochondrial fraction represents less than $5 \%$ of the activity in the supernatant (soluble) fraction.

Since both the IAA and the Tol-forming enzymes were clearly found in preponderant amounts in the supernatant fraction, a11 further experiments used the $35,000 \times \mathrm{g}$ supernatant fraction from seedling homogenates prepared in phosphate-EDTA buffer (without sucrose) as the enzyme preparation. Such preparations are referred to as cytoplasmic supernatant, or, after passage through Sephadex G-25, as 'SNS' enzyme.

\section{Spectrophotometric assay system:}

The assay system used thus far to observe IAAld metabolism is sensitive and specific since all ether soluble indole products can be separated by paper chromatography and estimated by colorimetry, but the procedure is time consuming. On the other hand, spectrophotometric assays involving measurements of pyridine nucleotides have the advantage of being both sensitive and rapid. However, because of the competing effects of aldehyde and alcohol dehydrogenaseș a separation of these enzymes is necessary for accurate estimation of the individual enzyme activities by spectrophotometric procedures. 
Alternatively, by assaying for aldehyde dehydrogenase at high $\mathrm{pH}$, the interference of the other enzyme might be minimised. A standard assay for aldehyde dehydrogenase (Racker, 1955) was tested using SNS enzyme. It was quickly discovered that at $\mathrm{pH}^{\prime}$ 's above 8.5 , NAD and IAAld-bis reacted non-enzymatically, giving rise to a specific absorption peak at $340 \mathrm{~m} \mu$. However, chromatography of an ether extract of the reaction mixture showed that IAA was not formed in this reaction and the indole product was not determined. Because of this non-enzymatic reaction with IAAld, another aldehyde substrate, propionaldehyde, was tested. It was chosen because it is not as volatile as acetaldehyde, yet it is reported to be an efficient substrate for aldehyde dehydrogenase (Erwin and Deitrich, 1966).

Using propionaldehyde as substrate, no activity was observed in the aldehyde dehydrogenase assay at $\mathrm{pH} 8.5$ or pH 9.5. At pH 7.0, however, alcohol dehydrogenase activity was measured when $\mathrm{NADH}_{2}$ was used as coenzyme. The reaction rate was linear with increasing enzyme concentrations (Fig. 2I). When the concentration of propionaldehyde was varied from 2 to $14 \mathrm{mM}$, keeping the $\mathrm{NADH}_{2}$ at a non-limiting concentration, a typical Michaelis-Menten curve was found (Fig. 22), and by plotting the data according to the method of Lineweaver and Burke, a $\mathrm{Km}$ of $1.4 \times 10^{-3} \mathrm{M}$ was obtained. By varying the concentration of $\mathrm{NADH}_{2}$ from 0.07 to $0.125 \mathrm{mM}$ and keeping the concentration of propionaldehyde at a non-limiting concentration, a $\mathrm{Km}$ of $1.7 \times 10^{-5} \mathrm{M}$ was obtained (Fig. 23). 


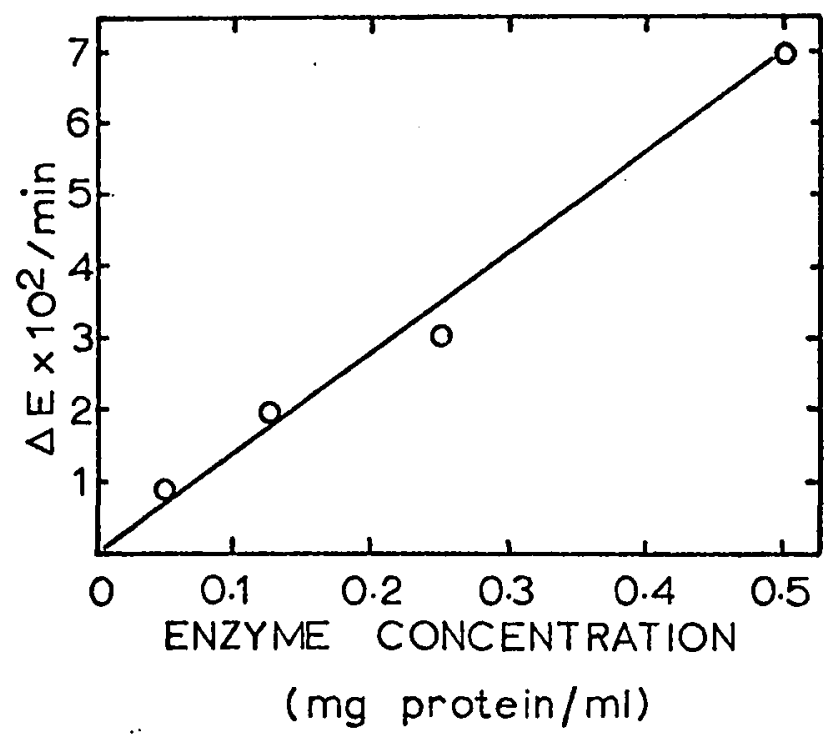

Figure 21. The relationship of reaction rate to enzyme concentration with propionaldehyde as substrate.

Reaction mixtures contained: $13 \mathrm{mM}$ propionaldehyde, $0.06 \mathrm{mM} \mathrm{NADH}$, an appropriate aliquot of enzyme and $0.1 \mathrm{M}$ phosphate buffer at $\mathrm{pH} 7.0$ to a final vol. of $3.0 \mathrm{ml}$.

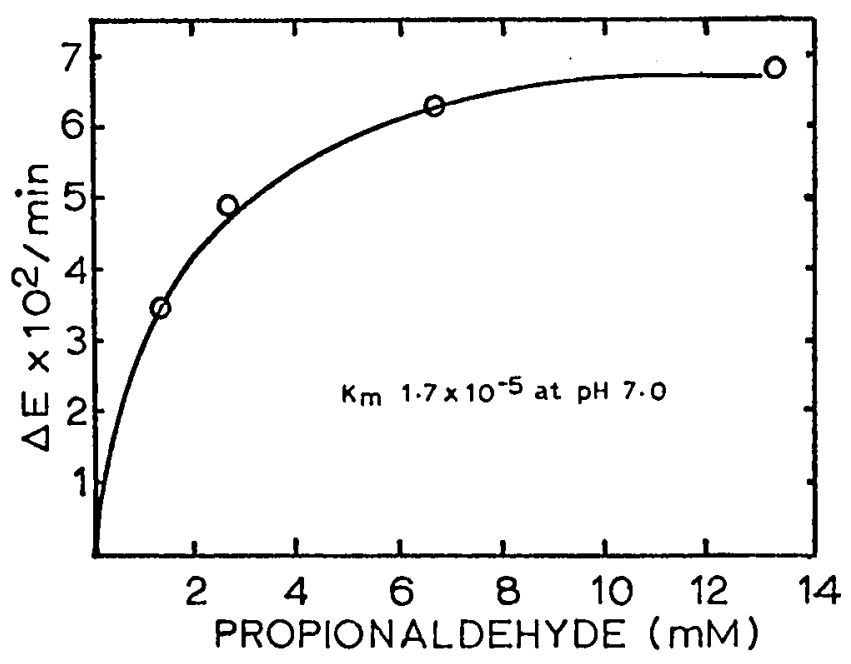

Figure 22. Reaction rate as a function of propionaldehyde concentration.

Reaction mixtures contained: 0.1.ml enzyme, $0.13 \mathrm{mM} \mathrm{NADH} 2$, an appropxiate amount of propionaldehyde and $0.1 \mathrm{M}$ phosphate buffer at $\mathrm{pH} 7.0$ to a final volume of $3.0 \mathrm{ml}$. 


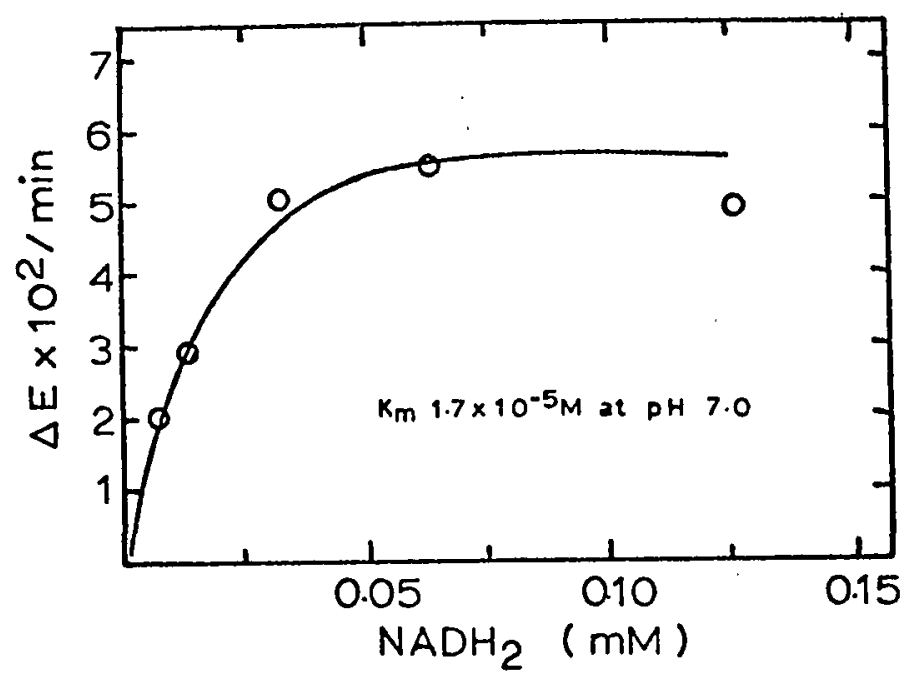

Figure 23. Reaction rate as a function of $\mathrm{NADH}_{2}$ concentration. Reaction mixtures contained: $0.1 \mathrm{ml}$ enzyme, $13 \mathrm{mM}$ propionaldehyde, an appropriate amount of $\mathrm{NADH}_{2}$ and $0.1 \mathrm{M}$ phosphate buffer at $\mathrm{pH} 7.0$ to a final volume of $3.0 \mathrm{ml}$.

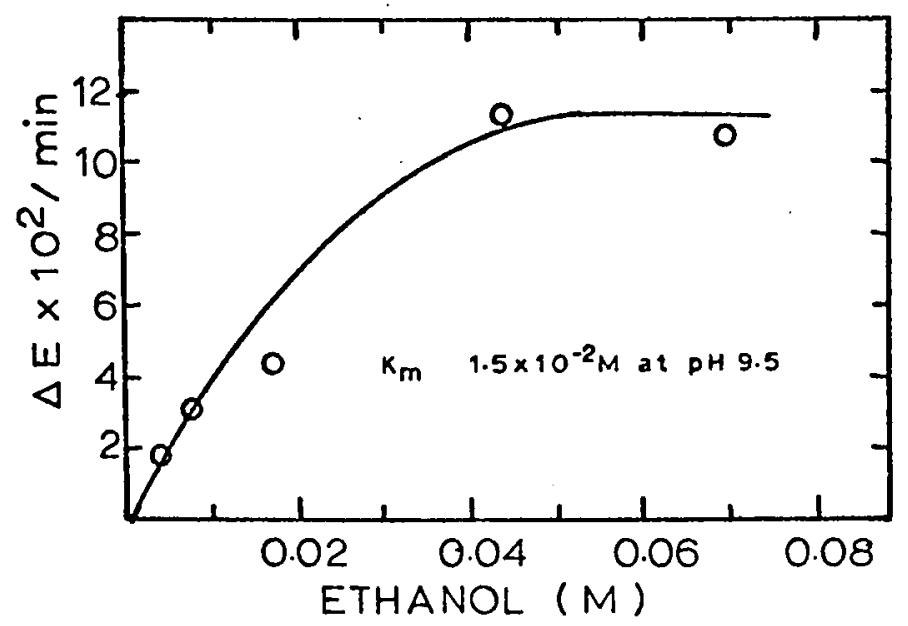

Figure 24. Reaction rate as a function of ethanol concentration.

Reaction mixtures contained: $0.1 \mathrm{ml}$ enzyme, $0.13 \mathrm{mM}$ NAD, an appropriate amount of ethanol and $0.05 \mathrm{M}$ pyrophosphate buffer at $\mathrm{pH} 9.5$ to a final volume of $3.0 \mathrm{ml}$. 
Alcohol dehydrogenase should also catalyse the reverse reaction, from alcohol to aldehyde, which should be promoted by alkaline $\mathrm{pH}$ and be dependent on the coenzyme, NAD. Ethanol was tested as substrate for the reverse reaction using pyrophosphate buffer at $\mathrm{pH} 9.5$. The reaction was found to be enzymatically catalysed and dependent on the presence of NAD. Varying the concentration of ethanol gave the reaction curve shown in Figure 24 with a $\mathrm{Km}$ of $2 \times 10^{-2} \mathrm{M}$.

Thus, it was shown by a spectrophotometric assay that an NAD-dependent alcohol dehydrogenase, present in the SNS enzyme, catalyses the reduction of propionaldehyde and the oxidation of ethanol. However, it still remained to be demonstrated that the same enzyme preparation would reduce IAAld .

A fresh preparation of the SNS enzyme, highly active with propionaldehyde as substrate, was tested using IAAIdbis as substrate and, a slow oxidation of $\mathrm{NADH}_{2}$ was observed. This reaction was dependent on the addition of IAAId and the reaction rate was linear with increasing concentrations of enzyme (Fig. 25). The reaction rate with IAAld expressed as $\Delta \mathrm{E} / \mathrm{min} . / \mathrm{mg}$ protein was 0.006 , whereas the rate with propionaldehyde was 0.760 . There was, therefore, a decrease in the rate of oxidation of 120-fold with IAAld compared to the rate of oxidation with propionaldehyde as substrate.

The concentration of IAAId-bis was varied from 0.2 to $4 \mathrm{mM}$ (Fig. 26) and, using a Lineweaver Burke plot, a $\mathrm{Km}$ of $4 \times 10^{-4} \mathrm{M}$ was determined. Attempts to demonstrate the 


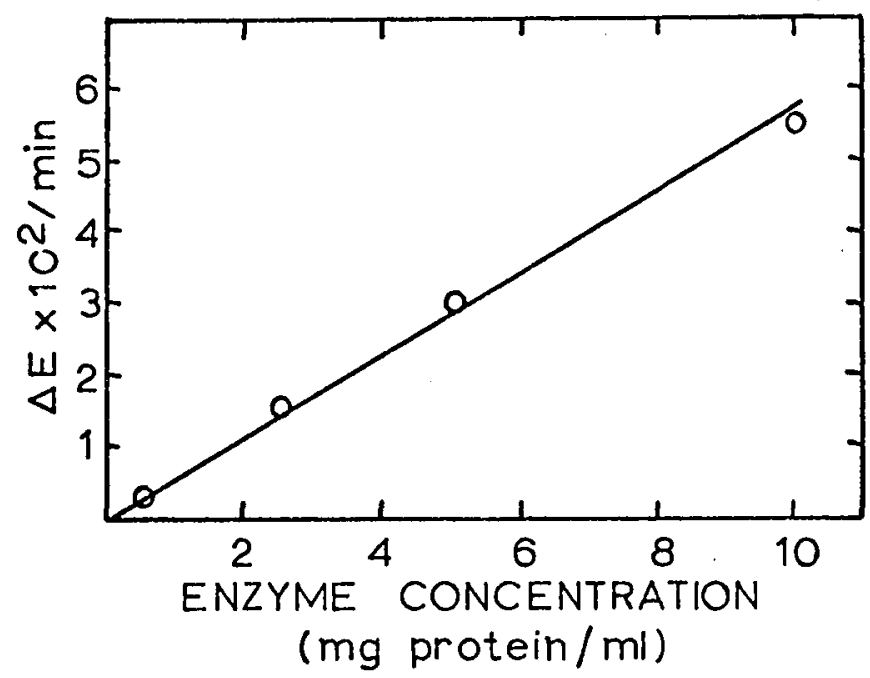

Figure 25. The relationship of reaction rate to enzyme concentration with IAAld as substrate.

Reaction mixtures contained: $2 \mathrm{mM}$ IAAld-bis, $0.06 \mathrm{mM} \mathrm{NADH}$, an appropriate amount of enzyme and $0.1 \mathrm{M}$ phosphate buffer at $\mathrm{pH} 7.0$ to a final volume of $3.0 \mathrm{ml}$.

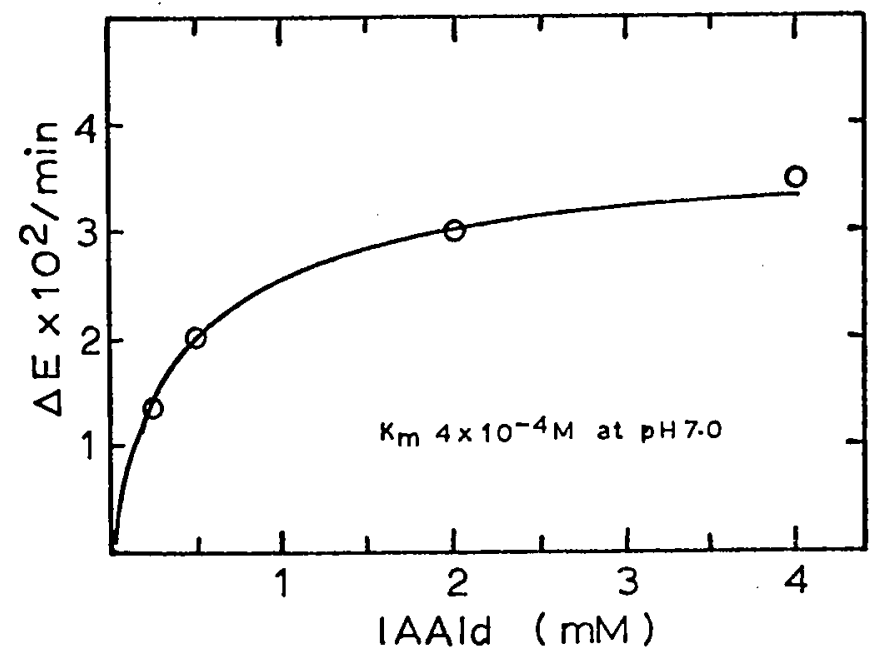

Figure 26. Reaction rate as a function of IAAld concentration.

Reaction mixtures contained: $1.0 \mathrm{ml}$ enzyme, $0.06 \mathrm{mM} \mathrm{NADH}$, an appropriate amount of IAAId and $0.1 \mathrm{M}$ phosphate buffer to a final volume of $3.0 \mathrm{ml}$. 
reverse reaction from Tol to IAAId spectrophotometrically have been unsuccessful, possibly because of the nonenzymatic reaction referred to earlier between the expected products of the reaction, IAAld and NAD.

\section{Stabilisation of the enzymes:}

From the above data it was not possible to decide whether a single alcohol dehydrogenase enzyme was catalysing the reduction of both substrates. Furthermore, it was not possible to measure the aldehyde dehydrogenase reaction spectrophotometrically, even when propionaldehyde was used as substrate. There was clearly a need to concentrate and separate the aldehyde dehydrogenase activity from the large excess of alcohol dehydrogenase present in the SNS enzyme fraction.

In the experiments reported so far, the assays were conducted as soon as possible after the preparation of the SNS fraction because of the loss of enzyme activity, even if the fraction were stored in ice. Purification of the enzymes was attempted by the method of Suzuki (1966) using $\mathrm{MnCl}_{2}$ and ammonium sulphate precipitation. The results from the first experiment (Table 20) show that some increase in specific activity was achieved by precipitation of inactive protein with $\mathrm{MnCl}_{2}$, but no concentration could be achieved using ammonium sulphate because activity was rapidly lost. Clearly, some means of stabilising the enzyme activity was required. In an attempt to overcome 
this problem, at the suggestion of Dr. E.A. Cossins, 2-mercaptoethanol (EtSH) was added to all media. The concentration added was $0.01 \mathrm{M}$ to the grinding medium (standard buffer) and $0.005 \mathrm{M}$ to the buffer used to equilibrate the Sephadex columns. These concentrations were found to give good preservation of the IAA and Tolforming activity in the SNS preparation for at least one week at $5^{\circ} \mathrm{C}$. At the same time, it was found that the formation of both IAld and ICA were considerably reduced by storage of the enzyme fraction overnight. Factors influencing the formation of these compounds from IAAld were not further investigated.

Table 20. Instability of alcohol dehydrogenase during fractionation of a cytoplasmic supernatant preparation in the absence of 2-mercaptoethanol.

Enzyme Fraction
Volume (ml)
Activity

$(\mathrm{U} / \mathrm{m} 1)^{*}$
Total Recovery Activity

(U)
Specific Activity (U/mg protein)

Without $\mathrm{MnCl}_{2}$ treatment

SNS

100

480

48,000

100

32

Following $\mathrm{MnCl}_{2}$ treatment

SNS

$0-40 \%\left(\mathrm{NH}_{4}\right)_{2} \mathrm{SO}_{4}$

- supernatant

- precipitate
90

87 5.5
410

37,800

79

68

5.

240
1,270 $\overline{14}$

* 1 unit of enzyme activity reduced the extinction at $340 \mathrm{mj}$ by $0.001 / \mathrm{min}$. under the standard assay conditions with propionaldehyde as substrate. 


\section{Ammonium sulphate precipitation:}

The preparation of ammonium sulphate fractions has already been described in the section dealing with the purification of TTP-transaminase. The same enzyme fractions were also tested for alcohol dehydrogenase activity using both propionaldehyde and IAAld as substrates and for aldehyde dehydrogenase using IAAld as substrate. A direct comparison can therefore be made of enzyme recovery and purification for TTP-transaminase, alcohol dehydrogenase and aldehyde dehydrogenase.

The results of the spectrophotometric assay for alcohol dehydrogenase with propionaldehyde as substrate are presented in Table 21. Treatment with $\mathrm{MnCl}_{2}$ did not reduce the activity in the SNS fraction, but the recovery of activity on subsequent ammonium sulphate precipitation was reduced from $66 \%$ in the absence of $\mathrm{MnCl}_{2}$ to $41 \%$ following $\mathrm{MnCl}_{2}$ treatment. However, the $\mathrm{MnCl}_{2}$ treatment increased the specific activity of alcohol dehydrogenase 5-fold in the SNS fraction. Without prior treatment with $\mathrm{MnCl}_{2}$ the greatest enzyme activity was found in the 40-50\% and 50-60\% ammonium sulphate fractions. Following $\mathrm{MnCl}_{2}$ treatment, the greatest activity was clearly in the 40-50\% fraction.

The results of the assay for alcohol dehydrogenase with IAAld as substrate are presented in Table 22 . They show interesting differences when compared with the data obtained with propionaldehyde (Table 21). In this 


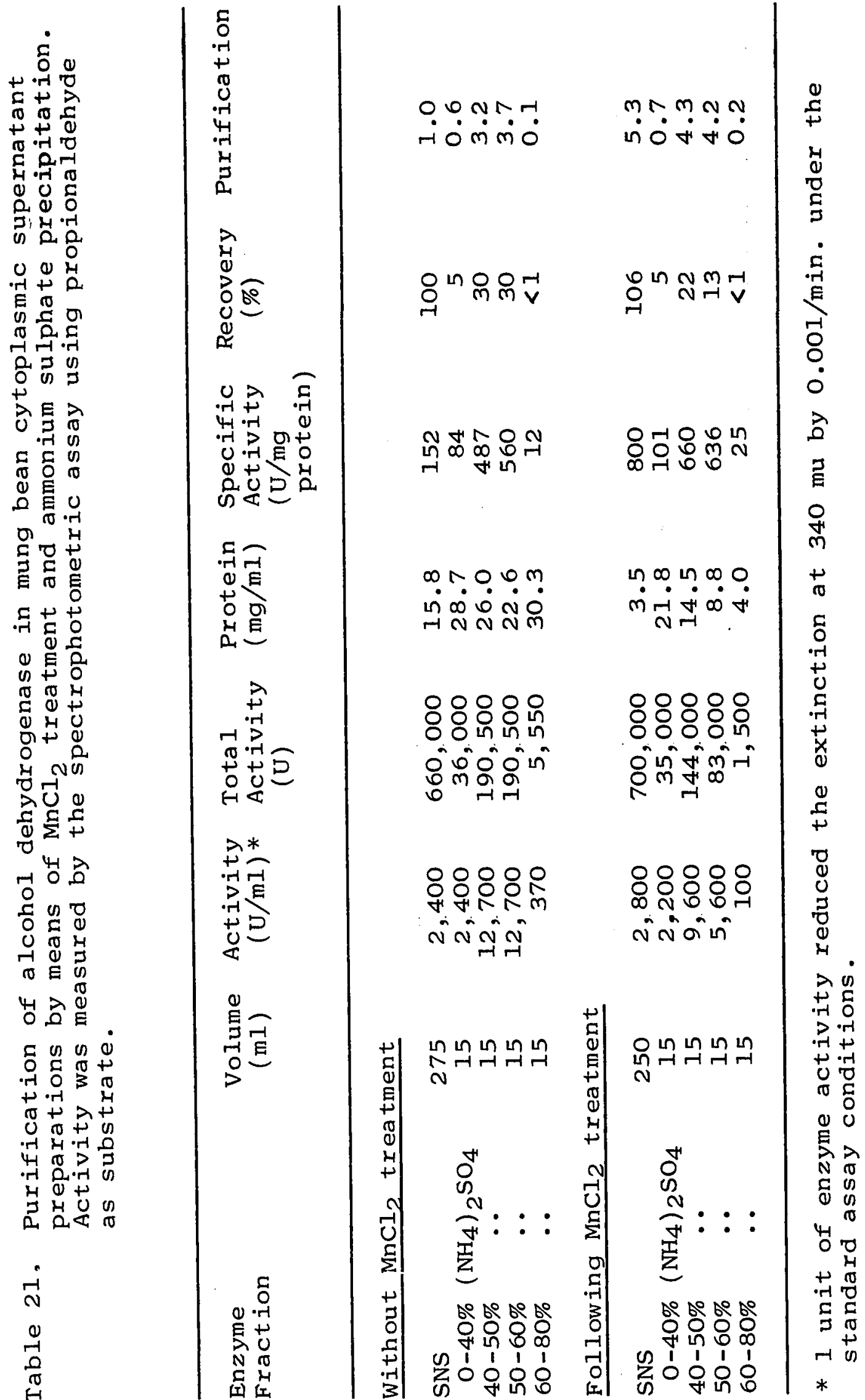




r

$\stackrel{4}{4}$

บ हี

ह

(0)

응

0 H

จ 0

$=\stackrel{\rho}{0}$

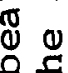

0

فำ

宁

5

(1) 8

o E

(I)

¿

䓅

H $\rightarrow 0$

$\nabla+$

D. 0

도 ?

$\nabla+0$

宁《苇

完.

O n

ता

แ

0 \% 1

ह

- $\begin{array}{r}1 \\ +\end{array}$

ه

it

-4 5 吕

$4+\infty$

क.

N

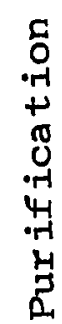

क्षे

85

0

番

. 0 क्ष

स०

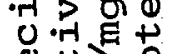

岂D

点

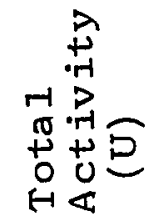

से *

고

记

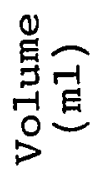

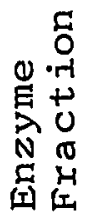

O NOO

तinio

$\infty \pi+0$

$\stackrel{\Perp}{\downarrow}$

$04 \pi \infty N$

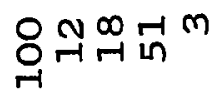

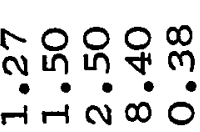

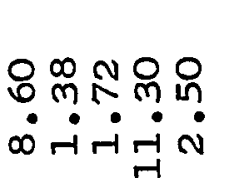

$\infty$ N $0 \mathrm{~m}$

i் $\dot{0} \dot{0}$

HNNM

응년요용

in 0 o

ㅇํㅇํำ

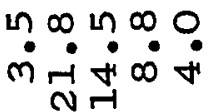

윰ํํ유

을은욤엄

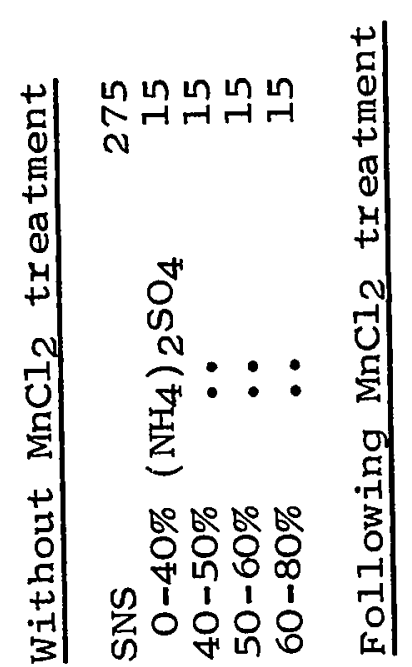

율ำำ

$\sim$

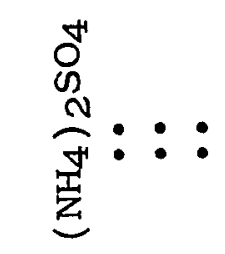

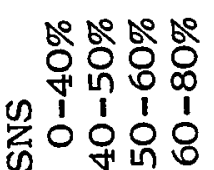

告

芴

分

登

品

$+$

동

$\stackrel{+}{0}$

5

$+$

$\stackrel{ \pm}{\dagger}$

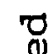

苋

究品

$? \cdot+$

मे.

员

00

蛋

귱

(1)

㟧

4
+1
0

E

$\exists \pi$

त 10 
experiment, there appeared to be a clear increase in the activity of the SNS fraction following $\mathrm{MnCl}_{2}$ treatment, but recovery of activity on subsequent ammonium sulphate precipitation was again reduced. Without prior treatment with $\mathrm{MnCl}_{2}$, $84 \%$ of the activity in the SNS fraction was recovered by ammonium sulphate precipitation and 51\% of the activity was found in the 50-60\% fraction. Following $\mathrm{MnCl}_{2}$ treatment, only $44 \%$ of the original activity was recovered in all fractions (this percentage is reduced to $33 \%$ if expressed in terms of the $\mathrm{MnCl}_{2}$-treated SNS) and $27 \%$ was found in the 50-60\% fraction.

When these results are compared with the data obtained with propionaldehyde, it can be seen that the peaks of activity, with respect to the two substrates, do not coincide. This observation indicates that there must be at least two enzymes with alcohol dehydrogenase activity, one of which (in the $50-60 \%\left(\mathrm{NH}_{4}\right)_{2} \mathrm{SO}_{4}$ fraction) appears capable of reducing IAAId much faster than the other.

Samples of each enzyme fraction were also tested using IAAld as the substrate in the presence of both NAD and $\mathrm{NADH}_{2}$ as cofactors, and enzyme activity was measured by extracting and assaying the amount of IAA and Tol formed after a 3-hour incubation period. The results of this indole product assay for alcohol dehydrogenase activity (Tol formation) are presented in Table 23 and for aldehyde dehydrogenase activity (IAA formation) in Table 24 . The recovery of alcohol dehydrogenase activity in the 


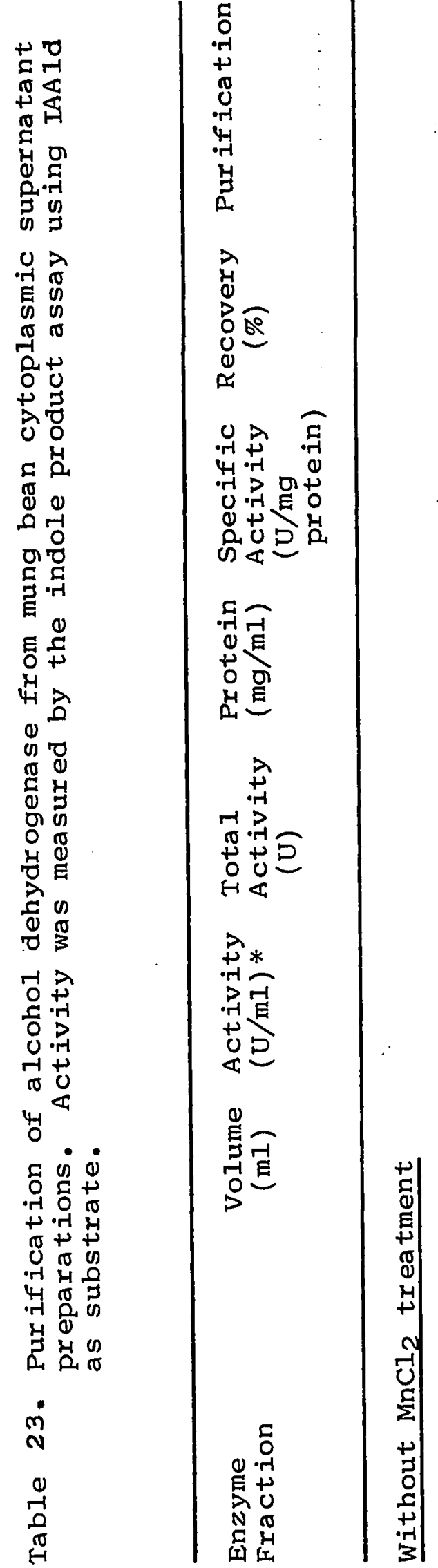

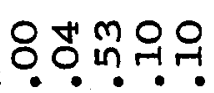

त००

NNmo

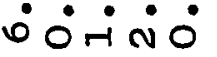

o

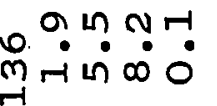

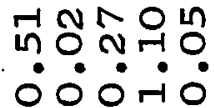

ฟै

mं0.

oro.

Uึஷ

ก $\infty$ ᄂ? $\infty$

m

年

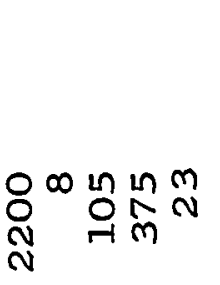

0. ํ. ‥?

कor nnt

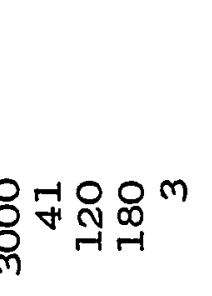

$\sum_{\substack{n \\ 0}}^{m}$

แก เก เก เก เก

Nलनात्म

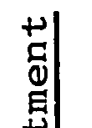

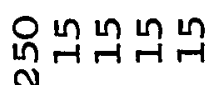

O... $0.0 \%$

N NDNO

N
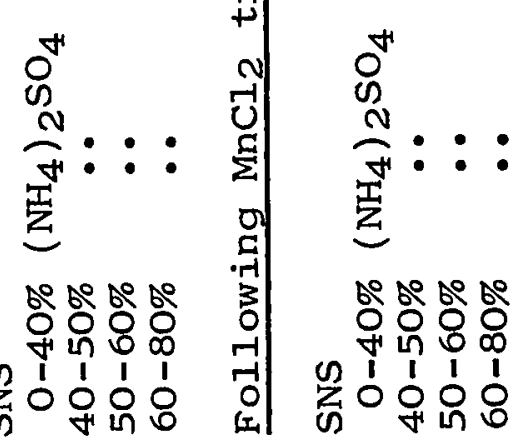

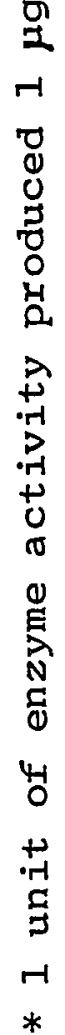




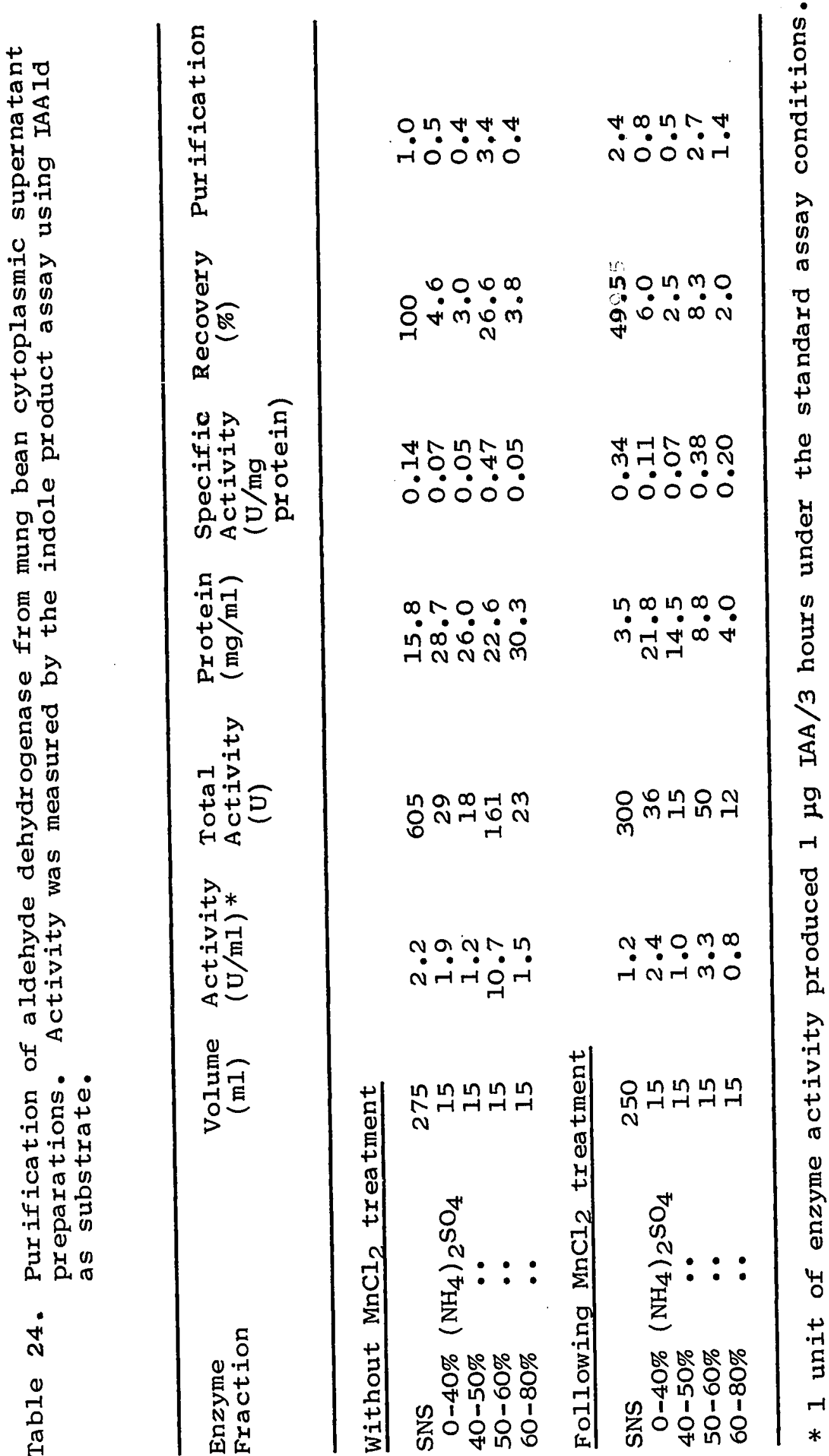


ammonium sulphate fractions was lower when measured by the indole product assay. This assay does not measure initial reaction rates and, with alcohol dehydrogenase, the reaction velocity is not linear with time. It is important to note, however, that the 50-60\% fraction showed the greatest activity irrespective of whether the cytoplasmic supernatant preparation had been treated with $\mathrm{MnCl}_{2}$ or not. There is also good correlation between the distribution of activity in the various fractions when the two assay methods are compared (Tables 22, 23 ).

In this experiment 50\% of the aldehyde dehydrogenase activity was lost with the $\mathrm{MnCl}_{2}$ treatment (Table 24), but in later experiments the loss was only about 20\%. Aldehyde dehydrogenase activity in the SNS preparations is very low and small differences in the assay for IAA are reflected by large percentage changes. The activity recovered in the ammonium sulphate fractions is of more interest. Without $\mathrm{MnCl}_{2}$ treatment, the greatest activity was found in the 50-60\% fraction, representing a 5-fold increase in activity/ml and a 3.4-fold increase in specific activity. Following $\mathrm{MnCl}_{2}$ precipitation, although the greatest aldehyde dehydrogenase activity was again recovered in the 50-60\% fraction, the $0-40 \%$ fraction was also active. The recovery of aldehyde dehydrogenase activity in two distinct fractions was demonstrated more clearly in another experiment, the results of which are presented in Figure 27. In this experiment, it was found that, following $\mathrm{MnCl}_{2}$ treatment, 


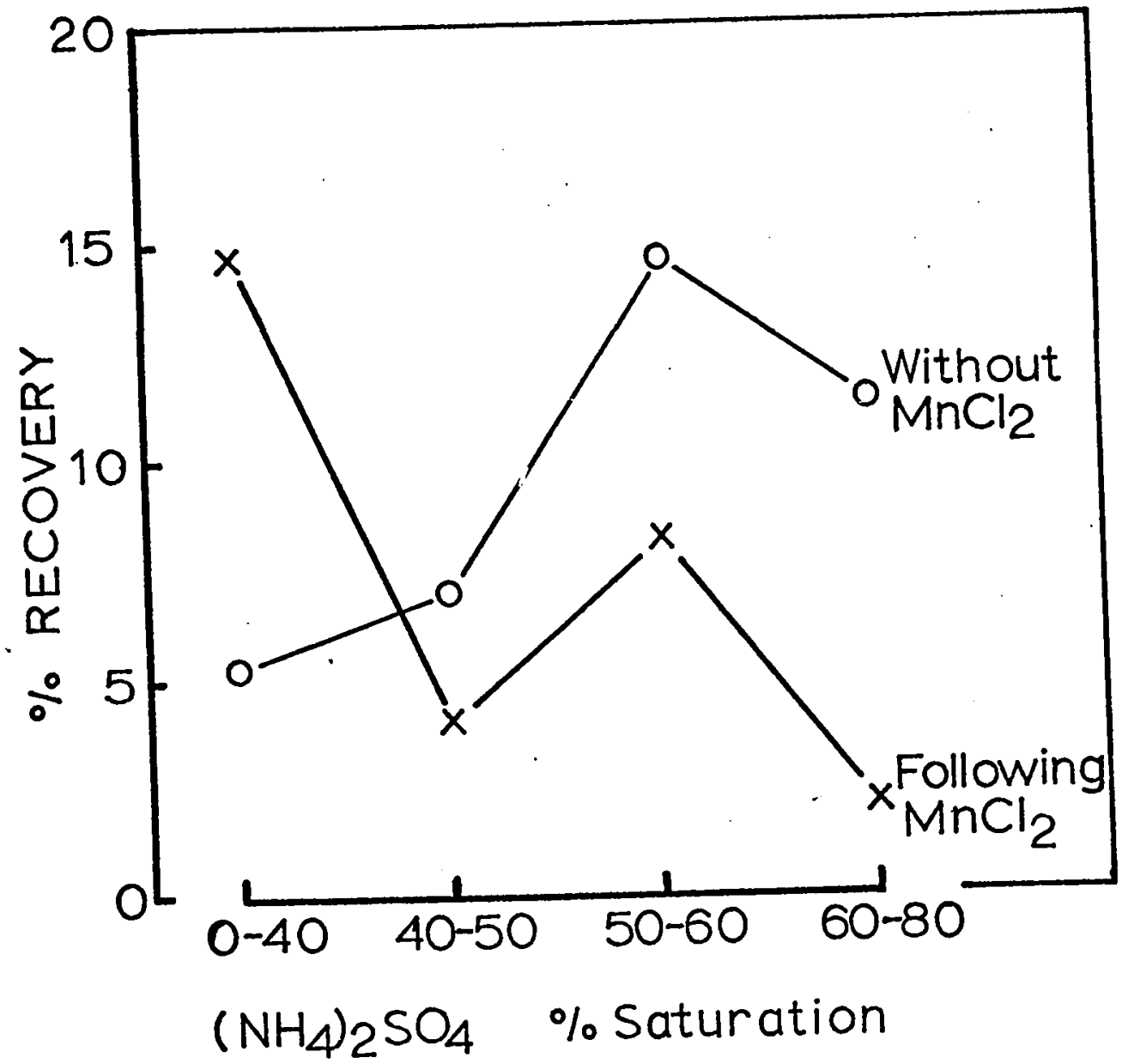

Figure 27. Recovery of aldehyde dehydrogenase in ammonium sulphate fractions without or following $\mathrm{MnCl}_{2}$ treatment. 
the aldehyde dehydrogenase activity in the 0-40\% fraction was greater than that in the 50-60\% fraction. The significance of this change in the precipltation properties of aldehyde dehydrogenase is not known but it should be noted that the distribution of TTP-transaminase and alcohol dehydrogenase were not altered by the $\mathrm{MnCl}_{2}$ treatment.

In a further experiment, the dependence of aldehyde dehydrogenase and alcohol dehydrogenase on the addition of $\mathrm{NAD}$ and $\mathrm{NADH}_{2}$ was rechecked for each ammonium sulphate fraction. A photograph of the chromatogram strips, taken after the density of each band had been recorded with the Photovolt densitometer, is presented in Figure 28. It can be seen that a small amount of Tol and only trace amounts of IAA were detected in the absence of cofactors. On the addition of NAD, IAA formation was greatly stimulated and the recovery of activity in the 50-60\% fraction was $63 \%$ (Table 25). Recovery of activity in all fractions was 106\%. This result indicates that the conversion of IAAld to IAA by the SNS fraction can be completely accounted for by the action of an NAD-dependent aldehyde dehydrogenase.

Tol formation was also greatly stimulated by the addition of $\mathrm{NAD}$, but even in the 50-60\% fraction, the amount produced was less than the amount of IAA. Thus the formation of Tol can be accounted for by the generation of $\mathrm{NADH}_{2}$ by aldehyde dehydrogenase. When $\mathrm{NADH}_{2}$ was added as cofactor, Tol formation was increased to a level that could not be measured in the densitometer because the central 
SUBSTRATE : I.AALD.

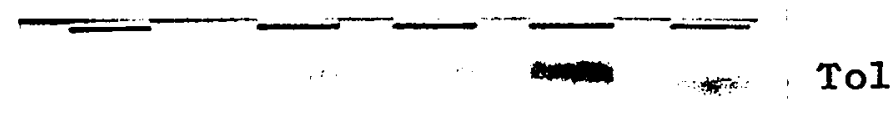

NO

COFACTORS

IAA

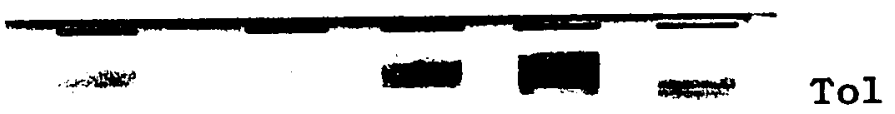

PLUS

NAD

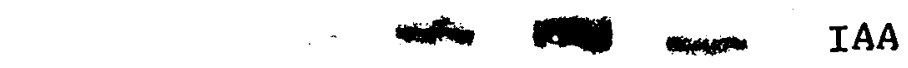

PLUS

$\mathrm{NADH}_{2}$

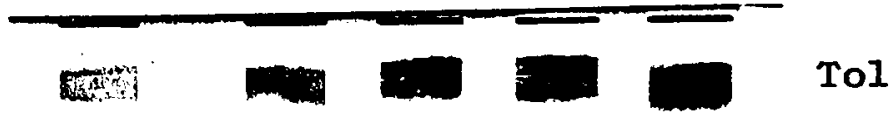

To1

IAA

Figure 28. Paper chromatograms of NEUTRAL + ACID ether extracts from reaction mixtures containing IAAld as substrate showing requirement for pyridine nucleotide cofactor. Except for variation of the cofactor, standard assay conditions were used. In all cases, extract equivalent to $I \mathrm{mi}$ enzyme was applied as a 2 inch band to the chromatograms which were developed in IAmW and dipped in DMAC reagent. The lower band on each chromatogram is IAA, the upper band is Tol. 


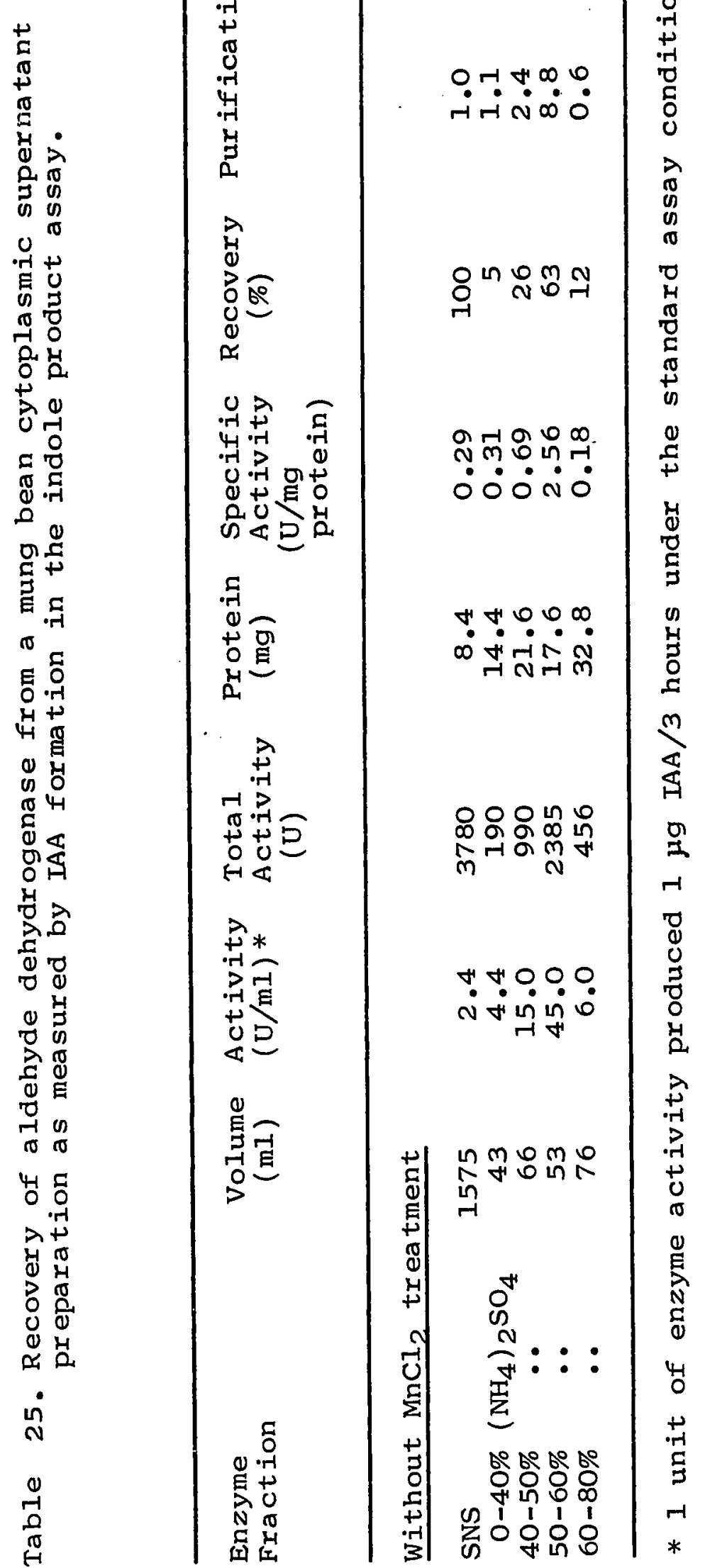


region of each Tol band overreacted with DMAC (Fig. 28). This only occurs when over 25 ug of Tol are present in a band 2 inches wide. The NAD generated by the alcohol dehydrogenase in these reaction mixtures would account for the IAA formed in this treatment.

\section{Oxidation of tryptophol:}

Since the above experiments clearly showed the presence of both alcohol and aldehyde dehydrogenases in the SNS enzyme preparations, it should be possible to demonstrate the metabolism of Tol to IAA via the expected intermediate, IAAld. Such a reaction would be favoured by high $\mathrm{pH}$ which would shift the equilibrium of the alcohol dehydrogenase towards the formation of IAAld. Accordingly, samples of ammonium sulphate fractions were tested at $\mathrm{pH} 8.5$ using Tol as substrate and NAD as cofactor. The results (Fig. 29) show that Tol was converted to IAA at about one tenth the rate of conversion of IAAld to IAA and, as expected, optimum activity was found in the 50-60\% ammonium sulphate fraction. When $10 \mathrm{mM}$ sodium bisulphite was added to the reaction mixture the formation of IAA was reduced by $78 \%$, which strongly suggests that IAAId was indeed an intermediate in the reaction sequence. 


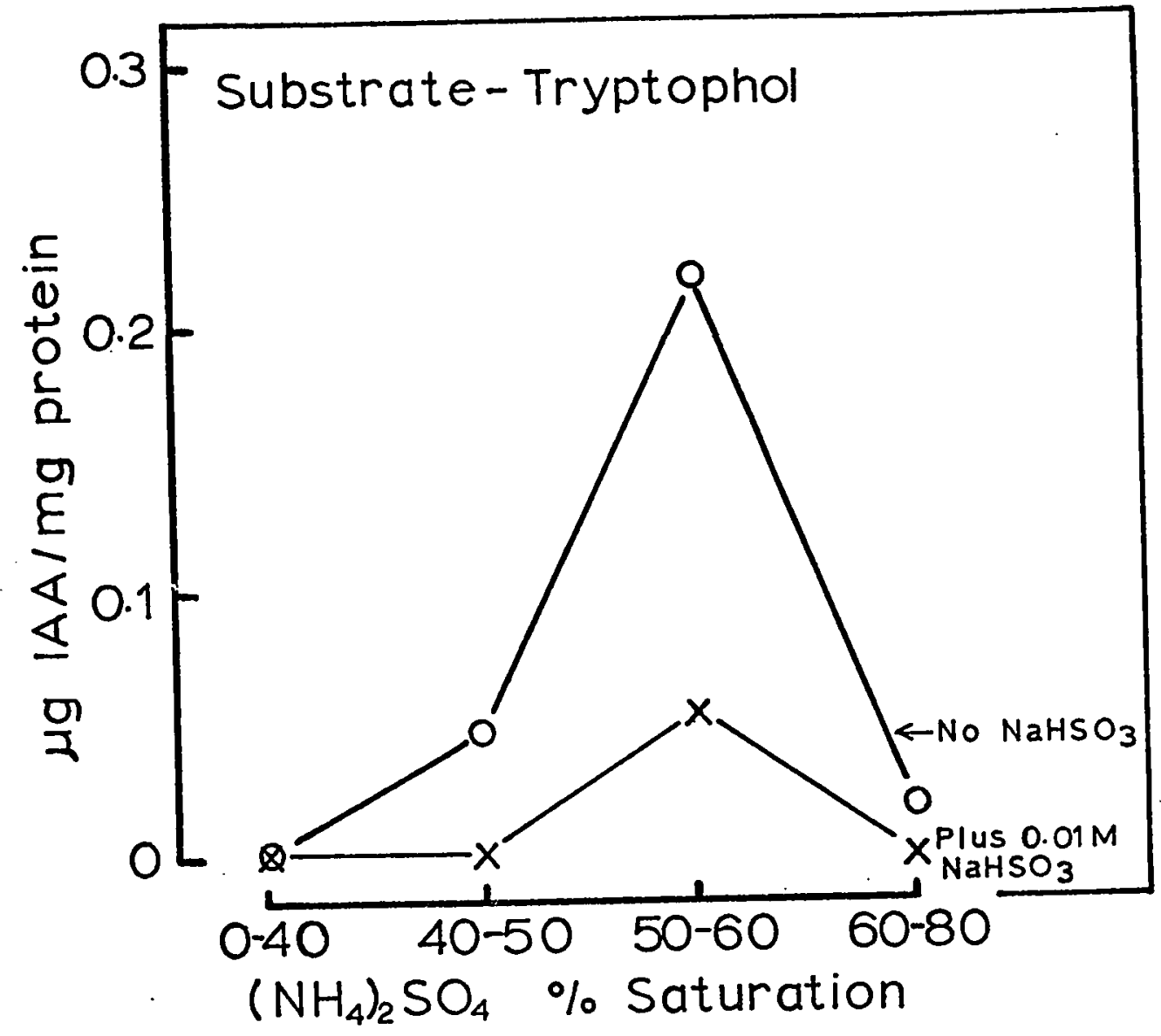

Figure 29. The conversion of tryptophol to IAA catalysed by ammonium sulphate fractions of a mung bean cytoplasmic supernatant preparation, in the presence or absence of $10 \mathrm{mM}$ sodium bisulphite. 


\section{7. $\mathrm{pH}$ fractionation:}

In order to separate the alcohol and aldehyde dehydrogenase enzymes, fractional precipitation by the progressive lowering of $\mathrm{pH}$ was attempted. This method has been successfully used in the purification of aldehyde dehydrogenases from yeast (Black, 1955) and liver (Racker, 1955) as well as from peanut cotyledons (Liu et al., 1965).

To measure $\mathrm{pH}$, a Metrohm combination electrode was used with a Beckman Zeromatic pH meter. The electrode was chilled in iced water and the meter was calibrated between pH 4.0 and $\mathrm{pH} 7.0$ as described in the Materials and Methods section.

A $30 \mathrm{ml}$ aliquot of cytoplasmic supernatant enzyme, prepared in the usual way in the presence of .01 M EtSH, was chilled to $2^{\circ} \mathrm{C}$ in crushed ice. The $\mathrm{pH}$ was then lowered by adding single drops of $0.1 \mathrm{M}$ citric acid to the supernatant in a $50 \mathrm{ml}$ centrifuge tube. The supernatant was constantly stirred with a small magnetic bar and the $\mathrm{pH}$ was monitored throughout.

The heavy precipitate which formed at $\mathrm{pH} 6.0$ was sedimented and discarded. Successive precipitates were then collected with the $\mathrm{pH}$ at $5.6,5.4,5.2,5.0,4.8$, 4.6 and 4.4 . Each precipitate was dissolved in $2.5 \mathrm{~m} 1$ of standard buffer and $1 \mathrm{ml}$ aliquots were assayed for alcohol and aldehyde dehydrogenase activity using ether extraction followed by paper chromatography as the indole product assay. It was found (Table 26 , Fig. 30) that aldehyde dehydrogenase was precipitated between $\mathrm{pH} 5.2$ 
Table 26. pH Precipitation of aldehyde dehydrogenase from mung bean cytoplasmic supernatant preparations .

Protein

Fraction

precipitated

at:
Aldehyde dehydrogenase

Total

Activity

(U) *
Specific

Activity

( $\mathrm{U} / \mathrm{mg}$

protein)
Alcohol dehydrogenase

Total Specific

Activity Activity

$(\mathrm{U}) *$

(U/mg

protein)

Without $\mathrm{MnCl}_{2}$ treatment

\begin{tabular}{|c|c|c|c|c|c|}
\hline $\begin{array}{rl}\mathrm{pH} & 6.0- \\
5.6 & - \\
5.4 & - \\
5.2 & - \\
5.0- & - \\
4.8-8 & - \\
4.6 & -\end{array}$ & $\begin{array}{l}-5.6 \\
-5.4 \\
-5.2 \\
-5.0 \\
-4.8 \\
-4.6 \\
-4.4\end{array}$ & $\begin{array}{l}0.3 \\
0.7 \\
1.5 \\
4.1 \\
7.4 \\
2.8 \\
1.2\end{array}$ & $\begin{array}{l}0.08 \\
0.10 \\
0.17 \\
0.76 \\
1.32 \\
0.74 \\
0.46\end{array}$ & $\begin{array}{l}4.6 \\
2.3 \\
1.7 \\
0.6 \\
0.4 \\
0.3 \\
0.2\end{array}$ & $\begin{array}{l}1.28 \\
0.32 \\
0.19 \\
0.11 \\
0.07 \\
0.08 \\
0.15\end{array}$ \\
\hline
\end{tabular}

Following $\mathrm{MnCl}_{2}$ treatment

\begin{tabular}{|c|c|c|c|c|c|}
\hline $\begin{array}{r}\mathrm{pH} \\
6.0 \\
5.6 \\
5.4 \\
5.2 \\
5.0 \\
4.8 \\
4.6\end{array}$ & $\begin{array}{l}-5.6 \\
-5.4 \\
-5.2 \\
-5.0 \\
-4.8 \\
-4.6 \\
-4.4\end{array}$ & $\begin{array}{l}0.1 \\
0.7 \\
1.4 \\
1.9 \\
2.2 \\
0.2 \\
0.2\end{array}$ & $\begin{array}{l}0.06 \\
0.22 \\
0.39 \\
0.53 \\
0.69 \\
0.10 \\
0.13\end{array}$ & $\begin{array}{l}1.2 \\
0.7 \\
0.4 \\
0.6 \\
0.4 \\
0.4 \\
0.3\end{array}$ & $\begin{array}{l}0.67 \\
0.22 \\
0.11 \\
0.17 \\
0.13 \\
0.20 \\
0.19\end{array}$ \\
\hline
\end{tabular}

* Reaction mixtures contained: $1 \mathrm{ml}$ of enzyme fraction, 3.8

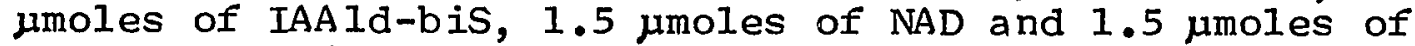
$\mathrm{NADH}_{2}$ to a final volume of $1.5 \mathrm{ml}$. The $\mathrm{pH}$ was 7.5 and incubation was at $35^{\circ} \mathrm{C}$ for 3 hours.

A unit of aldehyde dehydrogenase activity produced $1 \mathrm{\mu g}$ of IAA $/ 3$ hours.

A unit of alcohol dehydrogenase produced $1 \mu \mathrm{g}$ of Tol/3 hours under the standard assay conditions. 


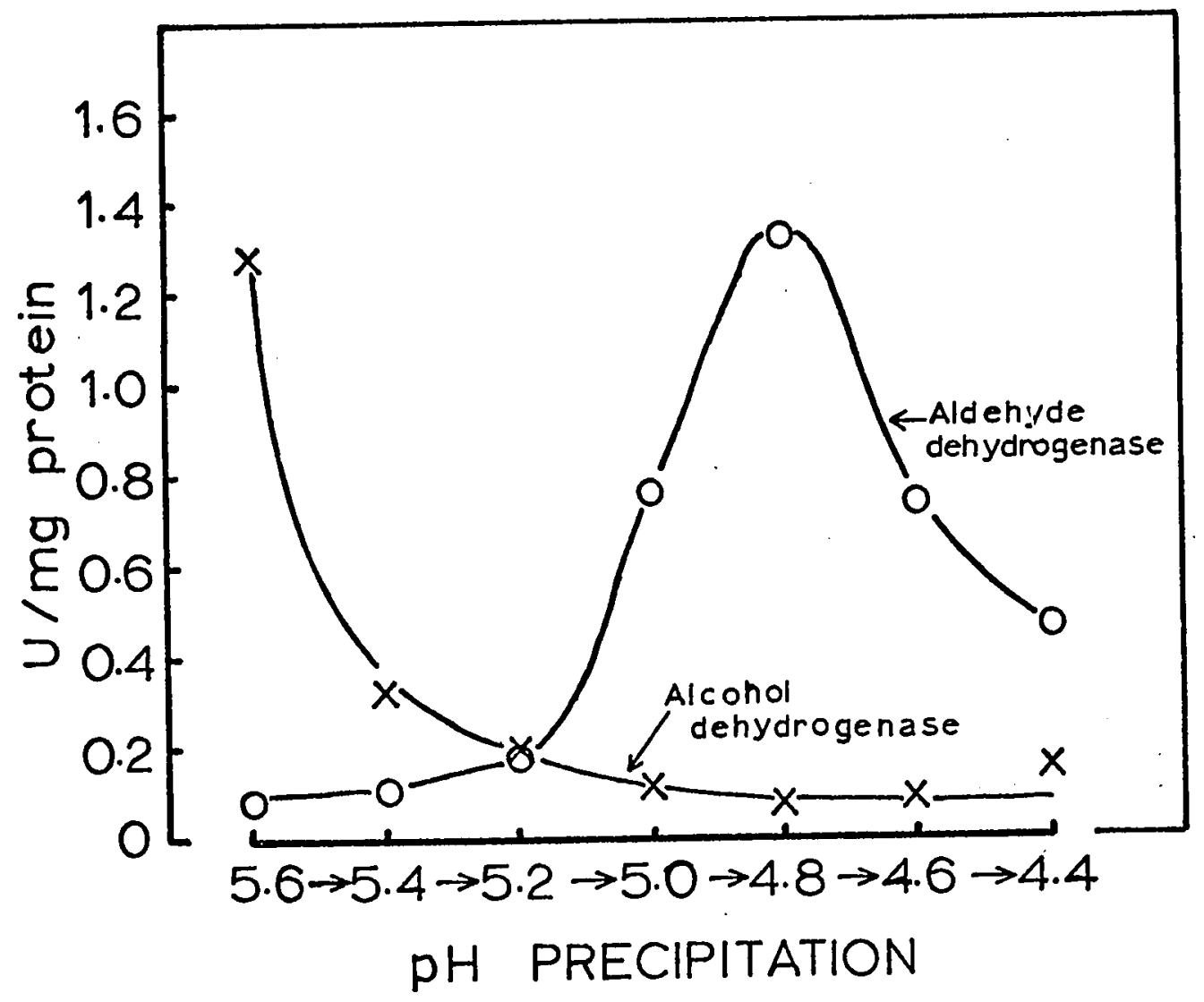

Figure 30. $\mathrm{pH}$ Precipitation of aldehyde dehydrogenase from a mung bean cytoplasmic supernatant preparation.

For composition of reaction mixtures and definition of enzyme units see Table 26. 
and $\mathrm{pH} 4.8$, whereas alcohol dehydrogenase activity was found in the $\mathrm{pH} 5.6$ precipitate and was barely detectable in the precipitates between $\mathrm{pH} 5.2$ and $\mathrm{pH} 4.4$.

An identical experiment was then carried out using $30 \mathrm{ml}$ of a cytoplasmic supernatant preparation which was first treated with $\mathrm{MnCl}_{2}$. The results again showed that aldehyde dehydrogenase was maximally precipitated between $\mathrm{pH} 5.2$ and 4.8 and thus could be separated from alcohol dehydrogenase (Table 26). However, the level of aldehyde dehydrogenase in the most active fraction was less than $30 \%$ of that obtained in the comparable fraction without $\mathrm{MnCl}_{2}$ treatment. Consequently, in further $\mathrm{pH}$ precipitation experiments the supernatant preparations were not treated with $\mathrm{MnCl}_{2}$.

It was clear from the first experiment reported in Table 26 that most of the alcohol dehydrogenase activity had not been recovered in the precipitates collected. Therefore, the alcohol dehydrogenase present in the cytoplasmic supernatant was either precipitated at $\mathrm{pH} 6.0$, denatured by the subsequent acidification treatment or still present in the supernatant at $\mathrm{pH} 4.4$. To examine these possibilities, a further $\mathrm{pH}$ precipitation experiment was carried out in which the level of alcohol dehydrogenase activity in the protein precipitates and in the remaining supernatant fraction after the removal of each precipitate was measured by the spectrophotometric assay using propionaldehyde as substrate. The results show (Table 27) that as the $\mathrm{pH}$ was lowered, alcohol dehydrogenase 
Table 27. The denaturation of alcohol dehydrogenase in mung bean cytoplasmic supernatant preparations with decreasing $\mathrm{pH}$.

\begin{tabular}{lccc}
\hline pH & $\begin{array}{c}\text { Activity in } \\
\text { Supernatant* } \\
(U) * * *\end{array}$ & $\begin{array}{c}\text { Loss of } \\
\text { Activity } \\
\text { (U) }\end{array}$ & $\begin{array}{c}\text { Activity in } \\
\text { Precipitate** } \\
\text { (U) }\end{array}$ \\
\hline 7.5 & 360,000 & & \\
6.0 & 320,000 & 40,000 & 4,500 \\
5.8 & 280,000 & 40,000 & 3,600 \\
5.6 & 248,000 & 32,000 & 2,200 \\
5.4 & 160,000 & 88,000 & 2,280 \\
5.2 & 60,000 & 100,000 & 1,530 \\
5.0 & 36,000 & 24,000 & 1,070 \\
4.8 & 10,000 & 26,000 & - \\
4.6 & - & 10,000 & - \\
4.4 & - & - & - \\
\hline
\end{tabular}

* $200 \mathrm{ml}$ of cytoplasmic supernatant were used. A $0.1 \mathrm{~m} 1$ aliquot of the supernatant at each $\mathrm{pH}$ was tested for alcohol dehydrogenase activity by the standard spectrophotometric assay using propionaldehyde as substrate.

* The precipitate collected at each $\mathrm{pH}$ was dissolved in $10 \mathrm{ml}$ of standard buffer and a $0.1 \mathrm{ml}$ aliquot was tested for alcohol dehydrogenase activity by the standard spectrophotometric assay using propionaldehyde as substrate.

*** A unit of enzyme activity decreased the absorption at $340 \mathrm{m \mu}$ by $.001 / \mathrm{min}$. under the standard assay conditions. 
activity was lost and at $\mathrm{pH} 5.0$ only $10 \%$ of the activity remained in the residual supernatant fraction. However, the precipitated protein fractions contained only a total of $4.7 \%$ of the activity which had been lost. These observations provide good evidence for inactivation of the alcohol dehydrogenase catalysing the reduction of propionaldehyde with decreasing $\mathrm{pH}$.

When the protein precipitates were also tested for IAAld-metabolising enzymes by the indole product assay, it was found that $64 \%$ of the aldehyde dehydrogenase in the original supernatant was recovered in the three fractions precipitating at $\mathrm{pH} 4.8,4.6$ and 4.4 . However, alcohol dehydrogenase activity was also recovered in these fractions, particularly in the $\mathrm{pH} 4.4$ precipitate in which about $4 \%$ of the original alcohol dehydrogenase was recovered. The results of this experiment indicate that, although most alcohol dehydrogenase was denatured by the decreasing $\mathrm{pH}$, a small percentage of the activity remained and was precipitated at $\mathrm{pH} 4.4$.

A further point to be considered is that, if the activity of alcohol dehydrogenase in the original cytoplasmic supernatant preparation was high, then the precipitates containing aldehyde dehydrogenase might be contaminated with alcohol dehydrogenase. This possibility was checked in a further experiment in which the $\mathrm{pH}$ of $30 \mathrm{ml}$ of a cytoplasmic supernatant preparation was lowered to $\mathrm{pH} 4.0$ in steps of $0.25 \mathrm{pH}$ units. As shown in Table 28 , $70 \%$ of the aldehyde dehydrogenase in the original 


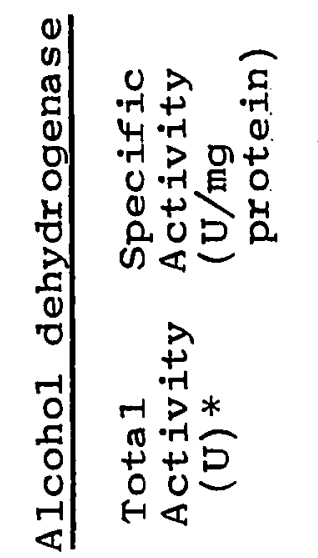

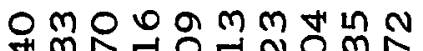
HMNAOHNOMN NOOOHOOHNH

$\wedge$

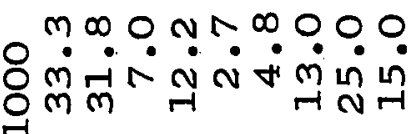

| $\wedge$

要

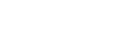

0
0
0
0
0
0
0
0
0
0
0
0
0
0
0
0
0
0
0

․․ำ.

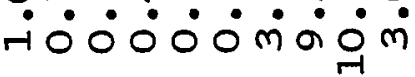

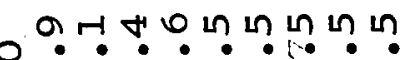
סำ

ते

出 क

C.

:

.

$+\pi$

to

-

त्र

00

댕

مـ

$\stackrel{4}{0}$

记

ำ

$\stackrel{0}{H}$

$\infty$
$N$
0
0
0
0
0

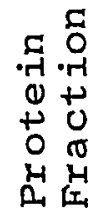

O

番

$0 \rightarrow \overparen{E}$

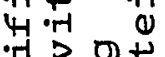

$0 . \rightarrow 00$

范员台

ㄱำกㄴ.

OOOOOOOOH

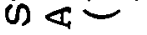

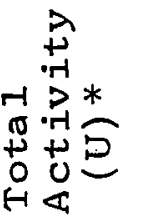

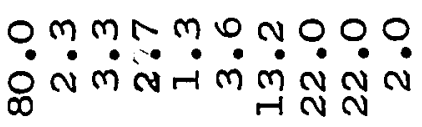

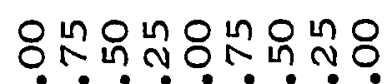
. ㅇํ

เก

$\begin{array}{lllllllll}1 & 1 & 1 & 1 & 1 & 1 & 1 & 1 & 1\end{array}$

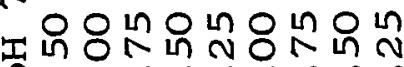

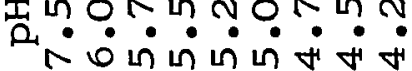
党资

0
0
0
6
0
0
0
0
0
0
0
0
0
0
0
0
0
0
0
5
0
0
5
0
0
0
0
0
0
0
0
0
0
0
0
0
0
0
0
0
0
0
0 
supernatant preparation was recovered in the three precipitates between $\mathrm{pH} 5.0$ and 4.25, whereas less than $4 \%$ of the alcohol dehydrogenase was found in these fractions. Although the alcohol dehydrogenase activity in the $\mathrm{pH} 6.0$ and 5.75 precipitates can probably be accounted for by soluble enzyme trapped in protein precipitates, the peak of alcohol dehydrogenase activity between $\mathrm{pH} 4.75$ and 4.0 appears to represent a true precipitation of the small percentage of activity which had not been inactivated.

If $\mathrm{pH}$ precipitation is to be used as a standard purification step for aldehyde dehydrogenase, it would be more convenient if the enzyme could be recovered in a single fraction. A $120 \mathrm{ml}$ sample of the same cytoplasmic supernatant preparation used in the previous experiment (Table 28) was adjusted to $\mathrm{pH} 5.0$ and the precipitate was removed. The $\mathrm{pH}$ of the supernatant was then lowered to pH 4.2 and the sample was divided into four aliquots of $30 \mathrm{ml}$ each. These aliquots were stored in an ice bath for $0,30,60$ or 120 minutes before centrifugation. Each protein precipitate was dissolved in $2.5 \mathrm{ml}$ of standard buffer at pH 7.0 and enzyme assays were performed in the usual manner. The results of this experiment are presented in Table 29. For comparison, the corresponding data for the three precipitates from $\mathrm{pH} 5.0$ to $\mathrm{pH} 4.25$ in Table have been combined and are also presented.

The recovery of aldehyde dehydrogenase in a single fraction obtained by lowering the $\mathrm{pH}$ from 5.0 to 4.2 is 


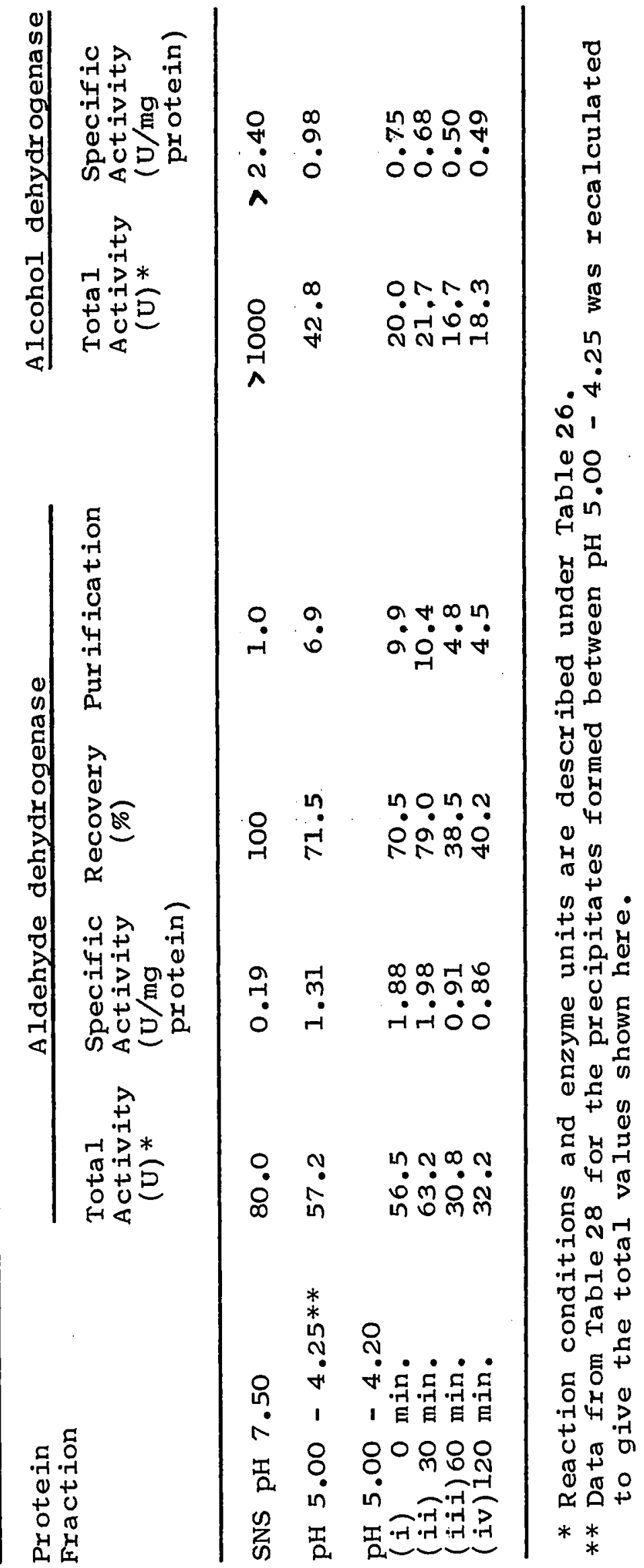


equivalent to the recovery in three separate fractions over this $\mathrm{pH}$ range, as shown in Table 28. The activity of aldehyde dehydrogenase at $\mathrm{pH} 4.2$ appears to be stable over a $30 \mathrm{~min}$. period, but a 50\% loss of activity was found on leaving the preparation at $\mathrm{pH} 4.2$ for $60 \mathrm{~min}$. or more. The protein content of the precipitates increased with time and the specific activity of the enzymes fell. The recovery of alcohol dehydrogenase in the single fraction was less than the activity recovered in three separate fractionation steps and was always less than $2 \%$ of the activity in the original SNS preparation. From these results it is clear that maximum recovery of aldehyde dehydrogenase from a cytoplasmic supernatant preparation can be achieved by collecting the precipitate formed between $\mathrm{pH} 5.0$ and 4.2 and redissolving this in standard buffer at $\mathrm{pH} 7.5$ within $30 \mathrm{~min}$. This procedure gives not only the greatest purification of aldehyde dehydrogenase but also the lowest contamination from alcohol dehydrogenase. If the activity of alcohol dehydrogenase is very high in the cytoplasmic supernatant preparation, a second $\mathrm{pH}$ precipitation may be necessary to obtain a preparation of aldehyde dehydrogenase that is free of alcohol dehydrogenase activity. 


\section{The Separation of Transaminase and Dehydrogenase Enzymes by Chromatography on Sephadex G-200}

Techniques have recently been developed for the separation of proteins on the bas is of molecular size using dextran gels. A simple column chromatographic procedure was reported by Andrews (1965) for determining the approximate molecular weights of different enzymes on the basis of their elution pattern from columns of Sephadex G-200. This method allows the separation of enzymes even in an impure state and can thus be used both as a method of protein purification and for determining approximate molecular weight.

A column of Sephadex G-200 (1.5 cm x $45 \mathrm{~cm})$ was prepared using fully swollen gel and was equilibrated with phosphate buffer ( $\mathrm{pH} 7.5$ ) containing 0.005 M 2-mercaptoethanol which was also used to elute the fractions. A sample of the enzyme mixture was pipetted on to the top of the column and the eluate was collected using a fraction collector fitted with a siphon (either 5.1 or $4.3 \mathrm{~m} 1$ ). Blue dextran 2000 (Pharmacia MW 2,000,000) and cytochrome C. (MW 12,000) were used as markers. Aliquots from each fraction were tested for enzyme activity by the standard assay procedures. The volume used to elute Blue dextron 2000 was taken as the void volume (Vo) of the column and this value was used to calculate Ve/Vo values, where Ve stands for the elution volume for any fraction. Using the value for $\mathrm{Ve} / \mathrm{Vo}$ for each peak of 
enzyme activity, an approximate molecular weight has been assigned to the enzyme on the basis of data reported by Andrews (1965).

In the first experiment, a column $1.5 \mathrm{~cm} \times 45 \mathrm{~cm}$ was used and $5.1 \mathrm{ml}$ fractions were collected. The protein sample to be fractionated was the $40-60 \%\left(\mathrm{NH}_{4}\right)_{2} \mathrm{SO}_{4}$ fraction from a cytoplasmic supernatant preparation that had not been treated with $\mathrm{MnCl}_{2}$. This sample was first desalted by passage through a column of Sephadex G-25 and a $6 \mathrm{ml}$ aliquot was pipetted on to the top of the Sephadex G-200 column. Each fraction eluted from the G-200 column was assayed for tryptophan transaminase activity by measuring the rate of glutamate formation, and also for both aldehyde and alcohol dehydrogenase activity using IAAld as substrate and measuring the formation of IAA and Tol. The results of these assays are presented in Table 30.

As seen from these results, both the TTP-transaminase and aldehyde dehydrogenase enzymes were eluted as single peaks at Ve/Vo 2.12 and 1.70 respectively. On the other hand, alcohol dehydrogenase was eluted with a major peak of activity at Ve/Vo 2.55 and a minor peak of activity at Ve/Vo 1.70, coinciding with the peak of aldehyde dehydrogenase activity.

In order to obtain better resolution of the peaks of enzyme activity, a longer column was prepared $(1.5 \mathrm{~cm} x$ $57 \mathrm{~cm})$, the protein sample volume was reduced to $4 \mathrm{mI}$ and the fractions were collected using a siphon of $4.3 \mathrm{ml}$. The protein sample was prepared from the 40-60\% $\left(\mathrm{NH}_{4}\right)_{2} \mathrm{SO}_{4}$ 


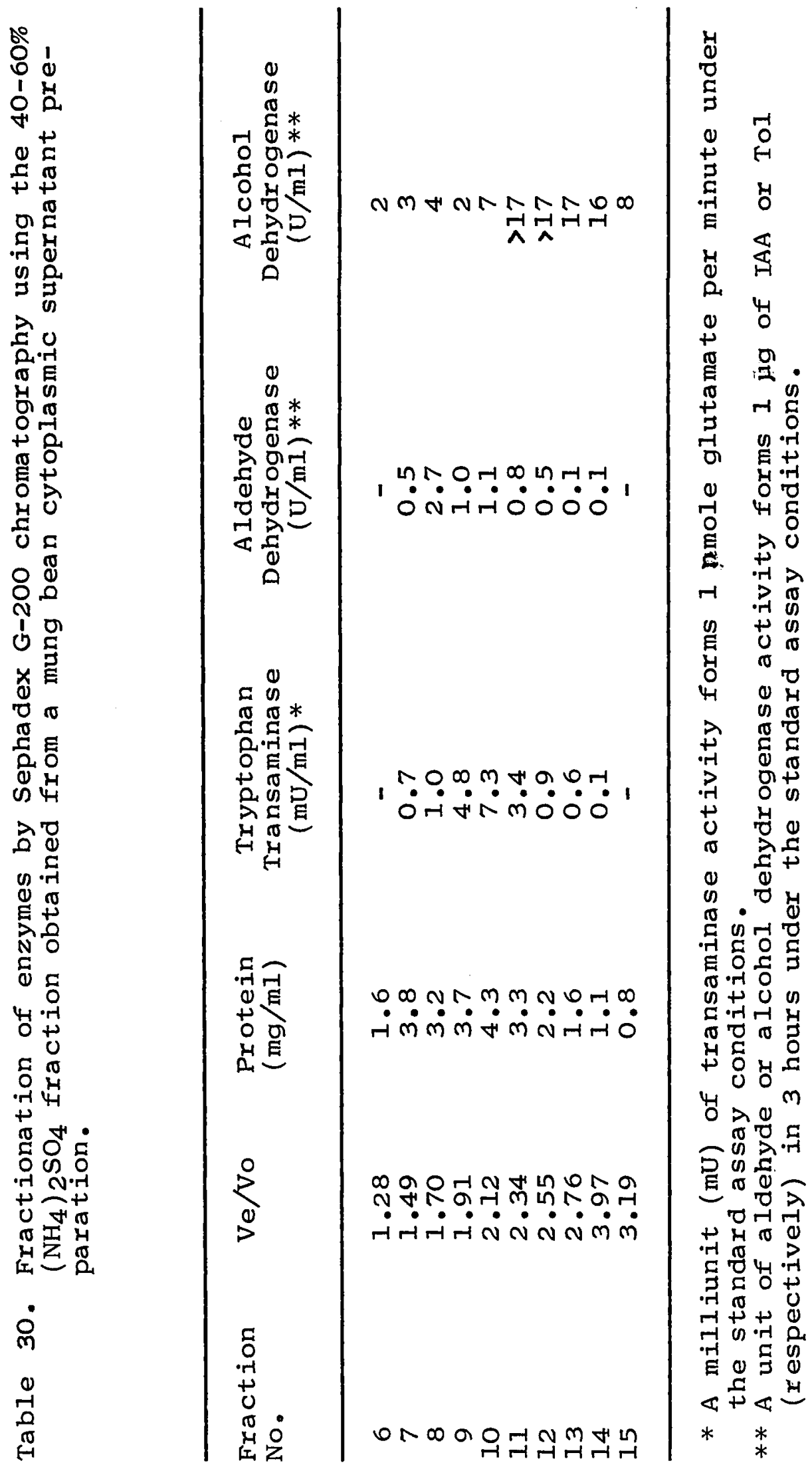


precipitate of an $\mathrm{MnCl}_{2}$-treated cytoplasmic supernatant. The precipitate was dissolved in standard buffer and desalted by passage through a column of Sephadex G-25. Each fraction eluted from the Sephadex G-200 column was assayed for enzyme activity as described above in the first experiment, but alcohol dehydrogenase was also assayed using the spectrophotometric assay with propionaldehyde as substrate. The results of this experiment are shown in Table 31.

It is clear from these results that the peak of activity of aldehyde dehydrogenase (Ve/Vo 1.72) does not coincide with the peak of alcohol dehydrogenase activity ( Ve/Vo 2.10) as measured by the spectrophotometric assay with propionaldehyde as substrate, nor does it coincide with the minor peak of activity (Ve/Vo 1.43) as measured by Tol formation when IAAld was used as substrate. This result suggests that the IAAld-reducing enzyme is different from the enzyme which reduces propionaldehyde. The Ve/Vo values for a duplicate separation of the same enzyme preparation were identical. The values obtained in the first experiment (Table 30 ) and the duplicate sets of data obtained in the second experiment (Table 31 ) have been averaged and an approximate molecular weight assigned on the basis of the results reported by Andrews (1965). These values are shown in Table 32 . In a recent paper, Cossins et al. (1968) estimated the molecular weight of alcohol dehydrogenase in peas to be approximately 60,000 , which agrees very well with the value of 56,000 found above 


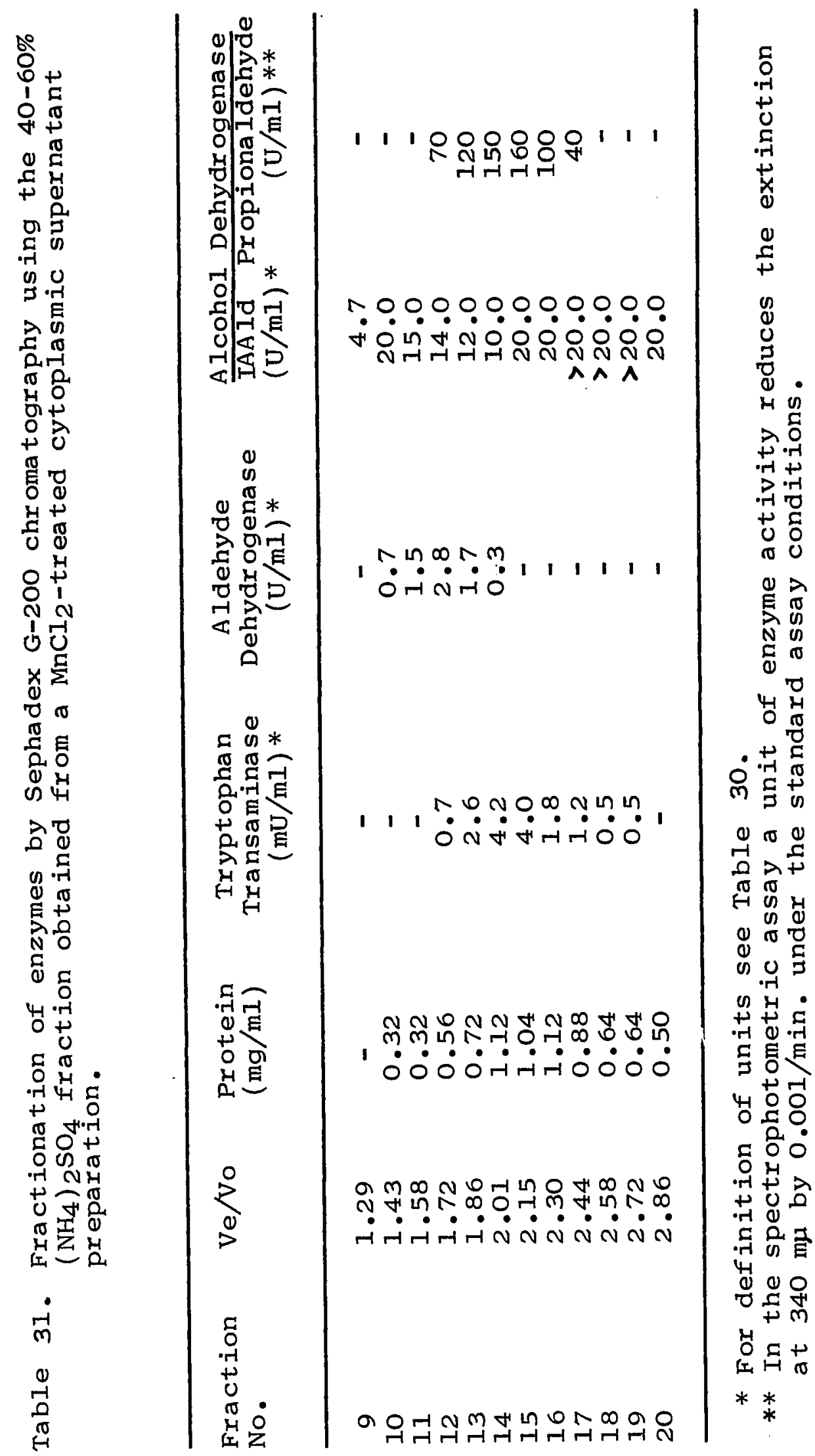


Table 32. Approximate molecular weights of the enzymes from mung bean cytoplasmic supernatant fractions.

Average Ve/Vo

MW

TTP-transaminase

Aldehyde dehydrogenase

Alcohol dehydrogenase

(i) IAAld as substrate

(ii) Propionaldehyde as substrate

2.10

1.75

1.53

2.48

2.10
56,000

112,000

186,000

24,000

56,000

when propionaldehyde was used as substrate. The reason for the widely differing molecular weights of 24,000 and 186,000 that were found for alcohol dehydrogenase when IAAld was used as substrate is not known. There may be two distinct alcohol dehydrogenases catalysing the reduction of IAAld; on the other hand, the peaks may represent aggregates of a single enzyme. 


\section{E. Investigation of Tomato Shoot Tip Enzymes}

The previous section has described experiments with enzymes extracted from etiolated mung bean seedlings. In this section the results of a series of experiments using enzyme fractions prepared from shoot tips of actively growing tomato plants will be presented.

\section{Intracellular distribution of tryptophan transaminase:}

Shoot tips of actively growing tomato plants were ground in a large porcelain mortar using $1 \frac{1}{2}$ volumes of buffered sucrose at $\mathrm{pH}$ 8.5. The brei was squeezed through cheesecloth and the filtrate was fractionated by differential centrifugation in exactly the same manner as the homogenate from mung bean seedlings. The high speed cytoplasmic supernatant was further purified by passage through Sephadex G-25. The pellet of washed mitochondria was divided into a soluble mitochondrial protein fraction and an insoluble mitochondrial fraction by the methods outlined previously (page 57).

Aliquots of all three enzyme fractions were assayed for transaminase activity in the presence and absence of both $30 \mathrm{mM}$ TTP and $10 \mathrm{mM} \alpha-K G$, as shown in Table 33. As seen from this data, in the absence of $\alpha-K G$ and TTP (reaction mixture No. 1), no glutamate was detected in any assay which indicated that proteolysis had not occurred in any fraction during the incubation period. With the addition of $\alpha-K G$ alone, only very small amounts of glutamate were formed, 
which indicated that endogenous free amino acids had been removed from the protein fractions by the Sephadex and mitochondrial washing procedures. Only in the presence of both $\alpha-K G$ and TTP was glutamate formed at a constant rate over the 6 hour incubation period. These findings are thus identical with the results previously obtained with mung bean enzyme preparations.

Table 33. Transaminase activity of tomato shoot-tip enzyme fractions.

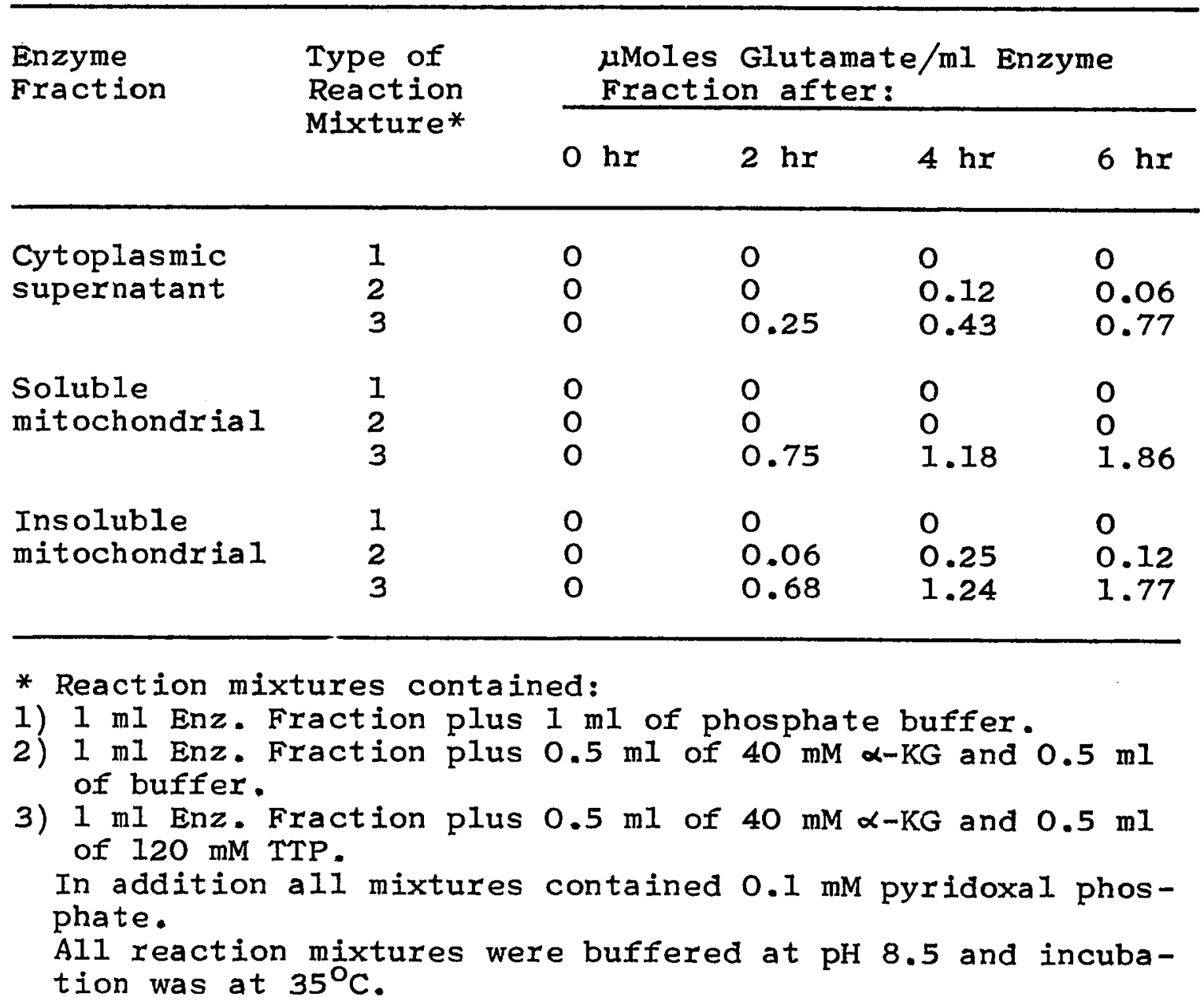


The distribution of the tryptophan transaminase activity and the specific activity of each enzyme fraction was also calculated (Table 34). As was found for mung bean seedlings (Table 5 ), over $90 \%$ of the recovered activity was in the supernatant fraction. The remaining $9.2 \%$ of recovered activity was almost equally distributed between the soluble and insoluble mitochondrial fractions.

Table 34. Intracellular distribution of transaminase activity in tomato shoot tip fractions.

\begin{tabular}{lcccccc}
\hline $\begin{array}{l}\text { Enzyme } \\
\text { Fraction }\end{array}$ & Vol & \multicolumn{2}{c}{ Enzyme Activity* } & $\begin{array}{c}\text { Protein } \\
\text { (mg/ml) }\end{array}$ & $\begin{array}{l}\text { Specific } \\
\text { Activity } \\
\text { (mU/mg } \\
\text { protein) }\end{array}$ \\
\hline $\begin{array}{l}\text { Cytoplasmic } \\
\text { supernatant }\end{array}$ & 280 & 1.8 & 504 & 90.8 & 6 & 0.3 \\
$\begin{array}{l}\text { Soluble } \\
\text { mitochondrial }\end{array}$ & 5 & 5.0 & 25 & 4.5 & 2 & 2.5 \\
$\begin{array}{l}\text { Insoluble } \\
\text { mitochondrial }\end{array}$ & 5 & 5.2 & 26 & 4.7 & 14 & 0.4 \\
$\begin{array}{l}\text { Total } \\
\text { mitochondrial }\end{array}$ & 10 & & 51 & 9.2 & & \\
\hline
\end{tabular}

* A milliunit (mU) of enzyme activity forms 1 nmole glutamate/ min. under standard assay conditions. 


\section{The oxidation and reduction of 3-indoleacetaldehyde:}

Tomato shoot tips ( $30 \mathrm{~g}$ ) were ground in $45 \mathrm{~m} 1$ of standard buffer (containing $0.01 \mathrm{M} \mathrm{EtSH}$ ) at $\mathrm{pH} 7.5$. The brei was squeezed through cheesecloth and centrifuged at $35,000 \times \mathrm{g}$ for $30 \mathrm{~min}$. A portion of the resulting cytoplasmic supernatant was purified by passage through a column of Sephadex G-25 to yield the SNS preparation. Both the cytoplasmic supernatant and SNS preparations were assayed for aldehyde and alcohol dehydrogenase activity.

As shown in Table 35, the formation of IAA and Tol was not completely dependent on the addition of added cofactors when the cytoplasmic supernatant preparation was used. However, with the SNS preparation no products were detected without the addition of pyridine nucleotide cofactors. On the addition of NAD only IAA was formed; when $\mathrm{NADH}_{2}$ was added, not only was Tol formed at the same rate as with the unsephadexed enzyme, but IAA was also formed. No products were detected when boiled enzyme preparations were used in the reaction mixtures. This experiment clearly demonstrated the presence of pyridine nucleotide-dependent aldehyde and alcohol dehydrogenase in tomato shoot tips.

3. Purification of the enzymes from tomato shoot tips:

Purification of the tryptophan transaminase and aldehyde dehydrogenase from tomato shoot tips was car:ied out essentially as described in the previous section for the mung 
Table 35. Oxidation and reduction of IAAld by tomato enzymes.

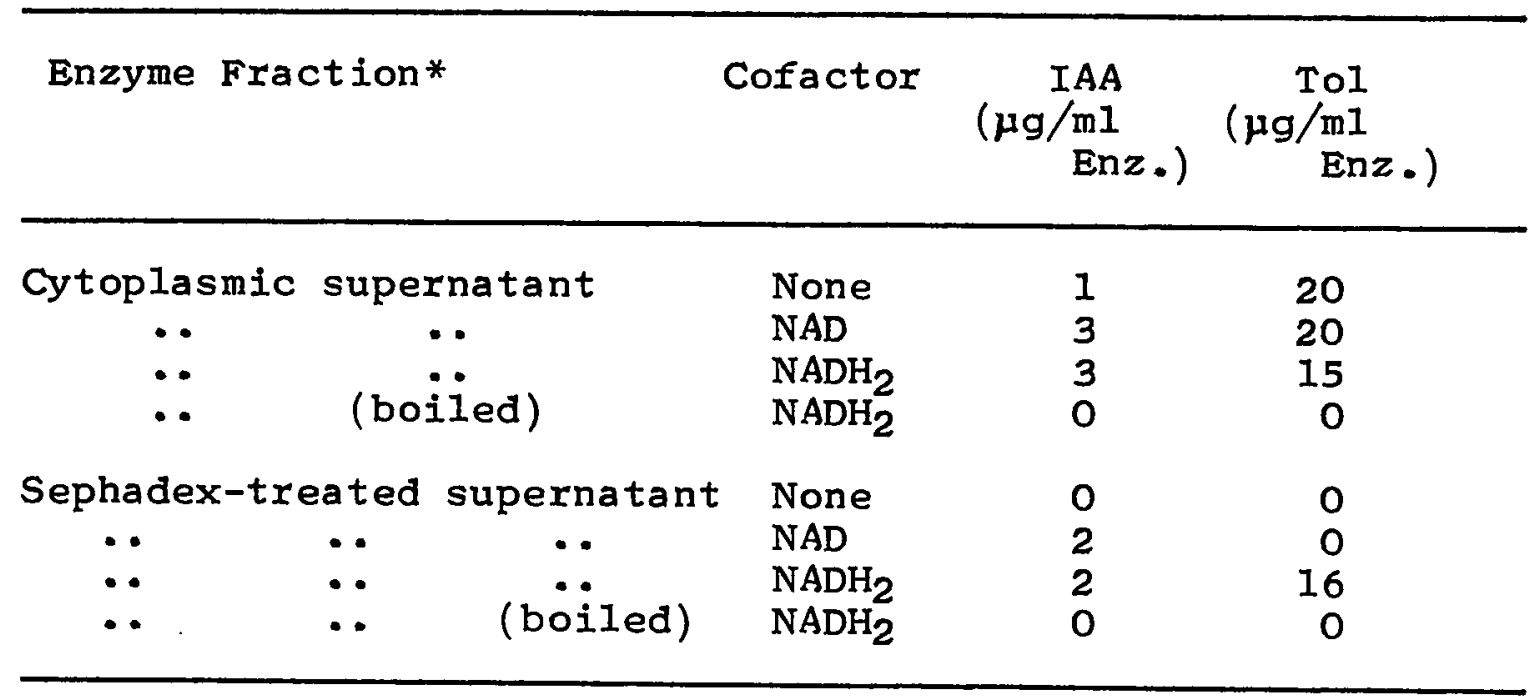

* Each reaction mixture contained $1 \mathrm{ml}$ of appropriate enzyme fraction, $3.8 \mathrm{mM}$ IAAld-bis and, where indicated, $1.5 \mathrm{mM}$ NAD or $\mathrm{NADH}_{2}$. The final volume was $1.5 \mathrm{ml}$ and the $\mathrm{pH}$ was 7.5. The reaction mixtures were incubated at $35^{\circ} \mathrm{C}$ for 3 hours. 
bean enzymes. A cytoplasmic supernatant preparation was prepared and, after precipitation of inactive protein with $\mathrm{MnCl}_{2}$, the clear supernatant was fractionated with successive additions of ammonium sulphate. Each fraction was tested for transaminase activity by the standard assay procedure and for aldehyde dehydrogenase activity using IAAld as substrate and chromatographic analysis to measure the formation of IAA.

As shown in Table 36, pretreatment of the supernatant preparation with $\mathrm{MnCl}_{2}$ resulted in the loss of $19 \%$ of the TTP-transaminase activity and did not increase the specific activity of the enzyme. On fractionation with ammonium sulphate, over $40 \%$ of the activity was recovered in the 40-50\% fraction with a purification of 7.4-fold. In this respect the enzyme from tomato shoot tips behaved similarly to the mung bean enzyme.

The results for the aldehyde dehydrogenase assay (Table 37) differ from results obtained with mung bean cytoplasmic preparations. With mung bean enzyme, the highest activity was always found in the 50-60\% ammonium sulphate fraction whereas for the tomato enzyme, $23 \%$ of the activity was recovered in the $0-40 \%$ fraction and $26 \%$ of the activity in the 40-50\% fraction. Although the formation of Tol from IAAld was measured quantitatively, it was observed that the peak of alcohol dehydrogenase activity was also in the $0-40 \%$ and the 40-50\% fraction. This result also is different from the results obtained with mung beans and appears to indicate different properties of the enzymes from the two types of plant. 


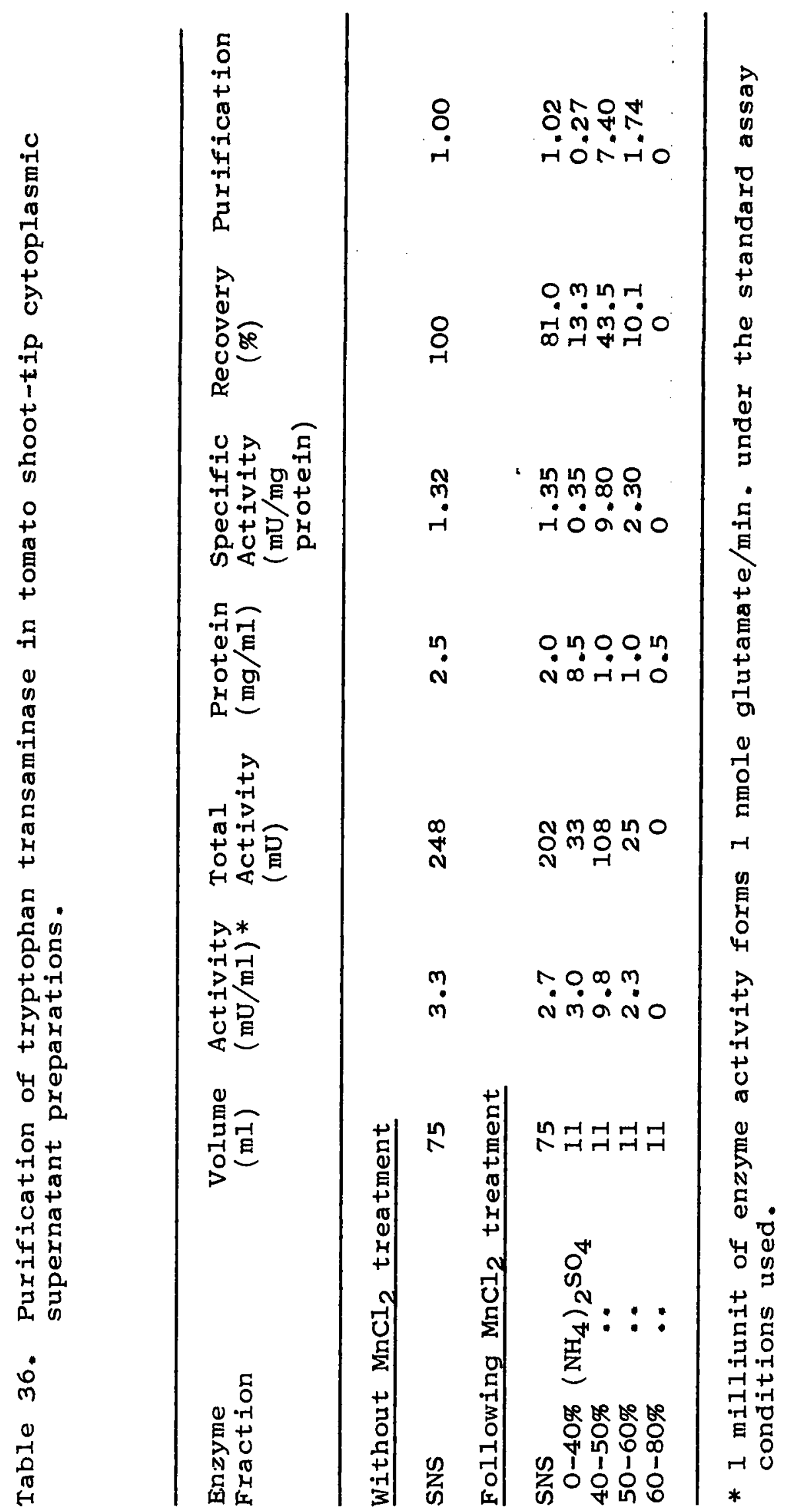




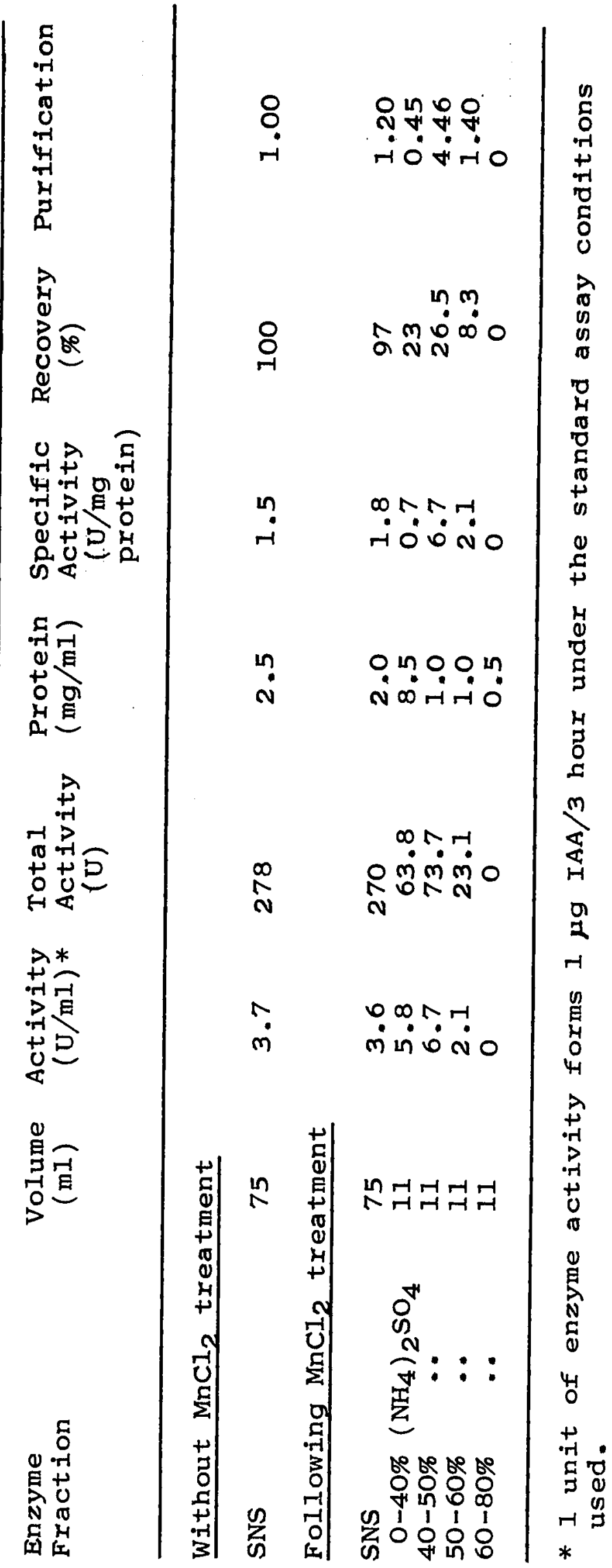




\section{Indole products formed from L-tryptophan:}

In preliminary experiments with enzyme fractions prepared from tomato shoot tip tissue, it was found that when the cytoplasmic supernatant fraction was incubated with the standard TTP-transaminase reaction mixture, To1 was formed. However, if this fraction was purified by passage through Sephadex G-25, Tol formation was no longer observed. This result suggested that Tol was formed by the action of the alcohol dehydrogenase described above, metabolising IAAld produced in the reaction mixture. In contrast, it should be noted that when similar enzyme fractions prepared from etiolated mung bean seedlings were treated in an identical manner, Tol was not detected.

It has been shown that both TTP-transaminase and alcohol dehydrogenase activity are present in the enzyme fractions from tomato shoot tips and mung bean seedlings. The difference in the capacity of these fractions to form Tol may, therefore, simply reflect a difference in their ability to produce IAAld from IPyA. Since one important difference between the two types of tissue was the growth of the plant material in the light or in darkness, it was decided to compare Tol formation by a tomato shoot tip preparation with both etiolated and light-grown mung bean preparations. The etiolated mung beans were grown for 3 days in the dark in the usual manner. The light-grown mung beans were grown for 2 days in the dark and were then grown in the light in a glass covered box to maintain high humidity for a further 2 or 4 days. It is 
realized that a second parameter, age, was being varied in this experiment and the effect of this factor was investigated in an experiment reported in the next section.

Cytoplasmic supernatant fractions without sephadex purification were used in this experiment. Sephadex purification was not carried out because the cofactor requirements of IPyA decarboxylation have not been determined and it was possible that some essential cofactor for this reaction might be removed by this filtration procedure. If the tomato enzyme produced Tol from IAAld, it should be possible to inhibit the reaction by the addition of $\mathrm{NaHSO}_{3}$ and to recover IAAld from the reaction mixture in a BASIC ether fraction. To test this possibility, either $10 \mathrm{mM}$ or $30 \mathrm{mM} \mathrm{NaHSO}$ was added to the tomato reaction mixtures. The $\mathrm{pH}$ of all mixtures was adjusted to 7.0 and incubation was for 6 hours. At the end of this time, $\mathrm{NaHSO}_{3}$ was added to all reaction mixtures to give a concentration of $0.1 \mathrm{M}$ to trap any IAAld present and prevent its extraction into the NEUTRAL ether fraction. NEUTRAL, ACID and BASIC ether extracts were then prepared.

The NEUTRAL ether extract was first examined by paper chromatography using IAmW as the developing solvent. Tol was detected in the extract from the tomato reaction mixture and the level was reduced by $\mathrm{NaHSO}_{3}$, as shown in Table 38. Tol was also detected in the extract from the light-grown mung bean reaction mixture, but was not found in the extract from the dark-grown mung bean system. The identification of Tol was confirmed by chromatography in BzAcW when the Rf 
and DMAC colour reaction observed was highly characteristic of authentic Tol.

Since the enzyme fractions had not been purified through Sephadex G-25, it is likely that most of the IPyA formed in the transamination reaction was broken down during the reaction period. This would account for the high levels of IAA, ICA and the unknown compound $x$ found in the ACID ether extracts of the tomato and mung bean systems. The fact that no trace of IPyA was detected in the extracts was due to the addition of $0.1 \mathrm{M} \mathrm{NaHSO}_{3}$ prior to extraction. This resulted in the formation of the bisulphite addition product of IPyA which is not soluble in ether. When $10 \mathrm{mM}$ or $30 \mathrm{mM} \mathrm{NaHSO}$ was added during the reaction period, the IPyA formed by transamination appeared to be stabilised because the levels of IAA, ICA and also the unknown compound $\mathrm{X}$ were reduced in the ether extracts.

Table 38. Measurement of Tol in NEUTRAL ether extracts of tomato and mung bean reaction mixtures.

Tomato shoot tips

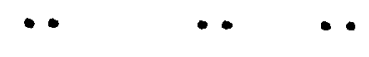

Mung bean dark-grown ( 3 day)

.. .. 1ight-grown (4 day)

.. .. light-grown (6 day)

$\begin{array}{cc}10 \mathrm{mM} \mathrm{NaHSO} & 0.23 \\ 30 \mathrm{mM} \mathrm{NaHSO} & 0.09 \\ & 0.00 \\ - & 0.00 \\ - & 0.23 \\ - & 0.23\end{array}$

* The basic reaction mixture contained $30 \mathrm{mM}$ TTP, $10 \mathrm{mM} \alpha-\mathrm{KG}$, $0.1 \mathrm{mM}$ pyridoxal phosphate, $0.24 \mathrm{mM}$ thiamine pyrophosphate and $1 \mathrm{mM} \mathrm{MgSO} 4$, and was adjusted to $\mathrm{pH} \mathrm{7.0.} \mathrm{Incubation} \mathrm{was}$ at $35^{\circ} \mathrm{C}$ for 6 hours. 
The BASIC ether extracts were chromatographed in IAmW and the results are shown in Table 39. After treatment with DMAC, a very weak purple band was found at $R f .90$ in all extracts except that from the dark-grown mung bean reaction system. This band might be IAAld but, if so, it was present in only very small amounts. However, a second crimson band was found on chromatograms of the tomato extracts at Rf.77 which reacted also with ninhydrin. These properties suggest that this band was tryptamine (Tam), a compound which was not found in any of the mung bean extracts. The identification of this compound as tryptamine was considerably strengthened by chromatography using BzAcW, in which both authentic Tam and the suspected band of Tam showed the same Rf. values and gave identical colour reactions with DMAC and ninhydrin. When the ability of tomato cytoplasmic supernatant and Sephadex-purified preparations to form Tam from TTP were compared, it was found that Tam was formed by both preparations. Activity was lost, however, when an attempt was made to precipitate the enzyme with $\left(\mathrm{NH}_{4}\right)_{2} \mathrm{SO}_{4} \cdot$ Although the amount of tryptamine formed is very low compared with the rate of IPyA formation by the same enzyme fractions, these results are of considerable interest because this represents one of the first real demonstrations of the decarboxylation of TTP to form Tam in a higher plant system.

Cytoplasmic supernatant preparations from tomato shoot tips were also tested for their ability to metabolise Tam and IPyA. With Tam as the substrate, no products were found in the NEUTRAL or ACID ether fractions and, therefore, no 


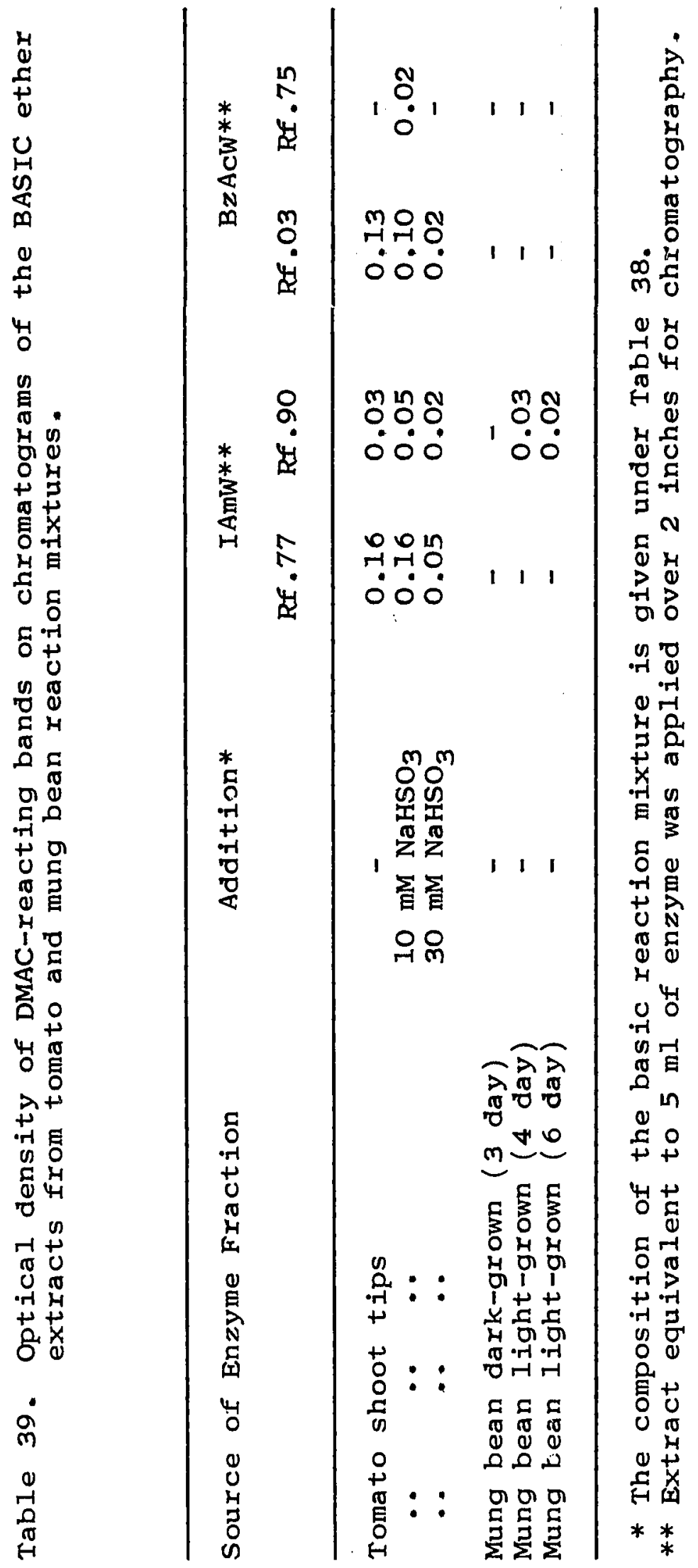


evidence was found for amine oxidase activity in tomato. With IPyA, many products including IAld, IAA and the unknown compound $x$ were found but the number and intensity of the bands were the same in the boiled enzyme system as in the normal (unboiled) system. Neither Tol nor IAAld were detected among these products and if these compounds were in fact formed enzymatically, they could represent only a very small proportion of the products formed non-enzymatically from IPyA. 
F. Activity of Enzyme Preparations from Light-grown Mung Beans

In the previous section it was shown that cytoplasmic supernatant preparations from tomato shoot tips and from light-grown mung beans were able to catalyse the formation of Tol from TTP, whereas a similar fraction from dark-grown mung beans did not have the capacity to form Tol. The tomato system was further investigated and it was shown that, in addition to Tol, the system also catalysed the decarboxylation of TTP to Tam. In this section the apparent difference in the ability of enzyme fractions from light-and dark-grown mung beans to form Tol was further investigated. BASIC ether extracts of the final reaction mixtures were also analysed for the presence of Tam and IAAld.

Table 40. Plant material used for comparison of light-and dark-grown mung beans.

\begin{tabular}{ccc}
\hline $\begin{array}{c}\text { Growth } \begin{array}{c}\text { in Dark } \\
\text { (days) }\end{array} \\
\text { Growth in Light } \\
\text { (days) }\end{array}$ & $\begin{array}{c}\text { Symbol } \\
\text { used: }\end{array}$ \\
\hline 5 & - & $3 \mathrm{D}$ \\
2 & - & $5 \mathrm{D}$ \\
2 & $1^{*}$ & $3 \mathrm{~L}$ \\
2 & $3^{*}$ & $5 \mathrm{~L}$ \\
\hline
\end{tabular}

* kept in high humidity box with continuous light. ** grown in growth cabinets. 
Five different samples of mung beans, grown either completely in the dark or for different periods of time in the light (Table 40), were ground in standard buffer and both cytoplasmic supernatant and SNS preparations were prepared in the usual manner. Each preparation was then tested for its ability to form Tol from ITP using exactly the same reaction conditions as those in the previous section. $\mathrm{NaHSO}_{3}$ was added to the final reaction mixture to give a concentration of $0.1 \mathrm{M}$ prior to extraction with ether so that any IAAld formed during the incubation period would be recovered in the BASIC ether fraction.

When the NEUTRAL ether extracts were chromatographed in IAmW, it was found that a number of other compounds all with Rf values around .85 prevented a determination of Tol. Chromatograms were therefore run in two directions using IAmW in the first direction, followed by $\mathrm{BzAcW}$ in the second. A blue spot corresponding to Tol was found on the chromatograms of extracts from the light-grown mung bean preparations but not from the dark-grown preparations. When extracts from the reaction mixtures containing the unsephadexed supernatant preparation were examined, the chromatograms from the lightgrown system again showed the presence of a blue band corresponding to the position of Tol. In both the 'Iight' and 'dark' extracts, a second purple band at Rf.73 was observed. On 2-directional chromatograms this compound was located at Rf.20 in BzAcW but no positive information on the identity of this compound is yet available. All chromatograms also contained a band of IAld. 
In the ACID ether extracts run in BzAcW, IAA and the unknown compound $\mathrm{X}$ were present on all chromatograms. The intensity of the spots was greatest in enzyme fractions from 12-day old mung beans. The entire BASIC ether extract, representing $10 \mathrm{ml}$ of enzyme fraction, was chromatographed in IAmW but neither IAAId nor Tam were detected on the chromatograms.

Aliquots of the reaction mixtures containing SNS enzyme were removed during the incubation period for a determination of glutamate formation. Although the $\mathrm{pH}$ of the reaction mixtures was 7.0 , the value of glutamate obtained can be taken as an index of relative transaminase activity. From the data (Table 41) it appears that the level of transaminase activity increased with the age of the plants in the light, whereas no significant increase in activity occurred in the dark-grown seedlings.

Table 41. Relative TTP-transaminase activity of 1ight-and dark-grown mung beans.

\begin{tabular}{lr}
$\begin{array}{l}\text { Type of Plant Material } \\
\text { used to prepare } \\
\text { Enzyme Fraction }\end{array}$ & $\begin{array}{l}\text { Glutamate For } \\
\text { nmoles/min./ml }\end{array}$ \\
\hline 3D & 4.84 \\
5D & 5.36 \\
3L & 5.02 \\
5L & 11.60 \\
\end{tabular}

* The reaction mixtures contained $30 \mathrm{mM}$ TTP, $10 \mathrm{mM} \alpha-\mathrm{KG}, 0.1 \mathrm{mM}$ pyridoxal phosphate, $0.24 \mathrm{mM}$ thiamine pyrophosphate and $1 \mathrm{mM}$ $\mathrm{MgSO}_{4}$, and was adjusted to $\mathrm{pH} 7.0$. Incubation was at $35^{\circ} \mathrm{C}$ for 6 houns. 
The ability of each SNS enzyme fraction to oxidise and reduce IAAld was also determined in a separate experiment. The results, presented in Table 42, show that Tol formation was greatest in the 3D seedlings, but there was significant activity in all fractions. IAA formation was greatest in both the $3 \mathrm{D}$ and $3 \mathrm{~L}$ seedlings. There was a reduction in the 5-day seedlings and a further reduction at 12 days. However, it is clear that all extracts contained both aldehyde and alcohol dehydrogenase activity. Both cytoplasmic supernatant and SNS enzyme fractions were also tested for their ability to metabolise Tam, but no reaction products were detected on chromatographic analysis of ether extracts from the final reaction mixture.

Table 42. Evidence of aldehyde and alcohol dehydrogenase activities in light - and dark-grown mung beans.

Type of Plant Material used to prepare

IAA ( $\mu \mathrm{g} / \mathrm{ml}$ enzyme)
To1 ( $\mu \mathrm{g} / \mathrm{mI}$ enzyme)

Enzyme Fraction*

$\begin{array}{rr}3 \mathrm{D} & 8.6 \\ 5 \mathrm{D} & 2.7 \\ 3 \mathrm{~L} & 8.6 \\ 5 \mathrm{~L} & 2.7 \\ 12 \mathrm{~L} & 1.3\end{array}$

* The reaction mixtures contained $1 \mathrm{ml}$ of the appropriate enzyme fraction, $3.8 \mathrm{mM}$ IAAld-bis, $1.5 \mathrm{mM}$ NAD and $1.5 \mathrm{mM}$ $\mathrm{NADH}_{2}$. The final volume was $1.5 \mathrm{ml}$ and the $\mathrm{pH}$ was 7.5 . The reaction mixtures were incubated at $35^{\circ} \mathrm{C}$ for 3 hours. 
A more detailed study was made of the activity of enzyme preparations from 12-day old mung bean seedlings which had been grown for 2 days in the dark and then for 10 days under fluorescent light in a growth cabinet. Only the aboveground portion of the plants $(500 \mathrm{~g})$ were chilled to $4^{\circ} \mathrm{C}$ and ground in $250 \mathrm{ml}$ of standard buffer at $\mathrm{pH} 7.5$. The brei was squeezed through cheesecloth and centrifuged once at $40,000 \times \mathrm{g}$ for $30 \mathrm{~min}$. to obtain a cytoplasmic supernatant fraction. A $200 \mathrm{ml}$ sample of this fraction was purified by passage through a large column of Sephadex G-25 (4.7 cm x $50 \mathrm{~cm})$.

In order to determine whether Tol and IAAld were formed from TTP by enzymes in this SNS preparation, reaction mixtures were set up containing $40 \mathrm{ml}$ aliquots of either the unsephadexed supernatant, the SNS preparation or a boiled aliquot of SNS. AII reaction mixtures contained $30 \mathrm{mM} \mathrm{TTP}, 10 \mathrm{mM} \alpha-\mathrm{KG}$, $0.1 \mathrm{mM}$ pyridoxal phosphate, $0.2 \mathrm{mM}$ thiamine pyrophosphate and $0.9 \mathrm{mM} \mathrm{MgSO}_{4}$. In addition, $1.5 \mathrm{mM} \mathrm{NADH} 2$ was added to one reaction mixture and $30 \mathrm{mM} \mathrm{NaHSO}$ was added to another. The final pH of all mixtures was adjusted to 7.0. At this $\mathrm{pH}$, transamination of TTP would occur at about 50\% the rate at $\mathrm{pH}$ 8.5, but the lower $\mathrm{pH}$ should favour decarboxylation of IPyA to IAAld and also the reduction of IAAId to Tol. Aliquots of the reaction mixtures were removed at 0,2 , 4, and 6 hours to determine glutamate formation as a measure of transamination. These results are shown in Table 43. Glutamate formation with the unsephadexed enzyme was very high, but this represents transamination of other endogenous amino acids as well as tryptophan. In the boiled enzyme system no 
glutamate formation was detected. The rate of transamination was reduced by $40 \%$ when $30 \mathrm{mM} \mathrm{NaHSO}$ was added to the reaction mixture. It is clear from the results, however, that an active TTP-transaminase was present in all reaction mixtures except the one with boiled SNS.

Table 43. Evidence for transaminase activity in cytoplasmic supernatant fractions from 12-day old mung bean seedlings.

Enzyme Preparation used in the Reaction System*
MMoles Glutamate/ml Enzyme after:

$0 \mathrm{hr} \quad 2 \mathrm{hr} \quad 4 \mathrm{hr} \quad 6 \mathrm{hr}$

\begin{tabular}{|c|c|c|c|}
\hline $\begin{array}{l}\text { Unsephadexed supernatant } \\
\text { SNS } \\
\text { SNS plus } 1.5 \mathrm{mM} \mathrm{NADH}{ }_{2} \\
\text { SNS plus } 30 \mathrm{mM} \mathrm{NaHSO} 3 \\
\text { SNS (boiled) }\end{array}$ & $\begin{array}{l}0 \\
0 \\
0 \\
0 \\
0\end{array}$ & $\begin{array}{l}3.10 \\
1.19 \\
2.06 \\
1.58 \\
0\end{array}$ & $\begin{array}{l}5.28 \\
3.38 \\
3.81 \\
2.56 \\
0\end{array}$ \\
\hline
\end{tabular}

* A11 reaction mixtures contained $30 \mathrm{mM}$ TTP, $10 \mathrm{mM} \alpha-\mathrm{KG}$, $0.1 \mathrm{mM}$ pyridoxal phosphate, $0.2 \mathrm{mM}$ thiamine phosphate, and $0.9 \mathrm{mM} \mathrm{MgSO}_{4}$ in $0.1 \mathrm{M}$ phosphate buffer at $\mathrm{pH} 7.0$.

Reaction mixtures were also prepared with the unsephadexed supernatant and SNS preparations using IAAId as substrate in the assay for aldehyde and alcohol dehydrogenase activity. The results of this assay, presented in Table 44 , show that both enzyme preparations contained the two dehydrogenases. In a further experiment, Tam was used as substrate, but on subsequent ether extraction and chromatography, no products of Tam deamination or oxidation could be detected. 
Table 44. Evidence for aldehyde and alcohol dehydrogenase activities in cytoplasmic supernatant fractions from 12-day old mung bean seedlings. Activity was measured by the indole product assay procedure.

Reaction System* contained:

Unsephadexed supernatant SNS
IAA

( $\mu \mathrm{g} / \mathrm{ml}$ enzyme) $\quad(\mu \mathrm{g} / \mathrm{m} 1$ enzyme)

* Each reaction sytem contained $1 \mathrm{ml}$ enzyme fraction, $3.8 \mathrm{mM}$ IAAId-bis, $1.5 \mathrm{mM} \mathrm{NAD}$ and $1.5 \mathrm{mM} \mathrm{NADH} 2$ at $\mathrm{pH} 7.5$. The reaction mixture was incubated at $35^{\circ} \mathrm{C}$ for 3 hours.

The reaction mixtures described above (Table 43) for the determination of transaminase activity were extracted for free indoles at the end of the 6-hour incubation period after $\mathrm{NaHSO}_{3}$ had been added to all the mixtures to a concentration of $0.1 \mathrm{M}$ to trap any IAAId formed as the bisulphite addition product. NEUTRAL, ACID and BASIC ether extracts were then prepared in the usual way. These extracts were analysed by paper chromatography and the indole products were revealed on the chromatograms by treatment with DMAC reagent.

\section{NEUTRAL ether extracts}

Aliquots of these extracts were first chromatographed in IAmW. A DMAC-reacting zone was found at Rf.90 in a 11 extracts except that from the reaction mixture containing boiled enzyme (Table 45). Although the Rf was identical with that of authentic Tol, it was clear from the grey-blue colour of the band that there was another compound present. In the 


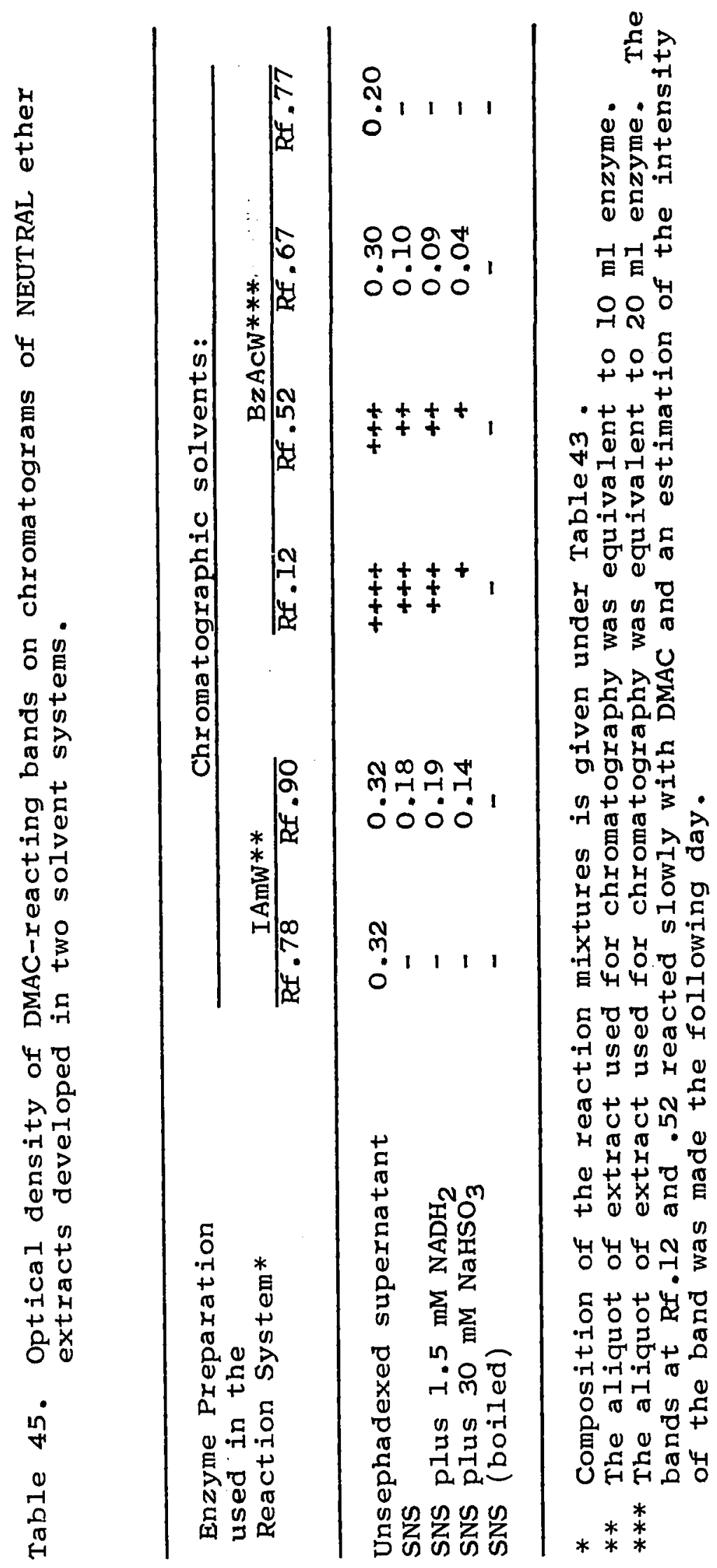


extract from the reaction mixture containing unsephadexed enzyme, a second purple DMAC-reacting zone was found at Rf.78. Aliquots of the extracts were then chromatographed in BzAcW. Tryptophol was found as a characteristic blue band at Rf.67 in all extracts except that from the boiled control. There was a marked reduction in Tol formation in the mixture containing SNS enzyme, and $\mathrm{NADH}_{2}$ did not increase the amount of Tol formed when it was added to the reaction mixture with SNS enzyme. $\mathrm{NaHSO}_{3}$ brought about a further reduction in Tol formation. A purple band was found at $R f .79$ in the extract from the reaction mixture containing unsephadexed enzyme. This band probably represents the compound previously detected in this extract at Rf.78 in IAmW.

In addition to these bands, two other bands were detected. One at Rf:12 reacted with DMAC to give a grey-blue colour which became more intense over several hours. The identity of this compound is not known. The other at $\mathrm{Rf} .52$ reacted slowly with DMAC to give blue-green colour overnight and with DNPH, an immediate red-brown colour was obtained which strongly suggested that this band was IAld. A further aliquot of the extract from the unsephadexed enzyme reaction mixture was chromatographed in BzAcE. The four bands detected in this extract were eluted with methanol and UV spectra were recorded.

The band eluted at $\mathrm{Rf} .52$ had a spectrum characteristic of IAld (Figure 31), giving further confirmation of the identity of this band. The eluate of the Tol band at Rf.67 had a typical indole spectrum (Fig. 31). When this spectrum 


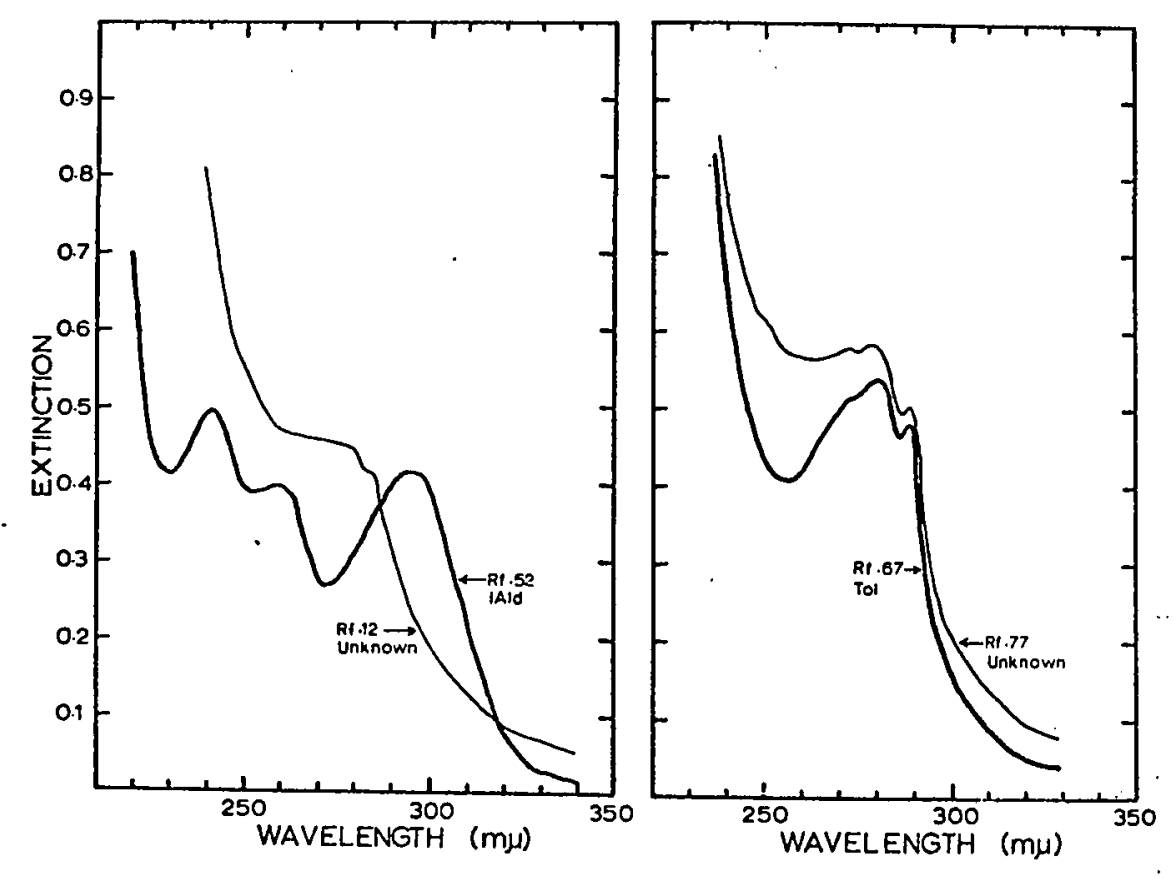

Figure 31. UV spectra of compounds eluted from chromatograms of NEUTRAL ether extract developed in BzAcW. Compounds were eluted at the following Rf's: .12, unknown; .52, IAld; .67, Tol; .77 , unknown. 
is considered in conjunction with the $R f$ of this band in two solvent systems and the characteristic colour reaction with DMAC, there can be little doubt that this band is Tol.

The spectrum of the eluate of the band at Rf.77 is also quite characteristic of an indole compound (Fig. 31). Its Rf in BzAcW is similar to IAAld, but since $\mathrm{NaHSO}_{3}$ was added to the reaction medium before extraction with ether, any IAAld present would be expected to appear in the BASIC ether extract. The $\mathrm{Rf}$ of this band and its purple colour reaction with DMAC are very similar to those shown by unknown compound $Y$, found previously in neutral ether extracts of reaction mixtures containing mung bean SNS enzyme and using TTP as substrate ( $p .136)$.

The spectrum of the band at $R f .12$ is also shown in Figure 31. Although there may be a contaminant present, the spectrum, with a peak at $278 \mathrm{m \mu}$ and a shoulder at $284 \mathrm{m \mu}$, suggests that this compound is also an indole but its identity is unknown.

\section{ACID ether extracts}

Although $\mathrm{NaHSO}_{3}$ was added to the reaction mixture prior to extraction, a small amount of IPyA might still be present in the ACID ether extract; therefore, these extracts were only chromatographed in BzAcW. Three bands were detected in all extracts except that from the boiled enzyme reaction mixture in which no bands were found. The Rf and colour reaction of two of these bands coincided exactly with those shown by authentic IAA and IPyA. The thizd band at Rf.24 has 
been referred to previously as unknown compound $\mathrm{X}$. The optical density of each band was recorded with the Photovolt densitometer and the results are presented in Table 46.

Table 46. Optical density of DMAC-reacting bands on chromatograms of ACID ether extracts developed in $\mathrm{BzACW}$.

Enzyme Preparation used in the Reaction Mixture*
Optical Density of Band** at:

$\begin{array}{ccc}R f .24 & R f .43 & R f .66 \\ \text { compound } X) & \text { (IPyA) } & \text { (IAA) }\end{array}$

\begin{tabular}{|c|c|c|c|}
\hline $\begin{array}{l}\text { Unsephadexed supernatant } \\
\text { SNS } \\
\text { SNS plus } 1.5 \mathrm{mM} \mathrm{NADH} 2 \\
\text { SNS plus } 30 \mathrm{mM} \mathrm{NaHSO} 3 \\
\text { SNS (boiled) }\end{array}$ & $\begin{array}{l}0.60 \\
0.54 \\
0.55 \\
0.45 \\
-\end{array}$ & $\begin{array}{l}0.21 \\
0.27 \\
0.27 \\
0.13 \\
-\end{array}$ & $\begin{array}{l}1.00 \\
0.43 \\
0.45 \\
0.48 \\
-\end{array}$ \\
\hline
\end{tabular}

* The composition of the reaction mixture is given under Table 43.

* The aliquot of extract used for chromatography was equivalent to $10 \mathrm{mI}$ enzyme.

It can be seen that more IAA was formed by the unsephadexed supernatant than by the SNS preparation, and also that the addition of $\mathrm{NaHSO}_{3}$ did not reduce IAA formation. It was shown that Tol formation was reduced by the addition of $\mathrm{NaHSO}_{3}$ and this suggests that Tol was being produced via IAAld as an intermediate, whereas IAA was not being formed via IAAld. UV spectra were obtained from methanol eluates of each of the bands and were compared with spectra of eluates of authentic IPyA and IAA run on adjacent chromatograms. The spectrum of the suspected IAA band is identical with that of 
authentic IAA and also with that of the unknown compound $X$ (Fig. 32). The spectrum of the suspected IPyA band was also identical with that of authentic IPyA. It should be noted that this spectrum is of the enol tautomer of IPyA (Schwarz, 1961), although in the reaction mixture the keto tautomer would have predominated (Spencer and Knox, 1962).

\section{BASIC ether extracts}

Aliquots of these extracts were first chromatographed in IAmW. No DMAC-reacting bands were detected in the extract of the boiled enzyme preparation and only a faint DMACpositive band was found at $R f .90$ in extracts of both the unsephadexed and sephadexed pxeparation (Table 47). However, a distinct purple band at Rf.90 was found on the chromatogram of the extract from the reaction mixture containing $30 \mathrm{mM}$ $\mathrm{NaHSO}_{3}$, coinciding in colour and appearance with authentic IAAld. When the BASIC extracts were chromatographed in BzAcW, the only DMAC-reacting band was at Rf.75 (Table 47). This band was very faint except from the extract of the reaction mixture containing $30 \mathrm{mM}$ bisulphite. On this chromatogram a distinct purple band was found which again coincided exactly with the Rf of authentic IAAld. The colour reaction and shape of the band were also identical with that of IAAld.

When chromatograms developed in BzAcW were sprayed with the DNPH reagent, a yellow band appeared at $\mathrm{Rf} .75$ on the chromatogram of the extract from the reaction mixture containing $30 \mathrm{mM} \mathrm{NaHSO}$. Authentic IAAld gave a similar yellow band 


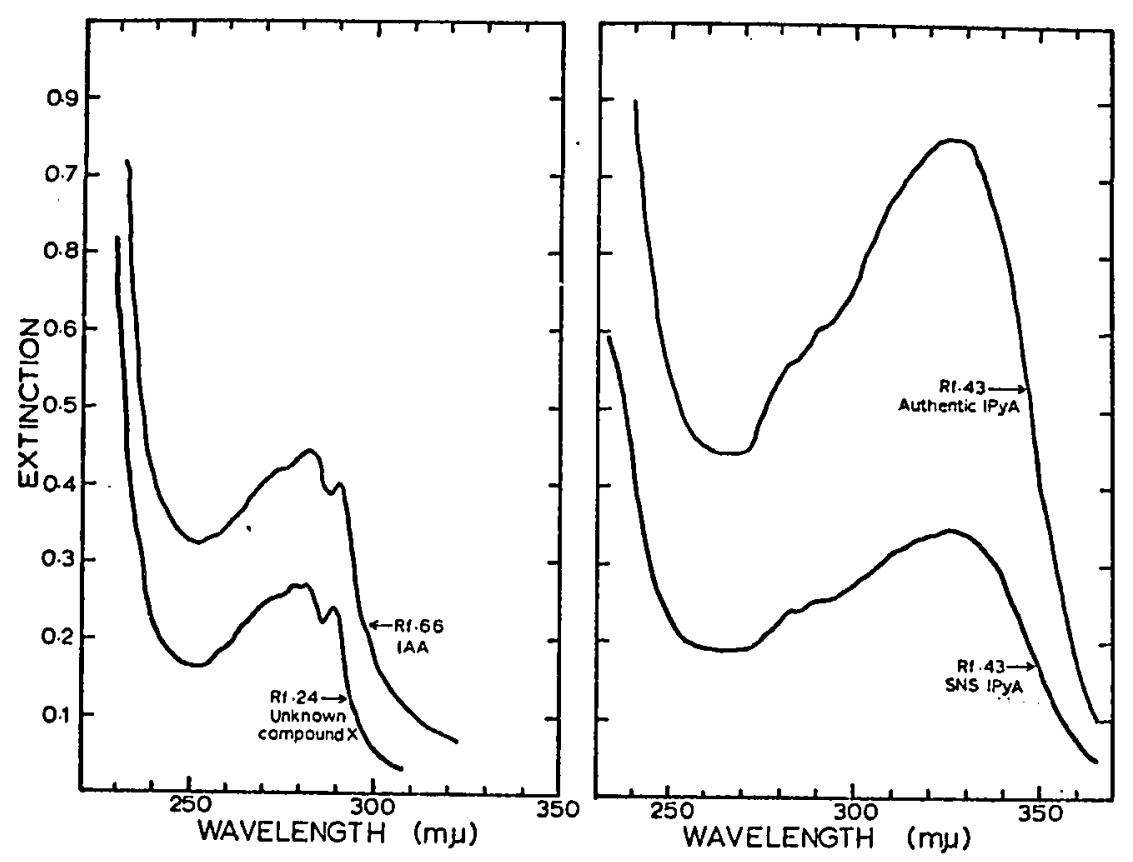

Figure 32. UV spectra of compounds eluted from chromatograms of ACID ether extracts developed in BzACW. Compounds were eluted at the following Rf's: .24 , unknown compound $x$; .66, IAA; .43, IPyA. For comparison, the spectrum of a sample of authentic IPyA, also eluted from a BzAcW chromatogram, is shown. 
Table 47. Optical density of DMAC-reacting bands on chromatograms of the BASIC ether extracts developed in two solvent systems.

Enzyme Preparation used in the Reaction Mixture*
Chromatographic solvents: $\operatorname{IAmW**}$ RI .90
$\mathrm{B} z A C W^{* * *}$

Rf .75

\section{Unsephadexed supernatant SNS \\ SNS plus $1.5 \mathrm{mM} \mathrm{NADH} 2$ \\ SNS plus $30 \mathrm{mM} \mathrm{NaHSO}$ \\ SNS (boiled)}

$$
\begin{aligned}
& 0.03 \\
& 0.04 \\
& 0.02 \\
& 0.13
\end{aligned}
$$

* The composition of the reaction mixture is given under Table 43.

** The aliquot of extract used for chromatography was equivalent to $10 \mathrm{ml}$ enzyme.

*** The aliquot of extract used for chromatography was equivalent to $20 \mathrm{ml}$ enzyme.

at the same Rf. The hydrazone bands of both the suspected IAAId and authentic IAAld were eluted with methanol and the eluates were chromatographed on a ILC-plate using BzE as the solvent. The suspected IAAld-DNPH co-chromatographed identically with the authentic IAAId-DNPH. In summary then, this result clearly demonstrates that IAAld was formed in the reaction mixture when TTP was used as substrate and that the IAAld could be trapped as the bisulphite adduct by the addition of $30 \mathrm{mM} \mathrm{NaHSO}$ to the reaction mixture. 


\section{DISCUSSION}

In recent years several workers have questioned whether higher plant tissues are able to convert tryptophan to IAA and they maintain that previous experiments have not taken adequate precautions to exclude the metabolic effects of bacterial contaminants (Libbert et al., 1966; Winter, 1966; Thimann and Grochowska, 1968). The case for this hypothesis was recently presented in two papers by Wichner and Libbert $(1968 a, b)$.They claim that when sterile plant tissues are used as a source of enzyme there is almost no conversion of TTP to IAA. In support of the hypothesis that bacteria are responsible for the conversion of TTP to IAA in extracts from non-sterile tissues, they show a stimulation of IAA formation by glucose, isolate bacterial strains which can form IAA from TTP, and show that antibiotics do not completely inhibit the IAAproducing activity of bacteria in short-term experiments. These authors also disclaim previous work from their own laboratory (Libbert, 1960; Libbert and Brunn, 196I) which claimed to demonstrate the formation of both Tam and IPyA in reaction mixtures containing pea seedling homogenates as a source of enzyme.

In the present work it is considered tha' most of the arguments of Wichner and Libbert do not apply for the following reasons:

1) Libbert and coworkers used only a low speed centrifugation $(1,800 \times \mathrm{g}$ for $15 \mathrm{min.})$ to prepare their 
enzyme preparation, whereas centrifugation at $35,000 \times \mathrm{g}$ for $30 \mathrm{~min}$. was used in the present work which would sediment most bacteria.

2) Libbert and coworkers used crude enzyme preparations without dialysis or gel filtration. In the present work, gel filtration through columns of Sephadex G-25 was used as a standard purification procedure.

3) Libbert and coworkers did not add any cofactors or $\alpha-K G$ to their reaction mixtures. In the present experiments, cofactors and reaction conditions were modified depending on the particular reaction under study in order to achieve rapid reaction rates which were linear with time.

4) In the present work partial purification of several of the enzymes was achieved. High speed supernatant preparations were used in this work and, moreover, the ammonium sulphate precipitates were dissolved, clarified by centrifugation and desalted by passage through a column of Sephadex G-25 before use.

In a recent study of the effect of bacterial. contamination on tryptophan metabolism in cell free systems, Gibson and Wightman (1968) prepared enzyme fractions from plants grown under sterile conditions and these preparations were then passed through a Millipore bacterial filter to ensure complete sterility. Both the original plants and enzyme preparations were checked for sterility by standard bacteriological procedures. The sterile enzyme preparation was 
found to exhibit identical transaminase activity to a supernatant fraction prepared as described in the present work and with both fractions, the rate of transamination was linear with time. Furthermore, Gibson and Wightman also demonstrated that bacteria in the supernatant fraction prepared from non-sterile plants were removed by filtration through a column of Sephadex G-25. In view of these additional findings, the present author feels that the arguments favouring the metabolic effects of bacterial contaminants in enzyme studies of this kind, are not applicable in relation to the present results.

The present work has investigated the intracellular distribution of TTP-transaminase using both etiolated mung bean seedlings and tomato shoot tips as a further development of the work by Wightman and Fowden (1966). These workers showed that an enzyme extracted from the mitochondria of etiolated mung bean seedlings could readily transaminate L-tryptophan. In both mung bean seedlings and tomato shoot tips it was found that over $90 \%$ of the TTP-transaminase activity was present in the cytoplasmic supernatant, but that 5-10\% of the activity was clearly associated with a mitochondrial fraction.

The cytoplasmic supernatant transaminase was investigated further and was partially purified using ammonium sulphate fractionation. If inactive protein in the extracts of mung bean seedlings was first precipitated with $\mathrm{MnCl}_{2}$, subsequent ammonium sulphate fractionation resulted in a 6-fold increase 
in specific activity. With a cytoplasmic supernatant preparation from tomato stem tips a 7-fold purification was achieved.

Further purification of the transaminase from mung bean seedlings was also achieved by the use of Sephadex G-200 chromatography. In one experiment the specific activity of TTP-transaminase in the most active eluates was 13-fold greater than the activity in the original supernatant. Gamborg and Wetter (1963) achieved a 17-fold purification of an aromatic amino acid transaminase from light-grown mung beans, but it is of interest that they were unable to recover any activity following ammonium sulphate precipitation.

Using the cytoplasmic supernatant enzyme from mung bean seedlings it was shown that there was almost no transaminase activity if pyruvate or oxalacetate were used as amino-group acceptors. This result agrees with the findings of Wightman with the mitochondrial enzyme (Wightman and Cohen, 1968). However, Gamborg and Wetter (1963) showed that the aromatic amino acid transaminase from light-grown mung beans used $\alpha-K G$ and pyruvate at the same rate. It therefore appears that there may be more than one TTP-transaminase on the mung bean, one of which is more active than the other with $\alpha-K G$ as the amino-group acceptor.

Furthermore, the activity of the enzyme which accepts pyruvate appears to be very low in the etiolated 4-day old seedlings but increases in the light-grown seedlings (Gamborg and Keeley, 1966). In the present study, the activity of 
the TTP-transaminase with $\alpha-K G$ as the amino-group acceptor was also shown to increase in light-grown mung bean seedlings, but these enzyme preparations were not tested with pyruvate as the amino-group acceptor. A complete study of the substrate specificity of the aromatic amino acid transaminases in mung bean tissues would be desirable.

Recent work in this laboratory has demonstrated the presence of TTP-transaminase in cabbage, wheat, scarlet runner beans and sunflower. The widespread occurrence of the enzyme in plant tissues indicates that this enzyme may play a very important role in the biosynthesis of auxin. The tissues examined in this laboratory have been used by other workers but the presence of the transaminase has not previously been recognised.

The presence of 3 -indolepyruvic acid in the final reaction mixtures containing SNS enzyme was clearly demonstrated by extracting the acid as its 2,4-dinitrophenylhydrazone, IPyA-DNPH. Thin-layer chromatographic methods were developed for separating neutral and acid hydrazones and it was shown that IPyA-DNPH exists in two forms. It is believed that the two forms represent geometric isomers about the $\mathrm{C}=\mathrm{N}$ band. This type of isomerisation has previously been shown for other $\alpha$-keto acid hydrazones (Isherwood and Cruikshank, 1954). The two isomers of IPyA-DNPH differ in their Rf, colour and UV spectra, and differences in the IR spectra were also noted. The UV spectra of both isomers showed a characteristic indole spectrum in addition to the 
absorption peak due to the hydrazone moeity and bands of both isomers gave a purple colour reaction with the DMAC reagent. The yellow form appears to be favoured kinetically but partial conversion to the orange form takes place whenever a sample of the yellow form is chromatographed in an acid-containing solvent. IPyA was also extracted from reaction mixtures as the free acid. However, if the SNS preparations were not purified through Sephadex G-25, the amount of IPyA present at the end of the incubation perfod was reduced considerably and a large increase in the levels of IAA, IAId and ICA was noted.

In view of the inability of most previous workers to detect IPyA as a reaction product in enzyme studies, it was of considerable interest in the present work to find that this compound accumulated in the transaminase reaction mixtures. Several factors can be cited to account for this. Firstly, when enzyme preparations are purified through Sephadex G-25, low molecular weight compounds which act as cofactors for peroxidase and other oxidative enzymes are removed. Secondly, the rate of transamination in the present experiments was 2-3\% of added tryptophan over a 6 hour period. With the more active ammoniur sulphate fractions, this conversion was increased to as high as $15 \%$. These values should be contrasted with the low rate of formation of IAA noted by earlier workers. A third point is the apparent stabilisation of IPyA in the proteinaceous reaction mixture. Although IAA and IAld were also found among the reaction 
products, their concentration was less than $10 \%$ that of IPyA unless unsephadexed enzyme was used.

In contrast, when attempts were made to use synthetic IPyA as a substrate, even at concentrations comparable to those found in the transaminase reaction mixture, spontaneous decomposition was always a problem. This breakdown of synthetic IPyA was evident during the preparation of the reaction mixtures and continued throughout the reaction period. A direct investigation of the enzymatic decarboxylation of IPyA has therefore proven very difficult. The addition of $\mathrm{NaHSO}_{3}$ to reaction mixtures reduced breakdown of IryA during the reaction period, but this treatment did not appear to alter the nature of the products. No enhancement or modification of the products was detected in the presence of enzyme fractions prepared from either etiolated mung bean seedlings or tomato stem tips when IPyA was used as substrate.

In an effort to overcome some of these problems, reaction systems were prepared in which IPyA was produced enzymatically by transamination of TTP and a study was made of the formation of neutral indole compounds in these reaction systems. When light-grown mung bean seedlings were used as a source of enzyme it was possible to demonstrate the formation of a compound identified as IAAld if $30 \mathrm{mM} \mathrm{NaHSO} \mathrm{H}_{3}$ was present in the reaction mixture during the incubation period. Identification of the compound as IAAld rests on the Rf value of the compound in two solvent systems and the formation 
of a 2,4-dinitrophenylhydrazone which co-chromatographed identically with authentic IAAId-DNPH on thin-layer chromatography.

Tryptophol was also formed from TTP when either tomato shoot tips or light-grown mung bean seedlings were used as a source of enzyme, but was not detected when dark-grown mung beans were used as a source of enzyme. The addition of $\mathrm{NaHSO}_{3}$ to the reaction medium reduced the amount of Tol formed which strongly suggests that the IAAld was the immediate precursor. Since Tol formation was never demonstrated when IPyA was used as substrate the possibility must be considered that IAAld can arise directly from TTP. Gordon (1961) suggested a mechanism for the formation of IAAld from TTP by the strecker degradation of $\alpha$-amino acids by dicarbonyls as shown below:

$\underset{\mathrm{O}}{-\mathrm{C}}-\underset{\mathrm{O}}{\mathrm{C}}-\mathrm{I}-\mathrm{CH}_{2}-\underset{\mathrm{NH}_{2}}{\mathrm{CH}}-\mathrm{COOH} \longrightarrow \mathrm{I}-\mathrm{CH}_{2}-\mathrm{CHO}+\mathrm{NH}_{3}+\mathrm{CO}_{2}+\underset{\text { OेH Oे }}{\mathrm{C}}=\underset{\mathrm{O}}{\mathrm{C}}$

This type of reaction would account for the proposed formation of IAAld from TTP using enzyme preparations from X-irradiated mung bean seedlings (Gordon, 1956), but Gordon and Paleg (1961) showed that the product of the reaction between orthoquinones and TTP was IPyA, not IAAld. In the present work, the possibility remains that a small amount of Tol may have been formed from IPyA but its presence was masked by some of the unknown breakdown products of IPyA. Hope (1963) demonstrated that Tol was formed when TTP-3- ${ }^{14} \mathrm{C}$ was fed to tomato shoots and Wightman (1964) 
extended this work by showing that Tol was also formed if 3-indolelactic acid (ILA) was fed to tomato shoots. On the bas is of these results it was suggested that ILA was decarboxylated to Tol in this tissue. Enzymatic decarboxylation of an $\alpha$-hydroxyacid has not been demonstrated, whereas the decarboxylation of an $\alpha$-ketoacid such as pyruvate is known and the reaction mechanism depends on nucleophillic attack of the $\alpha$-carbon by thiamine pyrophosphate. Since the $\alpha$-carbon of ILA is not easily susceptible to nucleophillic attack it is Iikely that ILA is oxidised to IPyA prior to decarboxylation. Gamborg, Wetter and Neish (1962) have demonstrated this reaction using glycollate oxidase and Gibson and Wightman (1968) have demonstrated the $\mathrm{NADH}_{2}$-dependent reduction of IPyA to ILA. This latter reaction is probably catalysed by an $\alpha$-ketoacid reductase (c.f. Weber and Zannoni, 1968) and furthermore, is probably reversible.

The presence of an NAD-dependent alcohol dehydrogenase in mung beans and tomatoes has been demonstrated in this thes is and the action of this enzyme would account for the formation of Tol in plant tissue. It is therefore suggested that the results of Hope (1963) and Wightman (1964) can be taken as strong supporting evidence for the formation of IAAId from IPyA in vivo.

The most significant findings of the present study arise from an investigation of the metabolism of IAAld. Two NADdependent enzymes were clearly demonstrated; one of these, aldehyde dehydrogenase, catalysed the oxidation of IAAld to 
IAA and the other, alcohol dehydrogenase, catalysed the reduction of IAAld to Tol. Both enzymes were located in the cytoplasmic supernatant fraction, although a small percentage of the activity may be associated with the mitochondrial fraction. It was found that the addition of 2-mercaptoethanol to al1 media prevented inactivation of these enzymes during purification. The enzymes were concentrated and partially purified by ammonium sulphate fractionation with the greatest activity being recovered in the 50-60\% fraction for both enzymes. Separation of the enzymes was achieved by pH fractionation. With this procedure, aldehyde dehydrogenase was precipitated between $\mathrm{pH} 5.0$ and 4.2 with a 10-fold increase in purification, whereas the activity of alcohol dehydrogenase was rapidly lost when the $\mathrm{pH}$ was reduced below 5.5 .

Following $\mathrm{MnCl}_{2}$ precipitation of inactive protein, the aldehyde dehydrogenase of etiolated mung beans was recovered in two distinct ammonium sulphate fractions, $0-40 \%$ and 50-60\%. On the other hand, the enzyme from tomato shoot tips was recovered equally in the 0-40\% and 40-50\% fractions. It is not known whether there is more than one enzyme present or whether there is a difference between the enzyme in the two plants examined. The enzyme from mung beans which precipitated in a 40-60\% ammonium sulphate fraction was chromatographed on columns of Sephadex G-200 and an approximate molecular weight of 112,000 was determined. The properties of the enzyme precipitating in the $0-40 \%$ fraction 
were not examined by Sephadex G-200 chromatography. The activity of aldehyde dehydrogenase was always much less than the activity of alcohol dehydrogenase in any of the enzyme preparations examined and the only assay for this enzyme measured the formation of IAA from IAAld over a 3 hour period. The substrate specificity of the aldehyde dehydrogenase has therefore not been determined. Using the methods outlined in this work, it should now be possible to prepare an enzyme fraction, free from alcohol dehydrogenase, in which aldehyde dehydrogenase activity could be measured by a spectrophotometric determination of $\mathrm{NADH}_{2}$ formation. The activity of alcohol dehydrogenase in cytoplasmic supernatant preparations from etiolated mung beans was determined using a spectrophotometric assay of $\mathrm{NADH}_{2}$ utilisation. By the use of two substrates, IAAld and propionaldehyde, it was demonstrated that there must be more than one alcohol dehydrogenase present, one of which was more active with IAAld as substrate. Partial separation of the enzymes was achieved by ammonium sulphate fractionation which showed that the 40-50\% and 50-60\% fractions were both highly active towards propionaldehyde, whereas activity towards IAAld was found predominantly in the 50-60\% fraction. Even in this fraction the activity towards IAAld was only 1\% the rate towards propionaldehyde. The results of chromatography through Sephadex G-200 also indicate the presence of more then one enzyme. 
One feature of the alcohol dehydrogenase was the rapid decline in reaction rate observed both in the spectrophotometric assay and the assay for Tol formation. In the case of the spectrophotometric assay, the reaction rate declined after the first minute, or, with very active preparations, even after 15 seconds. In the case of the assay for Tol formation, when samples were removed at 15 min. Intervals it was observed that Tol formation had almost ceased by $30 \mathrm{~min}$. The reason for this decline in reaction rate was not determined but the cause may be either substrate or product inhibition of the enzyme. It was shown, however, that there was good correlation between the activity of alcohol dehydrogenase with IAAId as substrate, as measured by the initial rate of $\mathrm{NADH}_{2}$ utilisation, and the final level of Tol present in the reaction mixtures after a 3 hour incubation period.

A number of physical and catalytic properties of the alcohol dehydrogenases from etiolated mung bean seedlings were determined and they are presented in Table 48, trgether with comparable data for pea seedling alcohol dehydrogenase from a recent paper by Cossins et al. (1968). In the present work it was also demonstrated that Tol could be converted to IAA and that the enzymes catalysing this conversion were located in the 50-60\% ammonium sulphate fraction. Since IAA formation was inhibited $78 \%$ by the addition of $10 \mathrm{mM} \mathrm{NaHSO}$, it is suggested that IAAld was an intermediate in the conversion. To the author's knowledge, this is the first demonstration of the conversion of Tol to IAA in a cell free system. 
Table 48. A comparison of some properties of the alcohol dehydrogenase from mung bean and pea seedlings.

Mung Bean Pea*

$\mathrm{Km}$ values $(\mathrm{m})$ Ethanol

Acetaldehyde Propionaldehyde IAAld

$\mathrm{NADH}_{2}$
$2.0 \times 10^{-2}(\mathrm{pH} 9.5)$

$1.4 \times 10^{-3}(\mathrm{pH} 7.0)$

$4.0 \times 10^{-4}(\mathrm{pH} 7.0)$

$1.7 \times 10^{-5}(\mathrm{pH} 7.0)$

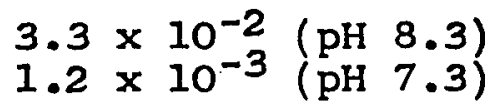

$6.6 \times 10^{-5}(\mathrm{pH} 8.5)$

Molecular weight

Acetaldehyde

Propionaldehyde

IAAId.

c. 60,000

c. 56,000

c. 24,000 , c. 186,000

* Data from Cossins et al. (1968)

To conclude, the enzymatic reactions studied in this work may be summarised as follows:

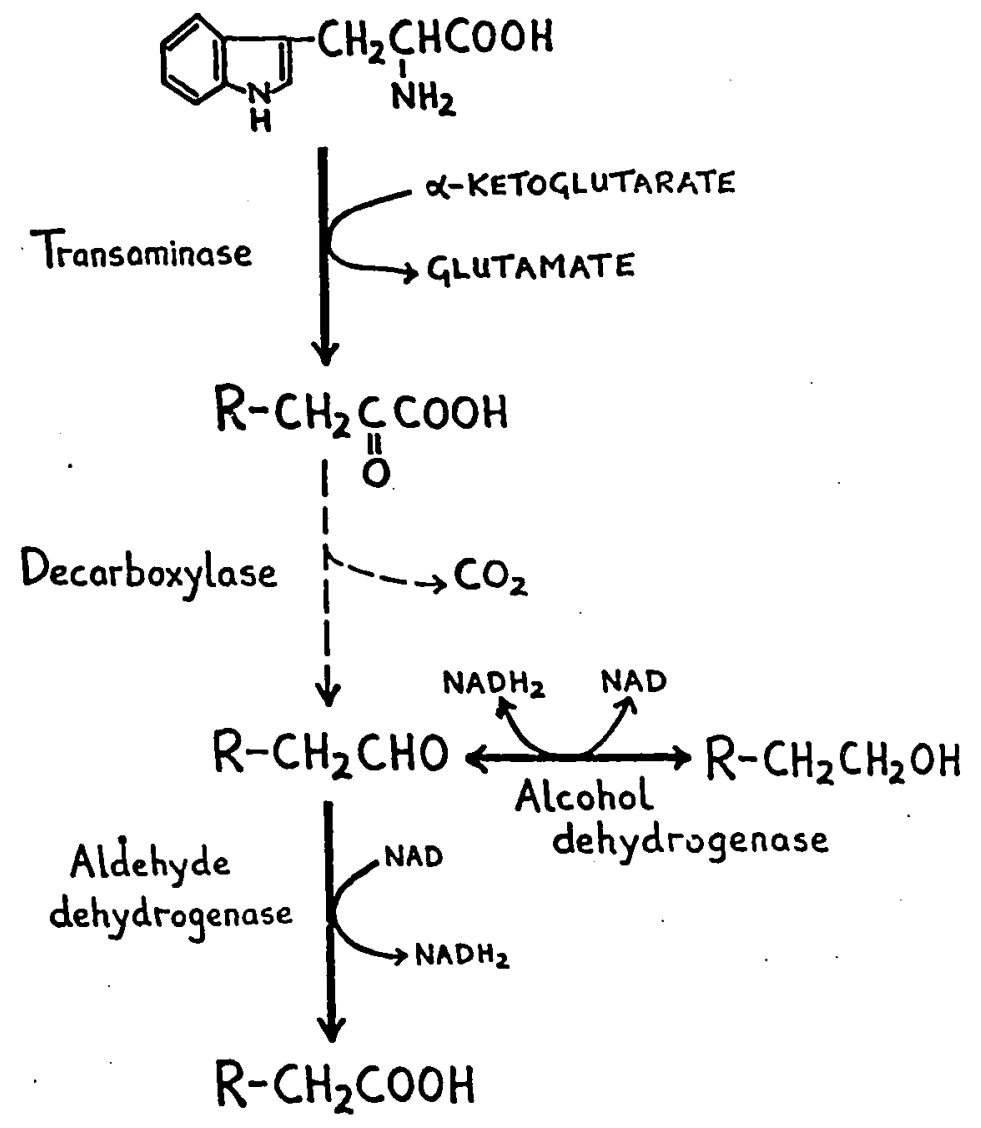


Evidence has been presented for the presence of a transaminase which catalyses the formation of IPyA from L-TTP and for two NAD-dependent enzymes which catalyse the formation of IAA and Tol from 3-indoleacetaldehyde. The intracellular localisation of these enzymes has been investigated and a partial purification of each of these enzymes has been achieved. Unequivocal evidence for the enzymatic decarboxylation of IPyA to IAAId is still lacking but there are several lines of evidence which point to this conversion. Although results from this type of study cannot be taken as proof of the activity of a particular enzyme in vivo, they do provide a sound basis for further study of the problem. 


\section{SUMMARY}

1. The intracellular localisation of tryptophan transaminase was studied using fractions prepared from both mung bean seedlings and tomato shoot tips. $90 \%$ of the enzyme activity was found in the cytoplasmic supernatant (SNS) after centrifugation at $35,000 \mathrm{x} g$ for 30 min. and less than $10 \%$ of the activity was found in the mitochondrial fraction.

2. $\alpha$-Ketoglutarate was found to be 12 times more effective than pyruvate as the amino group acceptor when the SNS preparation from mung bean seedlings was used as the source of transaminase enzyme.

3. Six-fold purification of TTP-transaminase was achieved by ammonium sulphate fractionation and further purification was achieved by gel filtration through Sephadex G-200.

4. From gel filtration studies using Sephadex G-200, the molecular weight of TTP-transaminase was estimated to be 56,000 .

5. The indole product of the reaction was extracted and identified as 3-indolepyruvic acid on the basis of chromatography and UV spectroscopy of both the free acid and its 2,4-dinitrophenylhydrazone. IR spectra were 
also recorded for the suspected IPyA-DNPH and were shown to be identical with that of authentic IPyA-DNPH.

6. When D-TTP was used as substrate, no glutamate was formed from $\alpha-K G$, indicating that TTP-transaminase was stereospecific for the L-isomer. However, a small amount of IAA was detected in the reaction medium and it is possible that other TTP-degrading enzymes are present.

7. In transaminase reaction mixtures, several other indole products were detected in addition to IPyA. These were IAA, ICA, IAAld and two unknown compounds, referred to as $\mathrm{X}$ and $\mathrm{Y}$.

8. Unknown compound $\mathrm{X}$ was an acidic indole and was shown to arise from IPyA even in the absence of an active enzyme fraction. Unknown compound $Y$ was a neutral indole and its formation was greatest by the $50-60 \%$ and $60-80 \%$ ammonium sulphate fractions. The identity of both of these compounds is not yet known.

9. Enzyme preparations from tomato shoot tips, but not from ming beans, catalysed the formation of a small amount of Tam from TTP, suggesting the presence of TTP-decarboxylase in tomato tissue. Activity was not lost on passage of the enzyme through Sephadex G-25, but no activity was recovered following ammonium sulphate fractionation. 
10. The intracellular locaiisation of enzymes which metabolise IAAld was also studied using cytoplasmic supernatant and mitochondrial enzyme fractions prepared from etiolated mung bean seedlings.

11. The presence of an aldehyde dehydrogenase and an a1cohol dehydrogenase catalysing the oxidation and reduction of IAAld respectively was clearly shown. Both enzymes were NAD-dependent and were located predominantly in the cytoplasmic supernatant fraction.

12. It was found necessary to add 2-mercaptoethanol to al1 media to prevent loss of dehydrogenase activity during purification procedures.

13. Aldehyde dehydrogenase from mung beans was precipitated mainly in the 50-60\% ammonium sulphate fraction with a $30 \%$ recovery, whereas the enzyme in tomato shoot tips was precipitated equally in the $0-40 \%$ and $40-50 \%$ fractions to give a total recovery of $50 \%$ of the enzyme activity.

14. Alcohol dehydrogenase activity was determined using two assay systems; one measured the formation of Tol from IAAld, and the second was a spectrophotometric assay which measured the initial rate of $\mathrm{NADH}_{2}$ utilisation when either IAAId or propionaldehyde were used as substrates.

15. Using the spectrophotometric assay, the kinetics of alcohol dehydrogenase were studied and $\mathrm{Km}$ values were 
determined for propionaldehyde, ethanol, IAAld, and $\mathrm{NADH}_{2}$. Where applicable, the values obtained compare very well with the values recently reported by Cossins et a1. (1968) for alcohol dehydrogenase from peas.

16. There appears to be more than one alcohol dehydrogenase in the cytoplasmic supernatant from mung bean seedlings. The enzyme catalysing the reduction of IAAld was precipitated mainly in the $50-60 \%$ ammonium sulphate fraction, whereas the enzyme catalysing the reduction of propionaldehyde was precipitated equally in the 40-50\% and $50-60 \%$ fractions.

17. Separation of aldehyde dehydrogenase from alcohol dehydrogenase was achieved by $\mathrm{pH}$ precipitation. Aldehyde dehydrogenase was precipitated between $\mathrm{pH} 5.0$ and 4.2, giving a 10-fold purification of the enzyme. The activity of alcohol dehydrogenase was rapidly lost when the $\mathrm{pH}$ was lower than 5.5 .

18. From gel filtration studies using Sephadex G-200, the molecular weight of aldehyde dehydrogenase was estimated to be 124,000 and the MW of the alcohol dehydrogenase catalysing the reduction of propionaldehyde was estimated to be 50,000 . On the other hand, the enzyme catalysing the reduction of IAAld was eluted in two peaks, the major peak was estimated to have an MW of 24,000 and the minor peak an MW of 180,000 . 
19. Conversion oI Tol to IAA was also demonstrated using a cytoplasmic supernatant preparation from mung bean seedlings. This oxidation to IAA was reduced by $78 \%$ in the presence of $10 \mathrm{mM} \mathrm{NaHSO}$ which strongly suggests the involvement of IAAId as an intermediate.

20. Using a cytoplasmic supernatant preparation from lightgrown mung bean seedlings or from tomato shoot tips, the conversion of TTP to Tol was demonstrated. The . enzyme preparations were shown to contain both TTPtransaminase and alcohol dehydrogenase activity and the formation of Tol was inhibited by the addition of $10 \mathrm{mM}$ or $30 \mathrm{mM} \mathrm{NaHSO}$, to the reaction mixture. With the mung bean preparation, the addition of $30 \mathrm{mM}$ $\mathrm{NaHSO}_{3}$ to the reaction mixture resulted in the accumulation of IAAld. This finding clearly points to the role of the compound as an important intermediate in the metabolism of TTP. 


\section{BIBLIOGRAPHY}

ANDREAE, W.A. and N.E. GOOD. 1955. The formation of indoleacetylaspartic acid in pea seediings. Plant Physiol., $30: 380-382$.

ANDREWS, P. 1965. The gel-filtration behaviour of proteins related to their molecular weights over a wide range. Biochem. J., 96 : 595-606.

ARNON, D.I. 1952. Glyceraldehyde phosphate dehydrogenase of green plants. Science, 116 : 635-637.

ATFIELD, "G.N. and C.J.O.R. MORRIS. 1961. Analytical separations by high-voltage paper electrophoresis. Amino acids in protein hydrolysates. Biochem. J., 81 : 606-614.

AUDUS, L.J. 1959. Plant Growth Substances. Leonard Hill Ltd., London.

BENTLEY, J.A. 1958. The naturally-occurring auxins and inhibitors. Am. Rev. Plant Physiol., 9 : 47-80.

BENTLEY, J.A., K.R. FARRAR, S. HOUSLEY, G.F. SMITH and W.C. TAYLOR. 1956. Some chemical and physiological properties of 3-indolylpyruvic acid. Biochem J. 64 : 44-49.

BLACK, S. 1955. Potassium-activated yeast aldehyde dehydrogenase. In: Methods in Enzymology. Vol 1, ed. S.P. Colowick and N.O. Kaplan, Academic Press, N.Y. 508-511.

BLASCHKO, H., D. RICHTER and H. SCHLOSSMANN. 1937. The oxidation of adrenalin and other amines. Biochem. J., 31 : 2187-2196.

BONNER, W.D. 1967. A general method for the preparation of plant mitochondria. In: Methods in Enzymology. Vol 10, ed. Estabrook and Pullman, Academic Press, N.Y., 126-135.

BONNICHSEN, R. 1965. Ethanol: determination with alcohol dehydrogenase and DPN. In: Methods of Enzymatic Analysis. ed. H.U. Bergmeyer, Academic Press, N.Y., 285-287.

BRAY, R.C. 1963. Xanthine oxidase. In: The Enzymes : Vol. 7, ed. P.D. Boyer, H. Lardy and K. Myrback. Academic Press, N.Y.: 533-556. 
CHEN, J. and W.G. BOIL. 1968. Tryptophan synthetase in shoot and root tissue of pea seedlings. Can. J. Botany, 1031-1041.

CHRISTIANSEN, G.S. and K.V. THIMANN. 1950. The metabolism of stem tissue during growth and its inhibition. III. Nitrogen metabolism. Arch. Biochem., 28 : 117-129.

CLARKE, A.J. and P.J.G. MANN. 1957. The oxidation of tryptamine to 3-indoleacetaldehyde by plant amine oxidase. Biochem. J. 65 : 763-774.

CONN, E.E. and S.L. SEKI. 1957. Federation Proc., $16: 167$. Ref. from M. Mazelis. 1962. J. Biol. Chem., 237 : 104-08.

CONN, E.E. and P.K. STUMPF. 1963. Outlines of Biochemistry. John Wiley and Sons, N.Y.,

COSSINS, E.A. and E.R. TUPNER. 1962. Losses of a lcohol and alcohol dehydrogenase activity in germinating seeds. Anrials Bot., 26 : 591-597.

COSSINS, E.A., L.C. KOPALA, B. BLAWACKY and A.M. SPRONK. 1968. Some properties of a higher plant alcohol dehydrogenase. Phytochemistry, 7 : 1125-1134.

CROSS, A.D. 1964. Introduction to Practical Infra-red Spectroscopy. Butterworths, London.

DANNENBURG, W.N. 1957. Conversion of radioactive tryptophan to indoleacetic acid by plant tissues: PhD Thesis. Texas A \& M College.

DANNENBURG, W.N. and J.L. LIVERMAN. 1957. Conversion of tryptophan-2-C 14 to indoleacetic acid by watermelon tissue slices. Plant Physiol., 32 : 263-269.

DAVIES, D.D. 1956. Soluble enzymes from pea mitochondria. J. ExptI. Botany, 7 : 203-218.

DAVIES, D.D. 1960. The purification and properties of glycolaldehyde dehydrogenase. J. Expt1. Botany, 11 : 289-295.

DEITRICH, R.A. 1966. Tissue and subcellular distribution of mammalian aldehyde-oxidizing capacity. Biochem. Pharmacol., 15 : 1911-1922.

DIXON, M. and E.C. WEBB. 1964. Enzymes. 2nd edition, I.ongmans, London.

ERWIN, V.G. and R.A. DEITRICH. 1966. Brain aldehyde dehydrogenase. Localization, purification and properties. J. Biol. Chem., 241 : 3533-3539. 
EWINS, A.J. 1911. Synthes is of 3- $\beta$-aminoethylindole. J. Chem. Soc., $99: 270-273$.

EWINS, A.J. and P.P. LAIDLAW. 1910. Synthes is of 3- $\beta$-aminoethylindole and its formation from tryptophan. Proc. Chem. Soc., 26 : 343.

FAWCETT, C.H. 1961. Indole auxins. Ann. Rev. Plant Physiol., 12 : 345-368.

FAWCETT, C.H., H.F. TAYLOR, R.L. WAIN and F. WIGHTMAN. 1957. The metabolism of certain acids, amides and nitriles within plant tissues. Proc. Roy. Soc. B., 148 : 543-570.

FLODIN, P. 1962. Dextran Gels and their Applications in Gel Filtration. Fharmacia Ltd., Uppsala.

GALE, E.F. 1957. Determination of amino acids by use of bacterial amino acid decarboxylases. In: Methods of Biochemical Analys is. Vol. 4, Interscience Publishers, N.Y., 285-306.

GALSTON, A.W. and W.S. HILLMAN. 1961. The degradation of auxin. In: Encyclopedia of Plant Physiology. Vol. XIV, Springer-Verlag, Berlin, 647-670.

GAMBORG, O.L. 1965. Transamination in plants. The specificity of an amino transferase from mung beans.

Can. J. Biochem., 43 : 723-730.

GAMBORG, O.L. and F.W. KEELEY. 1966. Aromatic metabolism in plants. 1. A study of the prephenate dehydrogenase from bean plants. Biochim. Biophys. Acta, 15 : 65-72.

GAMBORG, O.L. and L.R. WETTER. 1963. An aromatic amino acid transaminase from mung bean. Can. J. Biochem. Physiol., 41 : 1733-1740.

GAMBORG, O.L., L.R. WETTER and A.C. NEISH. 1962. The oxida$t i o n$ of some aromatic $\alpha$-hydroxy acids by glycollate:

$\mathrm{O}_{2}$ oxidoreductase. Phytochemistry, 1 : 159-168.

GIBSON, R.A. and F. WIGHTMAN. 1968. Unpublished results.

GOOD, N.E., W.A. ANDREAE, M.W.H. VAN YSSELSTEIN. 1956. Studies on 3-indoleacetic acid metabolism. II. Some products of the metabolism of exogenous indoleacetic acid in plant tissues. Plant Physiol., 31 : 231-235.

GORDON, S.A. 1956. The biogenesis of natural auxins. In: The Chemistry and Mode of Action of Plant Growth Substances. ed. R.L. Wain and F. Wightman, Butterworths, London, pp. 65-75.

GORDON, S.A. 1958. Intracellular localization of the tryptophan-indoleacetate enzyme system. Plant Physiol., $33: 23-27$. 
GORDON, S.A. 1961. The biogenesis of auxin. In: Encyclopedia of Plant Physiology. Springer-Verlag, Berlin, Vol. XIV, $620-646$.

GORDON, S.A. and L.G. PALEG. 1961. Formation of auxin from tryptophan through action of polyphenols.

Plant Physiol., 36 : 838-845.

GORDON, S.A. and F. SANCHEZ NIEVA. 1949a. The biosynthes is of auxin in the vegetative pineapple. I. Nature of the active auxin. Arch. Biochem., $20: 356-366$.

GORDON, S.A. and F. SANCHEZ NIEVA. 1949b. The biosynthesis of auxin in the vegetative pineapple. II. The precursors of indoleacetic acid. Arch. Biochem., 20:: 367-385.

GRAY, R.A. 1959. Preparation and properties of 3-indoleacetaldehyde. Arch. Biochem., Biophys., 81 : 480-488.

GREEN, A.A. and W.L. HUGHES. 1955. Protein fractionation on the basis of solubility in aqueous solutions of salts and organic solvents. In: Methods in Enzymology.

Vol. 1, ed. S.P. Colowick and N.O. Kaplan, Academic Press, N.Y., 67-90.

GREENBURG, J.B. and A.W. GALSTON. 1959. Tryptophan synthetase activity in pea-seedling extracts. Plant physiol., 34 : 489-494.

HARE, R.C. 1964. Indoleacetic acid oxidase. Bot. Rev., $30: 129-165$.

HEMBERG, T. 1958. Auxins and growth-inhibiting substances in maize kernels. Physiol. Plant., 11 : 284-311.

HENBEST, A.B., E.R.H. JONES, and G.F. SMITH. 1953. Isolation of a new plant growth hormone, 3-indolylacetonitrile. J. Chem. Soc., 1953, 3796-3801.

HITCHCOCK, A.E., W.W. SANFORD and P.W. ZIMMERMAN. 1955. Chromatographic determination of indole compounds in ethanolic extracts of tomato seedlings treated with indole-3-acetic acid. Plant Physiol., 30 : xi.

HOPE, H.J. 1963. Studies on the metabolism of tryptophan in the tomato plant Lycopersicum esculentum Mill. MSc. Thesis, Carleton University.

ISHERWOOD, F.A. and D.H. CRUICKSHANK. 1954. Chromatographic separation and analysis of mixtures of pyruvic, oxalacetic and alpha-ketoglutaric acids. Nature, 173: 121-122. 
JACOBY, G.A. and B.N. LA DU. 1964. Studies on the specificity of tyrosine $\alpha$-ketoglutarate transaminase.

J. Biol. Chem., 239 : 419-424.

JAKОВY, W.B. 1963. Aldehyde dehydrogenases. In: The Enzymes. Vol. 7, ed. P.D. Boyer, H. Lardy and K.Myrback, Academic Press, N.Y., 203-221.

JONES, E.R.H., H.B. HENBEST, G.F. SMITH and J.A. BENTLEY. 1952. 3-Indoleacetónitrile: a naturally-occurring plant growth hormone. Nature, 169 : 485-487.

JONES, L.A., J.C. HOLMES and R.B. SELIGMAN. 1956. Spectrophotometric studies of some 2,4-dinitrophenylhydrazones. Anal. Chem., 28 : 191-198.

KAPER, J.M. and H. VELDSTRA. 1958. On the metabolism of tryptophan by Agrobacterium tumefaciens.

Biochim. Biophys. Acta, 30 : 401-420.

KAPER, J.M., O. GEBHARD, C.J. VAN DEN BERG and H. VELDSTRA. 1963a. Studies on indolepyruvic acid. I. Synthes is and paper chromatography. Arch. Biochem. Biophys., 103 : $469-474$.

KAPER, J.M., O. GEBHARD, C.J. VAN DEN BERG and H. VELDSTRA. 1963b. Studies on indolepyruvic acid. II. Ultraviolet spectrophotometry. Arch. Biochem. Biophys., 103 : 475-87.

KATSUKI, H., H. KANAYUKI, T. YOSHIDA, C. KAWANO and S. TANAKA. 1961. Ana1. Biochem., 2 : 421-433. Ref. from R.T. Taylor and W.T. Jenkins. 1966. J. Biol. Chem., 241 : $4389-4395$.

KENTEN, R.H. 1953. The oxidation of phenylacetaldehyde by plant saps. Biochem. J., $55: 350-360$.

KENTEN, R.H. 1957. Latent phenolase in extracts of broad bean (Vicia faba L.) leaves. I. Activation by acid and alkali. Biochem. J., $67: 300-307$.

KENTEN, R.H. and P.J.G. MANN. 1952. The oxidation of amines by extracts of pea seedlings. Biochem. J., 50 : 360-369.

KHALIFAH, R.A., L.N. LEWIS, C.W. COGGINS JR. and P.C. RADLICK. 1965. Fluorometric, chromatographic and spectronic evidence for the non-indolic nature of citrus auxin. J. Expt1. Botany, 16 : 511-517.

KLAMBT, H.D. 1964. Pyridoxal phosphat-abhangige oxydative Decarboxylierung von L-Tryptophan durch MeerrettichPeroxydase. Z. Naturforschg. 19b : 449-450. 
KLUNGSOYR, S. 1964, Degradation of tryptophan in cel1-free preparations from Acetobacter xylinum. Régulateurs Naturels de la Croissance Végétale, C.N.R.S. Paris, 213-20.

KOUKOL, J. and E.E. CONN. 1961. The metabolism of aromatic compounds in higher plants. IV. Purification and properties of the phenylalanine deaminase of Hordeum vulgare. J. Biol. Chem., 236:2692-2698.

KRETOVITCH, W.L. 1965. Some problems of amino acid and amide biosynthesis in plants. Ann. Rev. Plant Physiol., 16 : 141-154.

KUMAR, S.A. and S. MAHADEVAN. 1963. 3-Indoleacetaldoxime hydro-lyase: a pyridoxal-5'-phosphate activated enzyme. Arch. Biochem. Biophys., 103: 516-518.

KUTACEK, M. and $Z$. PROCHAZKA. 1964. Méthodes de détermination et $d^{\prime}$ isolement des composés chez Crucifêres. In: Régulateurs Naturels de la Croissance Végétale. C.N.R.S., Paris, pp. 445-456.

LAIDLAW, P.P. 1911. The physiological action of indolethylamine. Biochem. J., $6: 141-150$.

LARSEN, P. 1939. Skototenin, ein neuer Streckungswuchsstoff in huheren Pflanzen. Naturwissenschaften 27: 549-550.

LARSEN, P. 1944. 3-Indole acetaldehyde as a growth hormone in higher plants. Dansk Bot. Ark. 11: 1-132.

LARSEN, P. 1949. Conversion of indole acetaldehyde to indoleacetic acid in excised coleoptiles and coleoptile juice. Amer. J. Bot., 36 : 32-41.

LARSEN, P. 195la. Formation, occurrence and inactivation of growth substances. Ann. Ref. Plant Physiol., 2 : 169-198.

LARSEN, P. 1951b. Enzymatic conversion of indole acetaldehyde and napthalene acetaldehyde to auxins. Plant Physiol., 26 : 697-707.

LARSEN, P. and T. AASHEIM. 1961. The occurrence of indole3-acetaldehyde in certain plant extracts. In: Plant Growth Reglation. Iowa State University Press,

LARSEN, P., A. HARBO, S. KLUNGSÖYR, and T. AASHEIM. 1962 . On the biogenes is of some indole compounds in Acetobacter xylinum. Physiol. Plant., 15 : 552-565.

LAWRENCE, J.M. and D.R. GRANT. 1963. Nitrogen mobilization in pea seedlings. II. Free amino acids. Plant Physiol., 38 : $561-566$. 
LEOPOLD, A.C. 1955. Auxins and Plant Growth. University of California Press, Berkeley, California.

LEWIS, L.N., R.A. KHALIFAH and C.W. COGGINS JR. 1965. The existence of the non-indole citrus auxin in several plant families. Phytochemistry, 4 : 203-205.

LIBBERT, E. 1961. Die Enzymatische Auxinbildung aus Tryptophan unter Einfluss eines nativen Inhibitors. Planta, 56 : 1-22.

LIBBERT, E. and K. BRUNN. 1961. Nachweis von Indol-3-brenztraubensaure und Indo1-3-athanol (Tryptophol) bei der enzermatischen Auxinbildung aus Tryptophan in vitro. Naturwissenschaften, $48: 741$.

LIBBERT, E., S. WICHNER, U. SCHIEWER, H. RISCH and W. KAISER. 1966. The influence of epiplytic bacteriae on auxin metabolism. Planta, 68 : 327-334.

LIN, 1959. correct citation should read CIVEN, M. ard W. KNOX. 1959. Pattern of levels of rat liver tryptophan transaminase. Science, 129 : 1672-1673.

LIN, E.C.C., B.M. PITT, M. CIVEN and W.E. KNOX. 1958a.. The assay of aromatic amino acid transaminations and keto acid oxidation by the enol borate-tautomerase method. J. Biol. Chem., 233 : 668-673.

LIN, E.C.C., B.M. PITT, M. CIVEN and W.E. KNOX. 1958b. Effect of vitamin $B_{6}$ deficiency on the basal and adapted levels of liver tyrosine and tryptophan transaminases. J. Biol. Chem., 233 : 1183-1185.

LIU, T., A. OPPENHEIM, and P. CASTELFRANCO. 1965. Ethy 1 alcohol metabolism in leguminous seedlings. Plant Physiol., 40 : 1261-1268.

LOVENBURG, W., H. WEISSBACH, and S. UDENDFRIEND. 1962. Aromatic L-amino acid decarboxylase. J. Biol Chem., 237 : 89-93.

LOWRY, O.H., J.N. ROSEBROUGH, A.L. FARR and R.J. RANDALL. 1951. Protein measurement with the Fol in phenol reagent. J. Biol. Chem., $193: 265-275$.

LUND, H.A. 1956. The biosynthes is of indoleacetic acid in the styles and ovaries of tobacco preliminary to the setting of fruit. Plant Physiol., 31 : 334-339.

MAHADEVAN, S. and K.V. THIMANN. 1964. Nitrilase. II. Substrate specificity and possible mode of action. Arch. Biochem. Biophys., 107 : 62-68. 
MANN, P.J.G. 1955. Purification and properties of the amine oxidase of pea seedlings. Biochem. J., 59:609-620.

MANN, P.J.G. 1961. Further purification and properties of the amine oxidase of pea seedlings. Biochem. J., 79 : 623-631.

MANSKE, R.H.F. 1931. A synthes is of methyl tryptamines and some derivatives. Can. J. Research, 5:592-600.

MARIIN, R.O. and P.K. STUMPF. 1959. Fat metabolism in higher plants. XII. $\alpha$-Oxidation of long-chain fatty acids. J. Biol. Chem., 234 : 2548-2554.

MAYER, A.M. 1966. Catechol oxidase: enzymic liberation from sugar beet chloroplasts. Phytochemistry, 5 : 1297-1301.

MAYER, A.M. and J. FRIEND. 1960. Localization and nature of phenolase in sugar-beet leaves. J. ExptI. Botany, 11 : 141-150.

MAZELIS, M. 1962. The pyridoxal phosphate-dependent oxidative decarboxylation of methionine by peroxidase.

I. Characteristics and properties of the reaction.

J. Biol. Chem., 237 : 104-108.

MAZELIS, M. and L.L. INGRAHAM. 1962. The pyridoxal phosphatedependent oxidative decarboxylation of methionine by peroxidase. II. Identification of 3-methylthiopropionamide as a product of the reaction. J. Biol. Chem., 237 : 109-112.

MEISTER, A. and P.A. ABENDSCHEIN. 1956. Chromatography of alpha-keto acid 2,4-dinitrophenylhydrazones and their hydrogenation products. Chem., 28 : 171-173.

MEISTER, A. and D. WELLNER. 1963. Flavoprotein amino acid oxidases. In: The Enzymes. Vol. 7, ed. P.D. Boyer, H. Lardy and K. Myrbyck, Academic Press, N.Y., PP. 609-48.

MITOMA, C. and S. UDENFRIEND. 1960. Bacterial tryptophan decarboxylase. Biochim. Biophys. Acta, 37 : 356-357.

NEISH, A.C. 1961. Formation of $m$ - and p-coumaric acids by enzymatic deamination of the corresponding isomers of tyrosine. Phytochemistry, 1 : 1-24.

NITSCH, J.P. 1952. Plant hormones in the development of fruits. Quart. Rev. Biol., 27 : 33-57.

OPPENHEIM, A. and P.A. CASTELFRANCO. 1967. An acetaldehyde dehydrogenase from germinating seeds. Plant Physiol., 42 : 125-132. 
PERLEY, J.E. and B.B. STOWE. 1966. The production of tryptamine from tryptophan by Bacillus cereus (KVT). Biochem. J., 100 : 169-174.

PHELPS, R.H. and L. SEQUEIRA. 1967. Synthesis of indoleacetic acid via tryptamine by a cell-free system from tobacco terminal buds. Plant Physio1., 42 : 1161-1163.

PITT, B.M. 1962. Oxidation of phenylpyruvates to aromatic aldehydes and oxalate. Nature, $196: 272-273$.

RACKER, E. 1955. Liver aldehyde dehydrogenase. In: Methods in Enzymology. Vol.I, ed. S.P. Colowick and N.O. Kaplan, Academic Press, N.Y., pp. 514-523.

RAISON, J.K., G. HENSON and K.G. RIENITS. 1966. The oxidation of gentisaldehyde by nicotinamideadenine dinucleotide-specific, aromatic aldehyde dehydrogenase from rabbit liver., Biochim. Biophys. Acta, 118 : 285-98.

RAJAGOPAL, R. 1967. Occurrence of indoleacetaldehyde and tryptophol in the extracts of etiolated shoot of Pisum and Helianthus seedlings. Physiol. Plant., 20 : 655-60.

RAJ AGOPAL, R. 1968. Occurrence and metabolism of indoleacetaldehyde in certain higher plant tissues under aseptic conditions. Physiol. Plant., 21 : 378-385.

RAMIREZ, F. and A.F. KIRBY. 1954. Geometrical isomerism and absorption spectra of dinitrophenylhydrazones. $\mathrm{J}$. Am. Chem. Soc., 76 : 1037-1044.

RAYLE, D.L. and W.K. PURVES. 1967. Isolation and identification of indole-3-ethanol (tryptophol) from cucumber seedlings. Plant Physiol., 42 : 520-524.

REED, D.J . and J . CRECELIUS. 1967. Light-induced inhibition of tryptophan decarboxylation in cell-free extracts of pea epicotyls. Plant Physiol., 42: 1303-1306.

RIDDLE, V.M. and M. MAZELIS. 1964. A role for peroxidase in biosynthesis of auxin. Nature, 202 : 391-392.

RIDDLE, V.M. and M. MAZELIS. 1965. Conversion of tryptophan to indoleacetamide and further conversion to indoleacetic acid by plant preparations. Plant Physiol., 40 : 481-484.

ROW, V.V., W.W. SANFORD and A.E. HITCHCOCK. 1961. Indole3-acetyl-D, L-aspartic acid as a naturally-occurxing indole compound in tomato seedlings. Contribs. Boyce Thompson Inst., 21 : 1-10. 
SCHINEIDER, E.A. 1965. Studies on the biosynthesis and degradation of 3-indoleacetic acid and gramine in barley shoots. PhD Thesis, Carleton University.

SCHWARZ, K. 1957. Espectros U.V. dos produtos da decomposiçao espontanea do acido indolpiruvico. Arq. Inst. Biol. (Sao Paulo) $24: 81-91$.

SCHWARZ, K. 1961. Separation of enol and keto tautomers of aromatic pyruvic acids by paper chromatography. Arch. Biochem. Biophys., 92 : 168-175.

SCHWARZ, K. and A.A. BITANCOURT. 1960. Further evidence of tauterism in chromatograms of indolyl-3-pyruvic acid. Biochem. J., $75: 182-187$.

SEELEY, R.C., C.H. FAWCETT, R.L. WAIN and F. WIGHTMAN. 1956. Chromatographic investigations on the metabolism of certain indole derivations in plant tissues. In: Chemistry and Mode of Action of Plant Growth Substances. ed. R.L. Wain and F. Wightman, Butterworths, London, pp. 234-247.

SHANTZ, E.M. 1966. Chemistry of naturally-occurring growthregulating substances. Ann. Rev. Plant Physiol., 17 : $409-438$.

SHAW, K.N.F., A. McMILLAN, A.G. GUDMUNDSON and M.D. ARMSTRONG. 1958. Preparation and properties of $\beta-3$-indoly 1 compounds related to tryptophan metabolism. $\mathrm{J}$. Org. Chem., 23 : 1171-1178.

SHIGEMURA, Y. and S.A. GORDON. 1960. The conversion of indoleacetaldehyde to indoleacetic acid by enzyme systems of Avena seedling coleoptiles. (Abstr.), Plant Physiol., 35 (Supp1.) : XXVIII.

SHUKLA, P.S. and S. MAHADEVAN. 1968. Indoleacetaldoxime hydro-Iyase. II. Purification and properties., Arch. Biochem, Biophys., 125 : 873-883.

SKOOG, F. 1937. The deseeded Avena test method for small amounts of auxin and auxin precursors. J. Gen. Physiol., $20: 311-334$.

SMITH, I. and M.J. SMITH. 1960. Ketoacids. In: Chromatographic and Electrophoretic Techniques. Vol. 1, Chromatography. ed. I. Smith, Heineman Medical Books, London, pp.261-290.

SPENCER, R.P. and W.E. KNOX. 1962. The glutathione-dependent indolepyruvic acid keto-enol tautomerase of rat liver. Arch. Biochem. Biophys., 96 : 115-124. 
STACHOW, C.S., I.L. STEVENSON and D. DAY. 1967. Purification and properties of nicotinamide adenine dinucleotide phosphate-specific benzaldehyde dehydrogenase from Pseudomonas. J. Biol. Chem., 242 : 5294-5300.

STAFFORD, H.A. and B. VENNESLAND. 1953. Alcohol dehydrogenase of wheat germ. Arch. Biochem. Biophys., 44 : 404-414.

STEINMAN, C.R. and W.B. JAKOBY. 1967. Yeast aldehyde dehydrogenase. I. Purification and crystallization. J. Biol. Chem., 242 : 5019-5023.

STOWE, B.B. 1955. The production of indoleacetic acid by bacteria. Biochem. J., 61 : ix.

STOWE, B.B. 1959. Occurrence and metabolism of simple indoles in plants. Fortschr. Chem. Org. Naturstoffe, 17 : 248-297.

STOWE, B.B. and K.V. THIMANN. 1954. The paper chromatography of indole compounds and some indole-containing auxins of plant tissues. Arch. Biochem. Biophys., 51 : 499-516.

SUND, H. and H. THEORELL. 1963. Alcohol dehydrogenases. In: The Enzymes. Vol. 7, ed. P.D. Boyer, H. Lardy and K. Myrback, Academic Press, N.Y., pp. 25-83.

SUZUKI, Y. 1966. Alcohol dehydrogenase (alcohol-NAD oxidoreductase) from pea seedling. Phytochemistry, 5 : 761-65.

TANGEN, O., F. FONNUM and R. HAAVALDSEN. 1965. Separation and purification of aromatic amino acid transaminases from rat brain. Biochim. Biophys. Acta, 96 : 82-90.

THIMANN, K.V. 1935. On the plant growth hormone produced by Rhizopus suinus. J. Biol. Chem., $109: 279-291$.

THIMANN, K.V. 1953. Hydrolys is of indole acetonitrile in plants. Arch. Biochem. Biophys., 44 : 242-243.

THIMANN, K.V. and M. GROCHOWSKA. 1968. The role of tryptophan and tryptamine as IAA precursors. In: Physiology and Biochemistry of Plant Growth Substrances. ed. F. Wightman and G. Setterfield. Runge Press, Ottawa (in press).

THIMANN, K.V. and S. MAHADEVAN. 1958. Enzymatic hydrolysis of indoleacetonitrile. Nature, 181 : 1466-1467.

THIMANN, K.V. and S. MAHADEVAN. 1964. Nitrilase. I. Occurrence, preparation and general properties of the enzyme. Arch. Biochem. Biophys., 105 : 113-141. 
TSUI, C. 1948. The role of $z$ inc in auxin synthesis in the tomato plant. Amer. J. Bot., 35 : 172-179.

UDENFRIEND, S., W. LOVENBERG and A. SJOERDSMA. 1959. Physiologically active amines in common fruits and vegetables. Arch. Biochem. Biophys., 85 : 487-490.

UTTER, M.F. 1963. Nonoxidative carboxylation and decarboxylation. In: The Enzymes. Vol. 5, ed. P.D. Boyer, H. Lardy and K. Myrbzck. Academic Press, N.Y., 319-340.

VENDRIG, J.C. 1967. Steroid derivatives as native auxins in Coleus. Ann. N.Y. Acad. Sci., 144: 81-93.

VIRTANEN, A.I. and T. LAINE. 1936. Investigations on the amino acids of plants. I. Tryptophan content of Leguminous plants at different stages of growth. Biochem. J., 30 : 1509-1513.

VLITOS, A.J. and W. MEUDT. 1954. The role of auxin in plant flowering. III. Free indole acids in short-day plants grown under photoinductive and nonphotoinductive daylengths. Contribs. Boyce Thompson Inst., 17 : 401-411.

WEBER. W.W. and V.G. ZANNONI. 1968. Reduction of aromatic $\alpha$-keto acids by lactate dehydrogenase isozymes and aromatic $\alpha$-keto acid reductase. Ann. N.Y. Acad. Sci., 151 : $627-637$.

WEISSBACH, H., W. KING, A. SJOERDSMA and S. UDENFRIEND. 1959. Formation of indole-3-acetic acid and tryptamine in anima1s. J. Biol. Chem., 234 : 81-86.

WEISSBACH, H., B.G. REDFIELD and S. UDENFRIEND. 1957. Soluble monoamine oxidase; its properties and action on serotonin. J. Biol. Chem., 229: 953-963.

WENT, F.W. and K.V. THIMANN. 1937. Phytohormones. MacMillan, New York.

WERLE, E. and G. MENNICKEN. 1937. Formation of tryptamine from tryptophan and of tyramine from tyrosine by animal tissues. Biochem. Z., 291 : 325-327.

WERLE, E. and F. ROEWER. 1950. Monoamine oxidase in plants. Biochem. Z., $320: 298-302$.

WEST, G.B. 1958. Tryptamines in edible fruits. J. Pharm. Pharmacol., 10 : 589-590.

WEST, G.B. 1959. Tryptamines in tomatoes. J. Pharm. Pharmacol., 11 : 319-320. 
WHITE, E.P. 1944. Alkaloids of the leguminosae. Part XIII Isolation of tryptamine from some Acacia species. N.Z. J. Science \& Tech., B, $25: 157-162$.

WHITE, E.P. 1957. Alkaloids of the leguminosae. Part XXVI Examination of further legumes, mainly Lupinus and Acacia species for alkaloids. N.Z. J. Science \& Tech., $\mathrm{B}, 38: 718-725$.

WICHNER, S. and E. LIBBERT. 1968a. Interactions between plants and epiphytic bacteria regarding their auxin metabolism. I. Detaction of IAA-producing epiphytic bacteria and their role in long duration experiments on tryptophan metabolism in plant homogenates. Physiol. Plant., 21 : 227-241.

WICHNER, S. and E. LIBBERT. 1968. Interactions between plants and epiphytic bacteria regarding their auxin metabolism. II. Influence of IAA-producing epiphytic bacteria on short-term IAA production from tryptophan in plant homogenates. Physiol. Plant., 21 : 500-509.

WIGHTMAN, F. 1962. Metabolism and biosynthesis of 3-indoleacetic acid and related indole compounds in plants. Can. J. Botany, 40 : 689-718.

WIGHTMAN, F. 1964. Pathways of tryptophan metabolism in tomato plants. In: Régulateurs Naturels de la Croissance Végétale, C.N.R.S., Paris, pp. 193-212.

WIGHTMAN, F., M.D. CHISHOLM, and A.C. NEISH. 1961. Biosynthesis of tryptophan and gramine in young barley shoots. Phytochemistry, 1 : 30-37.

WIGHTMAN, F. and D. COHEN. 1968. Intermediary steps in the enzymatic conversion of tryptophan to IAA in cell-free systems from mung bean seedlings. In: Biochemistry and Physiology of Plant Growth Substances. ed. F. Wightman and G. Setterfield. Runge Press, Ottawa (in press).

WIGHTMAN, F. and L. FOWDEN. 1966. Enzymic formation of 3-indolepyruvic acid from L-tryptophan by transamination. In: IUPAC Symposium on the Chemistry of Natural Products. Stockholm, 1966. pp. 166-167.

WILDMAN, S.G., M.G. FERRI and J. BONNER. 1947. The enzymatic conversion of tryptophan to auxin by spinach leaves. Arch. Biochem., $13: 131-144$.

WILSON, D.G., K.W. KING and R.H. BURRIS. 1954. Transamination reactions in plants. J. Biol. Chem., 208 : 863-874. 
WILTSHIRE, G.H. 1953. The oxidation of tryptophan in peaseedling tissues and extracts. Biochem. J., 55 : 408-16.

WINTER, A. 1964. Evidence for the occurrence of indolepyruvic acid in vivo. Arch. Biochem. Biophys., 106 : 131-137.

WINTER, A. 1966. A hypothetical route for the biogenesis of IAA. Planta, 71 : 229-239.

YAMAKI, $T$. and $K$. NAKAMURA. 1952. Formation of indoleacetic acid in maize embryo. Sci. Papers Coll. Gen. Ed. Univ. Tokyo, 2 : 81-98.

YOUNG, M.R. and A.C. NEISH. 1966. Properties of the ammonialyases deaminating phenylalanine and related compounds in Triticum aestivum and Pteridium aquilinum. Phytochemistry, 5 : $1121-\overline{1132 .}$

YOUNG, M.R., G.H.N. TOWERS and A.C. NEISH. 1966. Taxonomic distribution of ammonia-lyases for L-phenylalanine and L-tyrosine in relation to lignification. Can. J. Bot., 44 : 341-349.

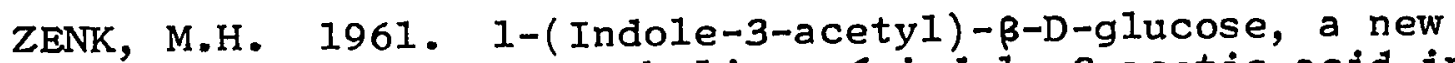
compound in the metabolism of indole-3-acetic acid in plants. Nature, 191 : 493-494. 